NBS

\title{
PUBLICATIONS
}

NAT' INST OF STANDARDS \& TECH R.I.C

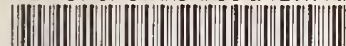

A11102789105

\section{PROGRESS IN ENVIRONMENTAL SPECIMEN BANKING}

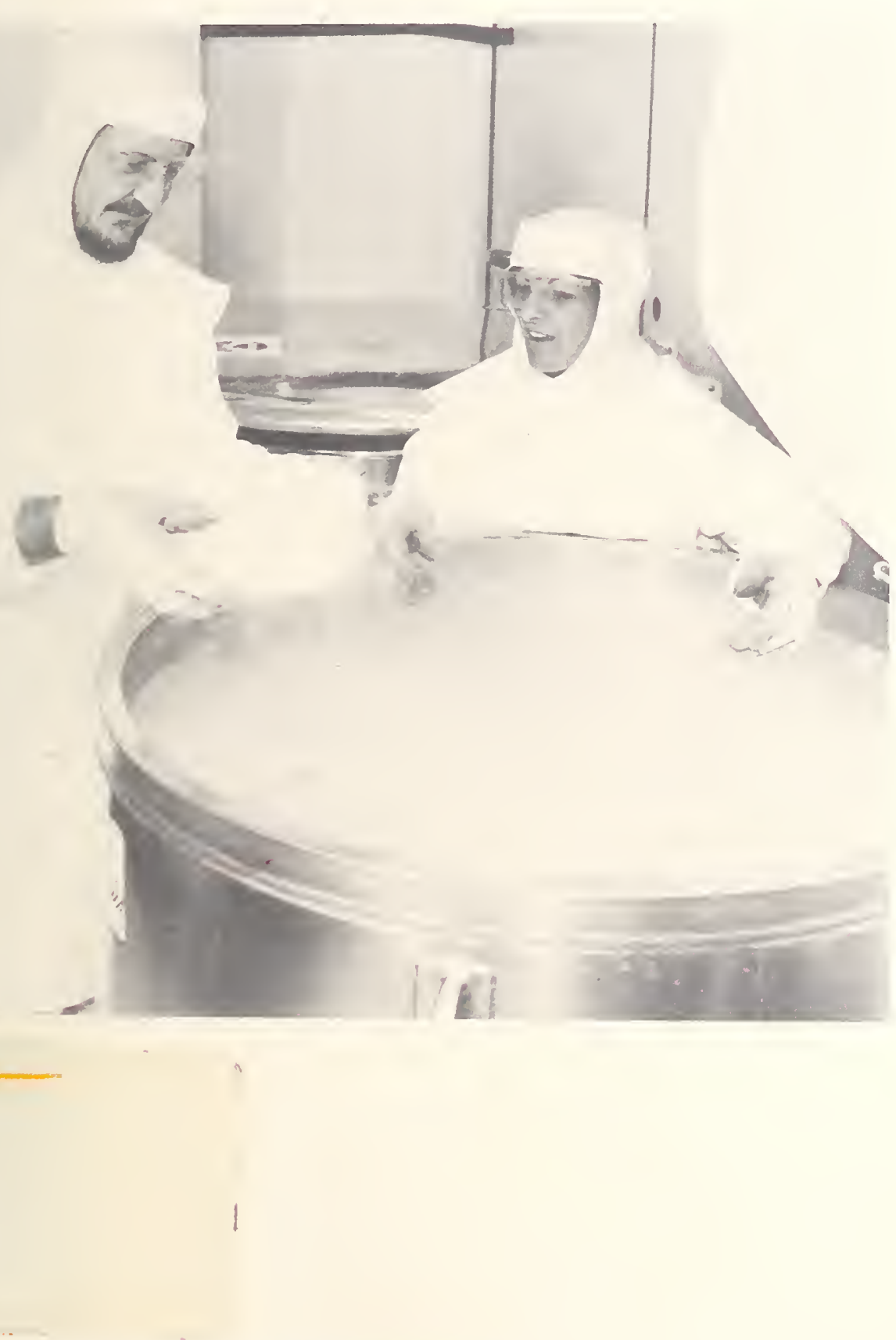

\author{
STEPHEN A. WISE \\ ROLF ZEISLER \\ GEORGE M. GOLDSTEIN \\ EDITORS
}

$Q C$

100

.457

\#740

1988

$c \cdot 2$

U.S. DEPARTMENT OF COMMERCE

NATIONAL BUREAU OF STANDARDS 
he National Bureau of Standards ${ }^{1}$ was established by an act of Congress on March 3, 1901. The Bureau's overall goal is to strengthen and advance the nation's science and technology and facilitate their effective application for public benefit. To this end, the Bureau conducts research to assure international competitiveness and leadership of U.S. industry, science ard technology. NBS work involves development and transfer of measurements, standards and related science and technology, in support of continually improving U.S. productivity, product quality and reliability, innovation and underlying science and engineering. The Bureau's technical work is performed by the National Measurement Laboratory, the National Engineering Laboratory, the Institute for Computer Sciences and Technology, and the Institute for Materials Science and Engineering.

\section{The National Measurement Laboratory}

Provides the national system of physical and chemical measurement; coordinates the system with measurement systems of other nations and furnishes essential services leading to accurate and uniform physical and chemical measurement throughout the Nation's scientific community, industry, and commerce; provides advisory and research services to other Government agencies; conducts physical and chemical research; develops, produces, and distributes Standard Reference Materials; provides calibration services; and manages the National Standard Reference Data System. The Laboratory consists of the following centers:
- Basic Standards ${ }^{2}$

- Radiation Research

- Chemical Physics

- Analytical Chemistry

\section{The National Engineering Laboratory}

Provides technology and technical services to the public and private sectors to address national needs and to solve national problems; conducts research in engineering and applied science in support of these efforts; builds and maintains competence in the necessary disciplines required to carry out this research and technical service; develops engineering data and measurement capabilities; provides engineering measurement traceability services; develops test methods and proposes engineering standards and code changes; develops and proposes new engineering practices; and develops and improves mechanisms to transfer results of its research to the ultimate user. The Laboratory consists of the following centers:
- Applied Mathematics

- Electronics and Electrical Engineering ${ }^{2}$

- Manufacturing Engineering

- Building Technology

- Fire Research

- Chemical Engineering ${ }^{3}$

\section{The Institute for Computer Sciences and Technology}

Conducts research and provides scientific and technical services to aid Federal agencies in the selection, acquisition, application, and use of computer technology to improve effectiveness and economy in Government operations in accordance with Public Law 89-306 (40 U.S.C. 759), relevant Executive Orders, and other directives; carries out this mission by managing the Federal Information Processing Standards Program, developing Federal ADP standards guidelines, and managing Federal participation in ADP voluntary standardization activities; provides scientific and technological advisory services and assistance to Federal agencies; and provides the technical foundation for computer-related policies of the Federal Government. The Institute consists of the following divisions:
- Information Systems Engineering

- Systems and Software Technology

- Computer Security

- Systems and Network Architecture

- Advanced Computer Systems

\section{The Institute for Materials Science and Engineering}

Conducts research and provides measurements, data, standards, reference materials, quantitative understanding and other technical information fundamental to the processing, structure, properties and performance of materials; addresses the scientific basis for new advanced materials technologies; plans research around cross-cutting scientific themes such as nondestructive evaluation and phase diagram development; oversees Bureau-wide technical programs in nuclear reactor radiation research and nondestructive evaluation; and broadly disseminates generic technical information resulting from its programs. The Institute consists of the following Divisions:
- Ceramics

- Fracture and Deformation ${ }^{3}$

- Polymers

- Metallurgy

- Reactor Radiation 


\section{Progress in Environmental Specimen Banking}

Stephen A. Wise', Rolf Zeisler ${ }^{1}$, and George M. Goldstein², Editors

${ }^{1}$ Center for Analytical Chemistry

National Bureau of Standards

Gaithersburg, MD 20899

${ }^{2}$ Health Effects Research Laboratory

U.S. Environmental Protection Agency

Research Triangle Park, NC 21771

Research Supported in part by:

Office of Health Research

Office of Research and Development

U.S. Environmental Protection Agency

Washington, DC 20460

April 1988

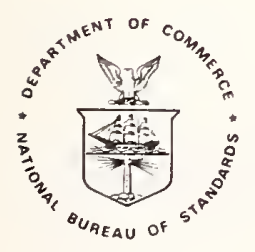

U.S. DEPARTMENT OF COMMERCE, C. William Verity, Secretary NATIONAL BUREAU OF STANDARDS, Ernest Ambler, Director 
Library of Congress Catalog Card Number: 88-600530

National Bureau of Standards Special Publication 740

Natl. Bur. Stand. (U.S.), Spec. Publ. 740, 217 pages (Apr. 1988) CODEN: XNBSAV

U.S. GOVERNMENT PRINTING OFFICE

WASHINGTON: 1988

For sale by the Superintendent of Documents, U.S. Government PrInting Office, Washington, DC 20402-9325 


\section{FOREWORD}

The American Specimen Bank Project has gone successfully through both feasibility and pilot phases, and the potential usefulness of such a specimen banking system is clearly evident. It is easy to imagine how stored samples can be used to show trends of various existing environmental chemicals, and how we can go back and analyze stored samples should additional chemicals of interest to our program offices appear. At this point in time, it is critical that we consider the overall objective and an organizational management scheme for the Specimen Bank Project on a national scale, since other U.S. government agencies have recently joined with the National Bureau of Standards (NBS) and Environmental Protection Agency (EPA) in the banking of environmental and nutritional specimens. Additional agencies may also join the effort--several having expressed interest in what a National specimen Bank can contribute. Consequently it has become important to consider formulation of a "charter" for a National Environmental Specimen Bank. This formal charter would indicate such things as the types of samples to be collected, stored, analyzed, and who might have access to these stored samples. This charter would also set up a policy board of members from the various agencies to guide the Specimen Bank efforts and oversee its management.

The effort of developing a National Environmental Specimen Bank must be coordinated with the various environmental monitoring networks presently in existence. The desired coordination between the Specimen Bank and the monitoring programs will also assist us in better assessing exposure and doses at the cellular sites where the toxic actions occur. The U.S. EPA is currently planning extensive research initiatives dealing with Human Exposure and Advanced Methods of Extrapolation. Both programs would benefit from Specimen Bank results.

It would also be relevant to assess the results from analyses of specimen bank tissues and the corresponding benefit to our regulatory programs. There is already a good indication that this may be possible as evidenced by the reduction in the level of lead in human blood and livers since EPA required a reduction in the lead content of gasoline.

The key to a successful Environmental Specimen Bank, and the most challenging effort, will be to establish a National Specimen Bank Program, to answer specific and hard scientific questions, questions such as: What is the trend for specific chemicals in the environment and in the human? What remedial actions need to be taken if the chemicals are on an upward trend? Are new chemicals appearing which we need to be concerned about? Have remedial actions taken been effective to reduce this environmental and health risk? The results of these questions will assist our policy makers and regulatory staffs to make better founded decisions in their effort to provide a better and healthier environment for all of us. In other words, we need to determine what we want and what we expect to obtain from such a specimen bank.

On an international scale, the Germans have developed a full National Environmental Specimen Bank, and several other countries such as Japan, Canada, and Sweden have seen the usefulness of Specimen Banking. Other countries may follow the lead established by the German-American cooperation. There is, 
already one international environmental monitoring effort underway (HEAL) and it is possible in this effort to do additional sample collection, storage and analyses on a global scale. Such efforts must be nurtured. We all live on this small planet and we breathe the same air. We have seen how events in our country will affect all of us. We need to discuss, in the near future, how and by what mechanisms we can bring about such international cooperation. Through an international, well-coordinated Environmental Specimen Bank Network, we should be able to ascertain the chemical trends in the environment which effect all of us, from acid rain to nuclear fall-out.

Frode Ulvedal, Ph.D.

Senior Health Scientist

Office of Health Research

U.S. Environmental Protection Agency 


\section{ABSTRACT}

In the past decade, interest in the concept of specimen banking for the archiving of biological and environmental samples for future analysis has increased significantly, and specimen banking is now recognized as an integral part of systematic environmental monitoring. Since the establishment of pilot Environmental Specimen Banking Programs in the U. S. and the Federal Republic of Germany (FRG) in the late 1970's, formal meetings have been held annually between representatives of these two programs to discuss results and future needs related to specimen banking. In recent years representatives of similar programs in Japan, Canada, and Sweden have joined in these meetings to expand the exchange of information.

In October, 1986, the 10th U.S.-German Seminar of State and Planning on Environmental Specimen Banking was held at the Virginia Institute of Marine Sciences in Gloucester Point, Virginia. At this meeting the current status of specimen banking activities in the U. S., FRG, Canada, and Japan was presented and discussed. This publication contains the proceedings of that meeting with contributions describing various activities related to banking and analysis of samples from aquatic, atmospheric, terrestrial, and human monitoring programs.

\section{DISCLAIMER}

Certain commercial equipment, instruments, or materials are identified in this report to specify adequately the experimental procedure. Such identification does not imply recommendation or endorsement by the National Bureau of Standards, nor does it imply that the materials or equipment identified are necessarily the best available for the purpose. 
TABLE OF CONTENTS

$\underline{\text { PAGE }}$

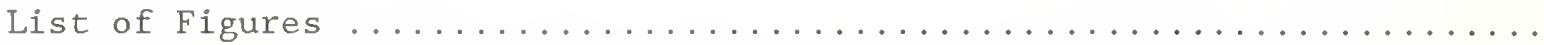

viii

List of Tables

xiii

\section{SECTIONS :}

1. Ongoing Activities of the Environmental Specimen Banking

Program in the Federal Republic of Germany - Ulrich Boehringer .....

2. Status of Specimen Banking Activities at National Bureau of

Standards - Stephen A. Wise, Barbara J. Koster, and

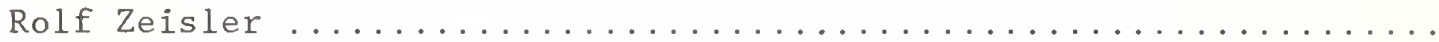

3. Specimen Banking: A Key Element of the National Oceanic and Atmospheric Administration's National Status and

Trends Program - Gunnar G. Lauenstein and John A. Calder ..........

4. Influence of Environmental Chemicals in the Aquatic

Environment - Istvan Gebefügi, Jan-Peter Lay, and

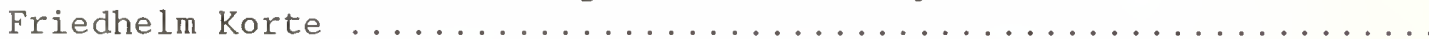

5. Analytical Methods for the Determination of Organic Contaminants in Marine Sediments and Tissues - Michele M. Schantz,

Stephen N. Chesler, Barbara J. Koster, and Stephen A Wise........

6. Comparative Investigations on Trace Metal Levels in Brown Algae and Common (Blue) Mussels at the Same Location in the Baltic Sea and the North Sea - M. Stoeppler, F. Backhaus, M. Burow, $\ddot{R}$. May, and C. Mohl

7. Inorganic Methods and Results for Marine Bivalves and Sediments - Susan F. Stone, Donald A. Becker, Barbara J. Koster, Peter A. Pella, Gerald Slater, Manoranjani, P. M. Tillekeratne,

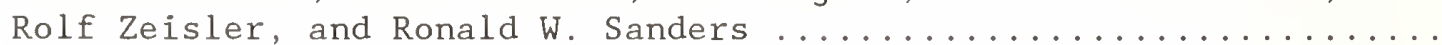

8. Improved Analytical Methodology for the Determination of PCBs and Pesticides in Human Liver Specimens - Reenie M. Parris,

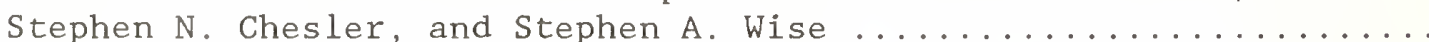

9. The Determination of Trace Elements in Human Livers - Rolf Zeisler,

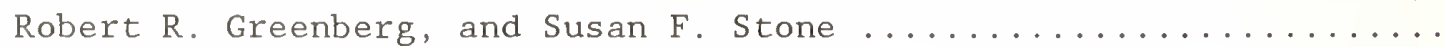

10. National Ambient Air Monitoring Program National Particulate

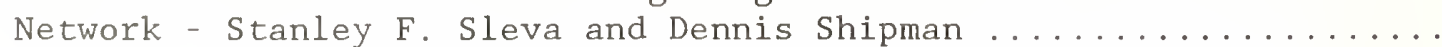

11. Chemicals in Indoor Air - Istvan Gebefügi and Friedhelm Korte ..... 
12. Banking of Atmospheric Particulate Matter Samples for Long-Term

Monitoring of Atmospheric Pollution and Related Reference

Material at the National Institute for Environmental

Studies - Yoshinari Ambe, Hitoshi Mukai, and Kensaku Okamoto ......

13. Analysis of PAH in Air Samples Obtained by Long- and Short-Term

Procedures - J. Jacob, G. Grimmer, K.-W. Naujack, and

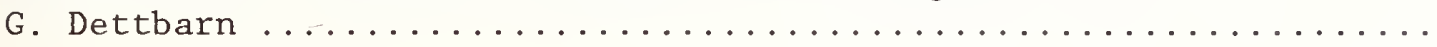

14. Trends and Effects of Environmental Contaminants Determined from Analysis of Archived Wildlife Samples - J. E. Elliott,

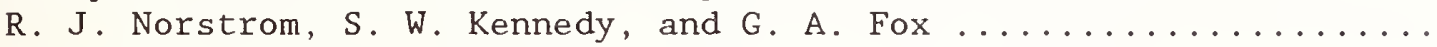

15. Wildlife as an Indicator for Environmental Contaminants in

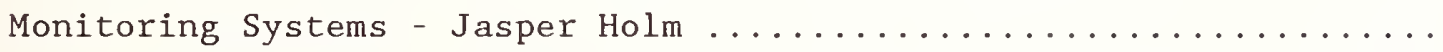

16. Regional Monitoring of Pollutants with Honey Bees - Jerry J.

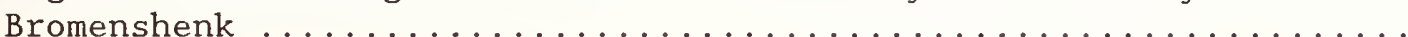

17. Quality Assurance as Applied to Long-Term Monitoring of Chemical Residues and Specimen Banking - R. Turle, R. J. Norstrom,

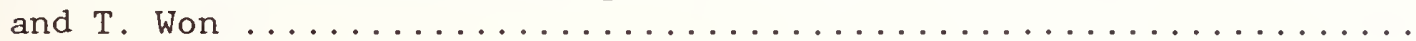

18. Preparation of Sample Material for Environmental Specimen Banking Purposes - Milling and Homogenization at Cryogenic

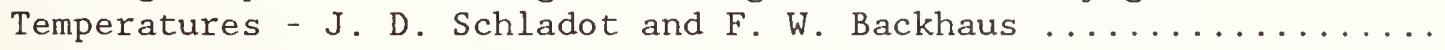

19. The Potential Role of Environmental Specimen Banking in Biosphere Reserves - William P. Gregg, Jr.

APPENDICES :

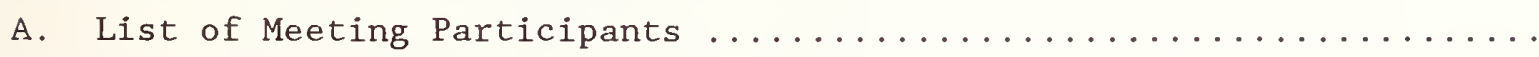




\section{LIST OF FIGURES}

Section 1:

Figure 1. Organization of the environmental specimen bank of the Federal Republic of Germany

Figure 2. Landscapes of the Federal Republic of Germany (published in: Hydrologischer Atlas der Bundesrepublik Deutschland)

\section{Section 2:}

Figure 1. Development of specimen banking activities at the National Bureau of Standards

\section{Section 3:}

Figure 1. Specimen bank sampling sites--Benthic Surveillance Project

Figure 2. Specimen bank sampling sites--Mussel Watch Project

\section{Section 4:}

Figure 1. Disappearance of hexachlorobenzene, pentachloronitrobenzene, and 4-chloroaniline from the water of experimental ponds

Figure 2. HCB-derived residues in an experimentally polluted small pond. A; Notonecta glauca, B; Libellula quadrimaculata, C; Lemna minor, D; Ranunculus aquatilus, and E; sediment

Figure 3. PCNB-derived residues in an experimentally polluted small pond. A; Notonecta glauca, B; Libellula quadrimaculata, C; Lemna minor, D; Ranunculus aquatilis, and $\mathrm{E}$; sediment

Figure 4. Disappearance of pentachloro- and 2,4,6-trichlorophenol from the water of the treated compartments

Figure 5. Dynamics of daphnia concentrations in the treated and untreated compartments

Figure 6. Concentration dynamics of three plankton species in the TCPtreated compartments

Figure 7. Dynamics of concentration of three plankton species in the PCP-treated compartment

Figure 8. Dynamics of concentrations of Chroococcus limneticus in the control compartments 
Figure 9. Dynamics of diatom concentrations (Nitzschia acicularis) in the treated and untreated compartments

Figure 10. Concentration dynamics of heterotrophic microorganisms in the water of the treated and untreated compartments

\section{Section 5:}

Figure 1. Flow diagram for the analysis of sediment samples

Figure 2. Flow diagram for the analysis of bivalve tissue samples

Figure 3. Chromatograms from the GC analysis of PAH fractions from a calibration solution (2) sediment extract, and (3) mussel extract

Figure 4. Chromatograms from the GC analysis of PCB fractions from a (1) calibration solution and (2) mussel extract

Figure 5. Chromatograms from the GC analysis of pesticide fractions from a (1) calibration solution, (2) sediment extract, and (3) mussel extract

Figure 6. Flow diagram of the procedure used by NOAA laboratories for analysis of the intercalibration sediment sample

\section{Section 6:}

Figure 1. Sampling locations for the comparative study of trace metal uptake and accumulation in brown algae (Fucus vesiculosus) and mussels (Mytilus edilus)

\section{Section 7:}

Figure 1. Sequential analysis procedure

\section{Section 8:}

Figure 1. Flow diagram of the analytical procedure

Figure 2. Gas chromatogram from the analysis of aminosilane Fraction I (electron capture detection)

Figure 3. Gas chromatogram from the analysis of aminosilane Fraction II (electron capture detection) 


\section{Section 9:}

Figure 1. Flow chart for the irradiation, decay and counting cycles of the activation analysis procedures

Figure 2. Comparison of As results in the 1984 human liver set using instrumental and radiochemical neutron activation analysis (INAA and RNAA) with recent literature data

Section 10:

Figure 1. Particulate sampling network - 1953

Figure 2. Particulate sampling network - 1986

\section{Section 11:}

Figure 1. Correlation between air humidity and PCP-concentrations in a model experiment

Figure 2. Lindane and pentachlorophenol accumulation on cotton surface

\section{Section 12:}

Figure 1. Banking program of atmospheric particulate matter samples

Figure 2. Sampling locations

Figure 3. Change of benzo[a]pyrene in atmospheric particles during storage

\section{Section 13:}

Figure 1. Schematic representation of the PAH-profile analysis of air suspended matter

Figure 2. Time-dependence of PAH-concentration during 24 hours (benzo[ghi] perylene, benzo[a]pyrene, dibenz[a,h] anthracene)

Figure 3. Time-dependence of PAH-concentration during 24 hours (benzo[b]naphtho[2,1-d] thiophene, benz [a] anthracene, benzo[e]pyrene)

Figure 4. Correlation between yield and boiling points of various PAH

Figure 5. Dependence of the yield on the air flow velocity 
Section 14:

Figure 1. PCB, DDE, oxychlordane and 2378-TeCDD concentrations in pools of Herring Gull eggs (8 to 10 eggs per pool) from Scotch Bonnet Island, Lake Ontario and Big Sister Island, Lake Michigan 19711982, as determined from re-analysis of samples stored in a specimen bank

Figure 2. High performance liquid chromatograms which illustrate the differences in liver porphyrin patterns in Herring Gull chicks from Port Colborne, 1974 (a) and Scotch Bonnet Island, 1974 (b)

Figure 3. Organochlorine levels (wet weight) in Northern Gannet eggs from Bonaventure Island, Quebec, 1969-1984, as determined from re-analysis of samples stored in a specimen bank

Section 15:

Figure 1. Regions for monitoring activities with wildlife in the east of Lower Saxony

Figure 2. Percentage frequency distribution of lead content in liver of various wildlife

Figure 3. Percentage frequency distribution of cadmium content in liver of various wildlife

Figure 4. Sum frequency function of random sample values for DDT in various wildlife

Figure 5. Sum frequency function of random sample values for PCB's in various wildlife

Figure 6. Toxic metal content in liver and kidney of roe deer in different areas of Lower Saxony (mean value in $\mathrm{mg} / \mathrm{kg}$ wet weight)

Section 17:

Figure 1. Standard of Aroclor 1254, EC detection, chromatographed on a $6^{\prime} \times 1 / 8 " \mathrm{OD}, 6 \% \mathrm{QF}-1$ and $48 \mathrm{SE30}$ on Chromosorb $\mathrm{W}$ (AW) column at $190^{\circ}, \mathrm{N}_{2}$ flow of $40 \mathrm{~mL} / \mathrm{min}$

Figure 2. A 1:1 mixture of Aroclors 1254 and 1260, chromatographed on a 60m DB-5 fused silica capillary column, EC detection, initial temperature $100^{\circ}$ for $2 \mathrm{~min}$, then $10^{\circ} / \mathrm{min}$. to $150^{\circ}$, then $3 \% \mathrm{~min}$ to $300^{\circ}$, the carrier velocity $25 \mathrm{~cm} / \mathrm{sec}$

Figure 3. DDE in Gannet eggs, Bonaventure Island, Quebec, 1969-76

Figure 4. PCBs in Gannet eggs from Bonaventure Island 1969-76 
Section 18:

Figure 1. Flow sheet showing the tasks of the environmental specimen bank Jülich

Figure 2. Flow sheet of Sample Preparation Procedure (SPP) for environmental species

Figure 3. Determination of grain size in fish material-dab (limanda limanda)

Figure 4. Homogeneity study of fish material-dab (limanda limanda) by determination of $\mathrm{Pb}$ and $\mathrm{Cd}$ in 6 random subsamples out of 950

Figure 5. Homogeneity study of fish material-dab (limanda limanda) by determination of As in six random subsamples out of 950

Figure 6. Homogeneity study of fish material-dab (limanda limanda) by determination of Se in six random subsamples out of 960 


\section{LIST OF TABLES}

\section{Section 1:}

Table 1. History of the Animals According to the Complete System of Nature Developed by the Knight Carl von Linné Designed by C.F.W. Roth, ca. 1783 Weimar, Garden-House of J.W. Goethe

Table 2. Preliminary List of Specimen Types in the Environmental Specimen Bank

\section{Section 2:}

Table 1. Existing and Proposed Projects in the Biomonitoring Specimen Banking Program

Table 2. Inventory of Specimens in the Biomonitoring Specimen Bank

\section{Section 3:}

Table 1. Trace Organic Contaminants to be Determined by the NS\&T Program's Specimen Banking Project

Table 2. Major and Trace Elements Determined for Archived Samples

Table 3. National Status and Trends Specimen Bank Inventory

\section{Section 5:}

Table 1. Mean Concentrations of Selected Organic Contaminants in NOAA Intercalibration Sediment ( $\mathrm{ng} / \mathrm{g}$ dry sediment)

Table 2. Concentrations of Selected Organic Contaminants in Six 1985 Benthic Surveillance Sediments (ng/g dry sediment)

Table 3. Concentrations of Selected Organic Contaminants in Six 1985 Mussel Watch Bivalve Tissue Samples (ng/g dry bivalve tissue)

\section{Section 6:}

Table 1. Contents of Trace Metals in Bimonthly Collected Samples of Algae (Fucus Vesiculosus) and Mussels (Mytilus Edulis) at Eckwarderhoerne (North Sea)

Table 2. Comparative Trace Metal Determinations in Algae and Mussels from the Same Collection Site, Summarizing Overview for Arsenic, Mercury, Lead, Cadmium, and Nickel 
Section 7:

Table 1. Elemental Concentrations for Selected Reference Materials (concentrations based on dry weight)

Table 2. Elemental Concentrations for Certified Reference Material IAEA Sediment SD-N-1/2 (concentrations in mg/kg dry weight)

Table 3. Elemental Concentrations for Selected Bivalve Samples (concentrations based on dry weight)

Table 4. Elemental Concentrations for NS\&T 1985 Benthic Surveillance Sediment Samples

\section{Section 8:}

Table 1. Range of Concentrations of Selected PCBs and Pesticides in 24 Human Liver Samples

\section{Section 9:}

Table 1. Ranges of Trace Element Concentrations in Selected Human Liver Specimens

Table 2. Limits of Detection $(\mu \mathrm{g} / \mathrm{kg}$ ) for Seven Critical Elements

\section{Section 10:}

Table 1. Comparison by Pollutant of National Air Monitoring Stations 1977 vs . 1986

Table 2. National Summary of SLAMS Monitors

\section{Section 11:}

Table 1. Pentachlorophenul, Lindane, Chlorinated Dibenzodioxin and Dibenzofuran in Samples of Wood, Dust, and Textiles

\section{Section 12:}

Table 1. Comparison of the Concentration of Benzo[a]pyrene in the Simultaneously Sampled Four Filters

Table 2. Change of $\mathrm{B}[\mathrm{a}] \mathrm{P}$ in Atmospheric Particles after 4 Years Storage

Table 3. Analytical Values for NIES Certified Reference Material No. 8 "Vehicle Exhaust Particulates" 


\section{Section 13:}

Table 1. PAH Profiles on Air Particulate Filters (ng $\mathrm{PAH} / \mathrm{m}^{3}$ )

Table 2. PAH-Profiles Collected on a Glass Fiber Filter and a Subsequent Porapak PS Filter (ng $\mathrm{PAH} / \mathrm{m}^{3}$ )

Table 3. PAH-Profiles on Glass Fiber Filters (ng $\mathrm{PAH} / \mathrm{m}^{3}$ )

Table 4. PAH-Profiles Recorded at a Vehicle-Exhaust Polluted Location

\section{Section 15:}

Table 1. Different Contaminations to be Expected in 5 Regions in the East of Lower Saxony

Table 2. Criteria for Bioindicators in Monitoring Studies

Table 3. Chlorinated Hydrocarbons in Organs of One Year old Roebucks from the Forest Near Braunschweig

Table 4. Limits of Detection for Elements Determined by ICP

\section{Section 17:}

Table 1. Pesticides Determined in Canadian Wildlife in 1968

Table 2. Changes in CWS Analytical Methodology for PCBs 1968-1986

Table 3. Analysis of Gannet Eggs from Bonaventure Island 1969

Table 4. Re-analysis of 1969 Gannet Eggs, Bonaventure Island

Table 5. Interlaboratory Comparison of CWS 1979 Reference Material

Table 6. Application of Acceptable Criteria

\section{Section 18:}

Table 1. Homogenization Study of Fish Material by Determination of Chlorinated Hydrocarbons 



\title{
SECTION 1 \\ ONGOING AGTIVITIES OF THE ENVIRONMENTAL SPECIMEN BANKING PROGRAM IN THE FEDERAL REPUBLIG OF GERMANY
}

\author{
Ulrich R. Boehringer \\ Umwel tbundesamt \\ Federal Environmental Agency \\ Bismarckplatz 1 \\ D-1000 Berlin, 33 \\ FEDERAL REPUBLIC OF GERMANY
}

\section{INTRODUCTION}

At the 8 th Seminar of State and Planning on Environmental Specimen Banking in Gaithersburg, I announced the intention of the German Federal Government to establish a permanent German Environmental Specimen Bank in 1985. The results obtained up to that time indicated that the pilot project on Environmental Specimen Banking would be concluded successfully. As you know, this plan of the Federal Government was realized. The first steps of this activity were presented at the 9 th seminar in Reisensburg last year.

At that seminar, I gave a survey of the areas for sampling and of the proposed specimens that were under discussion at that time. The progress made since then will be presented by my German colleagues in other sections of this publication. I will give a survey of the organization of the permanent bank and explain the list of the specimen types proposed.

\section{ORGANIZATION}

Under the supervision of the newly established Federal Ministry for the Environment, Nature Conservation and Nuclear Safety, the Federal Environmental Agency coordinates the permanent German bank. The ministry has to harmonize the program with the following three ministries (Figure 1): (1) the Federal Ministry for Research and Development, (2) the Federal Ministry for Youth, Family, Women and Health, and (3) the Federal Ministry for Food, Agriculture and Forestry.

The Umweltbundesamt (Federal Environmental Agency) guides the bank scientifically and administratively, harmonizes the project with other national and international activities, and initiates Research and Development projects. The database of the bank will be connected with the environmental information and documentation system of the agency. The Umweltbundesamt will also be the secretariat of the scientific advisory committee.

The work that needs to be done to run the bank is too specialized to be carried out by just one institution. Therefore, five institutes are at present involved in this program. 
First of all, the two banking facilities are in Jülich at the Nuclear Research Center (KFA) and in Münster at the Institute for Pharmacology and Toxicology of the Westphalian Wilhelm-University. The bank in Jülich is responsible for:

September 1986

Exrironmental scecamen. Bank of the

federa: Republic of Germany

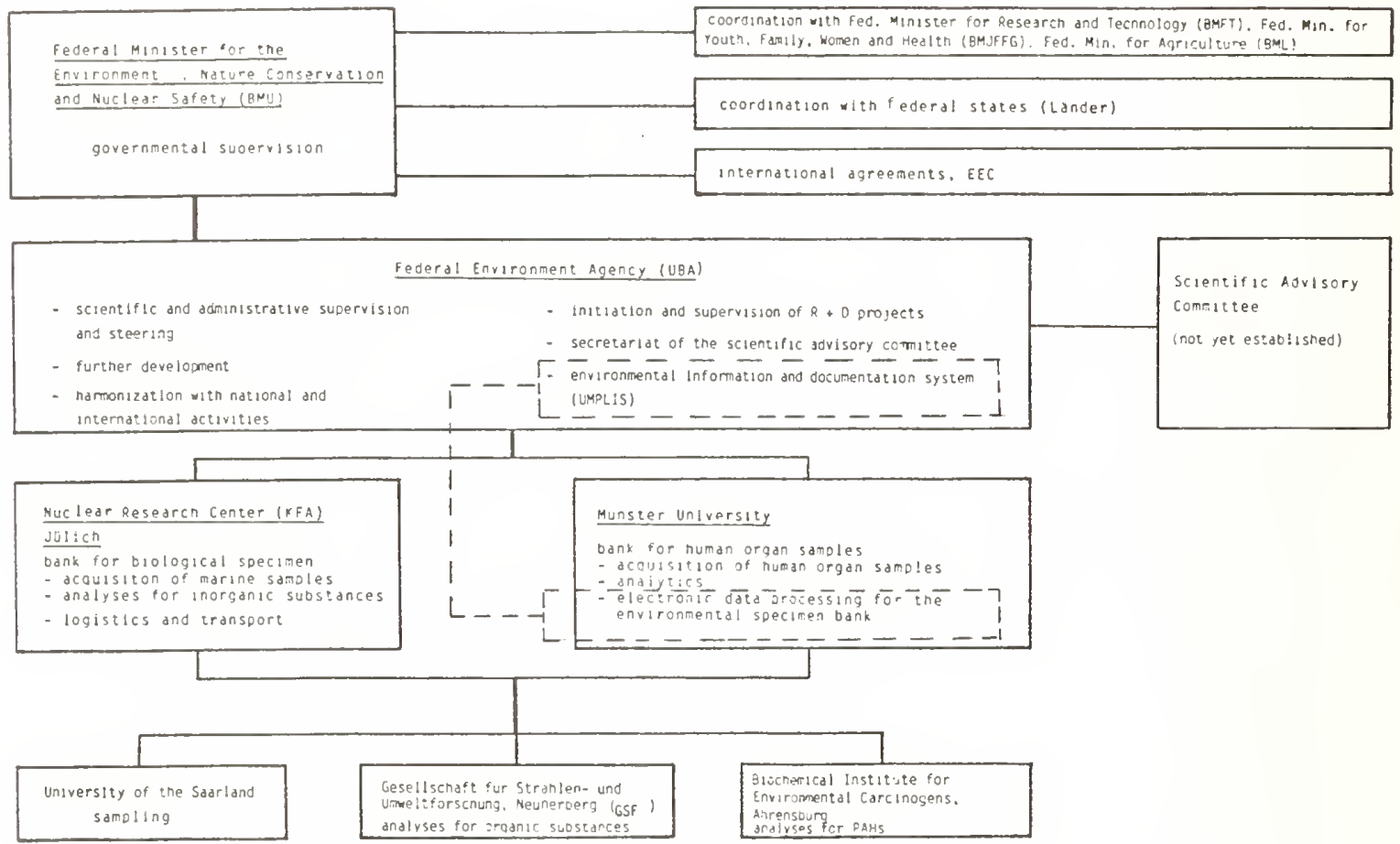

Figure 1. Organization of the environmental specimen bank of the Federal Republic of Germany

1. storage of the biological specimens, other than the human organ samples,

2. collecting the marine samples,

3. inorganic analyses, and

4. transportation of the samples under cryogenic conditions.

The university in Münster is responsible for all activities in the human sector: sampling, characterization, analysis, and storage. Additionally, the database for the German Environmental Specimen Bank will be set up in Münster.

The University of the Saarland, the Chair of Biogeography of this University, to be exact, is responsible for collecting the biological samples and for their characterization. The two other institutes, the Institute for 
Ecological Chemistry at the Gesellschaft für Strahlen - und Umweltforschung in Neuherberg near Munich and the Biochemical Institute for Environmental Carcinogens in Grosshansdorf near Hamburg, analyze the samples for halogenated organic ingredients and polycyclic aromatic hydrocarbons (PAH), respectively. In addition, several Research and Development projects are on-going or planned. These activities are described in detail in the papers in other sections of these proceedings (see Sections 4, 6, 11, 13, 15 and 18).

\section{SPECIMEN SELECTION AND AREA SELECTION}

After we had solved the technical questions involved in the operation of an environmental specimen bank, we had to select representative areas for sampling and the representative species that live in these areas. As you know, the plant and animal species were classified by the Knight Carl v. Linné. His compilation of zoological species, called the history of the animals, is shown in Table 1.

Carl v. Linné also founded the Museum of Natural History in Sweden at which an Environmental Specimen Bank is also located [1].

As you can see, Linné divided the animals up into mammals, birds, fishes, insects, worms, and amphibians. You can imagine how difficult it is to select representative and suitable species for an environmental specimen bank. For example, look at the mammals in Table 1. For man alone two species exist, the day species and the night species.

In following this compilation we had three workshops, where this problem of the selection of species was discussed extensively.

1. 1977 in Luxembourg:

The use of Biological Specimens for the Assessment of Human Exposures to Environmental Pollutants [2];

2. 1978 in Berlin:

Monitoring Environmental Materials and Specimen Banking [3]; and

3. 1982 in Saarbrücken:

Environmental Specimen Banking and Monitoring as Related to Banking [4].

It was agreed at these workshops that the three spheres, the human, the aquatic, and the terrestrial, should be represented in an environmental specimen bank.

In 1985, we had two meetings of experts for the selection of species for the German Environmental Specimen Bank. The following list shows the species proposed by the experts (Table 2). Some of these species have already proved suitable during the pilot project, e.g., grass, poplar leaves, zebra mussels, 
Table 1. History of the Animals According to the Complete System of Nature Developed by the Knight Carl von Linné Designed by C.F.W. Roth, ca, 1783 Weimar, Garden-House of J.W. Goethe

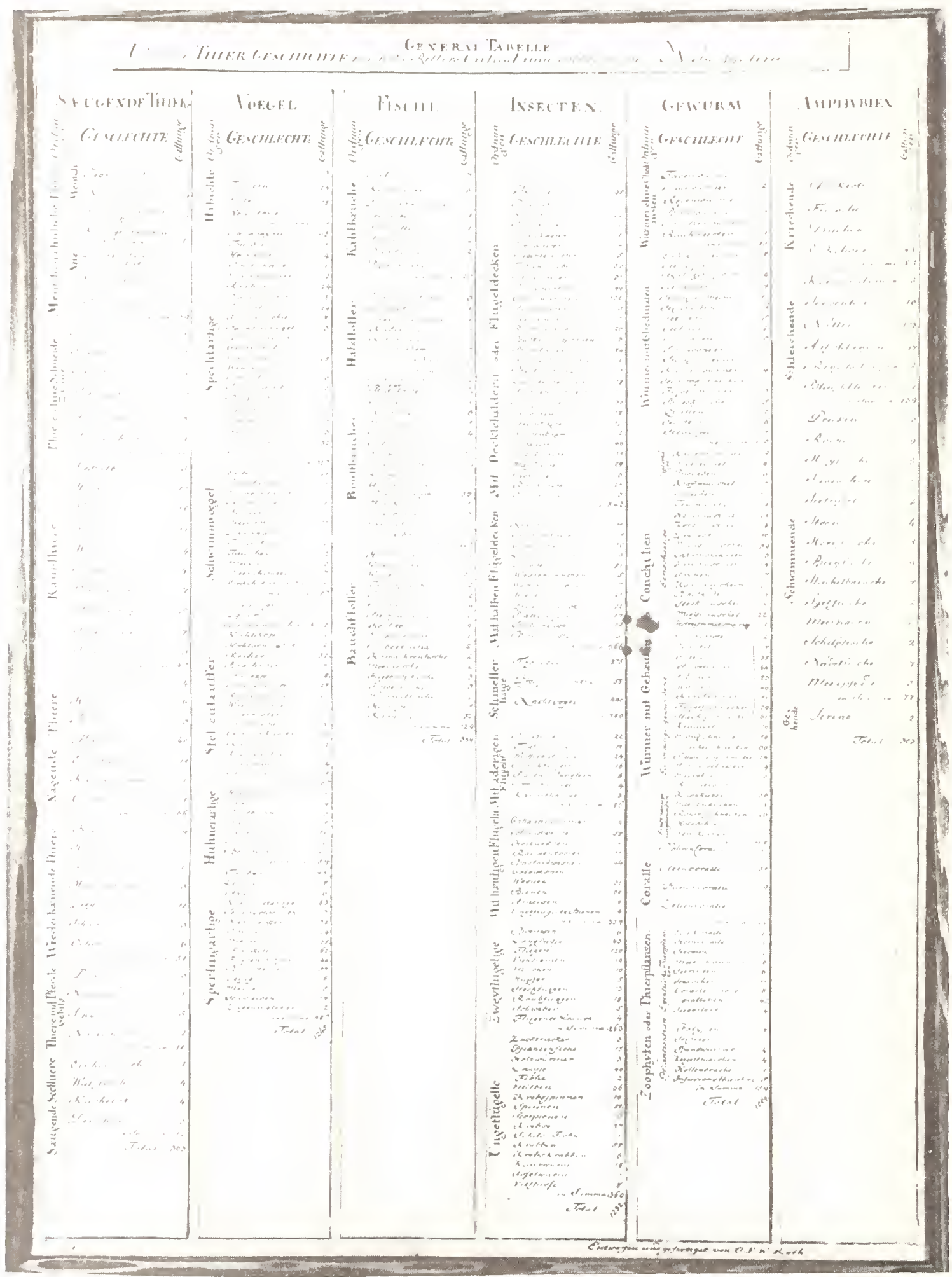




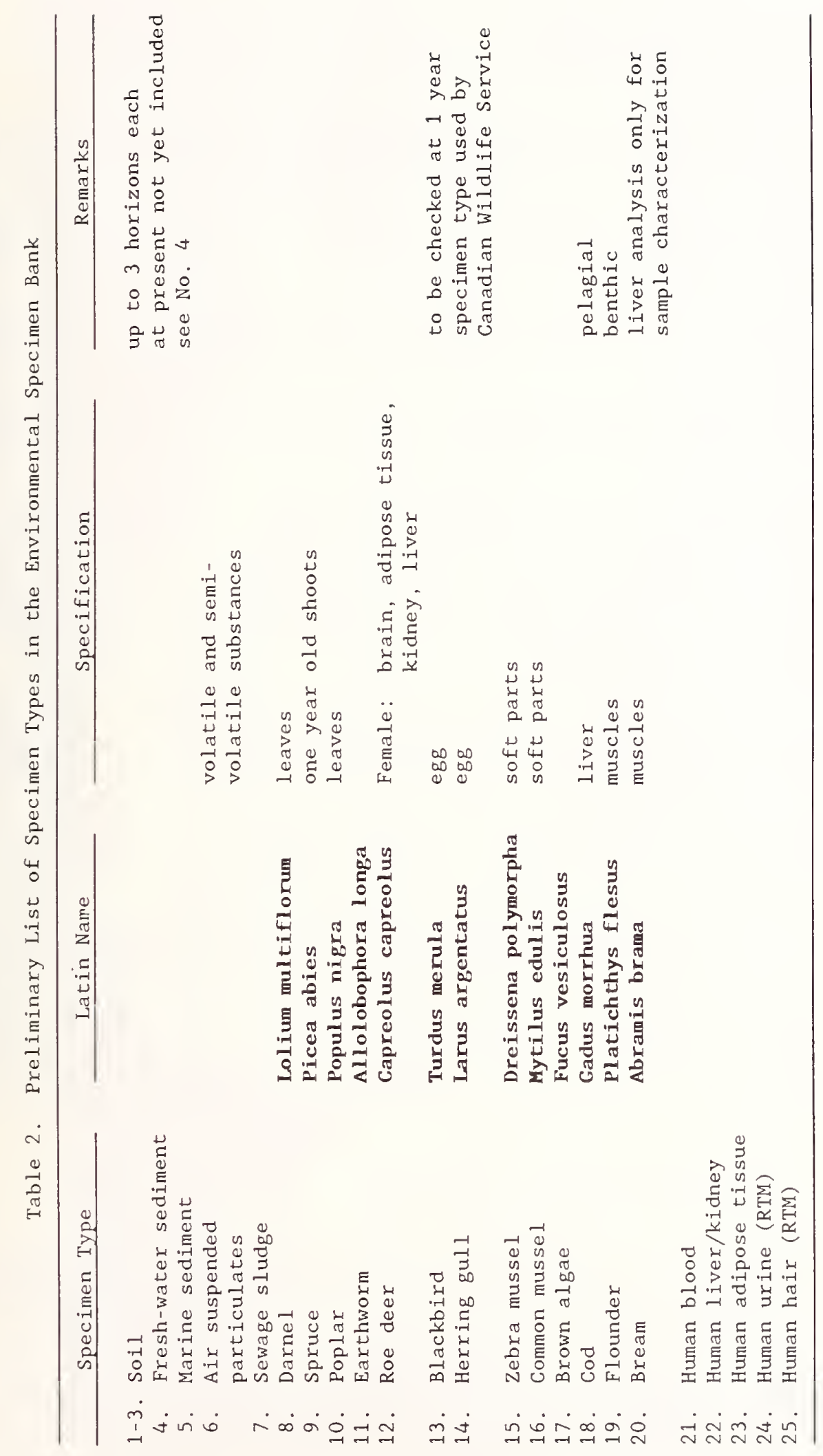


and algae. I will give some comments on other specimens investigated for inclusion in the permanent Specimen Bank.

1. Not enough sample materials can be obtained from the earthworm. Therefore, a research project is under way to investigate how the sampling method can be optimized. The other problem is how to remove the soil from the intestines. Three methods exist: to feed the earthworms cellulose, to dissect the earthworm and wash the soil out of the earthworm or to massage them.

2. A research project is in progress to investigate what tissue of the roe deer is best suited for the specimen bank.

3. Since we cannot obtain enough eggs from the black bird, we will have to choose another species. The pigeon is being discussed as a substitute species.

4. The Herring Gull (Larus argentatus) of the Great Lakes is not identical with the European Herring Gull. Furthermore, the European Herring Gull gets its food from waste dumps among other sources; it is a scavenger or a so-called food opportunist. Therefore, this species is not very representative for the environment.

5. For the marine sphere, we are presently discussing whether a tern species, the Sandwich Tern (Sterna sanvicensis), is suitable for the purposes of the bank.

6. The specimen "air-suspended particulates" has been added to the list since our last meeting.

The other main question has been the selection of areas. The Federal Republic of Germany has different types of landscapes, from the sea in the north to the Alpes in the south (Figure 2). Therefore, you find very different ecosystems and the question arises which of these are the most representative ones. Furthermore, the sampling areas should also be used for environmental monitoring and ecosystem research. The following lecture on the Selection of National Ecological Assessment Parks in the Federal Republic of Germany will give you information on this subject.

\section{INFORMATION SYSTEM}

Background information on the samples collected is essential for making a comprehensive trend analysis. We will start in the near future a research and development project to establish an information system for the database. Not only do we have to collect the information directly concerning the sample, e.g., sampling site, sampling date, characterization and storage, but it is also necessary to describe the system out of which the sample is collected, e.g., data on geography, meteorology, soil, land use, etc. The systems are dynamic; therefore, the data has to be updated regularly. Together with this information, the specimens can be classified and assessed much better. It will 


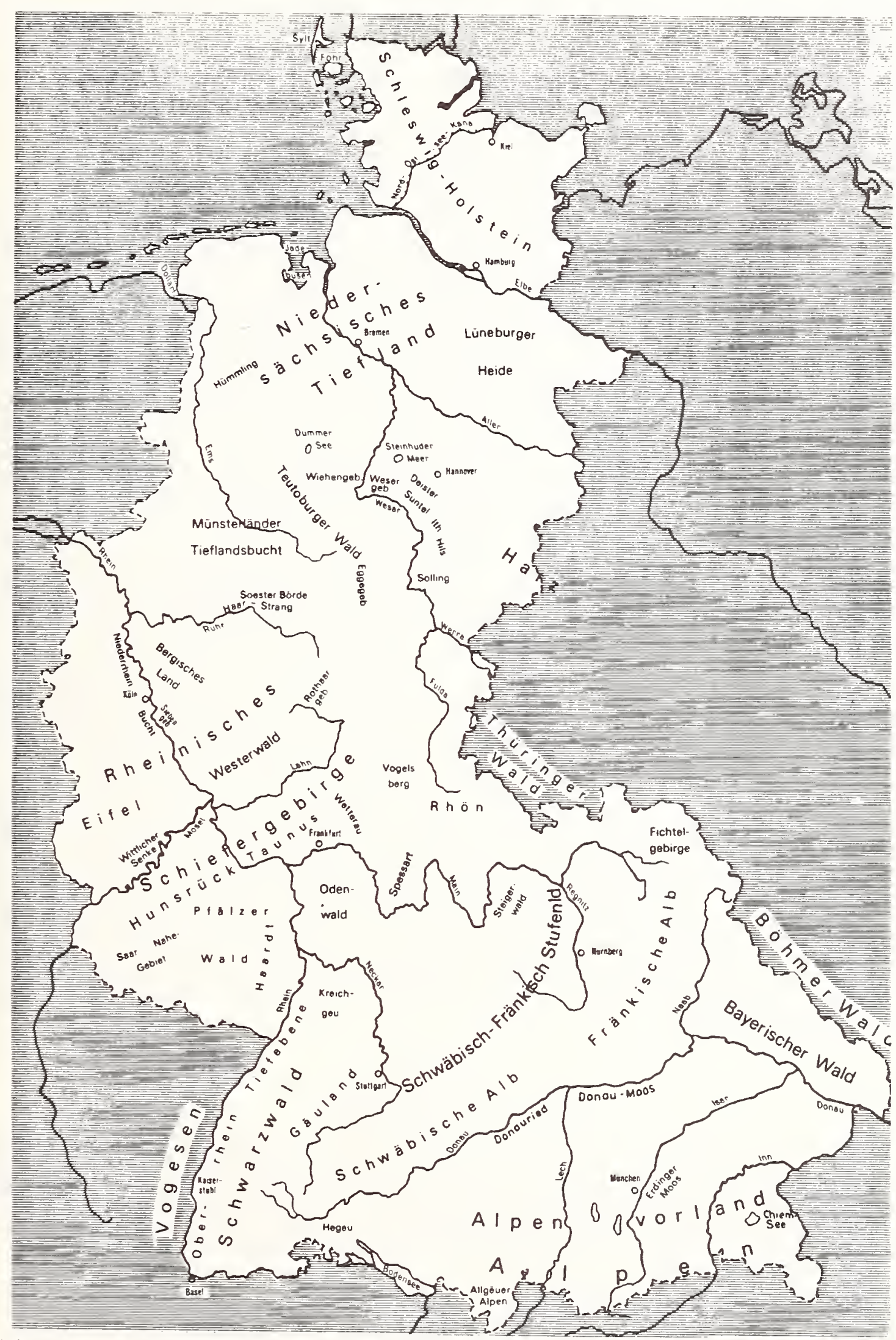

Figure 2. Landscapes of the Federal Republic of Germany (published in: Hydrologischer Atlas der Bundesrepublik Deutschland) 
take some time and effort until we know the minimum set of information needed for a sampling site.

\section{EXAMPLE FOR THE VALUE OF STORED SAMPLES}

In conclusion, I will present a recent result from the 6th International Symposium on Chlorinated Dioxins, held in Fukuoka, Japan, September 16-19, 1986. It is a classic example for the value of stored samples. The chlorinated dioxins, highly toxic chemicals in multiple animal species, are known to be the synthetic contaminants of certain synthetic chemicals. Relatively recently, it has been proposed that the chlorinated dioxins may be formed in trace amounts, at least, by the combustion of wood not treated with chemicals: the trace chemistry theory of the origin of dioxins.

If this is the case, chlorinated dioxins would have existed prior to the synthesis of chemicals known to contain trace amounts as contaminants, essentially at the beginning of this century. Thus, animals and man might have evolved in the presence of these compounds.

More recently, Hites and coworkers found, in sediment cores from the bottom of certain lakes, dioxins to have been present only relatively recently, probably related to chemical manufacture and possibly incineration.

Schecter and coworkers [5] (State University of New York) found in nonindustrialized countries low levels of dioxin in human tissues and higher levels $(1,200 \mathrm{ppt}$ ) in adipose tissue of persons in industrial countries. This suggests an anthropogenic origin of most polychlorinated dibenzodioxins.

To provide further data to test this hypothesis as to the anthropogenic origin of most dioxins, Schecter and coworkers analyzed human liver and lung tissue from two female Eskimos, frozen over a hundred years ago, and meat found in their home, as well as charred wood from an ancient California redwood tree. Since the lungs were found on histologic evaluation to have pneumoconiosis from burning of fuel combined with poor ventilation, lungs as well as liver were of interest. They found non detectable levels of dioxin. Therefore, the results are consistent with an anthropogenic origin for most dioxin and not with the above mentioned theory.

\section{ACKNOWLEDGMENT}

Let me conclude my remarks with thanks to Stephen A. Wise and his coworkers from National Bureau of Standards for organizing this seminar and to EPA for supporting it. We welcome the fact that other government agencies in the USA have joined the Environmental Specimen Banking Program. It demonstrates the increasing importance of this task for the future. 


\section{REFERENCES}

[1] Olsson, M. (1985), The Environmental Specimen Bank at the Swedish Museum of Natural History, International Review of Environmental Specimen Banking, S. A. Wise and R. Zeisler, Eds., NBS Spec. Publ. 706, U.S. Government Printing Office, Washington, DC, pp. 22-33.

[2] Berlin, A., Wolff, A. H., and Hasegawa, Y., Eds. (1979), The Use of Biological Specimens for the Assessment of Human Exposure to Environmental Pollutants, Martinus Nijhoff Publishers, The Hague, 368 pp.

[3] Luepke, N.-P., Ed. (1979), Monitoring Environmental Materials and Specimen Banking, Martinus Nijhoff Publishers, The Hague, 591 pp.

[4] Lewis, R. A., Stein, N., and Lewis, C. W., Eds. (1984), Environmental Specimen Banking and Monitoring as Related to Banking, Martinus Nijhoff Publishers, Boston, MA, $358 \mathrm{pp}$.

[5] Schecter, A., Gross, M., and Dekin, A. (1986), Human Tissue Levels of PCDD and PCDF in Over One Hundred Year Old Frozen Eskimo Tissue, Meat, and California Redwood Charcoal and Their Relation to the Trace Chemistry Theory of Dioxin Origin, Abstracts of Dioxin '86, 6th Int. Symp. on Chlorinated Dioxins and Related Compounds, Fukuoka, Japan, Sept. 16-19, 1986. 


\title{
SECTION 2
}

\section{STATUS OF SPECIMEN BANKING ACTIVITIES AT THE NATIONAL BUREAU OF STANDARDS}

\author{
Stephen A. Wise, Barbara J. Koster, and Rolf Zeisler \\ Center for Analytical Chemistry \\ National Bureau of Standards \\ Gaithersburg, Maryland 20899 \\ USA
}

\section{INTRODUCTION}

Since 1975 the National Bureau of Standards (NBS) and the U.S. Environmental Protection Agency (EPA) have been involved in the development of methods and procedures for environmental specimen banking. In 1975 the Federal Republic of Germany (FRG) and the U.S. EPA agreed to cooperate in the study of envirommental specimen banking activities and proposed the establishment of "pilot phase" specimen banks in both countries. The purpose of the EPA/NBS Environmental Specimen Bank Program was to determine the feasibility of longterm storage of environmental and biological specimens for the determination of inorganic and organic constituents. In 1980 a "pilot" environmental specimen bank was established at NBS to evaluate the feasibility of a large-scale National Environmental Specimen Bank. The pilot Environmental Specimen Bank program was to provide working experience in all aspects of specimen banking, e.g., in specimen collection, processing, storage, and analysis.

The approach of the EPA/NBS pilot Environmental Specimen Bank was to gain experience in the collection, storage, and analysis of four types of environmental accumulators: (1) human tissue, (2) marine tissue, (3) food, and (4) air. The goals of the pilot phase were:

1. To develop procedures for the sampling, processing, storage, and analysis of four types of environmental accumulators;

2. To evaluate and improve analytical methods for the determination of trace element and organic pollutants in biological matrices;

3. To evaluate the feasibility of long-term storage of environmental samples under various conditions;

4. To establish baseline data on selected environmental samples, and;

5. To evaluate the potential application of specimen banking for trend monitoring and for providing samples for retrospective analyses as concerns about new pollutants arise and as new analytical techniques are developed.

Since 1980 the EPA/NBS Pilot Environmental Specimen Bank has been involved in the collection, storage, and analysis of the first sample type, human liver tissue. However, the remaining three sample types (i.e, marine, food, and air 
accumulators) were not incorporated fully into the EPA pilot banking program as originally proposed.

During the past year the specimen banking concept at NBS has been modified to reflect the interests of other agencies in specimen banking activities. A proposed concept for the development of specimen banking activities at NBS is outlined in Figure 1. The development of the specimen banking concept consists of three phases: the pilot phase, project phase, and network phase. The pilot phase is near completion and has been described briefly above and in other publications [1-3]. The project phase and proposed network phase are described in the following sections.

\section{PROJECT PHASE}

In 1986 the program moved towards a "project phase" of the Biomonitoring Specimen Bank Research Project. This title reflects the change from solely environmental aspects to the inclusion of specimens of nutritional and medical importance. At present there are five existing specimen banking activities within the NBS specimen banking program, and several other projects are proposed for incorporation into the program in the coming years (see Table 1).

Table 1. Existing and Proposed Projects in the Biomonitoring Specimen Banking Program

EXISTING PROJECTS:

1. EPA Environmental Specimen Bank Program (human livers)

2. NOAA NS\&T Marine Monitoring Program

3. NCI Chemoprevention Program

4. IAEA/USDA/FDA Trace Nutrients in Human Diet Project

5. NOAA Alaska Marine Mammal Archive

PROPOSED PROJECTS:

1. EPA Human Adipose Tissue Monitoring Program

2. National Health and Nutrition Examination Survey (NHANES-III)

\section{A. Existing Projects}

\section{EPA Specimen Bank Program}

The EPA-NBS Specimen Bank Program will continue to serve as the focal point for specimen banking-related activities during the project phase. The pilot phase of the EPA specimen banking activities resulted in a number of outputs including the following:

1. Development of protocols for the sampling, processing, and storage of environmental/biological specimens (e.g., human liver and 


\section{SPECIMEN BANK CONCEPT}

$1980-1985$

PILOT PHASE

\section{NATIONAL ENVIRONMENTAL SPECIMEN BANK}

1986 - 1990

PROJECT PHASE

\section{BIOMONITORING SPECIMEN BANK RESEARCH PROJECT}

COORDINATING COMMITTEE

Participants' Meeting

$1990+$

NETWORK PHASE
NATIONAL BIOMONITORING SPECIMEN BANK SYSTEM

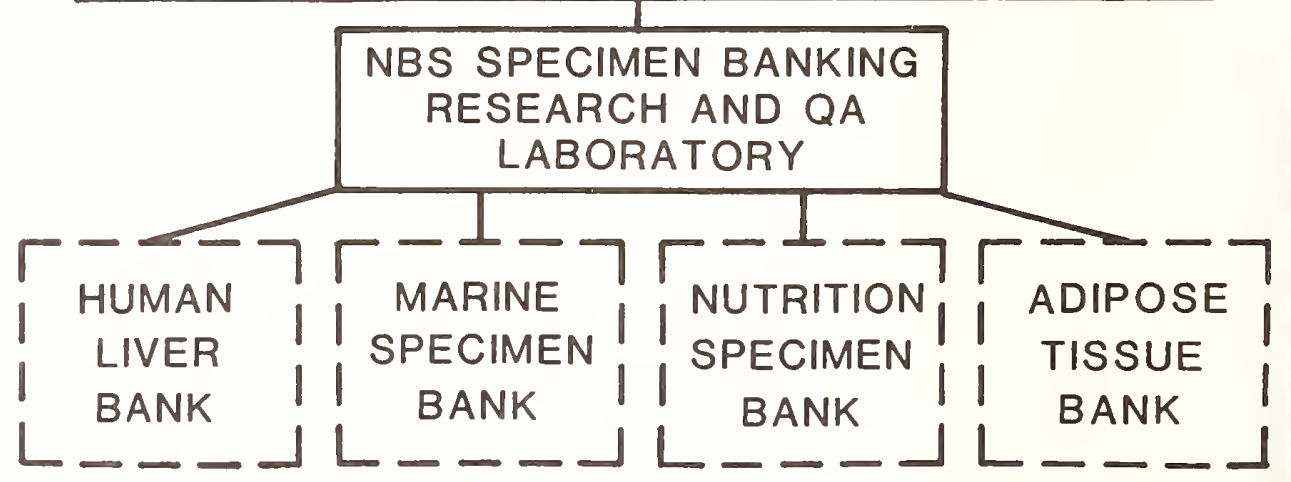

Figure 1. Development of specimen banking activities at the National. Bureau of Standards 
marine bivalves); development of cryogenic homogenization procedures for biological specimens;

2. Improved analytical methods for the determination of inorganic and organic constituents in environmental/biological samples;

3. Analytical baseline data for inorganic constituents on 96 liver specimens from three collection periods (1980, 1982, and 1984); analytical data for organic constituents (PCBs and pesticides) on 60 liver specimens from two collection periods (1982 and 1984);

4. An archive of over 500 human liver specimens and a large collection of mussels which are available for future investigations.

The expertise developed during the EPA pilot project has been implemented in other specimen bank projects at NBS as well as by researchers in other programs. For example, sampling and homogenization procedures for human liver and mussels developed in the pilot project were used as the starting point for the development of the protocols used in the National Status and Trends Program sponsored by the National Oceanic and Atmospheric Administration (NOAA) (see discussion below). The existing analytical data base on inorganic and organic constituents in human livers collected from 1980 to the present and the over 400 unanalyzed specimens in the bank represent a substantial resource and a unique opportunity for EPA to investigate pollution trends. During the next year the activities of the EPA-NBS project will be directed towards the evaluation of the analytical data base for possible trends and the evaluation of the compositional stability of the human liver specimens stored under different conditions.

NOAA National Status and Trends Program

In 1985 a specimen banking project was initiated at NBS with the National Oceanic and Atmospheric Administration (NOAA) as part of their National Status and Trends (NS\&T) Program to monitor the U.S. marine environment [4]. The NS\&T program consists of two monitoring programs: (1) the Benthic Surveillance Project, in which sediment and fish tissue (muscle and liver) are collected annually from approximately 50 coastal sites and (2) the Mussel Watch Project, in which bivalves (mussels and oysters) and sediment are collected annually from approximately 150 coastal sites. As part of the NOAA NS\&T program, NBS provides the following specimen banking activities:

1. Develop sampling, homogenization, and storage protocols for sediment, bivalve, fish muscle, and fish liver samples;

2. Archive specimens of sediment and tissue from 12 sites of the Benthic Surveillance Project and mussels/oysters and sediment from 30 sites in the Mussel Watch Project each year; a complete set of samples from all sites will be archived after five years. 
3. Analyze selected samples of sediment, bivalves, and fish livers for the determination of selected trace elements (15 elements) and organic compounds (organochlorine pesticides, PCBs, and PAH);

4. Analyze sediment and tissue intercalibration materials as quality assurance exercises.

In addition to the specimen banking activities for the NOAA NS\&T program, NBS is involved in the NOAA NS\&T program as the laboratory responsible for organic analysis quality assurance activities. These activities include the preparation and distribution of control and/or intercalibration materials and calibration solutions to the various laboratories involved in making analytical measurements for the NS\&T program and organizing annual quality assurance workshops to discuss the quality of the analytical data generated within the program. NOAA is also supporting NBS in the preparation of a marine sediment to be issued as a Standard Reference Material for the determination of organic pollutants. Both of these activities complement and support the efforts related to specimen banking of marine specimens.

\section{IAEA/FDA/USDA/NBS Nutrients in Human Diet Program}

NBS, the Food and Drug Administration (FDA), and the Department of Agriculture (USDA) are collaborating in a coordinated research program sponsored by the International Atomic Energy Agency (IAEA) to obtain comparative data on the dietary intakes of 23 nutritionally important minor and trace elements in a number of developing and developed countries [5]. In the U. S. effort, which combines the expertise of the three participating government agencies, four aspects are addressed: (1) benchmark total diet samples from the FDA Total Diet Study (TDS) are prepared and analyzed to provide data for the IAEA project; (2) representative portions of these benchmark samples are stored in the NBS specimen bank facility; (3) research is carried out to develop analytical techniques for the determination of a number of constituents in total diet samples and to develop a total diet reference material; (4) the immediate and long-term stability of such total diet samples with respect to organic and inorganic nutrients during handling and storage are investigated.

Several tasks related to the total diet study are included in the expansion of specimen banking activities to this field:

1. Bank aliquots of mixed total diet samples based on the FDA market basket collections;

2. Methods development, analyses, and quality assurance;

3. Intercomparison of analytical methods for trace elements in existing dietary reference materials;

4. Preparation of U.S. mixed diet research material from the 200 different food groups in the FDA Total Diet Study $(10 \mathrm{~kg})$; and

5. Determination of long-term stability of trace constituents in the total diet composite. 
Future collections of this total diet sample will include the variations in season as well as the four major areas of FDA's TDS. Within several years, a complete inventory of the FDA market basket survey will exist in the proposed Biomonitoring Specimen Bank.

\section{National Cancer Institute (NCI) Chemoprevention Program}

As part of a quality assurance program of the National Cancer Institute Chemoprevention Program, NBS is serving as the reference laboratory for the NCI contract laboratories involved in the determination of nutrients in human serum. The following analytes are currently included in the study: zinc, selenium, beta-carotene, retinol, alpha-tocopherol, and ascorbic acid. As part of this program NBS prepares and distributes intercalibration samples to the various laboratories. Since the long-term stability of these nutrients in serum (frozen and lyophilized) is unknown, selected intercalibration serum samples and calibration solutions have been archived under various storage conditions. These samples are periodically removed from the bank and analyzed to determine the stability of these nutrients in the specimens. These stability investigations will provide additional information on the behavior of various matrices with respect to long-term specimen banking.

\section{NOAA Alaska Marine Mammals Tissue Archive}

NOAA will be banking selected tissues from marine mammals for the future determination of contaminants associated with offshore oil and gas development. A pilot program has been initiated to develop and implement sample collection protocols for liver, muscle, and adipose tissue from marine mammals. Fur bearing seals will be the first specimen type included in this study. Additional species of Alaska marine mammals from will be incorporated into the archive in future years.

\section{B. Proposed Projects}

Several other projects have been discussed as possible additions to the Biomonitoring Specimen Bank Program to broaden the scope of specimen banking activities within the program.

\section{EPA Human Adipose Tissue Monitoring Program}

Since the mid-1960's, EPA has conducted a monitoring program to measure organochlorine pesticides and $\mathrm{PCB}^{\prime} \mathrm{s}$ in human adipose tissue. At present adipose tissue samples are collected from approximately 1000 sites across the U.S. Portions of the tissue specimens have been stored when excess material was available after analyses. Recently, this tissue monitoring program has expanded their analytical procedures to include volatile organics as well as the semi-volatile compounds measured in the past. EPA has expressed interest in including NBS in this program to serve in a quality assurance and specimen banking role. NBS could store a small, representative number of specimens from the program under more rigid conditions to serve as reference samples and to investigate storage stability. 
National Health and Nutrition Examination Survey (NHANES-III)

As the National Center for Health Statistics (NCHS) plans the third National Health and Nutrition Examination Study (NHANES-III), with participation of the EPA, the Centers for Disease Control (CDC), and other interested agencies, the opportunity exists to incorporate the concept of specimen banking into the program to enhance the usefulness of the data gathered. As part of NHANES-III, aliquots of the serum and urine specimens analyzed in the various assays (or a selected fraction of the total specimens analyzed) should be banked for future analysis. Discussions are in progress concerning how specimen banking activities can best be utilized in NHANES-III.

\section{NETWORK PHASE}

The project phase will provide experience in the sampling, processing, storage, and analysis of a variety of biological matrices as summarized in Table 2. The existing projects in the "project phase" now include three of the four environmental accumulators originally intended for the EPA/NBS pilot Environmental Specimen Bank Program (i.e., human, marine, and food). The project phase will also bring together the different government agencies responsible for contaminants, nutrients, and biologically important constituents in these various matrices to coordinate their efforts in specimen banking. This cooperation will form the basis for the establishment of a National Biomonitoring Specimen Bank System consisting of a network of satellite banks directed towards specific projects as illustrated in Figure 1. EPA/NBS Specimen Bank would serve as a resource facility to conduct research related to the needs of specimen banking and as a quality assurance laboratory for the analytical measurements required in the various satellite banking programs.

\section{REFERENCES}

[1] Zeisler, R., Harrison, S. H., and Wise, S. A. (1983), The Pilot National Environmental Specimen Bank - Analysis of Human Liver Specimens, NBS Spec. Publ. 656, U.S. Government Printing Office, Washington, DC, 135 pp.

[2] Zeisler, R. and Wise, S. A. (1985), Quality Assurance and Protocols in Sample Preparation of Biological Samples, In: Biological Reference Materials: Availability, Uses, and Need for Validation of Nutrient Measurements, W.R. Wolf, Ed., John Wiley \& Sons, Inc., New York, NY, pp $257-279$.

[3] Wise, S. A. and Zeisler, R. (1984), The Pilot Environmental Specimen Bank Program, Environ. Sci. Technol. 18, 302A-307A.

[4] Lauenstein, G. G. and Calder, J. A. (1988), Specimen Banking: A Key Element of the National Oceanic and Atmospheric Adminstration's National Status and Trends Program, In: These Proceedings. 


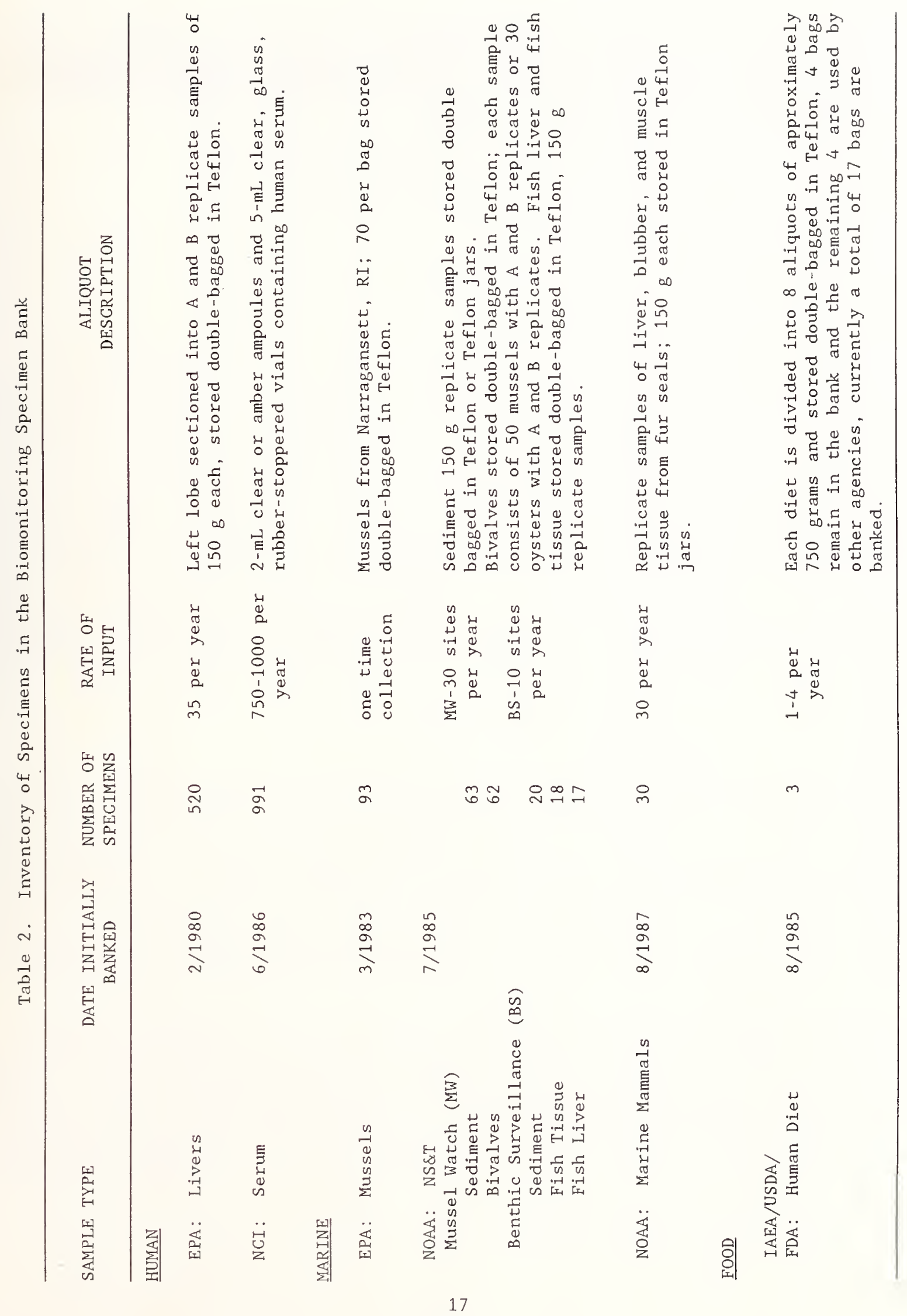


[5] Co-ordinated Research Programme on Human Daily Dietary Intakes of Nutritionally Important Trace Elements as Measured by Nuclear and Other Techniques, International Atomic Energy, Vienna, Austria. Report of the First Research Coordination Meeting Gaithersburg, Beltsville and Washington, DC, March 19-22, 1985. 


\title{
SECTION 3
}

\section{SPECIMEN BANKING: A KEY ELFMENT OF THE NATIONAL OCEANIC AND ATMOSPHERIC ADMINISTRATION'S NATIONAL STATUS AND TRENDS PROGRAM}

\author{
Gunnar G. Lauenstein and John A. Calder \\ National Oceanic and Atmospheric Administration \\ Rockville, Maryland 20852 \\ USA
}

\section{SUMMARY}

The National Oceanic and Atmospheric Administration has initiated a Specimen Bank for estuarine and coastal samples, as part of its National Status and Trends Program. During the first year, sample collection protocols were developed for the collection of benthic fish, bivalve molluscs, and associated sediments. Specimens from over 40 sites nationwide have now been submitted for inclusion in the Specimen Bank, which is housed at the National Bureau of Standards in Gaithersburg, Maryland. Because specimens are preserved at liquid nitrogen vapor temperature, degradation is expected to be minimal for decades. The specimens will provide the opportunity to derive retrospective baseline values for environmental contaminants of future concern and to reevaluate the past when new and improved analytical procedures become available in the future. Analyses of selected samples collected during the first year are presently under way for organic and trace elemental contaminants to provide a basis for assessing stability of the specimens while in storage.

\section{INTRODUCTION}

The concept of retrospective analysis prompted experiments that compared chemical constituents in environmental materials preserved for other purposes with chemical constituents in freshly collected samples. In the 1960's, for example, pollution was studied in Sweden by researchers who compared chemical constituents of recent samples of bird tissues with those of bird skins preserved in academic and museum collections dating from 1840 [1]. In the 1960 's, the kepone content in shellfish and sediments from the James River (Virginia) was similarly determined and compared with archived tissue samples to establish the earliest date of this chemical's occurrence in the river [2].

In the United States, a pilot Environmental Specimen Bank Program was established in 1980 at the National Bureau of Standards (NBS), sponsored in part by the Environmental Protection Agency. Other Federal agencies, including the Food and Drug Administration, Department of Agriculture, National Cancer Institute, and the National Oceanic and Atmospheric Administration (NOAA), of which the Ocean Assessments Division is a part, have joined in specimen banking activities at NBS. 


\section{BACKGROUND}

In 1984, NOAA's Ocean Assessments Division (OAD) initiated a new program called the National Status and Trends (NS\&T) Program, within which a series of activities are being undertaken to quantify the current status and long-term temporal and spatial trends of key contaminant concentrations and biological indicators of contaminant effects in United States coastal and estuarine environments [3]. The program's purposes are to provide highly reliable data on concentrations of toxic chemicals in marine fish, shellfish, and sediments; to measure biologic parameters that accurately reflect anthropogenic stress; and to assess marine environmental quality and recommend Federal actions needed to maintain or to improve it. Key questions the program intends to answer are 1) what are the current environmental quality conditions of the nation's coastal zone, and 2) are these conditions getting better or worse?

Sampling and analysis for the NS\&T Program are performed with well understood methods and adherence to statistical requirements so that a known confidence level can be assigned to all data. Sampling at all sites is conducted in a uniform manner, using the same techniques. Analytical procedures adhere to quality assurance protocols that have been established for all laboratories participating in the NS\&T Program. The activities include a series of interlaboratory comparison exercises using appropriate reference material and the convening of specialized technical education and training workshops [3].

The NS\&T Program has two monitoring efforts, the Benthic Surveillance Project and the Mussel Watch Project. Under the Benthic Surveillance Project, samples are collected annually from over 50 sites around the United States coastline, including Alaska. Both benthic fish and associated sediments are sampled. Sediments were selected because they are known reservoirs of contaminants; bottom fish were selected because they are reliable indicators of local pollution effects and because their exposure to toxic chemicals is linked primarily to bottom sediments.

Under the Mussels Watch Project, samples are collected annually from over 150 sites around the United States coastlines, including Alaska and Hawaii. As in the Benthic Surveillance Project, not only are organisms collected but associated sediments are collected as well.

Bivalve molluscs are a logical choice as sentinel organisms since they have the ability to concentrate environmental contaminants, they are cosmopolitan, they have the ability to tolerate contaminated environments, they are sessile, and they appear to have a minimal ability to metabolize organic contaminants, including petroleum hydrocarbons, PCBs, and DDT [4-6].

One element of the NS\&T Program is the archiving of samples from both the Benthic Surveillance and Mussel Watch projects. The methods of collection, preparation, and storage of samples for a specimen banking program are critical to maintaining the integrity of the sample and its value for future analytical

comparisons. The methods used in the specimen banking component of the NOAA NS\&T Program are described in this paper. 


\section{BENTHIC SURVEILLANCE SPECIMEN BANKING PROTOCOLS}

For the Benthic Surveillance Project, two duplicate aliquots of $150 \mathrm{~g}$ each are collected for both benthic fish liver and muscle tissue. Duplicate $150 \mathrm{~g}$ samples of sediments are taken from depositional sites near to the fish collection sites. Approximately 10 sites, of the 50 NS\&T Benthic Surveillance sites, are added to the Specimen Bank each sampling season (Figure 1).

Special precautions are taken with the dissection tools both during a dissection and after the tools are cleaned. Before initiating a set of dissections and after sharpening the titanium knives, the tools are wiped of extraneous materials, scrubbed in a detergent solution, rinsed with tap water followed by a distilled water rinse and finally transferred to a fume exhaust hood where they are carefully rinsed with methylene chloride.

To ensure that tissues are not contaminated, fish are necropsied in positive-pressure hoods using only specially cleaned materials and tools. For the dissection, two tool groups are used, one for the removal of the liver samples and the other for fish muscle collection. Each tool group in turn has two sub-sets. The first set of tools in each group is used to enter the sampling field, i.e., to cut through the body wall to access the body cavity (for liver) or to cut through the potentially contaminated epidermis to sample fish muscle [7]. The actual removal of the liver or muscle tissue occurs with the use of titanium knives. These knives are used to avoid the problem of iron and/or chromium contamination of samples.

Dissected tissue replicates are placed into pre-cleaned Teflon bags, which had been packaged under Class-100 clean room conditions, and then the bags are heat sealed and placed in a second bag that is also heat sealed.

For the Benthic Surveillance Project, two duplicate sediment aliquots of $150 \mathrm{~g}$ each are also taken at each site. Samples are collected with the use of a box corer. Two $50 \mathrm{~g}$ subsamples, (replicates A\&B) are taken using Teflon cylindrical corers from each of three sampled stations per site. These are then composited in Teflon bags to yield two duplicate $150 \mathrm{~g}$ composites per site. To ensure that only a minimum of sample degradation occurs following collection, samples of fish tissue and sediments are frozen in liquid nitrogen in the field.

\section{MUSSEL WATCH SPECIMEN BANKING PROTOCOLS}

The NS\&T Program's Mussel Watch Project also supplied duplicates of bivalves and sediment samples from 30 sites nationwide (Figure 2). Each site consisted of three stations; each station provided two batches of approximately 16-18 mussels (mytilus edulis/mytilus californianus) or two batches of 10 oysters (crassostrea virginical) for a total of approximately 100 mussels or 60 oysters per site. After collection, the bivalves are sorted for size on a noncontaminating tray and then rinsed with seawater and scrubbed with a noncontaminating brush. Bivalves are divided into two batches and then sealed in Teflon bags for storage. Sediment samples for the Mussel Watch Project are handled in the same manner as for the Benthic Surveillance work. Due to 

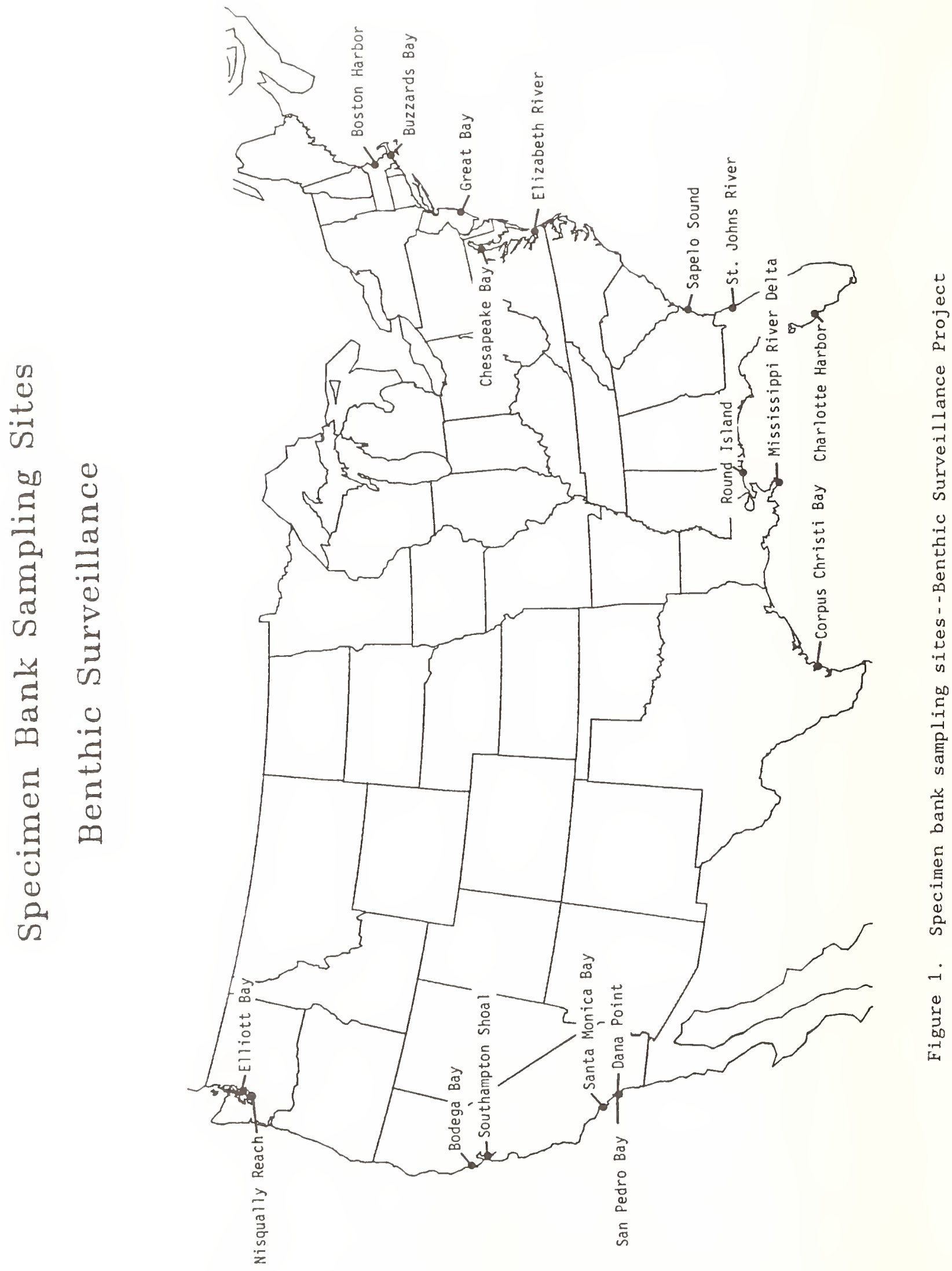

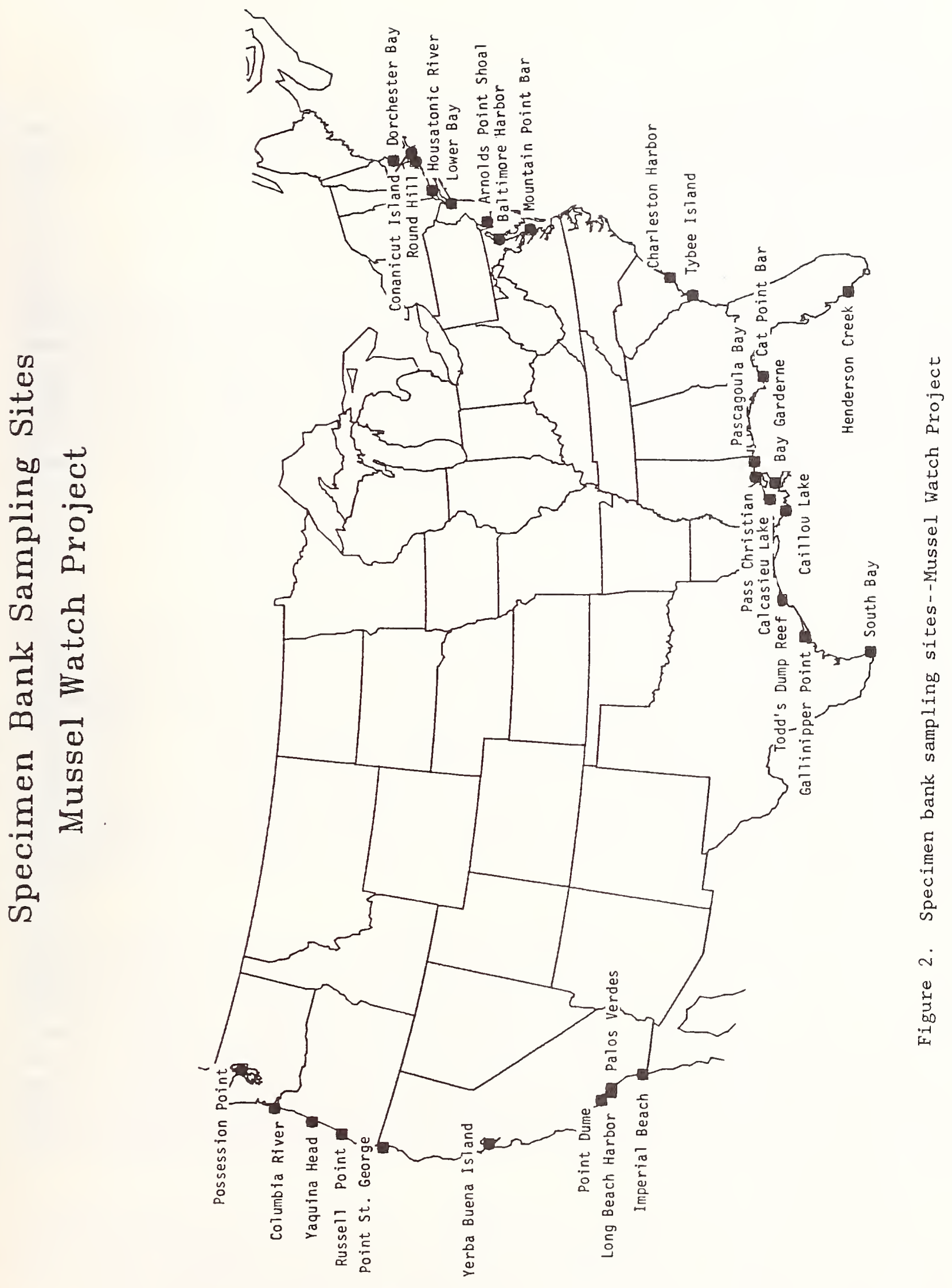
logistical difficulties, the large sample volume and the possibility that bivalves may explode if immersed fresh in liquid nitrogen, samples from the Mussel Watch Project are stored and shipped on dry ice before the final storage in liquid nitrogen freezers at the NBS.

\section{NS\&T Cryogenic Storage Facility}

Because of its long-term experience with cryogenic specimen storage and related specimen banking activities, the NBS was selected for the NS\&T Specimen Bank. The facilities available at NBS for storage of NS\&T materials include a Class-100 clean-air laboratory designed to minimize sample contamination from the laboratory environment during sample handling, processing, and storage. The laboratory has two sections, one for trace element analysis and the other for trace organic analysis. An additional room has been designed for long-term storage of environmental and biological samples and contains the NS\&T liquid nitrogen vapor freezer whose volumetric capacity of 500 liters can be maintained at temperatures ranging from -120 to $-150{ }^{\circ} \mathrm{C}$.

\section{Analyses}

Using a Teflon disk mill developed by the NBS, a portion of the tissue samples sent to the Specimen Bank are homogenized at cryogenic temperatures. Cryogenic homogenization reduces loss of volatile components and reduces the likelihood of changes in sample composition due to thawing and refreezing. Experiments with mussel tissue indicate that after homogenization, virtually all the frozen material passes through a $0.46 \mathrm{~mm}$ mesh sieve [8].

Environmental contaminants of concern to the NS\&T Program include aromatic hydrocarbons, chlorinated organics including polychlorinated biphenyls, and trace elements (Tables 1 and 2). Using the following methods, the NBS will supply the NS\&T Program with data for some samples included in the Specimen Banking portion of the program.

For the determination of organic contaminants, the sample homogenate is first mixed with precleaned anhydrous sodium sulfate and internal standards are added. The sodium sulfate mixture is then soxhlet extracted using methylene chloride. The fractions containing the aromatic hydrocarbons, polychlorinated biphenyls, and chlorinated organics are isolated using a silica microfractionation column, gel permeation column, and finally an aminosilane liquid chromatographic column. The concentrated fractions are analyzed by gas chromatography using flame ionization detection or liquid chromatography using fluorescence detection for the aromatic hydrocarbons and by gas chromatography using election capture detection for the polychlorinated biphenyls and chlorinated organics [9].

Selected trace elements are determined in the sediment and tissue samples using a combination of instrumental neutron activation analysis and $\mathrm{x}$-ray fluorescence analysis. The combination of these two techniques has been demonstrated to provide data for up to 44 elements in bivalve samples [10]. 


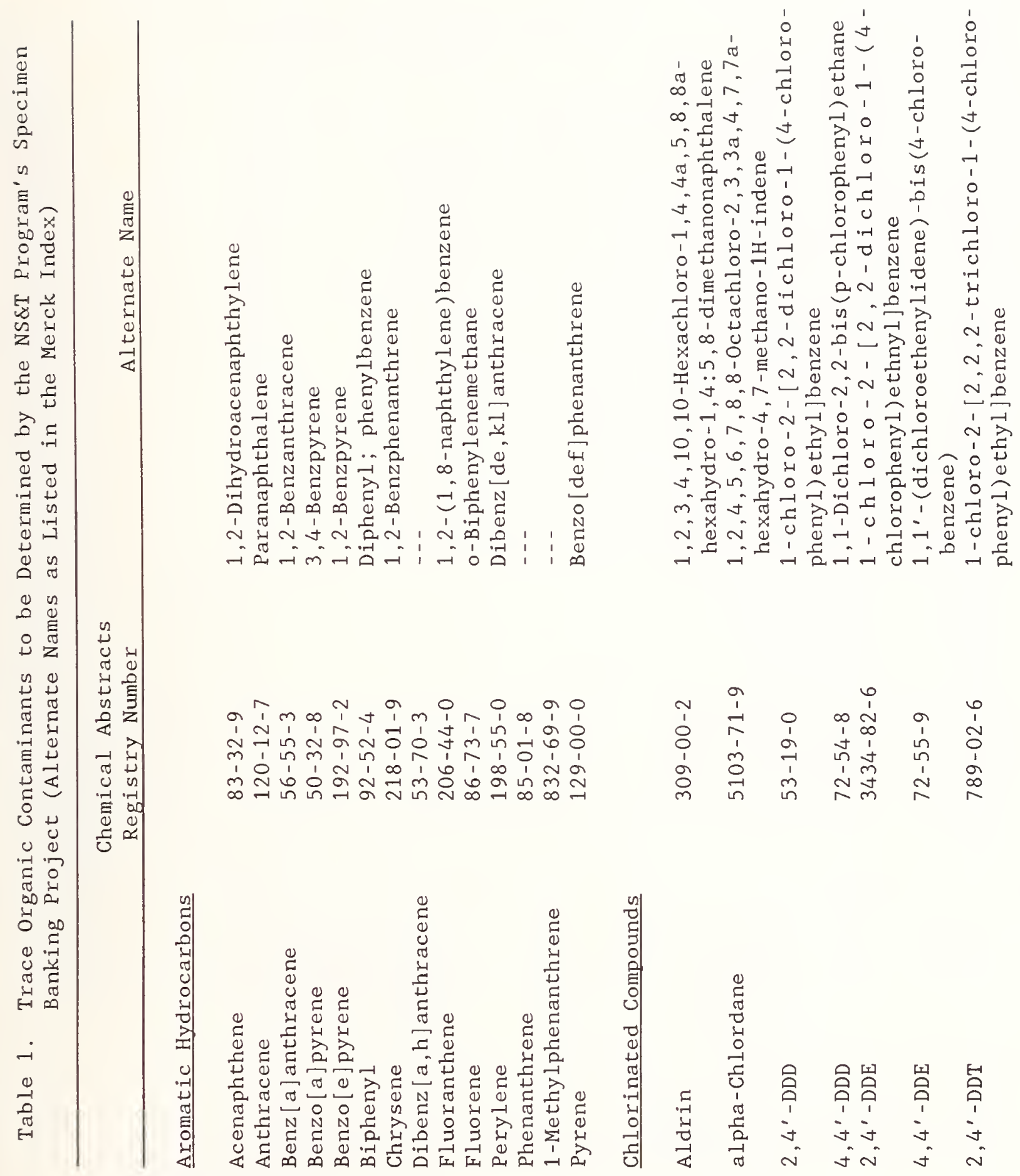




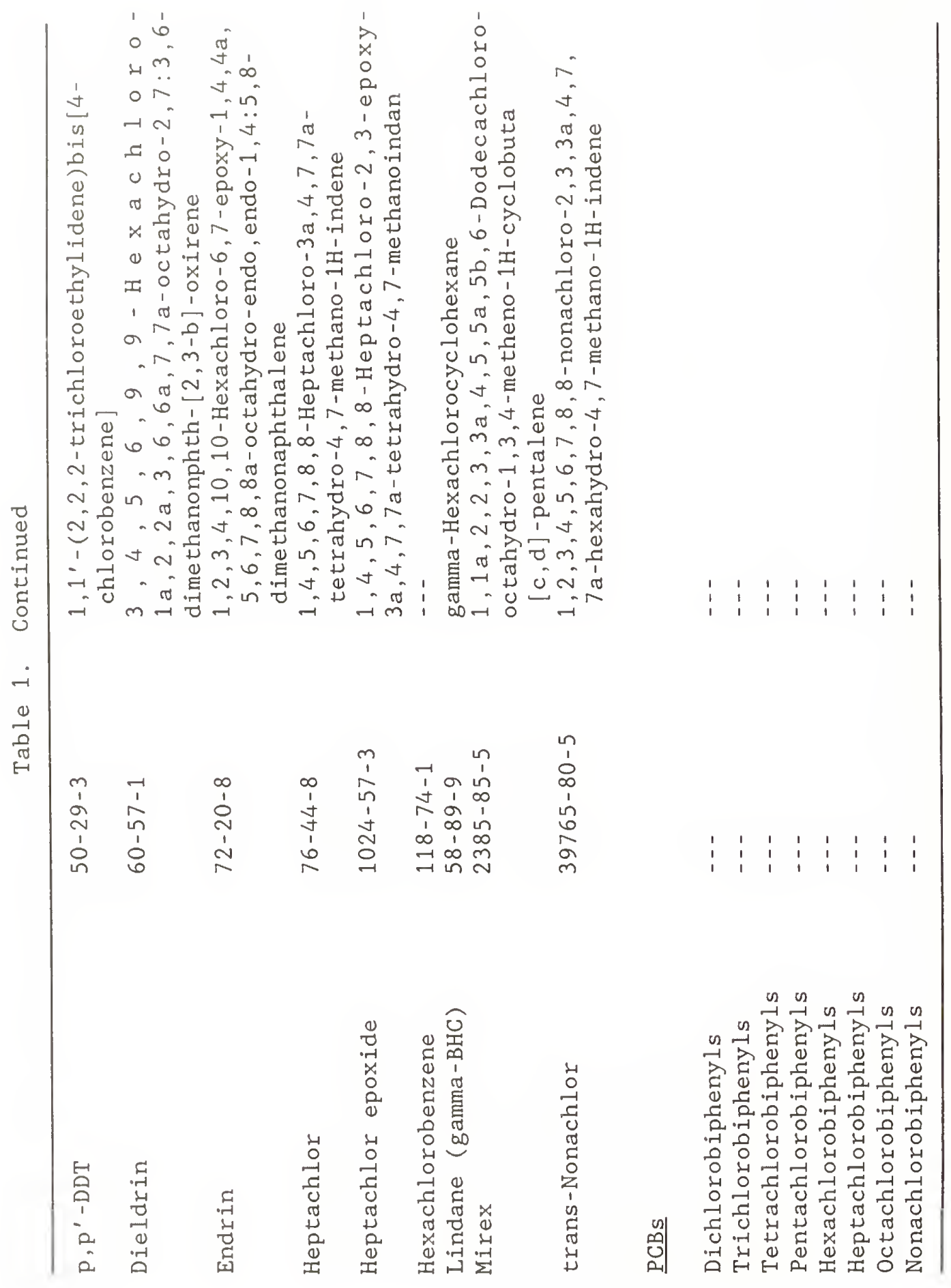


Table 2. Major and Trace Elements Determined for Archived Samples (in order of atomic number)

\begin{tabular}{llc}
\hline & & $\begin{array}{c}\text { Chemical Abstracts } \\
\text { Registry Number }\end{array}$ \\
\hline $\mathrm{Al}$ & Aluminum & $7429-90-5$ \\
$\mathrm{Si}$ & Silicon & $7440-21-3$ \\
$\mathrm{Cr}$ & Chromium & $7440-27-3$ \\
$\mathrm{Mn}$ & Manganese & $7439-96-5$ \\
$\mathrm{Fe}$ & Iron & $7439-89-6$ \\
$\mathrm{Ni}$ & Nickel & $7440-02-0$ \\
$\mathrm{Cu}$ & Copper & $7440-50-8$ \\
$\mathrm{Zn}$ & Zinc & $7440-66-6$ \\
$\mathrm{As}$ & Arsenic & $7440-38-2$ \\
$\mathrm{Se}$ & Selenium & $7782-49-2$ \\
$\mathrm{Sn}$ & Tin & $7440-31-5$ \\
$\mathrm{Sb}$ & Antimony & $7440-36-0$ \\
$\mathrm{Ag}$ & Silver & $7440-22-4$ \\
$\mathrm{Cd}$ & Cadmium & $7440-43-9$ \\
$\mathrm{Hg}$ & Mercury & $7439-97-6$ \\
$\mathrm{~Pb}$ & Lead & $7439-92-1$ \\
\hline
\end{tabular}

\section{CONCLUSIONS}

Sample collection protocols developed and used for the collection of benthic fish, bivalve molluscs, and associated sediments have provided specimens from over 40 sites nationwide (Table 3), which have now been submitted for inclusion in the Specimen Bank housed at the National Bureau of Standards in Gaithersburg, Maryland. Specimens are preserved at liquid nitrogen vapor temperature to inhibit degradation for decades. Initial analysis of archived samples provides data that is used for Quality Assurance purposes since the data can be compared to data generated by other NS\&T projects. In addition, this primary data set will allow a quantification of archived sample degradation, if any. Future analysis of specimens will allow the derivation of baseline values for newly defined environmental contaminants and a reassessment of the past when new and improved analytical procedures became available.

\section{REFERENCES}

[1] Olsson, M. (1985), The Environmental Specimen Bank at the Swedish Museum of Natural History, In: International Review of Environmental Specimen Banking, S. A. Wise and R. Zeisler, Eds., NBS Spec. Publ. 706, U.S. Government Printing Office, Washington, DC, pp 26-32.

[2] Huggett, R. J., Nichols, M. M., and Bender, M. E., (1980), Kepone Contamination of the James River Estuary, In: Contaminants and Sediments, Vol. I, R. A. Baker, Ed., Ann Arbor Science, Ann Arbor, MI, pp 33-52. 
Table 3. National Status and Trends Specimen Bank Inventory

\begin{tabular}{|c|c|c|c|c|c|c|}
\hline $\begin{array}{l}\text { Archive } \\
\text { iD\# }\end{array}$ & $\begin{array}{l}\text { Collectio } \\
\text { Daie }\end{array}$ & Location & Site & Species & $\frac{N}{\text { Latitude }}$ & $\begin{array}{c}\text { W } \\
\text { Longitude }\end{array}$ \\
\hline BS1S001 & 19Jul85 & Dana Point & & & 3326.8 & 11741.5 \\
\hline BS1F002 & 19Jul85 & Dana Point & & White croaker & 3326.8 & 11741.5 \\
\hline BS1L003 & 29Jul85 & Dana Point & & White croaker & 3326.8 & 11741.5 \\
\hline BS1F005 & 18Ju'85 & Dana Point & & White croaker & 3326.8 & 11741.5 \\
\hline BS1L006 & 18Jul85 & Dana Point & & White croaker & 3326.8 & 11741.5 \\
\hline $\mathrm{BS} 1 \mathrm{SO} 07$ & 21Jul85 & San Pedro Bay & & & 3344.5 & 11610.5 \\
\hline BS1F008 & 20Jul85 & San Pedro Bay & & White croaker & 3344.5 & 11610.5 \\
\hline BS1L009 & 20Jul85 & San Pedro Bay & & White croaker & 3344.5 & 11610.5 \\
\hline BS1SO 10 & 12Aug85 & Elliott Bay & & & 4741.0 & 12221.0 \\
\hline BS1F011 & 12Aug85 & Elliott Bay & & English sole & 4741.0 & 12221.0 \\
\hline BS1L012 & $12 A u g 85$ & Elliott Bay & & English sole & 4741.0 & 12221.0 \\
\hline BS1S013 & $14 A \cup 985$ & Nisqually Reach & & & 4741.0 & 12244.5 \\
\hline BS1F014 & 13 Aug85 & Nisqually Reach & & English sole & 4741.0 & 12244.5 \\
\hline BS1L015 & $13 A$ ug85 & Nisqually Reach & & English sole & 4741.0 & 12244.5 \\
\hline BS1S016 & 05 Sep 85 & Round Island, MS & & & 3019.0 & 8836.0 \\
\hline BSIF017 & 04 Sep85 & Round Island, MS & & Atlantic croaker & 3019.0 & 8836.0 \\
\hline BS1L018 & 04 Sep85 & Round Island, MS & & Atlantic croaker & 3019.0 & 8836.0 \\
\hline BS1S019 & 09Sep85 & Miss. R. Dolta & & & 2905.0 & 8904.0 \\
\hline BS1F020 & 08 Sep85 & Miss. R. Delta & & Atlantic croaker & 2905.0 & 8904.0 \\
\hline BS1L021 & O8Sep85 & Miss. R. Delta & & Atlantic croaker & 2905.0 & 8904.0 \\
\hline $\mathrm{BS} 1 \mathrm{SO} 22$ & 23Sep85 & Corpus Christi & & & 2750.0 & 9717.0 \\
\hline BS1F023 & 20Sep85 & Corpus Christi & & Atlantic croaker & 2750.0 & 9717.0 \\
\hline BS1L024 & 20 Sep85 & Corpus Christi & & Atlantic croaker & 2750.0 & 9717.0 \\
\hline BS1SO25 & $140 \operatorname{ct} 85$ & Charlotte Harbor & & & 2651.0 & 8207.0 \\
\hline BS1F026 & $140 \operatorname{ct} 85$ & Charlotte Harbor & & Spot & 2651.0 & 8207.0 \\
\hline BS1L027 & $140 \operatorname{ct} 85$ & Charlotte Harbor & & Spot & 2651.0 & 8207.0 \\
\hline $\mathrm{BS} 1 \mathrm{SO} 28$ & 17Jul85 & Chesapeake Bay & & Spot & 3855.7 & 7625.0 \\
\hline BS1F079 & 27Mar86 & Great Bay & & Winter Flounder & 3931.0 & 7423.0 \\
\hline BS 15080 & $25 \mathrm{Mar} 86$ & Great Bay & & & 3931.0 & 7423.0 \\
\hline BS1L083 & 08Apr86 & Boston Harbor & & Winter Flounder & 4220.0 & 7100.0 \\
\hline BS1F084 & 08Apr86 & Boston Harbor & & Winter Flounder & 4220.0 & 7100.0 \\
\hline BS1S085 & 08Apr86 & Boston Harbor & & & 4220.0 & 7100.0 \\
\hline BS1L086 & 07apr 86 & Buzzards Bay & & Winter Flounder & 4135.0 & 7045.0 \\
\hline BS1F087 & 07Apr86 & Buzzards Bay & & Winter Flounder & 4135.0 & 7045.0 \\
\hline BS1S088 & OBApr86 & Buzzards Bay & & & 4135.0 & 7045.0 \\
\hline BS1F097 & 29Jun86 & Bodge Bay & & Starry Flounder & 3818.0 & 12302.0 \\
\hline BS1L098 & 29Jun86 & Bodge Bay & & Starry Flounder & 3818.0 & 12302.0 \\
\hline BS1S099 & 30Jun86 & Bodge Bay & & & 3818.0 & 12302.0 \\
\hline BS1F100 & 08Jul86 & Southampton Shoal & & Starry Flounder & 3754.0 & 12225.0 \\
\hline BS1L101 & OQJu!86 & Southampton Shoal & & Starry Flounder & 3754.0 & 12225.0 \\
\hline $\mathrm{BS} 1 \mathrm{~S} 102$ & O8Jul86 & Southampton Shoal & & & 3754.0 & 12225.0 \\
\hline BS1F103 & 16Jul86 & Santa Monica Bay & & Hornyhead Turbot & 3353.0 & 11826.0 \\
\hline BS1L104 & $16 \mathrm{Jul} 86$ & Santa Monica bay & & Hornyhead Turbot & 3353.0 & 11826.0 \\
\hline BS1S105 & $16 \mathrm{Jul} 86$ & Santa Monica Bay & & & 3353.0 & 11826.0 \\
\hline $\mathrm{BS} 1 \mathrm{~F}_{106}$ & 19 Jul86 & Dana Point & & Hornyhead Turbot & 3327.0 & 11742.0 \\
\hline BS1L107 & 19Ju'86 & Dana Point & & Hornyhead Turbot & 3327.0 & 11742.0 \\
\hline BS1S108 & 19Jul86 & Dana Point & & & 3327.0 & 11742.0 \\
\hline BS1S109 & 28Jul86 & Elizabeth River & & & 3650.0 & 7622.0 \\
\hline BS 15110 & 26 Jul86 & Lower Chesapeake & & & 3710.0 & 7610.0 \\
\hline BS1S111 & $18 A \cup g 86$ & St. John's River & & & 3024.0 & 8133.0 \\
\hline BS1L112 & 19 Aug86 & St. John's River & & Atlantic Croaker & 3024.0 & 8133.0 \\
\hline BSiF 113 & 29 Aug86 & St. John's River & & Atlantic Croaker & 3024.0 & 8133.0 \\
\hline BS1S114 & 15 Aug86 & Sapelo Sound & & & 3133.0 & 8114.0 \\
\hline BS1L115 & 13 Aug86 & Sapelo Sound & & Atlantic Croaker & 3133.0 & 8114.0 \\
\hline $\mathrm{BS} 1 \mathrm{~F}_{116}$ & 14 Aug86 & Sapelo Sound & & Atlantic Croaker & 3133.0 & 8114.0 \\
\hline MW1M029 & 11Jan86 & San Diego & Imperial Beach & M. californianus & 3240.8 & 11708.2 \\
\hline MW1Y030 & 11Jan86 & Galveston Bay & Todd's Dump & C. virginica & 2930.1 & 9454.0 \\
\hline MW1SO31 & 10Jan86 & Galveston Bay & Todd's Dump & & 2130.1 & 9454.0 \\
\hline MW1SO32 & 20Jan86 & San Diego & Imperial Beach & & 3236.0 & 11710.0 \\
\hline MW1M033 & 27Jan86 & Palos Verdes & Royal Palms State Park & M. calitornianus & 3343.5 & 11819.6 \\
\hline MW1M034 & 27Jan86 & Anaheim Bay & West & M. callornianus & 3344.2 & 11807.9 \\
\hline MW1Y035 & $04 \mathrm{Feb} 86$ & Savannah River Estuary & Tybee Island & C. virginica & 3344.2 & 8050.6 \\
\hline MW1SO36 & $05 F e b 86$ & Savannah River Estuary & Tybee Island & & 3158.8 & 8050.6 \\
\hline MW1M037 & $06 F_{e b 86}$ & Point Dume & & M. californianus & 3400.2 & 11848.4 \\
\hline MW1SO38 & 31Jan86 & Matagorda Bay & Gallinipper Point & & 2835.0 & 9634.0 \\
\hline MW 1 Y039 & 31Jan86 & Matagorda Bay & Gallinipper Point & c. virginica & 2835.0 & 90634 \\
\hline MW1SO40 & 24Jan86 & Lower Laguna Madre & South Bay & & 2602.6 & 9710.5 \\
\hline MW1Y041 & 24Jan86 & Lower Laguna Madre & South Bay & C. virginica & 2602.6 & 9710.5 \\
\hline MW1SO42 & 18Jan86 & Calcasieu Lake & St. John's Island & & 2951.0 & 9323.0 \\
\hline MW1Y043 & 18Jan86 & Calcasieu Lake & St. John's Island & C. virginica & 2951.0 & 9323.0 \\
\hline MW1 Y044 & $12 F_{\theta b} 86$ & Charleston Harbor & Fort Johnson & C. virginica & 3243.7 & 7951.9 \\
\hline MW1SO45 & 11 Feb86 & Charleston Harbor & Fort Johnson & & 3243.7 & 7951.9 \\
\hline
\end{tabular}


Table 3. (Continued)

\begin{tabular}{|c|c|c|c|c|c|c|}
\hline MW1M046 & 23Jan86 & Buzzards Bay & Round Hill & M. odulis & 4132.2 & 7055.1 \\
\hline MW1SO47 & $05 \mathrm{Feb} 86$ & Buzzards Bay & Round Hill & & 4132.2 & 7055.1 \\
\hline MW1M048 & 13Jan86 & Boston Harbor & Dorchester Bay & M. edulis & 4218.1 & 7102.0 \\
\hline MW1SO49 & $16 \operatorname{Jan} 86$ & Boston Harbor & Dorchester Bay & & 4218.1 & 7102.0 \\
\hline MW1M050 & 03 Feb86 & Narragansett Bay & Conanicut Island & M. edu.lis & 4129.8 & 7123.2 \\
\hline MW1S051 & 03Feb86 & Narragansett Bay & Conanicut Island & & 4129.8 & 7123.2 \\
\hline MW1SO52 & $12 F_{e b} 86$ & Anaheim Bay & West Jetty & & 3344.0 & 11806.0 \\
\hline MW1M053 & $12 F_{e b} 86$ & Long Island Sound & Housatonic River & M. odulis & 4110.1 & 7306.6 \\
\hline MW1S054 & 13Feb86 & Long Island Sound & Housatonic River & & 4110.1 & 7306.6 \\
\hline MW1M055 & 21Jan86 & Whidboy Island & Possession Point & M. odulis & 4753.2 & 12225.3 \\
\hline MW1M056 & 04Feb86 & Yaquina Head & & M. calitornianus & 4440.6 & 12404.7 \\
\hline MW1M057 & 06Feb86 & Coos Bay & Russell Point & M. odulis & 4753.2 & 12413.0 \\
\hline MW1S058 & $29 \operatorname{Jan} 86$ & Whidbey Island & Possession Point & & 4754.7 & 12220.7 \\
\hline MW1S059 & 07Feb86 & Coos Bay & Russell Point & & 4326.1 & 12413.0 \\
\hline MW1S060 & 08Feb86 & Yaquina Head & & & 4437.0 & 12400.4 \\
\hline MW1S061 & $01 \mathrm{Mar} 86$ & Point Dume & & & 3359.9 & 11846.9 \\
\hline MW1Y062 & 04Mar86 & Chesapeake Bay & Smith Point & C. virginica & 3747.6 & 7617.1 \\
\hline MW1SO63 & $04 \mathrm{Mar} 86$ & Chesapeake Bay & Smith Point & & 3747.6 & 7617.1 \\
\hline MW1S064 & 18 Feb86 & Palos Verdes & Royal Palms State Park & & 3343.5 & 11819.6 \\
\hline MW1S065 & 20 Feb86 & Rookery Bay & Henderson Creek & & 2601.8 & 8143.8 \\
\hline MW1Y066 & $20 F_{e b} 86$ & Rookery Bay & Henderson Creek & C. virginica & 2601.8 & 8143.8 \\
\hline MW1S067 & 05Feb86 & Mississippi Sound & Pascagoula Bay & & 3021.1 & 8837.0 \\
\hline MW1Y068 & 05Feb86 & Mississippi Sound & Pascagoula Bay & C. Virginica & 3021.1 & 8837.0 \\
\hline MW1S069 & 06Feb86 & Mississippi Sound & Pass Christian & & 3019.8 & 8919.6 \\
\hline MW1Y070 & 06Feb86 & Mississippi Sound & Pass Christian & C. virginica & 3019.8 & 8919.6 \\
\hline MW1S071 & $27 F \theta b 86$ & Cat Point Bar & Apalachicola Bay & & 2943.0 & 8452.5 \\
\hline MW1Y072 & 27Feb86 & Cat Point Bar & Apalachicola Bay & C. virginica & 2943.0 & 8452.5 \\
\hline MW1Y073 & $12 \mathrm{Mar} 86$ & Baltimore Harbor & Mountain Point Bar & C. virginica & 3904.4 & 7624.7 \\
\hline MW1SO74 & 12Mar86 & Baltimore Harbor & Mountain Point Bar & & 3904.4 & 7624.7 \\
\hline MW1M075 & 15Mar86 & Hudson Raritan Estuary & Lower Bay & M. odulis & 4034.2 & 7403.4 \\
\hline MW1S076 & 13Mar86 & Hudson Raritan Estuary & Lower Bay & & 4034.2 & 7403.4 \\
\hline MW1M077 & $25 \mathrm{Mar} 86$ & Delaware Bay & Arnolds Point Shoal & C. virginica & 3923.1 & 7525.9 \\
\hline MW1S078 & $25 \mathrm{Mar} 86$ & Delaware Bay & Arnolds Point Shoal & & 3923.1 & 7525.9 \\
\hline MW1M081 & 04Mar86 & Columbia River & Fort Stevens & M. edulis & 4613.9 & 12400.5 \\
\hline MW1SO 82 & 04Mar86 & Columbia River & Fort Stevens & & 4613.9 & 12351.9 \\
\hline MW1Y089 & $26 \mathrm{Mar} 86$ & Brenton Sound & Bay Garderne & C. virginica & 2935.9 & 8938.5 \\
\hline MW1S090 & $26 \mathrm{Mar} 86$ & Brenton Sound & Bay Garderne & & 2935.9 & 8938.5 \\
\hline MW1Y091 & 29 Mar86 & Caillou Lake & & C. virginica & 2915.3 & 9055.5 \\
\hline MW1SO92 & $29 M a r 86$ & Caillou Lake & & & 2915.3 & 9055.5 \\
\hline MW1S093 & 11 Apr 86 & San Francisco Bay & San Mateo Bridge & & 3735.8 & 12214.5 \\
\hline MW1M094 & 11 Apr86 & San Francisco Bay & San Mateo Bridge & M. odulis & 3735.8 & 12214.5 \\
\hline MW1S095 & 21Apr86 & Point St. George & & & 4143.3 & 12113.9 \\
\hline MW1M096 & 29Apr 86 & Point St. George & & M. californianus & 4144.9 & 12412.4 \\
\hline
\end{tabular}

Key for first column fourth letter

$\mathrm{F}=$ Fish muscle sample

$\mathrm{L}=$ Liver sample

$M=$ Mussel sample

$\mathrm{S}=$ Sediment Sample

$\mathrm{Y}=$ Oyster sample

Species key

Atlantic croaker

English sole

Micropogon undulatus

Hornyhead Turbot

Parophrys velulus

Spot

Plouronichthys verticalis

Starry flounder

White croaker

Winter flounder

American oyster

Blue mussel
California mussel

Leiostomus xanthurus

Platichthys stellatus

Genyonomus lineatus

Pseudopleuronecles americanus

Crassostrea virginica

Mytilus edulis

Mytilus californianus 
[3] Ocean Assessments Division (1986), The National Status and Trends Program for Marine Environmental Quality, FY86 Program Description, National Oceanic and Atmospheric Administration, Ocean Assessments Division, Rockville, MD, $35 \mathrm{pp}$.

[4] Tripp, B. W. and Farrington, J. W. (1984), Using Sentinel Organisms to Monitor Chemical Changes in the Coastal Zone: Progress or Paralysis, Submitted to the Coastal Society, 9 th Annual Conference, Atlantic City, NJ .

[5] Farrington, J. W. (1983), Bivalves as Sentinels of Coastal Chemical Pollution: The Mussel (and Oyster) Watch, Oceanus 1983, Vol. 26, No. 2, pp 18-29.

[6] Farrington, J. W., Albaiges, J., Burns, K. A., Dunn, B. P., Eaton, P., Laseter, J. L., Parker, P. L., and Wise, S. A. (1980), Fossil Fuels, In: The International Mussel Watch, National Academy of Sciences, $70 \mathrm{pp}$.

[7] Patterson, C. C. and Settle, D. M. (1976), The Reduction of Orders of Magnitude Errors in Lead Analyses of Biological Materials and Natural Waters by Evaluating and Controlling the Extent and Sources of Industrial Lead Contamination Introduced During Sample Collecting, Handling, and Analysis, In: Accuracy in Trace Analysis: Sampling, Sample Handling, and Analysis, P. D. LaFleur, Ed., NBS Special Publication 442, U.S. Government Printing office, Washington, DC, pp 321-351.

[8] Zeisler, R., Langland, J. K., and Harrison, S. H. (1983), Cryogenic Homogenization of Biological Tissues, Anal. Chem. 55, 2431-2434.

[9] Schantz, M. M., Chesler, S. N., Koster, B. J., and Wise, S. A., (1988), Analytical Methods for the Determination of Organic Contaminants in Marine Sediments and Tissues, In: These Proceedings.

[10] Stone, S. F., Zeisler, R., and Sanders, R. W. (1987), Sequential Determination of 44 Trace Elements in Marine Bivalves, Anal. Chem., In press. 


\section{SECTION 4 \\ INFLUENCE OF ENVIRONMENTAL CHEMICALS IN THE AQUATIC ENVIRONMENT \\ Istvan Gebefügi, Jan-Peter Lay, and Friedhelm Korte Gesellschaft für Strahlen-und Umweltforschung, mbH, München Institut fūr Ökologische Chemie D-8042 Neuherberg FEDERAL REPUBLIC OF GERMANY}

\section{INTRODUCTION}

Since 1976, a research group at the institute has been carrying out field experiments with xenobiotics in small natural ponds. The aim of these investigations is to study the fate of environmental chemicals and their effect on population dynamics of several species. Further information for interpreting laboratory results from chemical testing experiments and verification by longterm experiments is needed. Our knowledge about the occurrence of environmental chemicals in aquatic systems is limited; neither the corresponding residues of the chemical nor the biologicals have been thoroughly investigated.

We expected data about effects by single doses in short-term as well as long-term experiments with continuously low dosages of environmental chemicals. The ecotoxicological behavior was studied by the elucidation of the influence of the chemicals on population dynamics of phyto- and zooplankton species and by observation of the fate of chemicals by measuring the concentrations in water, sediment, and biota (accumulation studies) [1-3].

As a first example of our investigations, the results of a long-term field study will be shown. The object of this work was the elucidation of the longterm behavior, dispersion, accumulation, and metabolism of hexachlorobenzene, pentachloronitrobenzene, and 4-chloroaniline (Parachloroaniline) in small experimental ponds. The concentrations of the chemicals during the application phase were chosen to be environmentally relevant, but still enabling residue studies in parts of the systems over several vegetation periods. Aromatic organochlorine compounds are known to be persistent in the aquatic environment. Out of this group of contaminants, $\mathrm{HCB}$ and pentachloronitrobenzene (PCNB) have been used as examples for highly chlorinated chemicals, and 4-chloroaniline (4-CA) as a lower chlorinated compound.

\section{EXPERIMENTAL SECTION}

For the implementation of the program, six small ponds were dug in a marsh-meadow near a larger pond. After 12 months, a high diversity of plants and animals could be observed in all ponds. One experimental pond was treated with each of the following chemicals: HCB, PCNB, 4-CA, the others served as controls. The average size of the ponds was $2-3 \mathrm{~m}$ in diameter and about $0.8 \mathrm{~m}$ in depth. During the investigation period, the biotopes had no continuously measurable influx or drain of water. 
The concentration of each chemical in the water was maintained at about 50 $\mu \mathrm{g} / \mathrm{L}$ (50 ppb) over a period of 4 to 6 weeks. The total amounts of the chemicals applied during the dosing period, calculated as concentrations, were 250 $\mu \mathrm{g} / \mathrm{L}$ for $\mathrm{HCB}$ and PCNB, and $480 \mu \mathrm{g} / \mathrm{L}$ for $4-\mathrm{CA}$. The chemicals were applied with traces of the respective ${ }^{14} \mathrm{C}$-labelled materials to allow low level counting analysis.

\section{RESULTS AND DISCUSSION}

In Figure 1, the decrease in concentrations of $\mathrm{HCB}$ and $\mathrm{PNCB}$ in the water is shown, they have a comparable course.

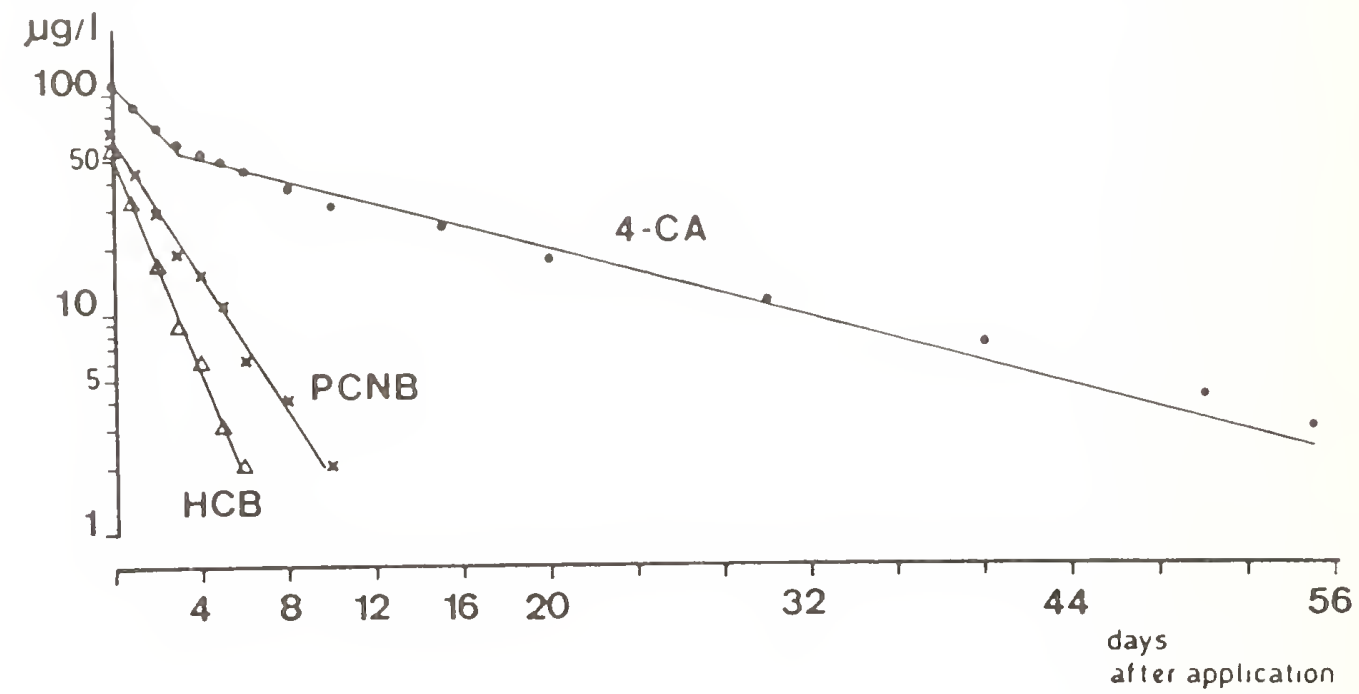

Figure 1. Disappearance of hexachlorobenzene, pentachloronitrobenzene, and 4-chloroaniline from the water of experimental ponds

It was found that after 1.3 days (for HCB) and 1.8 days (for PNCB) after the last application, 50 of of the initial concentrations still could be detected in the water phase. The rapid decrease of both chemicals in the water may be caused by evaporation into the atmosphere and mainly by adsorption to sediment or absorption by biota. As residue analyses demonstrate, the biocides in the water were quickly transported to the bottom sediment which then acted as pool for further dispersion (via water) into the biota.

Figure 2 shows the HCB-derived residues in an experimentally polluted pond. In the sediment of the HCB-treated biotope, there is a buildup phase of residues over several weeks, followed by a very slow declining phase. A similar disappearance of residues can be observed in all fauna species. In the PNCB-biotope (Figure 3), comparable residual concentrations for all analyzed samples were measured. The residual behavior of 4-CA, chemically quite different from the other model substances, follows a similar but not equal residual pattern, with a high initial buildup of concentrations in the biota and slow decline in the sediment. The concentrations of 4-CA in gold fish 


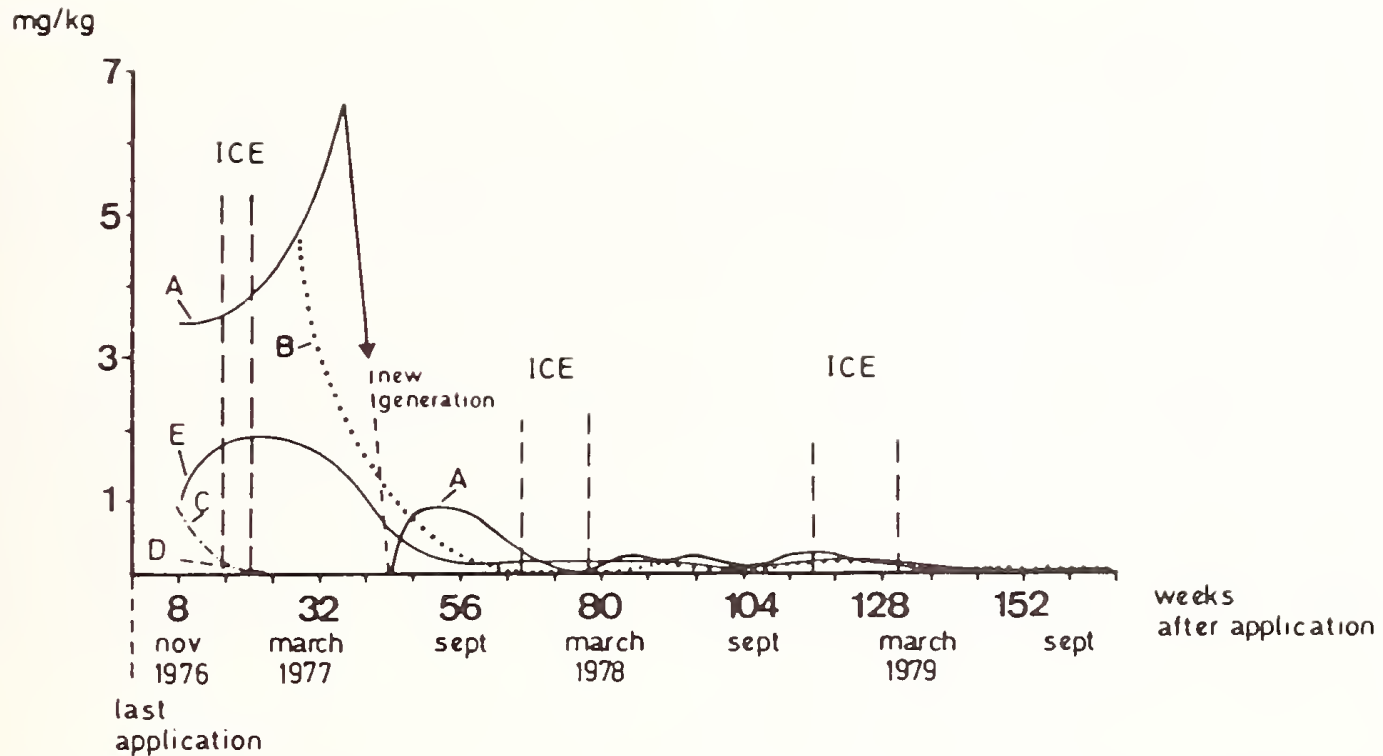

Figure 2. HCB-derived residues in an experimentally polluted small pond.

A; Notonecta glauca, B; Libellula quadrimaculata, C; Lemna minor,

$D$; Ranunculus aquatilus, and $\mathrm{E}$; sediment

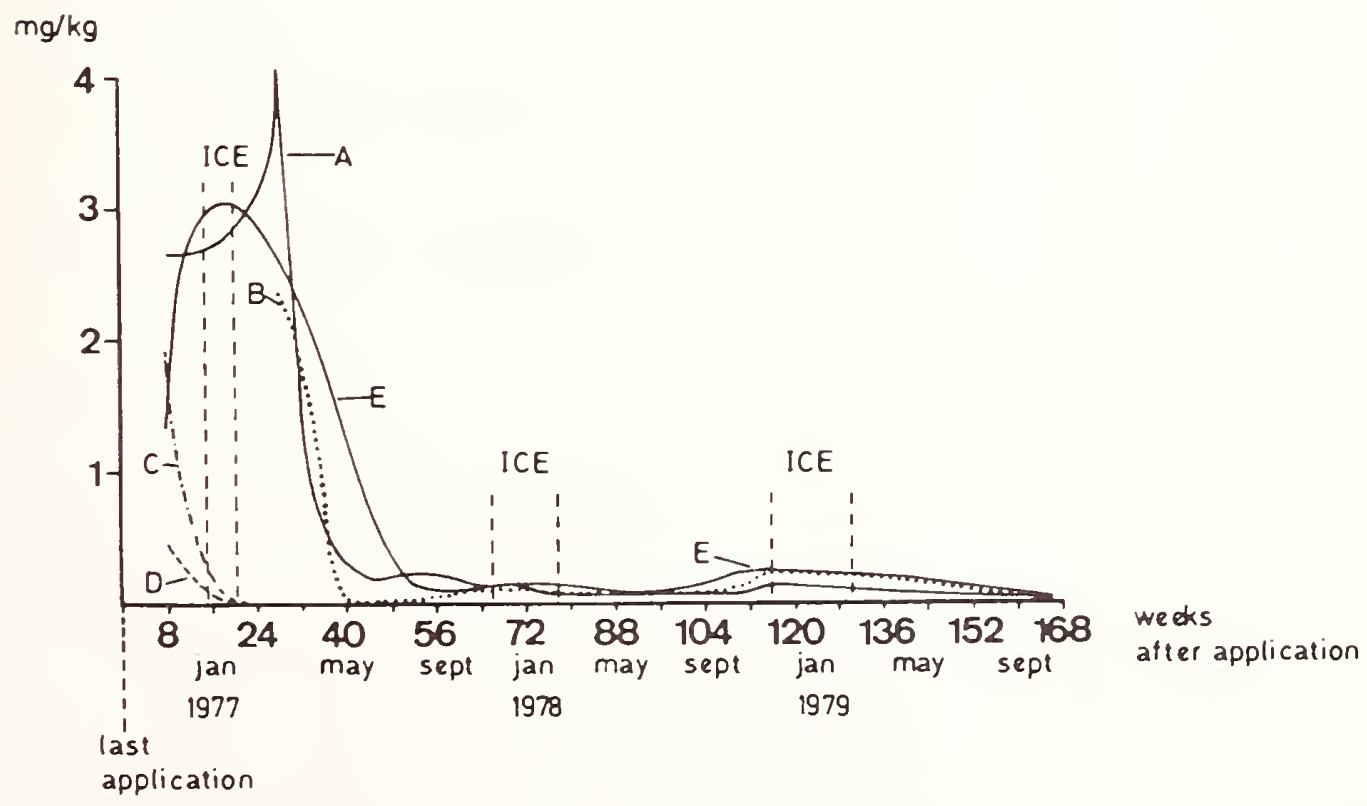

Figure 3. PCNB-derived residues in an experimentally polluted small pond. A; Notonecta glauca, B; Libellula quadrimaculata, C; Lemna minor, $\mathrm{D}$; Ranunculus aquatilis, and $\mathrm{E}$; sediment 
(Carassius auratus) were determined in the gastrointestinal tract, muscles, fat, and whole body.

The highest initial levels were found in the gastrointestinal tract (about $8 \mathrm{mg} / \mathrm{kg}$ ) and the highest level after 10 weeks in the fat (about $7 \mathrm{mg} / \mathrm{kg}$ ). In the same time, the concentration in the whole body was reduced, maybe the most important result with respect to "Environmental Sample Banking."

In a short-term experiment, the effects of 2,4,6-trichlorophenol (TCP) and pentachlorophenol (PCP) on the population dynamics of several planktonic species were studied. For this investigation, a natural pond was divided into six compartments with tubes of $50 \mathrm{~cm}$ diameter resulting in a volume of about $200 \mathrm{~L}$ each. TCP and PCP were applied into the water with single doses of 5 $\mathrm{mg} / \mathrm{L}$ and $1 \mathrm{mg} / \mathrm{L}$, respectively. These are equivalent to about three times the $\mathrm{EC}_{50}$ for $\mathrm{TCP}$ and two times the $\mathrm{EC}_{50}$ for $\mathrm{PCP}$ as determined in laboratory toxicity tests with Daphnia magna.

\section{A. Disappearance of TCP and PCP From Water}

As shown in Figure 4, the concentration of both chemicals declined to about $10 \%$ of their initial values 24 days after treatment. This decrease may be due to evaporation from water, to adsorption to seston and absorption by biota. It is evident that significant residues of the two chemicals remained in the aqueous layer over the whole experimental period of 24 days, and thus were available for bioaccumulation and adverse affects to planktonic organisms.

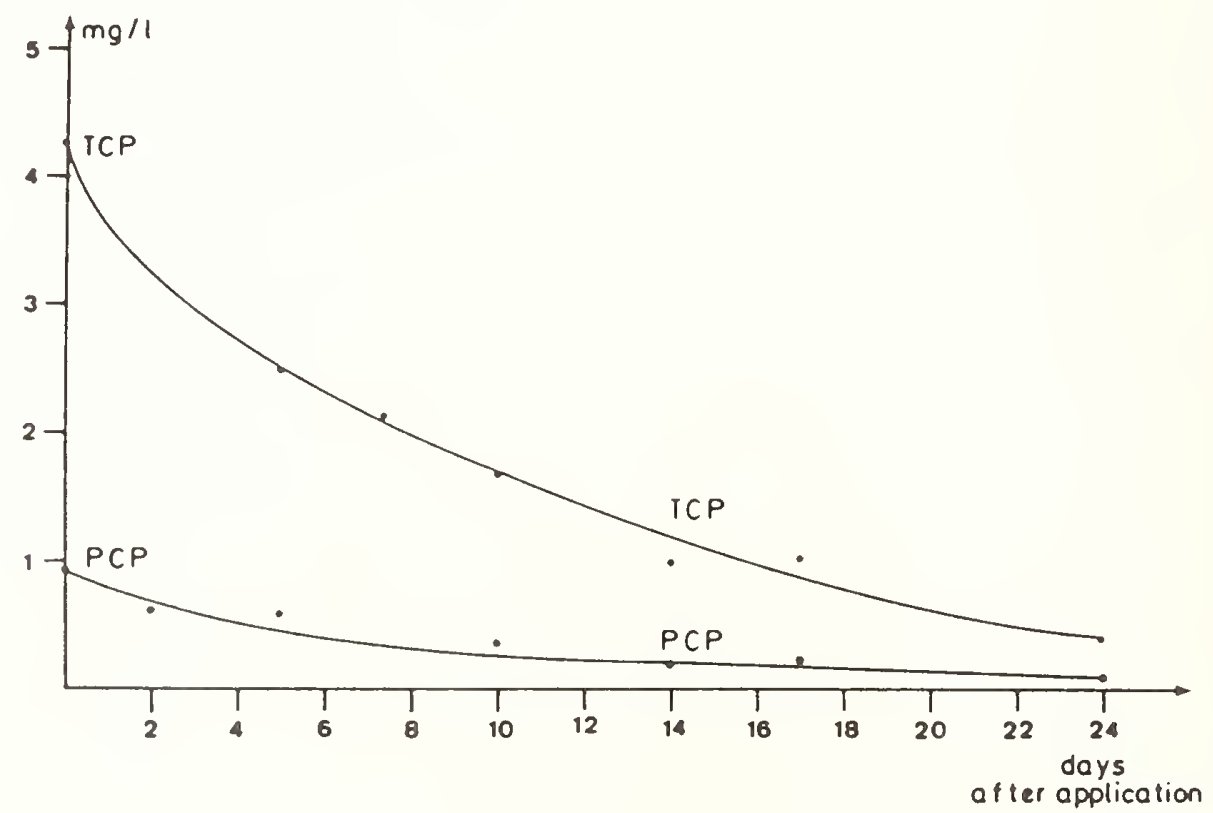

Figure 4. Disappearance of pentachloro- and 2,4,6-trichlorophenol from the water of the treated compartments 


\section{B. Effects of TCP and PCP and BIOTA}

As expected from the applied concentrations, both chemicals were highly lethal to Daphnia pulex (Figure 5). Three (PCP) and nine days (TCP) after the applications, the total daphnia populations declined to zero and did not recover during the 24 days of the experiment. Considering the important intermediate role of daphnia in the food chain as consumers of algae and detritus, it can be assumed that their disappearance affected the stability of the phytoplankton and planktonic predator communities. Therefore, changes in the community structure of the phytoplankton could have been caused either directly by the chemicals or indirectly by changes in daphnia densities.

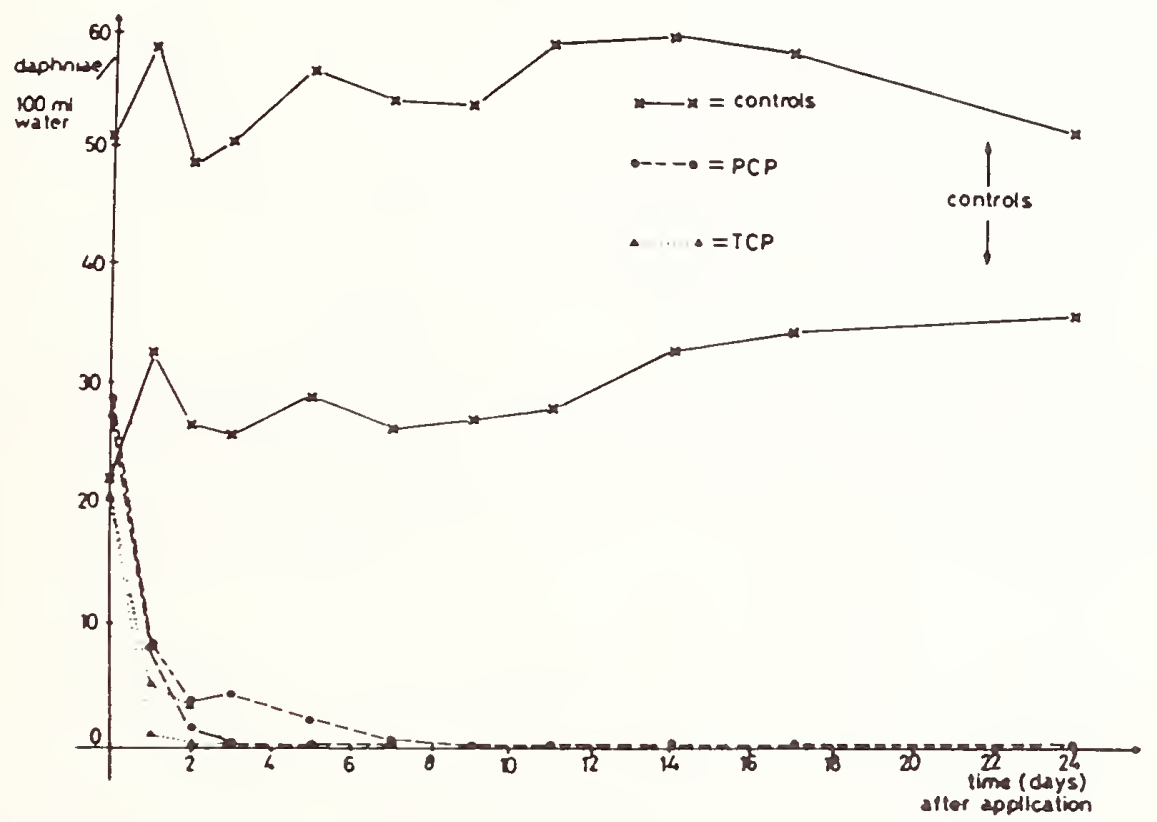

Figure 5. Dynamics of daphnia concentrations in the treated and untreated compartments

\section{Phytoplankton}

In Figures 6, 7 and 8 , the population dynamics of three selected phytoplankton species are presented. Chroococcus limneticus (blue-algae), Trachelomonas hispida (flagellate) and Euglena acus (flagellate) were selected as representatives of blue-green/mixotrophic species because of their natural abundance and characteristic response to the chemical perturbation.

In the TCP as well as in the PCP treated compartments, the population densities of these autotrophic and mixotrophic plankton showed distinctive trends in response to chemical exposure. As compared to their control population, C. limnetus decreased significantly demonstrating direct sensitivity to the chemical pollutant (primary effect), whereas the mixotrophic species showed a significant increase after chemical treatment. This increase may mainly be a consequence of the reduced grazing pressure by daphnia (secondary effect) or 


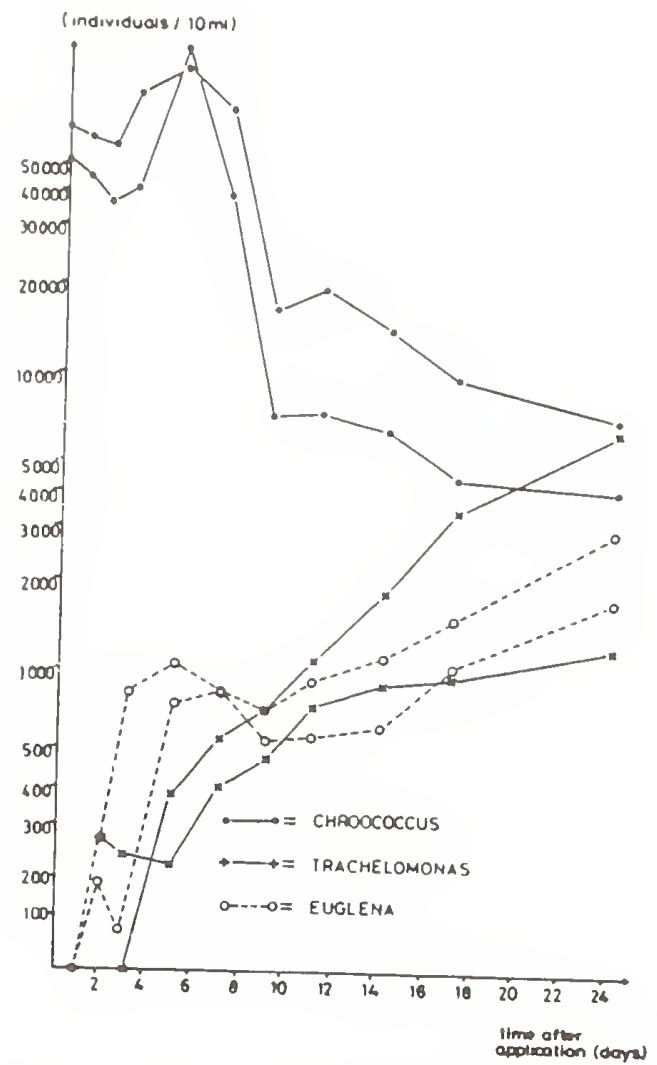

Figure 6. Concentration dynamics of three plankton species in the TCP-treated compartments

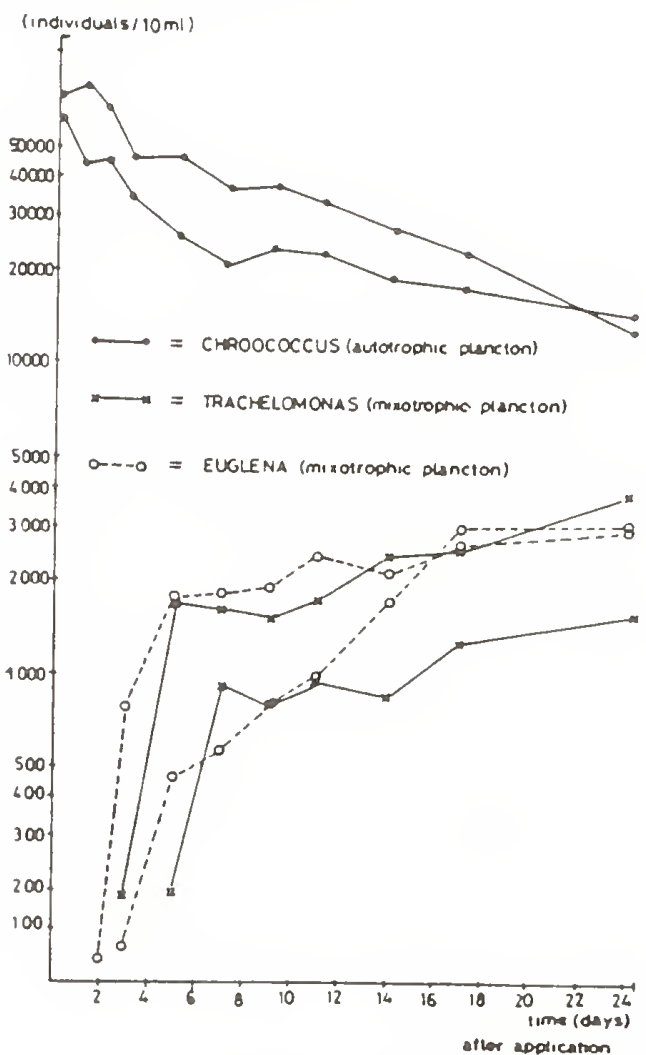

Figure 7. Dynamics of concentration of three plankton species in the PCP-treated compartment 


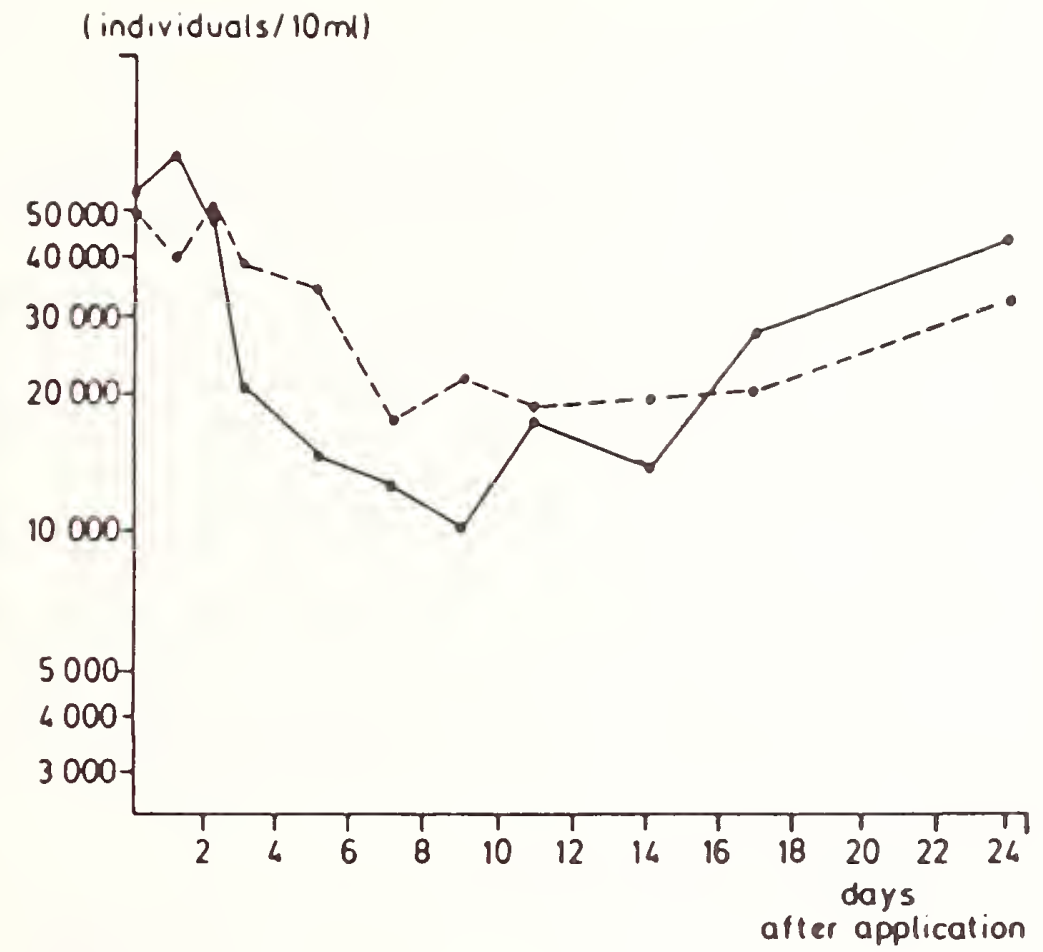

Figure 8. Dynamics of concentrations of Chroococcus limneticus in the control compartments. Note: Trachelomonas spec. and Euglena spec. were not presented in the control compartments

interspecific competition and probably not a direct consequence of chemical exposure.

As shown in Figure 9, the presence of PCP and TCP in the water results in the complete elimination of diatoms (Nitzschia acicularis) 11 and 17 days, respectively, after chemical application. The high sensitivity of diatoms to both chemicals is in agreement with the classification of these species as representatives of clean water associations according to water quality standard II [4]. In the control compartments, a species equilibrium appears after a slight decrease in numbers at the beginning of experiment due to effects of compartmentalization. The increase of heterotrophic microorganisms (bacteria) in all treated compartments, following the reduction of the autotrophic organisms, exemplifies the drastic alteration of the structure in the contaminated biotopes (Figure 10). Watanabe [5] found a comparable increase six weeks after single application of PCP by field soil. 


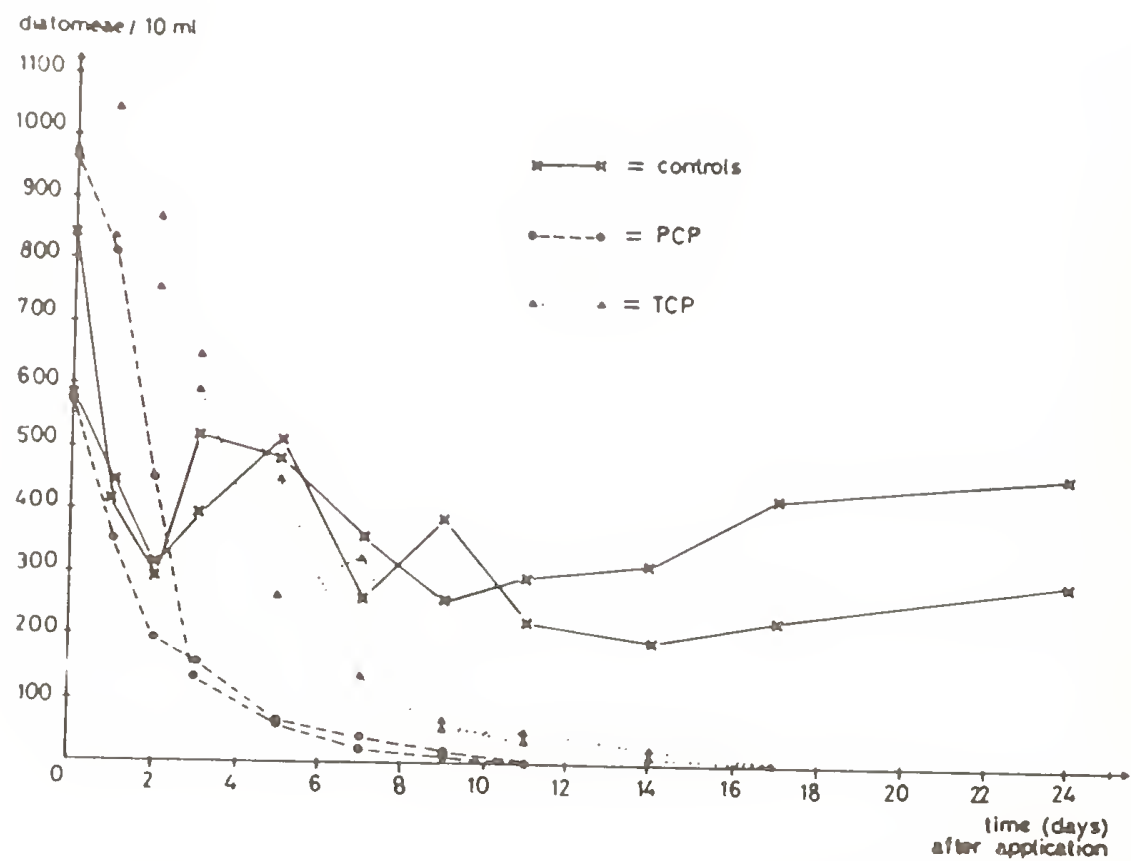

Figure 9. Dynamics of diatom concentrations (Nitzschia acicularis) in the treated and untreated compartments

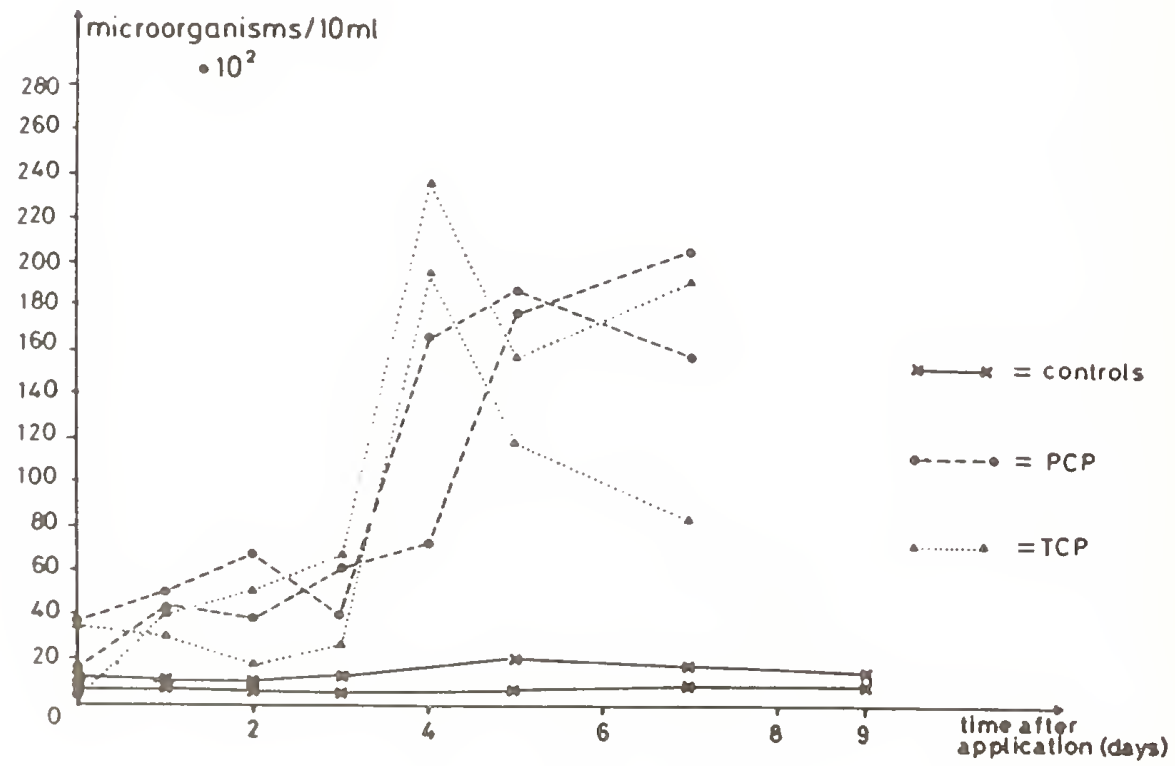

Figure 10. Concentration dynamics of heterotrophic microorganisms in the water of the treated and untreated compartments 


\section{CONCLUSIONS FOR SPECIMEN BANKING}

For the purpose of sampling design strategies for Environmental Specimen Banking, the following items have to be pointed out:

1. sediments can lose/decrease their chemical contents (concentrations). It is reasonable (suggestive) to collect and store "fresh" or new sediments (e.g., sediments following one vegetation period) for surveying and comparing the concentrations of organic chemicals.

2. Data of residue kinetics for organochlorine chemicals suggest that fat tissue (adipose tissue) from fish samples should be stored in addition to liver and muscle tissue.

3. Knowledge about population figures (density, dynamics) in the water collecting sites are necessary information to characterize the sampling sites for aquatic ESB-samples.

\section{REFERENCES}

[1] Lay, J. P., Schauerte, W., and Klein, W. (1984), Effects of Trichloroethylene on the Population Dynamics of Phyto- and Zooplankton in Compartments of a Natural Pond, Environ. Pollut. 33, 75-91.

[2] Schauerte, W., Lay, J. P., Klein, W., and Korte, F. (1982), Long-Term Fate of Organochlorine Xenobiotics in Aquatic Ecosystems, Ecotoxicology and Environmental Safety 6, 560-569.

[3] Schauerte, W., Lay, J. P., Klein, W., and Korte, F. (1982), Influence of 2,4,6-Trichlorophenol and Pentachlorophenol on the Biota of Aquatic Systems, Chemosphere 11, 71-79.

[4] Streble, H. and Krauter, D. (1974), Mikroflora and Mikrofauna des Süsswassers, Kosmos, Stuttgart, 36-37.

[5] Watanabe, I. (1977), Pentachlorophenol-Decomposing and PCP-Tolerant Bacteria in Field Soil Treated with PCP, Soil Biol. Biochem. 7, 99-103. 


\title{
SECTION 5
}

\section{ANALYTICAL METHODS FOR THE DETERMINATION OF ORGANIC CONTAMINANTS IN MARINE SEDIMENTS AND TISSUES}

\author{
Michele M. Schantz, Stephen N. Chesler, Barbara J. Koster, \\ and Stephen A. Wise \\ Center for Analytical Chemistry \\ National Bureau of Standards \\ Gaithersburg, Maryland 20899 \\ USA
}

\section{INTRODUCTION}

Samples representative of the marine environment were one of the four types of specimens originally proposed for storage in the Pilot Environmental Specimen Bank established at the National Bureau of Standards (NBS) in conjunction with the Environmental Protection Agency. In 1985, NBS began archiving marine sediment, fish tissue, and bivalve molluscs as part of the National Oceanic and Atmospheric Administration's (NOAA) National Status and Trends (NS\&T) Program. The purpose of the NS\&T program is to quantify the current status, as well as long-term trends, of contaminant concentrations and biological indicators of contaminant effects in the United States' coastal and estuarine environments [1]. The NBS Environmental Specimen Bank receives samples from two NS\&T activities, the Benthic Surveillance Project and the Mussel Watch Project. In the Benthic Surveillance Project, benthic fish samples (muscle and liver tissue) and sediment samples are archived from 12 sites per year of the 50 sampling sites within the project. In the Mussel Watch project, bivalve molluscs and sediments are archived from 30 sites per year of the 150 sampling sites within the project. The collection of specimens for the NS\&T specimen banking activity are described in more detail elsewhere [2].

For each sample to be archived, NBS receives duplicate samples (designated as $A$ and $B$ ) of approximately $150 \mathrm{~g}$ each, in the case of the sediment, fish liver, and fish muscle, or, in the case of the bivalve molluscs, either 30 oysters or 50 mussels per sample. Sediments from six of the 1985 Benthic Surveillance Project sites and bivalve molluscs from six of the Mussel Watch Project sites were selected for inorganic and organic analysis at NBS. For these samples, one of the duplicates was shucked (bivalve molluscs only), homogenized, and subsampled for analysis. The analyses of the twelve samples and an intercalibration sediment sample provided by NOAA for the determination of selected polycyclic aromatic hydrocarbons ( $\mathrm{PAH}$ ), chlorinated pesticides, and polychlorinated biphenyls (PCBs) are discussed in this paper.

\section{EXPERIMENTAL SECTION}

Subsamples from the "B" portions of six sediment samples received from the 1985 Benthic Surveillance collection were analyzed for organic contaminants. Samples from the following Benthic Surveillance sites were selected for 
analysis: Chesapeake Bay, MD; Mississippi River Delta, LA; Corpus Christi, TX; Dana Point, CA; Nisqually Reach, WA; and Elliott Bay, WA. Subsamples of the "B" portions of six samples received from the 1985 Mussel Watch collection were also analyzed. Samples from the following Mussel Watch sites were selected for analysis: Pascagoula Bay, FL (oysters, Crassostrea virginica); San Diego, CA (mussels, Mytilus californianus); Fort Johnson, SC (oysters, Crassostrea virginica); Galveston Bay, TX (oysters, Crassostrea virginica); Baltimore Harbor, MD (oysters, Crassostrea virginica); and Dorchester Bay, MA (mussels, Mytilus edulis). These same samples were analyzed for the determination of inorganic contaminants as described elsewhere [3].

Flow diagrams of the analytical procedures used for the analyses of the sediment and bivalve tissue samples are shown in Figures 1 and 2, respectively. An aliquot of wet sediment or bivalve tissue was first mixed with precleaned sodium sulfate. Known amounts of appropriate internal standards were added to the tissue/sodium sulfate mixture. The following internal standards were used: 1-butyl pyrene for the determination of PAH, deuterated 4,4' DDT for the determination of chlorinated pesticides, and PCB \#198 $\left(2,2^{\prime}, 3^{\prime}, 3^{\prime}, 4^{\prime}, 5^{\prime}, 5^{\prime}, 6^{\prime}\right.$ octachlorobiphenyl) for the determination of PCBs. This mixture was then Soxhlet extracted using methylene chloride, and the extracts were evaporatively concentrated to approximately $300 \mu \mathrm{L}$.

For the sediment extracts (Figure 1), the concentrate was placed onto a small precleaned silica column (Sep Pak, Waters Associates, Milford, MA) where the more polar components of the sediment extract were retained. For the bivalve tissue samples (Figure 2), the concentrated extracts were injected onto a liquid chromatographic preparative scale size exclusion column $(10 \mu \mathrm{m}$ polystyrene/divinylbenzene gel column, $100 \AA$, $25 \mathrm{~mm}$ i.d. x 60 cm, Polymer Laboratories, Inc., Amherst, MA). The void volume of the system plus a lipid fraction were discarded before collection of the fraction of interest (i.e., the fraction containing the $\mathrm{PAH}$, chlorinated pesticides, and PCBs). For both the sediment and bivalve samples, the fractions collected were concentrated to approximately $400 \mu \mathrm{L}$ for the final liquid chromatographic fractionation on an aminosilane column ( $\left.\mathrm{LC}-\mathrm{NH}_{2}\right)$.

At this point, the samples were divided in half (approximately $200 \mu \mathrm{L}$ each). One aliquot was used for the $\mathrm{LC}-\mathrm{NH}_{2}$ isolation of the $\mathrm{PAH}$ fraction, and the other aliquot was used for the $\mathrm{LC}-\mathrm{NH}_{2}$ isolation of the chlorinated pesticide and $\mathrm{PCB}$ fractions. In both cases, the column used to isolate the fractions was a semi-preparative aminosilane column (7.9 mm i.d. x $30 \mathrm{~cm}, \mu$ BondaPak $\mathrm{NH}_{2}$, Waters Associates, Milford, MA). The PAH fractionation procedure has been described previously [4-8]. For the fractionation of the chlorinated pesticides and PCBs, the mobile phase was $100 \%$ hexane for the PCBs and lower polarity pesticides. The pesticides of interest in this fraction were hexachlorobenzene, heptachlor, aldrin, 2,4' DDE, 4,4' DDE, and mirex. At this point, the mobile phase was changed to 58 methylene chloride in hexane for elution of the more polar pesticides. The pesticides of interest included in this fraction were lindane, heptachlor epoxide, $\alpha$-chlordane, trans-nonachlor, dieldrin, 2,4' DDD, 4,4' DDD, 2,4' DDT, and 4,4' DDT. Further details of this fractionation procedure will be published elsewhere [9]. At least two calibration solutions containing the compounds of interest and the same 


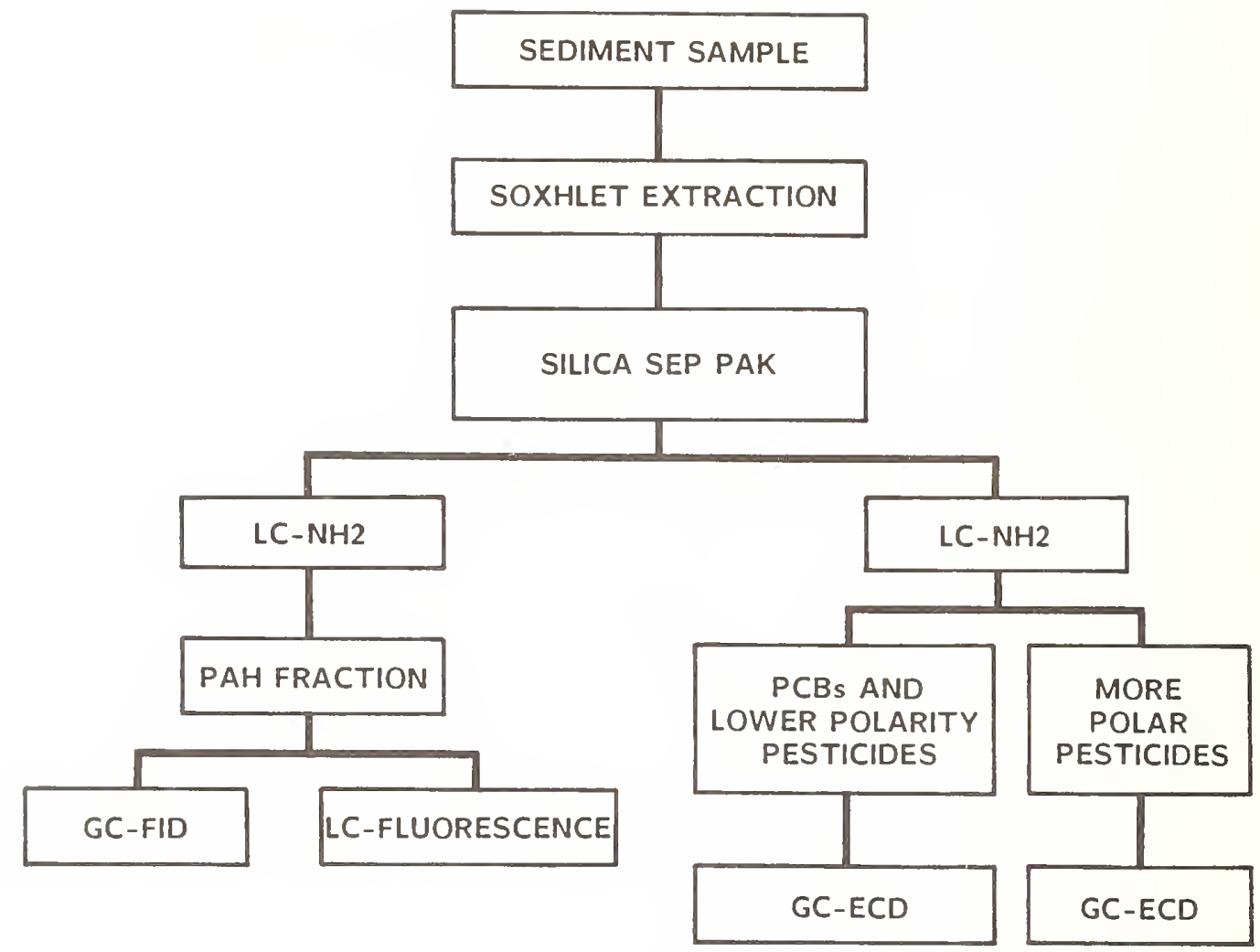

Figure 1. Flow diagram for the analysis of sediment samples

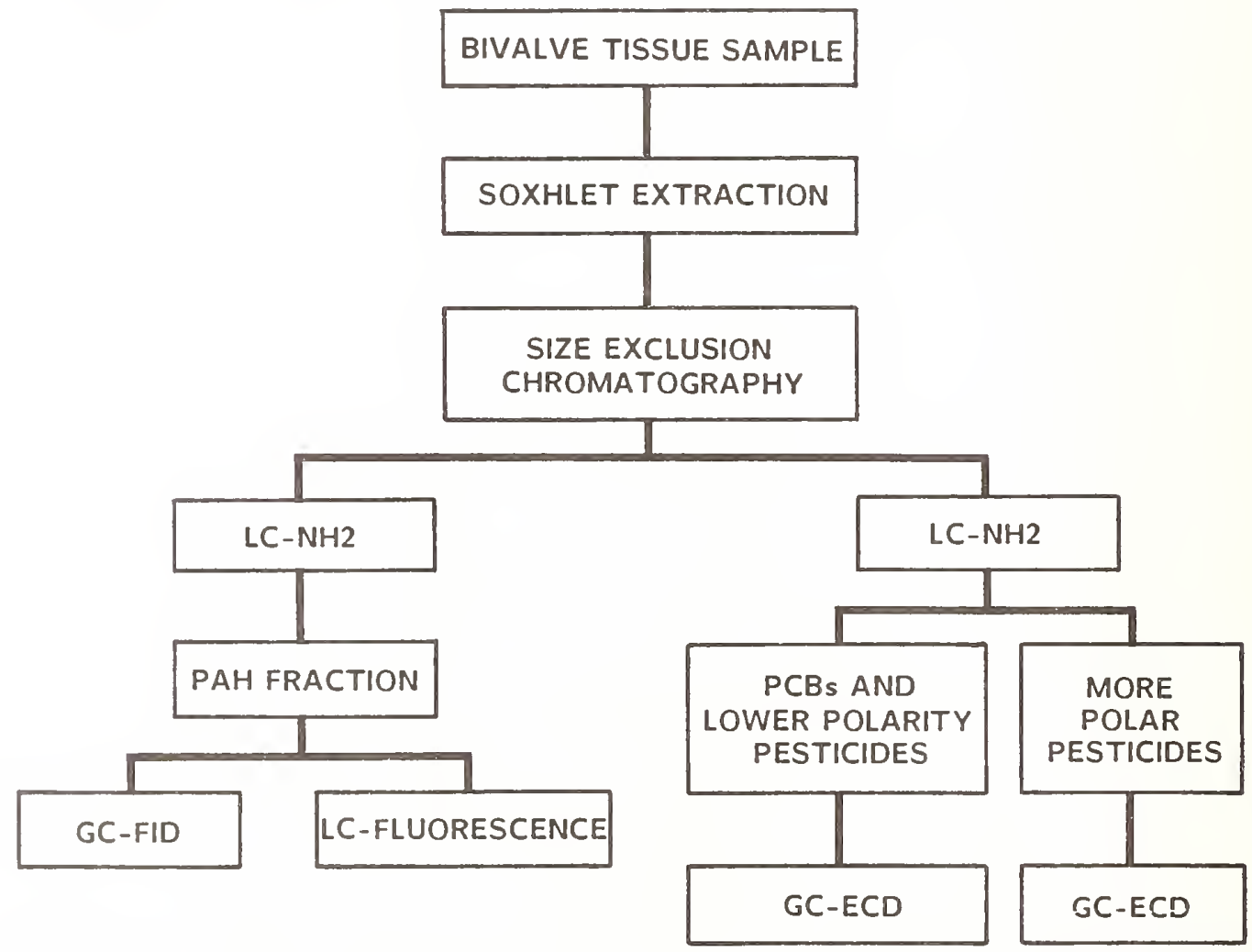

Figure 2. Flow diagram for the analysis of bivalve tissue samples 
internal standards were taken through identical Soxhlet extraction and fractionation steps.

The three fractions from the $\mathrm{LC}-\mathrm{NH}_{2}$ step were evaporatively concentrated to $200 \mu \mathrm{L}$ for gas chromatographic (GC) analysis. The column used was an immobilized nonpolar fused silica capillary $(30 \mathrm{~m} \times 0.25 \mathrm{~mm}$ i.d., $0.25 \mu \mathrm{m}$ coating thickness). For GC analysis of the PAH fraction, a flame ionization detector (FID) was used, and $2 \mu \mathrm{L}$ of the sample was injected in a splitless mode using hydrogen as the carrier gas. For the GC analysis of the other two fractions, an electron capture detector (ECD) was used. As above, $2 \mu \mathrm{L}$ of the sample was injected but in a split mode using helium as the carrier gas. For the analysis of the intercalibration sediment sample, a reversed-phase LC method with fluorescence detection was also used to determine the PAH $[8,9]$. This LC-fluorescence method provides a second analytical technique for comparison with the GC analyses, and this method will be used to determine PAH in sediment and bivalve samples in which the PAH concentrations are too low for measurement by the GC procedure.

\section{RESULTS AND DISCUSSION}

In Figure 3, chromatograms are shown for the GC analysis of the PAH fraction from (1) a calibration solution (2) a sediment extract, and (3) a mussel extract. Chromatograms from the GC analyses of the PCB and pesticide fractions from mussel and sediment extracts are shown are shown in Figures 4 and 5 .

An intercalibration sediment sample distributed by NOAA was analyzed using the method shown in Figure 1 and by three laboratories utilizing the method shown in Figure 6 [10]. The method shown in Figure 6 uses two gravity-fed chromatographic columns, a silica/alumina column which separates the saturated hydrocarbons from the aromatic hydrocarbons and a Sephadex LH-20 column which removes the lipid and biogenic material. Using the method shown in Figure 6 , one fraction containing the $\mathrm{PAH}, \mathrm{PCBs}$, and chlorinated pesticides is obtained. The results ( in $\mathrm{ng} / \mathrm{g}$ dry weight) from the analysis of the intercalibration sediment sample are compared in Table 1 . There was good agreement among the laboratories for the determination of $\mathrm{PAH}$ concentrations. The agreement among all the laboratories for the PCB and pesticide concentrations, however, was not as good.

Sediment samples from six sites in the Benthic Surveillance project were analyzed for the determination of PAH, PCBs, and pesticides. The concentrations (given in terms of $\mathrm{ng} / \mathrm{g}$ dry sediment) of selected compounds in these sediment samples are summarized in Table 2. The concentrations for individual $\mathrm{PAH}$ range from less than the detectable limit to $5280 \mathrm{ng} / \mathrm{g}$ dry weight of chrysene/triphenylene in the Corpus Christi, TX sediment. The majority of the pesticide concentrations are less than the detectable limit. The highest PCB congener concentration (58 ng/g dry weight of PCB \#153) was also found in the Corpus Christi, TX sediment.

Subsamples of bivalve specimens from six sites in the Mussel Watch Project were also analyzed. The concentrations (given in terms of $\mathrm{ng} / \mathrm{g}$ dry tissue) of 


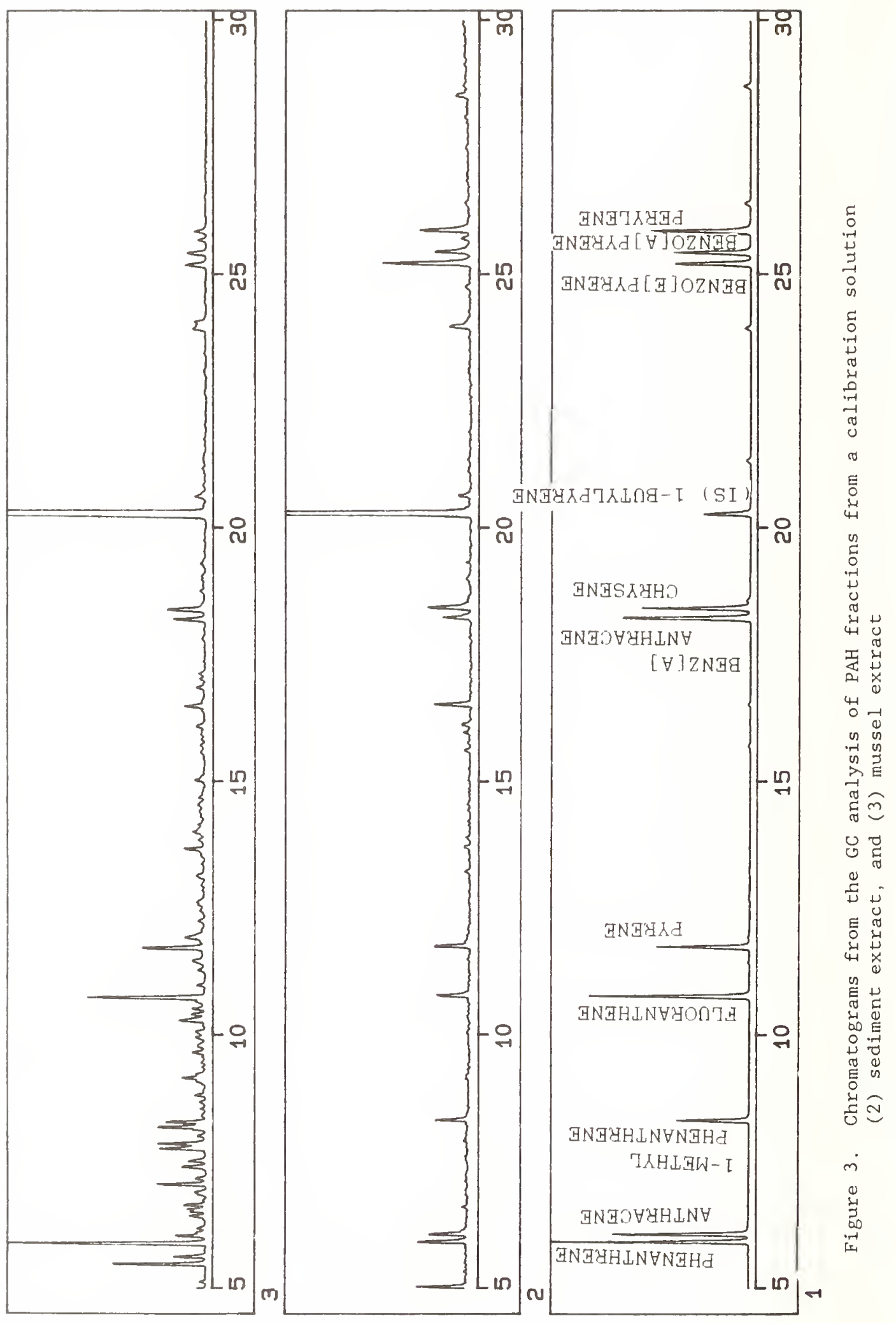




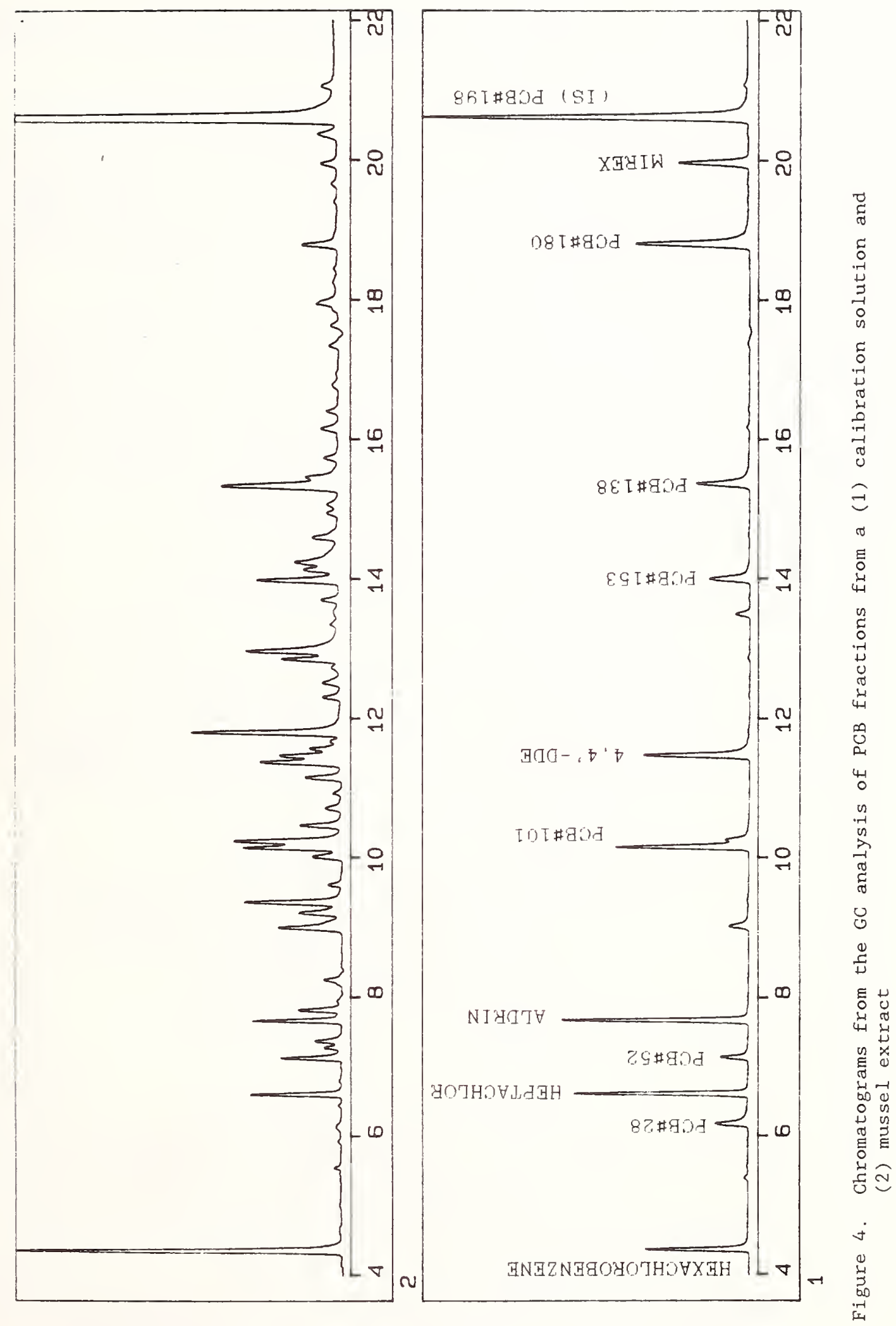




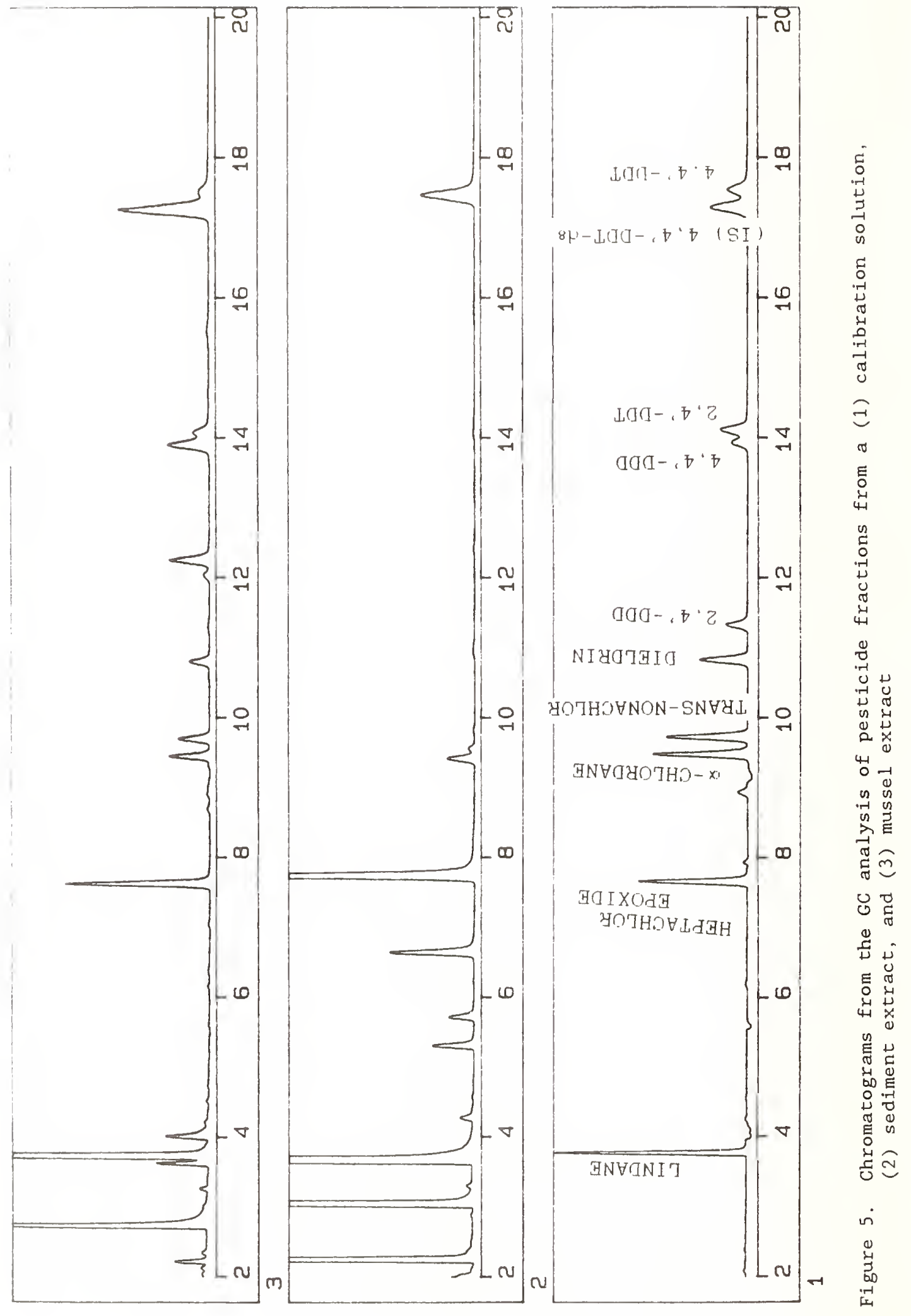




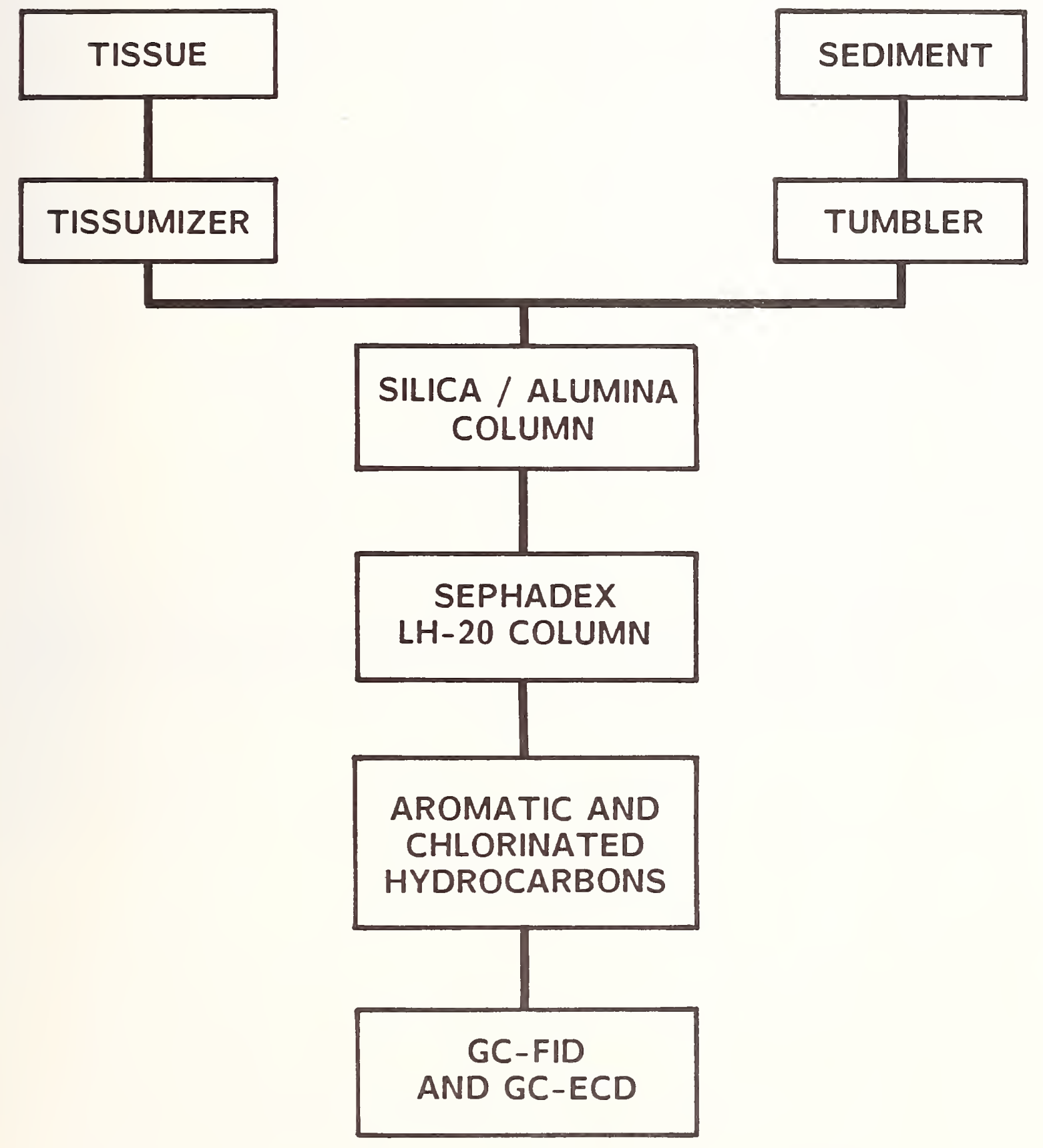

Figure 6. Flow diagram of the procedure used by NOAA laboratories for analysis of the intercalibration sediment sample 
Table 1. Mean Concentrations of Selected Organic Contaminants in NOAA Intercalibration Sediment ( $\mathrm{ng} / \mathrm{g}$ dry sediment)

\begin{tabular}{|c|c|c|c|c|c|}
\hline Compound & Lab $1^{\mathbf{a}}$ & Lab $2^{a}$ & Lab $3^{a}$ & NBS $-G^{\mathbf{b}}$ & NBS $-L^{b} C^{b}, \mathbf{c}$ \\
\hline Phenanthrene & 2300 & 2200 & 3200 & $2420(220)$ & $2280(170)$ \\
\hline Anthracene & 510 & 650 & 730 & $710(60)$ & $490(40)$ \\
\hline Fluoranthene & 3900 & 3700 & 5600 & $3660(430)$ & $3420(190)$ \\
\hline Pyrene & 4100 & 3900 & 5800 & $3930(360)$ & $3640(260)$ \\
\hline $\begin{array}{l}\text { Benz [a] anthracene } \\
\text { Chrysene }+\end{array}$ & 1500 & 1400 & 2100 & $1840(200)$ & $1390(110)$ \\
\hline Triphenylene & 2600 & 2100 & 3600 & $2700(190)$ & \\
\hline Benzo[e]pyrene & 1600 & 1400 & 2000 & $1860(100)$ & \\
\hline Benzo[a] pyrene & 1800 & 1700 & 2700 & $2540(170)$ & $2140(140)$ \\
\hline Perylene & 510 & 460 & 710 & $770(40)$ & $570(30)$ \\
\hline Hexachlorobenzene & 0.4 & 0.6 & 32 & $<0.5$ & \\
\hline Heptachlor epoxide & $<0.3$ & $<0.8$ & $<2$ & $0.6(0.1)$ & \\
\hline$\alpha$-Chlordane & 0.9 & 2 & 2 & $<0.2$ & \\
\hline Trans-nonachlor & 0.4 & 0.9 & $<1$ & $0.9(0.1)$ & \\
\hline $4,4^{\circ}-\mathrm{DDE}$ & 7 & 10 & 9 & $1.9(0.1)$ & \\
\hline $2,4^{\prime}-\mathrm{DDT}$ & 4 & 5 & $<2$ & $1.4(0.1)$ & \\
\hline $4,4^{\prime}-\mathrm{DDT}$ & $<0.5$ & 10 & $<2$ & $2.4(0.1)$ & \\
\hline PCB \#47 & 8 & 9 & 14 & $9.5(0.4)$ & \\
\hline PCB \#101 & 70 & 64 & 63 & 117 (5) & \\
\hline PCB \#153 & 110 & 77 & 72 & $127(8)$ & \\
\hline PCB \#194 & 8 & 17 & 9 & $10.0(0.4)$ & \\
\hline \multicolumn{6}{|c|}{$\begin{array}{l}\text { a Reference }[10] \\
{ }^{b} \text { Numbers in parentheses are standard deviations of a single measurement and } \\
<\text { numbers indicate minimum detectable limit for the compound in the sample. } \\
{ }^{c} \text { LC-fluorescence analysis of PAH fraction }\end{array}$} \\
\hline
\end{tabular}


Table 2. Concentrations of Selected Organic Contaminants in Six 1985 Benthic Surveillance Sediments (ng/g dry sediment) ${ }^{a}$

\begin{tabular}{|c|c|c|c|c|c|c|}
\hline Compound & $\mathrm{CB}^{\mathrm{b}}$ & $\mathrm{MRD}^{\mathrm{c}}$ & $\mathrm{CC}^{\mathrm{d}}$ & $\mathrm{DP}^{\mathbf{e}}$ & $\mathrm{NR}^{\mathrm{f}}$ & $E B^{B}$ \\
\hline Phenanthrene & $2040(230)$ & $50(2)$ & $490(70)$ & $170(10)$ & $120(20)$ & $400(10)$ \\
\hline Anthracene & $930(30)$ & 50 (4) & $<50$ & $140(10)$ & 30 (1) & $180(10)$ \\
\hline Fluoranthene & $1060(50)$ & $20(3)$ & $540(10)$ & $230(20)$ & $100(10)$ & $640(30)$ \\
\hline Pyrene & $1040(70)$ & $260(30)$ & $1800(140)$ & $300(20)$ & $120(4)$ & $250(20)$ \\
\hline $\begin{array}{l}\text { Benz [a] anthracene } \\
\text { Chrysene }+\end{array}$ & $<50$ & $<20$ & $<50$ & $40(4)$ & $50 \quad(3)$ & $260(30)$ \\
\hline Triphenylene & $1650(10)$ & $50(2)$ & $5280(220)$ & $70(10)$ & $90(2)$ & $640(40)$ \\
\hline Benzo[e]pyrene & $870(80)$ & $100(10)$ & $760(30)$ & $140(4)$ & $60(10)$ & $330(30)$ \\
\hline Benzo[a]pyrene & $1130(50)$ & $160(10)$ & $2130(270)$ & $630(20)$ & $130(20)$ & $500(20)$ \\
\hline Perylene & $<50$ & $<20$ & $<50$ & $120(10)$ & $<30$ & $<50$ \\
\hline Hexachlorobenzene & $<23.3$ & $10.3(0.7)$ & $<13.4$ & $6.5(0.3)$ & $<1.7$ & $<5.2$ \\
\hline Heptachlor epoxide & $<3.5$ & $<0.3$ & $<2.7$ & $5.2(0.1)$ & $<0.2$ & $<0.8$ \\
\hline$\alpha$-Chlordane & $<1.7$ & $<0.2$ & $<1.2$ & $<0.4$ & $<0.1$ & $<0.4$ \\
\hline Trans-nonachlor & $<2.6$ & $<0.2$ & $<1.8$ & $<0.6$ & $<0.2$ & $<0.5$ \\
\hline $4,4^{\prime}-\mathrm{DDE}$ & $3.9(0.2)$ & $<0.2$ & $<3.1$ & $<0.5$ & $<0.2$ & $1.6(0.1)$ \\
\hline $2,4^{\prime}-\mathrm{DDT}$ & $<0.5$ & $<0.1$ & $<0.4$ & $<0.1$ & $<0.1$ & $<0.1$ \\
\hline $4,4^{\prime}-\mathrm{DDT}$ & $<0.7$ & $<0.1$ & $<0.5$ & $<0.2$ & $<0.1$ & $<0.1$ \\
\hline PCB \#47 & $<9.4$ & $<0.8$ & $<14.8$ & $<1.7$ & $<0.7$ & $<2.1$ \\
\hline PCB \#101 & $15.5(0.6)$ & $9.3(0.2)$ & $51.9(3.5)$ & $18.0(0.9)$ & $<0.4$ & $24.1(0.4)$ \\
\hline PCB \#153 & $<2.5$ & $6.6(0.1)$ & $58.0(3.1)$ & $13.7(0.4)$ & $5.2(0.2)$ & $33.3(0.4)$ \\
\hline PCB \#194 & $18.9(1.0)$ & $4.3(0.1)$ & $19.9(1.0)$ & $9.5(0.3)$ & $0.3(0.1)$ & $34.9(0.5)$ \\
\hline \multicolumn{7}{|c|}{ 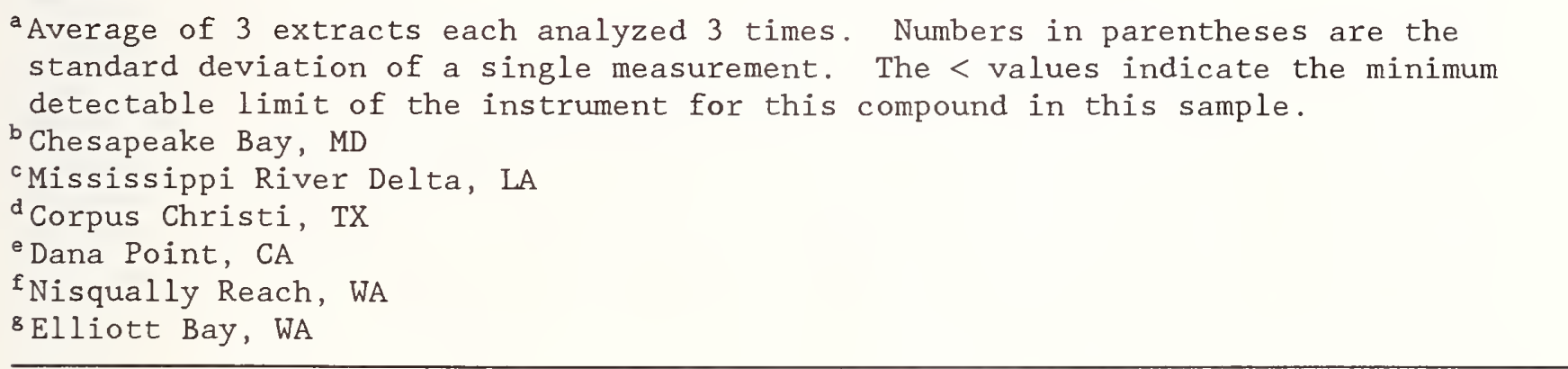 } \\
\hline
\end{tabular}


selected compounds are summarized in Table 3. The PAH concentrations are, in general, lower in the bivalve tissue samples (Table 3 ) than in the sediment samples (Table 2) with values ranging from below the minimum detectable limit to $270 \mathrm{ng} / \mathrm{g}$ dry weight of phenanthrene in the Dorchester Bay, MA mussel tissue. The 4,4'-DDE concentrations are higher in the bivalve tissue samples than in the sediment samples ranging from $7 \mathrm{ng} / \mathrm{g}$ dry tissue in the Galveston Bay, TX oysters to $163 \mathrm{ng} / \mathrm{g}$ dry tissue in the San Diego, CA mussels. The highest PCB congener concentration in the bivalve tissue samples was $93 \mathrm{ng} / \mathrm{g}$ PCB\#101 (Dorchester Bay, MA).

\section{CONCLUSIONS}

The procedures described in this paper were used to analyze an intercalibration sediment, as well as six sediment and six bivalve samples collected as part of the NOAA NS\&T Specimen Banking program. The liquid chromatographic fractionation steps provide relatively clean fractions containing the analytes of interest. These methods will be used to provide baseline values for organic contaminants in representative marine specimens banked for the NS\&T program.

\section{ACKNOWLEDGEMENT}

The authors acknowledge the assistance of Gunnar G. Lauenstein in the coordination of the Specimen Banking activities for the NS\&T Program of NOAA. We acknowledge the cooperation and assistance of the following individuals in the collection of samples: Sandy Freitas (Battelle New England Marine Laboratory), Andy Lissner (Pacific Northwest Laboratory), Gary Wolff (Texas A \& M University). Robert C. Clark, Jr., (National Marine Fisheries Northwest and Alaska Fisheries Center), Peter Hanson (National Marine Fisheries Southeast Fisheries Center), and Vincent Zdanowicz (National Marine Fisheries Northeast Fisheries Laboratory). We acknowledge the assistance of Kevin Diamond in the preparation of the bivalve specimens from the NS\&T Program. This work was supported in part by the Ocean Assessments Division, NOAA.

\section{REFERENCES}

[1] Ocean Assessments Division (1986), The National Status and Trends Program for Marine Environmental Quality, FY86 Program Description, National Oceanic and Atmospheric Administration, Ocean Assessments Division:

Rockville, MD, $35 \mathrm{pp}$.

[2] Lauenstein, G. G. and Calder, J.A. (1988), Specimen Banking: A Key Element of the National Oceanic and Atmospheric Administration's National Status and Trends Program, In: These Proceedings.

[3] Stone, S. A., Becker, D. A., Koster, B. J., Pella, P. A., Sleater, G., Tillekeratne, M. P. M., and Zeisler, R. (1988), Inorganic Analytical Methods and Results for Marine Bivalves and Sediments, In: These Proceedings. 
Table 3. Concentrations of Selected Organic Contaminants in Six 1985 Mussel Watch Bivalve Tissue Samples (ng/g dry bivalve tissue) ${ }^{a}$

\begin{tabular}{|c|c|c|c|c|c|c|}
\hline Compound & $\mathrm{PB}^{\mathrm{b}}$ & $S D^{c}$ & $\mathrm{FJ}^{\mathrm{d}}$ & $\mathrm{GB}^{\mathrm{e}}$ & $\mathrm{BH}^{\mathrm{f}}$ & $\mathrm{DB}^{\mathrm{B}}$ \\
\hline Phenanthrene & $<20$ & $<30$ & $<50$ & $<40$ & $90(10)$ & $270(20)$ \\
\hline Anthracene & $80(10)$ & $<30$ & $<40$ & $50(10)$ & $30(10)$ & $30(10)$ \\
\hline Fluoranthene & $100(10)$ & $<20$ & $<170$ & $260(10)$ & $<30$ & $<100$ \\
\hline Pyrene & $90(10)$ & $<30$ & $170(10)$ & $200(10)$ & $40(10)$ & $130(10)$ \\
\hline $\begin{array}{l}\text { Benz [a] anthracene } \\
\text { Chrysene }+\end{array}$ & $<80$ & $<40$ & $50(10)$ & $70(10)$ & $<20$ & $70(10)$ \\
\hline Triphenylene & $210(20)$ & $50(10)$ & $110(10)$ & $<50$ & $50(10)$ & $210(10)$ \\
\hline Benzo[e]pyrene & $40(10)$ & $50(10)$ & $70(10)$ & $<40$ & $20(10)$ & $80(10)$ \\
\hline Benzo[a]pyrene & $<90$ & $50(10)$ & $<50$ & $<30$ & $<30$ & $60(10)$ \\
\hline Perylene & $<40$ & $<50$ & $<60$ & $<30$ & $<40$ & $<40$ \\
\hline Hexachlorobenzene & $<0.2$ & $0.6(0.1)$ & $1.0(0.1)$ & $3.1(0.3)$ & $15.2(0.1)$ & $1.5(0.1)$ \\
\hline Heptachlor epoxide & $<0.2$ & $<0.2$ & $<0.7$ & $<0.2$ & $<0.1$ & $5.5(0.2)$ \\
\hline$\alpha$-Chlordane & $<0.1$ & $0.8(0.1)$ & $<0.4$ & $<0.2$ & $3.5(0.1)$ & $12.4(0.2)$ \\
\hline Trans-nonachlor & $<0.2$ & $<0.2$ & $<1.6$ & $2.2(0.1)$ & $2.5(0.1)$ & $6.1(0.2)$ \\
\hline $4,4^{\prime}-\mathrm{DDE}$ & $10.8(0.6)$ & $163.4(5.9)$ & $8.4(0.8)$ & $7.3(0.7)$ & $14.6(0.3)$ & $28.1(1.0)$ \\
\hline $2,4^{\prime}-\mathrm{DDT}$ & $<0.6$ & $76.0(2.2)$ & $<0.3$ & $<0.3$ & $13.6(1.0)$ & $0.6(0.1)$ \\
\hline $4,4^{\prime}-\mathrm{DDT}$ & $<0.8$ & $14.7(1.3)$ & $<2.4$ & $<1.3$ & $<0.5$ & $0.7(0.1)$ \\
\hline $\mathrm{PCB} \# 47$ & $<0.9$ & $3.0(0.1)$ & $4.0(0.2)$ & $<1.8$ & $3.0(0.1)$ & $49.8(3.7)$ \\
\hline PCB\#101 & $11.3(0.9)$ & $13.7(0.8)$ & $5.7(0.3)$ & $10.2(0.3)$ & $10.8(0.9)$ & $93.0(4.4)$ \\
\hline PCB\#153 & $16.9(0.9)$ & $30.0(0.6)$ & $9.2(0.3)$ & $11.9(0.3)$ & $13.0(0.2)$ & $79.7(2.5)$ \\
\hline PCB\#194 & $<0.4$ & $0.4(0.1)$ & $0.3(0.1)$ & $<0.4$ & $<0.3$ & $0.2(0.1)$ \\
\hline \multicolumn{7}{|c|}{ 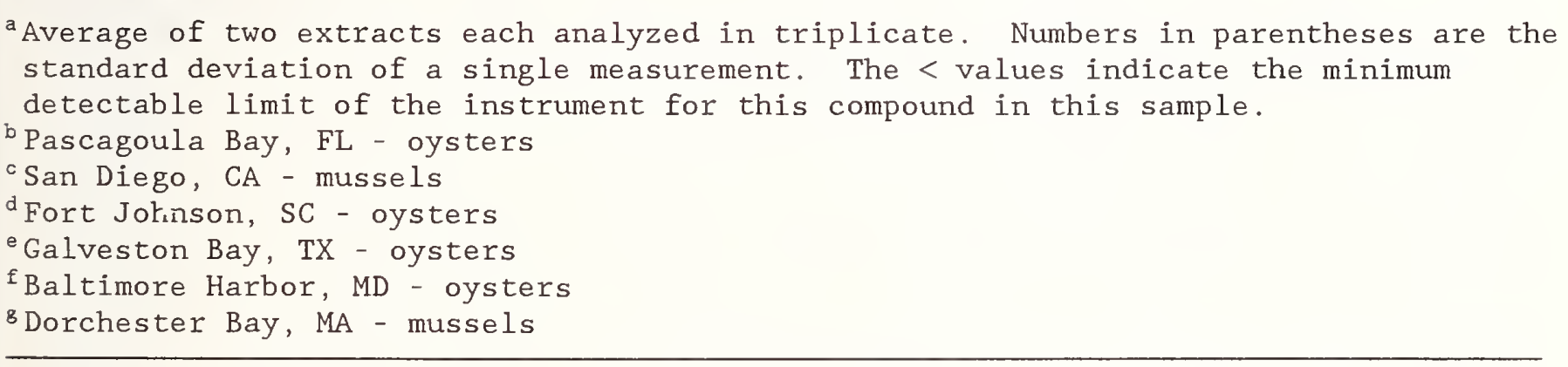 } \\
\hline
\end{tabular}


[4] Wise, S. A., Chesler, S. N., Hertz, H. S., Hilpert, L. R., and May, W. E. (1977), A Chemically Bonded Aminosilane Stationary Phase for the HighPerformance Liquid Chromatographic Separation of Polynuclear Aromatic Compounds, Anal. Chem. 49, 2306-2310.

[5] Hertz, H. S., Brown, J. M., Chesler, S. N., Guenther, F. R., Hilpert, L. R., May, W. E., Parris, R. M., and Wise, S. A. (1980), Determination of Individual Organic Compounds in Shale Oil, Anal. Chem. 52, 1650-1657.

[6] Wise, S. A., Benner, B. A., Chesler, S. N., Hilpert, L. R., Vogt, C. R., and May, W. E. (1986), Characterization of the Polycyclic Aromatic Hydrocarbons from Two Standard Reference Material Air Particulate Samples, Anal. Chem. 58, 3067-3077.

[7] May, W. E. and Wise, S. A. (1984), Liquid Chromatographic Determination of Polycyclic Aromatic Hydrocarbons in Air Particulate Extracts, Anal. Chem. 56, 225-232.

[8] Kline, W. F., Wise, S. A., and May, W. E. (1985), The Application of Perdeuterated Polycyclic Aromatic Hydrocarbons (PAH) as Internal Standards for the Liquid Chromatographic Determination of PAH in a Petroleum Crude Oil and Other Complex Mixtures, J. Liquid Chromatogr. 8, 223-237.

[9] Parris, R. M., Wise, S. A., and Chesler, S. N., Unpublished Manuscript.

[10] MacLeod, W. D., Jr (1986), Trace Analysis and Quality Assurance for Extractable Organic Chemicals, In: Summary Report of NOAA-NBS Quality Assurance Workshop, December 1985,1986; J. K. Taylor, Ed., NBSIR 86-3446, National Bureau of Standards, Gaithersburg, MD, pp. 4-11. 


\title{
SECTION 6
}

\section{COMPARATIVE INVESTIGATIONS ON TRACE METAL LEVEIS IN BROWN ALGAE AND COMMON (BLUE) MUSSELS AT THE SAME LOCATION IN THE BALTIC SEA AND THE NORTH SEA}

\author{
M. Stoeppler, F. Backhaus, M. Burow, K. May, and C. Mohl \\ Institute of Applied Physical Chemistry \\ Nuclear Research Center (KFA) Jūlich \\ D-5170 Jülich \\ FEDERAL REPUBLIC OF GERMANY
}

\section{SUMMARY}

In order to obtain basic data for trace metal contents in a marine algae (Fucus vesiculosus) in comparison to a marine mussel (Mytilus edulis), arsenic, cadmium, lead, total mercury, methylmercury, and selenium have been determined in specimens found close together at several locations in the North Sea and the Baltic Sea. The results indicate that the levels of cadmium, total mercury, methylmercury, selenium and possibly lead are somewhat to significantly higher in mussels, whereas higher arsenic and nickel levels are found in algae. From these data it appears that the simultaneous use of algae and mussels, at least for a distinct investigation period, may have advantages for the Environmental Specimen Bank in the Federal Republic of Germany.

\section{INTRODUCTION}

During preliminary research of the Pilot Environmental Specimen Bank (ESB) Program of the Federal Republic of Germany performed from 1976 to 1984 and from similar investigations at the National Bureau of Standards (NBS) in the United States of America, it has been shown that specimen banking from the present state-of-the-art is now feasible [1-8]. Thus, the Federal Government decided in 1984 to establish a permanent ESB in the Federal Republic of Germany beginning in January 1985. Since the pilot phase was predominantly aimed at technical, analytical and organizational studies, the first part of the permanent operation was a transition program. This phase aims mainly at identification and selection of representative sampling areas and appropriate species for environmental monitoring and assessment in addition to current collection and storage of already identified specimen types. From the beginning, our institute was responsible for tasks in the marine environment. Thus, prior to and within the transition phase of the ESB program, we performed some investigations with marine species. The first species selected, as a result of collaboration with the Institute of Marine Research of the University at Kiel, F.R.G., was the brown algae (seaweed, Fucus vesiculosus) as a community forming dominant species in coastal areas of the Baltic as well as of the North Sea. In order to obtain reliable data for variations of trace metal contents with location and season, we started a long-term study of sampling and analysis in bimonthly intervals in 1982 including sea water analysis for baseline levels. The results achieved so far indicate some seasonal dependence of metal levels at nonpolluted sites in the Baltic Sea with the highest values observed in the 
winter and the lowest values occuring in the summer, as best documented for arsenic [9].

While it is supposed that algae incorporate trace elements predominantly from the dissolved state, bivalves as filter feeders are able to scavenge metals and organometallic compounds from particulate matter $[10,11]$. By including the Common (or Blue) mussel (Mytilus edulis) in our marine research and collection program, we would be able to make use of already existing international mussel watch programs [12,13] and of the experience of the U.S. Environmental Specimen Bank with this specimen [4,8]. In this context, it is of importance to compare values obtained for both species collected at exactly the same site and at the same time. The goal was to find out if those values could be used at least partly to distinguish between dissolved and total metal levels or if other important differences, e.g., due to physiological reasons, could be seen and used for monitoring purposes. In this preliminary evaluation, the data found for mussels and algae collected from selected locations in 1984, 1985, and 1986 are reported, some facts discussed, and the preliminary conclusions drawn.

\section{SAMPLING SITES}

Mussels as well as algae have been collected at the same site and at different times at the following locations: Eckwarderhoerne, Nordstrand and List/Sylt (North Sea), Glücksburg, Kronsgaard, Langholz, Kiel Strande, and Dahme (Baltic Sea) as shown in Figure 1. At the Eckwarderhoerne site, Jade Bay, we performed a detailed, study which is still ongoing, with bimonthly collections starting in February 1985 that will include the analysis of trace metals in water.

The above mentioned areas, except Nordstrand serve as current collection sites for biannual collection and long-term storage of algae and mussels for permanent banking. Within this concept, however, all sampling sites in the western Baltic Sea contribute to a composite sample for the ESB since this area can be considered as an area that has only minimal metal pollution thus providing baseline levels for the marine species now under study.

\section{EXPERIMENTAL SECTION}

\section{A. Sampling and Sample Preparation}

Fucus vesiculosus occurs in large communities in the littoral region of the collection area and thus can be easily collected manually at low tide wearing precleaned polyethylene gloves. Usually a sample amount of approximately $800 \mathrm{~g}$ from each community (6-7 randomly taken individual specimens) is collected at the sampling site. The algae are then further prepared as follows. Adhering material (small animals, plants, inorganic parts) were separated first, e.g., with plastic forceps. The sample is then rinsed three times in a stainless steel sieve with clear seawater from the sampling site. Excess water is removed by rotating the sieve in the air. Next, the algae are transferred into weighed stainless steel vessels and immediately placed in 


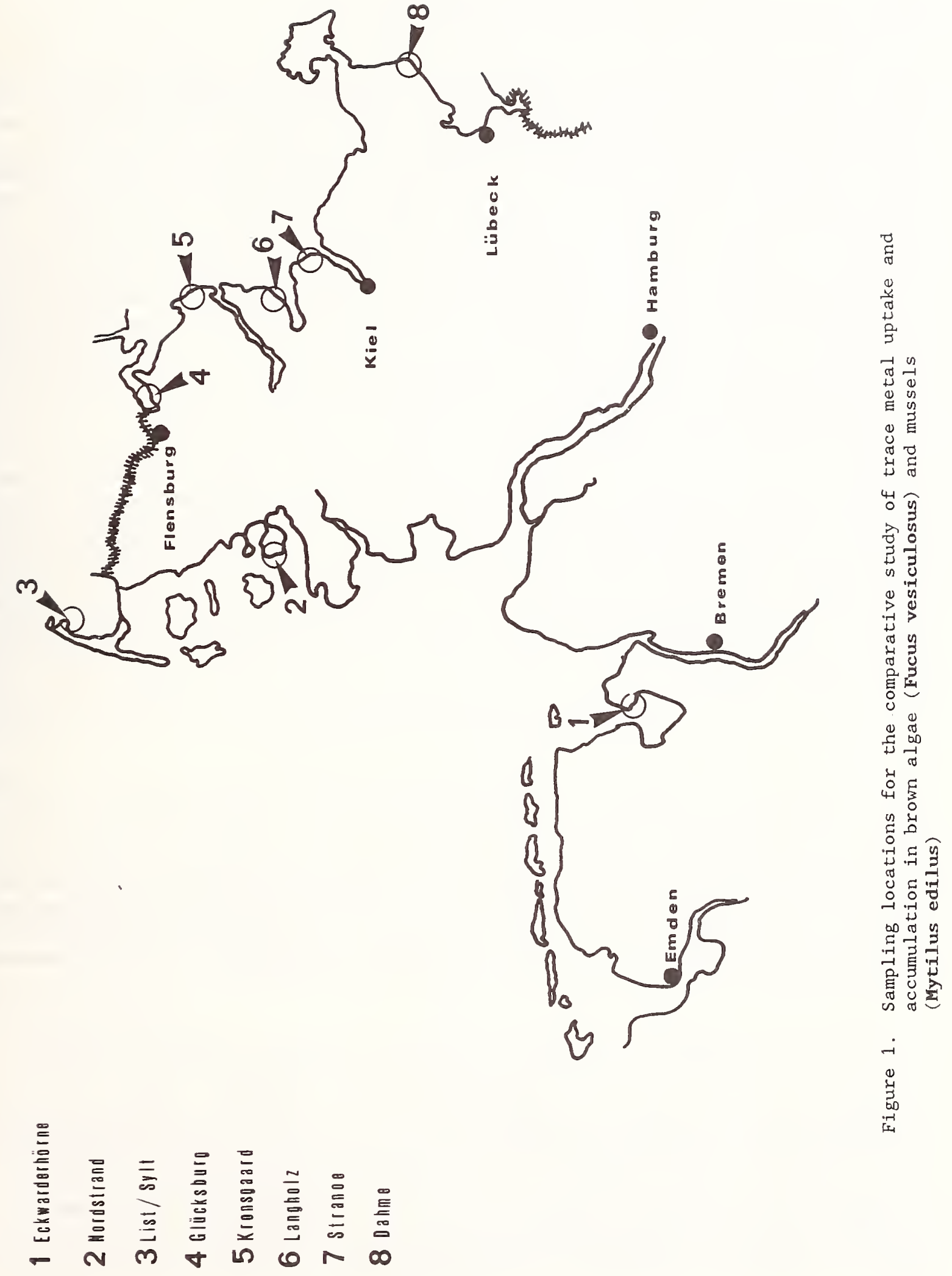


cryogenic transport containers where a temperature below $-150^{\circ} \mathrm{C}$ is maintained over liquid nitrogen (gas phase storage).

Mytilus edulis also occur in rather large communities at the investigated sites providing enough material for the preparation of representative samples. At low tide approximately 200 single mussels, shell length from 2 to $6 \mathrm{~cm}$ (equivalent to approximately $1000 \mathrm{~g}$ soft tissue) have been collected, rinsed, and stored as described above for algae. The mussels were not allowed to depurate in our experiments. Usually all sampling sites have been treated in the same manner during a sampling campaign and the deep frozen samples transported to the Environmental Specimen Bank in Jülich in special vans.

Preparation of the samples for metal analysis is performed in the following manner. The samples are thawed overnight in clean benches (class 100 environment) until the material is just below $0{ }^{\circ} \mathrm{C}$. Algae can be passed directly through a mincer made from an aluminum alloy, while the mussels have to be dissected (separation of soft parts from the shells) prior to homogenization in a household mixer.

A subsample of approximately $100 \mathrm{~g}$ (fresh weight) is taken from each homogeneous material and stored at $-20{ }^{\circ} \mathrm{C}$ for a few days until subsequent analysis of total mercury and methylmercury. The remaining material is then subjected to a freeze drying procedure on PTFE coated steel dishes and followed by a moisture content determination. Subsequently, the whole materials are milled with agate ball mills until the particle size is < $200 \mu \mathrm{m}$. The latter procedure is controlled by sieving. The material is then transferred into $250-\mathrm{mL}$ polyethylene bottles with wide necks and stored in the dark at $15^{\circ} \mathrm{C}$ until analysis.

\section{B. Analytical Procedure}

Total mercury analysis is performed on fresh material after wet digestion with a mixture of nitric and perchloric acid in closed quartz vessels [14] using instrumentation designed and optimized in our laboratory that allows the routine determination of total mercury at the low $\mu \mathrm{g} / \mathrm{kg}$-level [2,7]. Analysis of methylmercury starts with a simple hydrochloric acid cleanup, ion exchange separation of $\mathrm{CH}_{3} \mathrm{HgCl}$ from ionic mercury, $\mathrm{UV}$ decomposition of methylmercury and subsequent determination as ionic mercury [15]. Quality assessment of the latter procedure has been done via gas chromatography with Electron Capture Detection (ECD).

Total and inorganic arsenic as well as total selenium is determined in all materials as described elsewhere in detail using the hydride technique after different sample treatment procedures with electrothermal atomization by use of a PE MHS-20-system [9]. The remaining elements cadmium, lead, and nickel are determined after pressurized decomposition of 0.2-0.3 g subsamples (dry weight) with ultrapure or purified (e.g., by low boiling distillation) analytical grade nitric acid in PTFE vessels $[2,7]$ by the application of improved GFAAS (Graphite Furnace AAS) procedures [7,16]. Evaluation is performed, wherever possible, against Environmental Specimen Bank Specific Reference Materials in order to maintain an optimal accuracy and precision for routine measurements [17]. 


\section{RESULTS AND DISCUSSION}

Table 1 summarizes all the data obtained for total arsenic, selenium, mercury, lead, cadmium, and nickel in bimonthly collected samples of algae and mussels starting with February 1985 at Eckwarderhoerne site, Jade Bay, North Sea (see Figure 1). At this site, we have also started water analysis which will be discussed elsewhere since the bimonthly collection and comparative investigation will be continued and expanded to other elements, since at tile moment no clear seasonal variations can be seen.

In Table 2 the results are summarized for comparative measurements of the above mentioned elements, except selenium, in algae and mussels at various collection sites from spring 1984. This includes Nordstrand and List/Sylt from the North Sea, as well as Strande, Kronsgaard, Dahme, Langholz, and Glücksburg from the Baltic Sea.

From Tables 1 and 2, it is evident that there can be seen some obvious differences in elemental contents between both specimen types which at least, will stimulate further detailed comparative studies for the benefit of the ESB program in the FRG. Due to the fact that the mussels were not allowed to depurate during this series of experiments and that it appears from more recent studies with algae that uptake may occur also from particulate matter [18], the differences found have to be evaluated further. Nevertheless, these data clearly show that, irrespective of uptake mechanisms, arsenic and nickel values certainly are higher in algae, while selenium, mercury, cadmium, and possibly lead are higher in mussels. It is also interesting to note that mussels contain higher methylmercury levels. From the ratio total mercury to methylmercury in algae, one could speculate that the aqueous phase has a methylmercury level that is well below $10 \%$ of total mercury. An excess appears to be due to uptake from particulate matter or biological enrichment.

\section{ACKNOWLEDGMENTS}

The authors express their gratitude to the following Federal Ministries that financially supported the whole ESB Program coordinated by the Federal Environmental Agency (Unweltbundesamt): Until December 1984, Bundesministerium fur Forschung und Technologie, until June 1986, Burndesministerium des Inneren and recently Bundesministerium fur Umwelt, Naturschutz und Reaktorsicherheit, Bonn, FRG, to Mrs. M. Roth and Mr. N. Commerscheidt for their valuable technical assistance.

\section{REFERENCES}

[1] Boehringer, U. R., Ed. (1981), Umweltprobenbank, Ergebnisse der Vorstudien und Projektierung der Pilotphase, Umweltbundesamt, Berlin.

[2] Kayser, D., Boehringer, U. R., and Schmidt-Bleek, F. (1982), The Environmental Specimen Banking Project of the Federal Republic of Germany, Pilot Phase, Environmental Monitoring and Assessment 1, 241-255. 


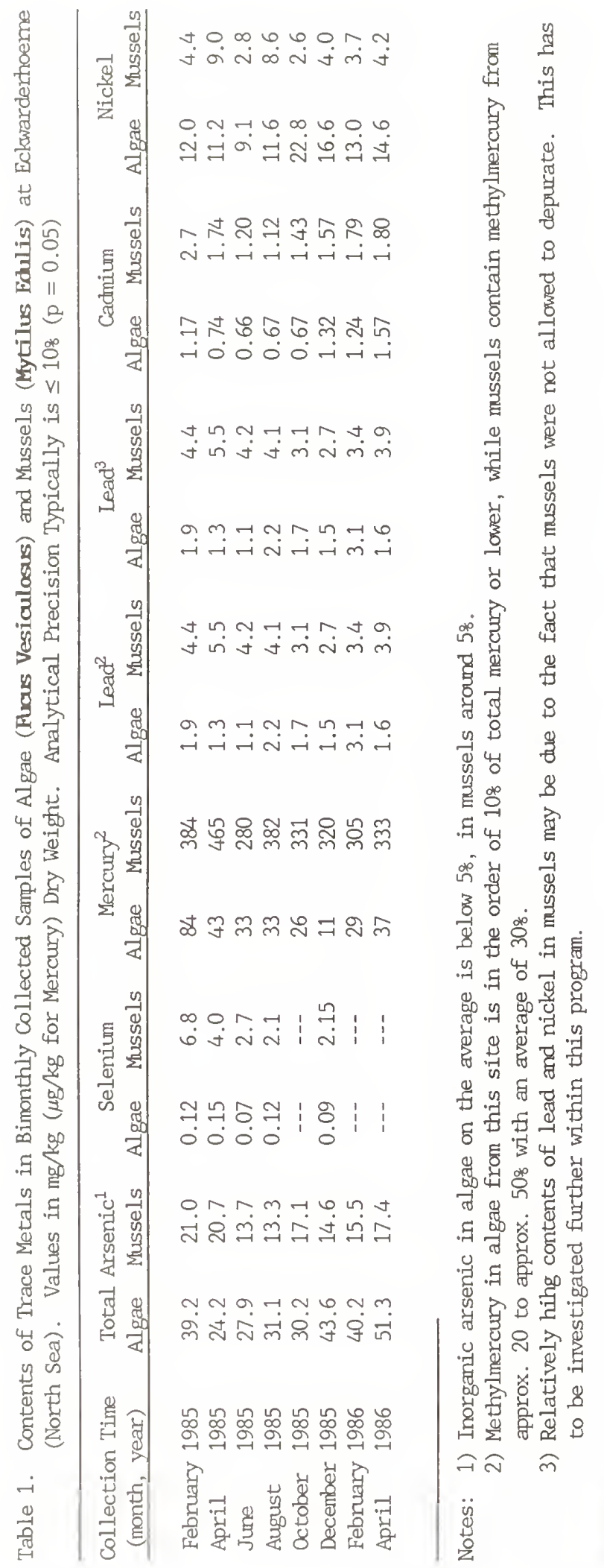




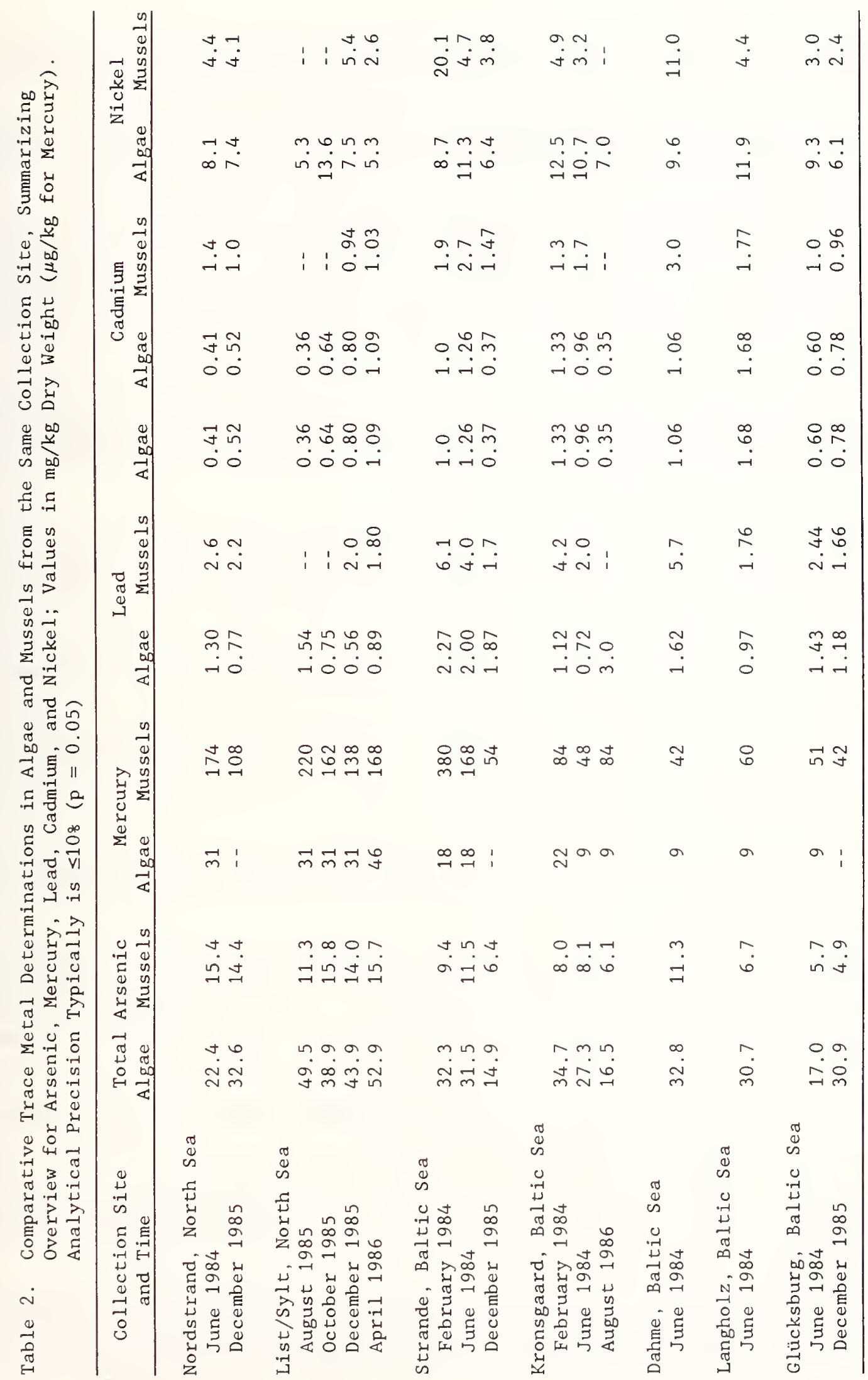


[3] Stoeppler, M., Dürbeck, H.W., and Nürnberg, H.W. (1982), Environmental Specimen Banking: A Challenge in Trace Analysis, Talanta 29, 963-972.

[4] Lewis, R. A., Stein, N., Lewis, C. W., Eds. (1984), Environmental Specimen Banking and Monitoring as Related to Banking, Martinus Nijhoff Publishers, Boston, MA, 358 pp.

[5] Stoeppler, M., Backhaus, F., Schladot, J. D., and Nürnberg, H. W. (1984), Concept and Operational Experiences of the Pilot Environmental Specimen Bank Project in the Federal Republic of Germany, In: Environmental Specimen Banking and Monitoring as Related to Banking, R. A. Lewis, N. Stein, and C. W. Lewis, Eds., Martinus Nijhoff Publishers, Boston, MA, pp 95-107.

[6] Nürnberg, H. W. (1984), Realization of Specimen Banking, Summary and Conclusions, In: Environmental Specimen Banking and Monitoring as Related to Banking, Lewis, R. A., Stein, N., Lewis, C. W., Eds., Martinus Nijhoff Publishers, Boston, MA, pp 23-66.

[7] Stoeppler, M. (1985), Trace Metal Analysis for the German Environmental Specimen Bank, In: Biological Reference Materials: Availability, Uses and Need for Validation of Nutrient Measurements, Wolf, W. R., Ed., John Wiley, Inc., Chichester, 281-297.

[8] Wise, S. A. and Zeisler, R., Eds. (1985), International Review of Environmental Specimen Banking, NBS Spec. Publ. 706, 54 pp.

[9] Stoeppler, M., Burrow, M., Backhaus, F., Schramm, W., and Nürnberg, H.W. (1986), Arsenic in Seawater and Brown Algae of the Baltic and the North Sea, Marine Chemistry 18, 321-334.

[10] Philipps, D. J. H. (1977), The Use of Biological Indicator Organisms to Monitor Trace Metal Pollution in Marine and Estuarine Environments - A Review, Environ. Pollut. 13, 281-317.

[11] Stoeppler, M. (1979), Choice of Species, Sampling and Sample Pretreatment for Subsequent Analysis and Banking of Marine Organisms Useful for Mercury, Lead and Cadmium Monitoring, In: Monitoring Environmental Materials and Specimen Banking, Luepke, N. P., Ed., Martinus Nijhoff Publishers, Boston, MA, pp 555-572.

[12] Goldberg, E. D., Ed. (1980), The International Mussel Watch, National Academy of Sciences, Washington, DC, $248 \mathrm{pp}$.

[13] Popham, I.D. (1985), Musseling in On Heavy Metal Pollution in Estrarine Environments Using Principal Components, Can. Tech. Rep. Fish, Aquat. Sci. 1268, 81-90.

[14] May, K. and Stoeppler, M. (1984), Pretreatment Studies with Biological and Environmental Materials, IV. Complete Wet Digestion in Partly and Completely Closed Quartz Vessels for Subsequent Trace and Ultratrace Mercury Determinations, Fresenius. Z. Anal. Chem. 317, 248-251. 
[15] May, K., Stoeppler, M., and Reisinger, K. (1987), Studies in the Ratio Total Mercury/Methylmercury in the Aquatic Food Chain, Toxicological and Environmental Chemistry 13, 153-157.

[16] Stoeppler, M., Mohl, C., Novak, L., and Gardiner, P.E. (1986), Application of the STPF Concept to the Determination of Aluminum, Cadmium, and Lead in Biological and Environmental Materials, In: Welz, B., Herausg, Fortschritte in der atomspektroskopischen Spurenanalytik, Band 2, VCH-Verlagsges. mbH, Weinheim, $419 \mathrm{pp}$.

[17] Stoeppler, M., Backhaus, F., and Schladot, H.D., and Commerscheidt, N. (1987), Environmental Specimen Bank Specific Reference Materials, Fresenius. Z. Anal. Chem. 326, 707-711.

[18] Luoma, S.N., Bryan, G.W., and Langston, W.J. (1982), Scavenging of Heavy Metals from Particulates by Brown Seaweed, Marine Poll. Bull. 11, 394-396. 
INORGANIC ANALYTICAL METHODS AND RESULTS FOR MARINE BIVALVES AND SEDIMENTS

\author{
Susan F. Stone, Donald A. Becker, Barbara J. Koster, Peter A. Pella, \\ Gerald Sleater, Manoranjani P. M. Tillekeratne ${ }^{1}$, and Rolf Zeisler \\ Center for Analytical Chemistry, \\ National Bureau of Standards \\ Gaithersburg, Maryland 20899 \\ USA \\ and \\ Ronald W. Sanders, \\ Pacific Northwest Laboratory, \\ Richland, Washington 99352 \\ USA
}

\title{
I. INTRODUCTION
}

When studying the elemental composition of biological and environmental samples, analytical chemists are frequently confronted with the limitations of a particular analytical technique when applied to unique or small samples. Generally, any analytical technique or even several techniques can only determine a fraction of the elements contained in the samples. Since it can be assumed that most of the elements in the periodic table occur at various levels in every biological or environmental matrix and may be important for various reasons, an analytical technique or combination of procedures that covers all elements may be desirable.

An ideal combination of analytical methods would fulfill many of the following requirements: 1) each individual technique can in principle assay all elements; 2) the elemental quantitation is feasible from major components to ultratrace constituents; 3) the techniques are non-destructive; 4) the procedures provide for internal quality control, e.g., via independent determinations of selected elements; and 5) only validated techniques are used which are suitable for routine analysis.

A unique sequence of instrumental analytical methods has been investigated that included non-destructive analyses steps by X-ray fluorescence (XRF), prompt gamma activation analysis (PGAA), instrumental neutron activation analysis (INAA), and final destructive steps utilizing NAA with radiochemical separations (RNAA) for additional sensitivity [1]. This approach has been applied to twelve bivalve samples and six sediment samples from the National Oceanic and Atmospheric Administration (NOAA) National Status and Trends (NS\&T) program [2], as well as to a collection of mussels from the National Bureau of Standards (NBS) / Environmental Protection Agency (EPA) Specimen Bank Program [3].

\footnotetext{
${ }^{1}$ Current address: Sri Lanka Standards Institution, Colombo, Sri Lanka
} 


\section{EXPERIMENTAL SECTION}

\section{A. Sample Preparation - Bivalves}

Marine bivalves were collected from Narragansett Bay, R. I. (more than 5000 organisms) and recently from 30 collection sites (60 to 100 organisms from each) as part of the NOAA National Status and Trends Program. The species involved were Mytilus edulis, Mytilus californianus, and Crassostrea virginica. The organisms were scrubbed, rinsed, cooled at dry ice temperatures, shipped to NBS and then stored in liquid nitrogen vapor $\left(-150^{\circ} \mathrm{C}\right)$ in the NBS/EPA Specimen Bank. The organisms had been separated into batches and sealed in Teflon bags. Each batch consisted of 50 to 60 mussels or 30 oysters. One batch from the Narragansett collection and two batches of mussels and four batches of oysters from the 1985 NS\&T collection were selected for analysis. After a batch was selected for analysis, the bivalves were shucked at $-5^{\circ} \mathrm{C}$. A shucking implement with a titanium blade and Teflon handle was employed. After the shell was opened, the contents were scooped out with another titanium instrument and placed in clean Teflon bags for storage in liquid nitrogen until the tissues were homogenized.

A cryogenic homogenization procedure [4] was used for the next step of sample preparation. The vessels used for pre-fracturing and grinding were constructed of Teflon, to minimize contamination from trace metals. Disk mills of two different capacities $(0.4$ and $1 \mathrm{~kg}$ ) were used to prepare the mussel homogenate. The resulting fine powder of fresh frozen tissue has been shown to have adequate homogeneity so that $1 \mathrm{~g}$ subsamples are representative of the bulk sample [5].

Following homogenization, portions of the powder were subsampled into Teflon jars and stored at liquid nitrogen vapor temperatures. Just prior to analysis, a subsample was removed from storage and freeze-dried. This dry material was then pressed into pellets with a $\mathrm{KBr}$ pellet press (\#186-0025 Perkin Elmer Corp., Norwalk, CT) to prepare it for the analytical techniques.

\section{B. Sample Preparation - Sediments}

Duplicate samples of bottom sediments from Benthic Surveillance sites were collected and banked as part of the NS\&T program. Each sample consisted of a combination of aliquots, approximately $50 \mathrm{~g}$ each, from three stations per site. Each aliquot was obtained from a box core or grab sampler using a cylindrical Teflon corer. After a sample was taken, sediment was pushed out of the top of the container and the top $3 \mathrm{~cm}$ of the core (approximately $50 \mathrm{~g}$ ) was sliced off and scooped into a clean Teflon bag using a titanium knife. Two additional station aliquots were combined into the same Teflon bag to obtain a total site sample of about $150 \mathrm{~g}$. The bags were then sealed and stored in liquid nitrogen.

Six sediment samples were selected from the 1985 NS\&T collection and removed from cryogenic storage. They were then partially thawed and thoroughly mixed in the Teflon bags. Approximately 50\% of the wet material was used for organic analysis [6]. The remaining portion was freeze-dried. The dried samples were transferred to Teflon jars, frozen at $\mathrm{LN}_{2}$ temperature, and 
ground/mixed with Teflon balls at cryogenic temperatures with a Spex Mixer/Mill (Model 8000, Spex Industries, Edison, N.J.). Pellets from the dry material were then prepared as described above for neutron activation analysis.

Additional sample preparation was necessary for the XRF procedure [7]. The sample aliquots used for XRF analysis were prepared as fused glass disks, in the ratio of 1 part sample to 12 parts lithium tetraborate (LTB) flux. Because each sample had a different loss on ignition (LOI) during fusion, this ratio did not hold when the samples were fused directly. To maintain the constant ratio, the samples, as received, were first ignited at $1050{ }^{\circ} \mathrm{C}$ (the fusion temperature) and the LOI of each was determined. The ignited sample material was then fused. The elemental concentrations determined for the fused aliquots were converted to sample concentrations by use of the LOI.

\section{Sequential Analysis Scheme For Bivalves}

The sequence of analytical steps followed in this procedure has been described elsewhere [1] and is illustrated in Figure 1. Only a single $250 \mathrm{mg}$ aliquot of freeze-dried tissue is needed to obtain quantitative results on the listed elements. This sample is usually pelletized and four assays are first performed using the XRF-BFP technique. Then, the same sample aliquot is repelletized and PGAA is applied to it. After the collection of the prompt gamma spectra, the pellet is submitted to a short irradiation followed by two decay and counting cycles for the INAA assay. After sufficient decay for safe handling, the pellet is submitted to a long irradiation followed by two decay and counting cycles. All the information that can be obtained non-destructively has been recorded at this point and the sample is then submitted to a radiochemical separation.

\section{Analysis Procedure For Sediments}

Separate aliquots of freeze-dried material were used for each procedure because of the delicate nature of the pellets, which easily disintegrated during handling. An INAA procedure similar to the above mentioned procedure was applied to the sediment samples to obtain results for 32 elements. The applications of XRF and PGAA were investigated to increase the information that can be obtained from a single aliquot. However, XRF could only be done via the fusion technique [7], and also PGAA had to use different aliquots. Therefore, these methods have been used only to study their feasibility and results from these techniques are only included from the initial evaluation analyzing control materials.

Silicon measurements via an epithermal neutron activation analysis (ENAA) procedure [8] were added to the analytical techniques applied to the sediments. This procedure is non-destructive and could be incorporated into a sequential analysis scheme. However, it presently lacks the sensitivity required for the determination of silicon in biological tissues, and so could not be used for the biological tissue analyses. 


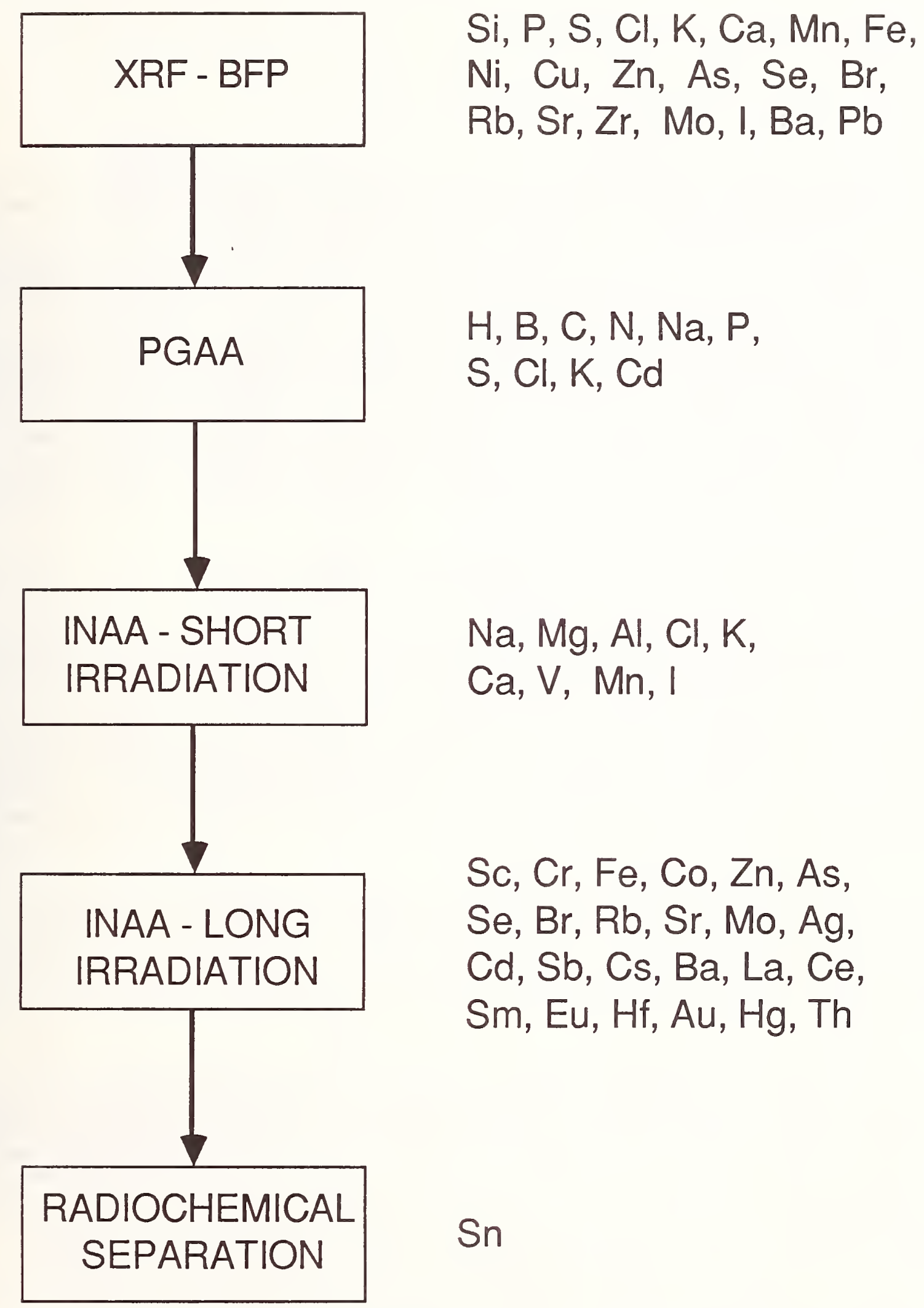

Figure 1. Sequential analysis procedure. A single $250 \mathrm{mg}$ aliquot of freeze-dried tissue is carried through the individual analytical methods in sequence to obtain quantitative results for 45 elements. Titanium is not reported in this work because implements containing this element are used. 


\section{E. Quality Assurance}

The sequential analysis procedure provides for internal quality assessment on each individual sample through determinations of several of the elements by more than one technique. However, to obtain additional information and since no sequential procedure was carried out on the sediments, Standard Reference Materials (SRMs) from the National Bureau of Standards and other Certified Reference Materials (CRMS) were used during the initial evaluation of the new sediment procedure. The following control materials were used in these analyses: SRM 1566 Oyster Tissue [9], the National Institute of Environmental Sciences (NIES) CRM No. 6 "Mussel Tissue Powder" [10], and International Atomic Energy Agency (IAEA) CRM Sediment SD-N-1/2 [11]. During sample analysis, at least one sample of a reference material was used with each set of samples (a set being samples of similar type analyzed under the same conditions). These reference materials do not undergo any sample preparation except drying and pelletizing.

\section{RESULTS AND DISCUSSION}

Tables 1 and 2 summarize the results obtained in the initial evaluation of the analytical procedures. The performance of the sequential analysis scheme for the bivalve samples was tested via the analyses of the NIES CRM No. 6 and SRM 1566. The results of these analyses are summarized in Table 1 . For the sediment samples, the CRM SD-N-1/2 was used to evaluate the performance of the analysis procedures. These results are included in Table 2. These data indicate the elemental coverage by the individual techniques, the betweentechnique agreement, as well as comparability with the corresponding certified values.

The sequential analysis scheme was used for the characterization of the seven selected bivalve samples, and includes results for 45 elements. The results for each batch are summarized in Table 3. This table contains pertinent mean concentrations and uncertainties. The elemental concentrations vary greatly among the species as well as among the collection sites, as expected.

In Table 4, the INAA results for the sediment samples are given. The sediment samples presented different analytical problems because of spectral interferences, which were not serious in the analyses of the bivalve samples. The following significant interferences made a determination of the respective elements almost always impossible. After correcting for the terbium interference at the $392 \mathrm{keV}$ line, tin was no longer instrumentally detectable. A radiochemical separation is necessary for its determination. Both silver and selenium were at the detection limit for INAA in most of the sediments. The two main silver lines had interferences; europium at the $657 \mathrm{keV}$ line and scandium at $889 \mathrm{keV}$, which greatly overshadowed the silver's $884 \mathrm{keV}$ line. Selenium, at $264 \mathrm{keV}$, had a tantalum interference.

Copper was not detectable by INAA due to the high levels of sodium and chlorine (this was also true of the bivalve samples). The XRF analyses were 
Table 1. - Elemental Concentrations for Selected Reference Materials (concentrations based on dry weight)

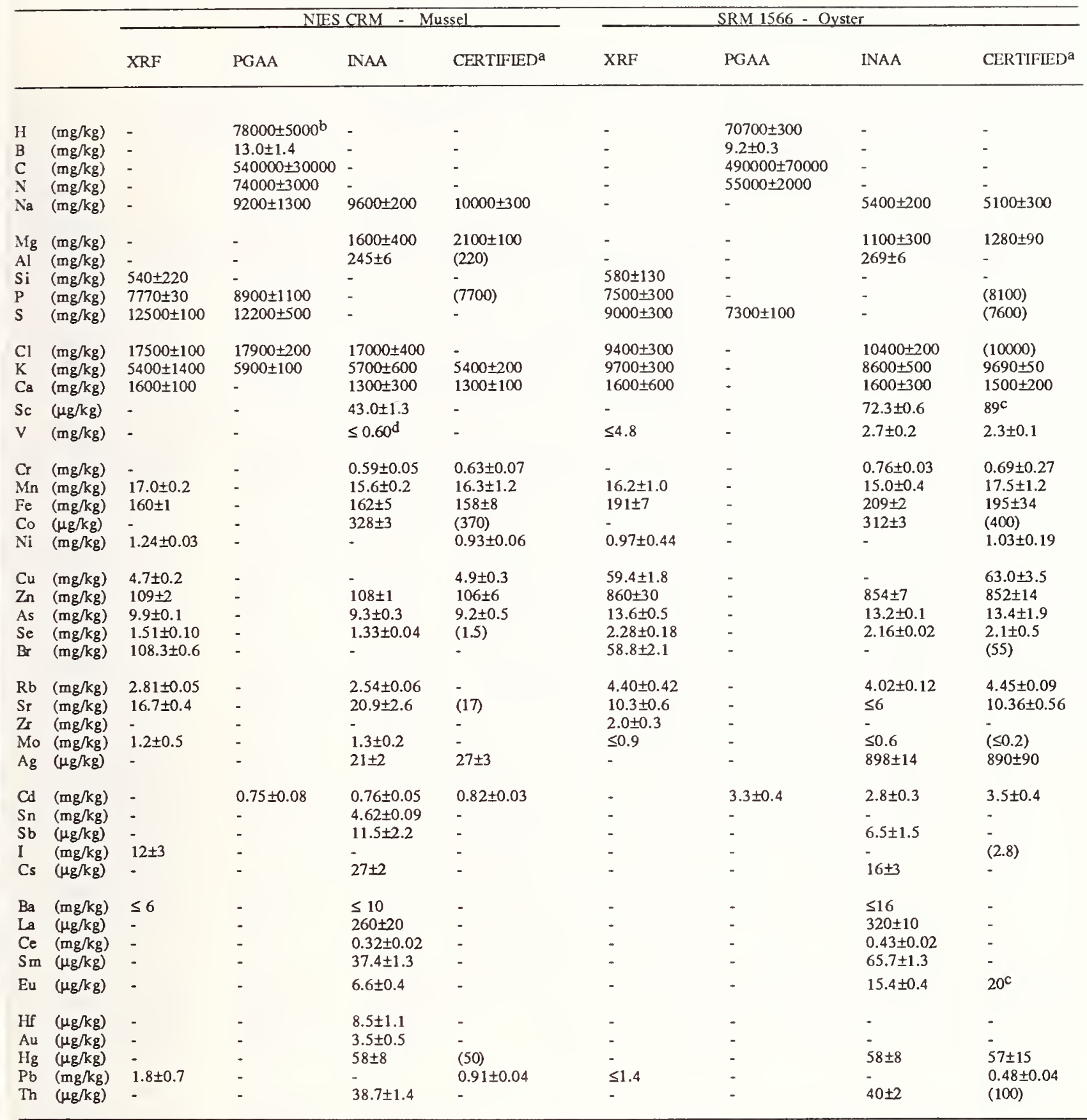

${ }^{a}$ Certified concentrations and their uncertainties, as well as information values ( ), are given as defined in the Certificates of Analysis (9,10)

buncertainties are 1s sample standard deviation

cConcentrations are literature values (13)

${ }^{d}$ Limits of detection are given as defined in Ref. 12 
Table 2. Elemental Concentrations for Certified Reference Material IAEA Sediment SD-N-1/2

(Concentrations in $\mathrm{mg} / \mathrm{kg}$ dry weight)

\begin{tabular}{|c|c|c|c|c|}
\hline & XRF & PGAA & INAA & CERTIFIED \\
\hline 11 & - & $21810 \pm 180^{\mathrm{a}}$ & - & - \\
\hline B & - & $80.3 \pm 1.0$ & $\cdot$ & * \\
\hline C & - & $550000 \pm 140000$ & - & - \\
\hline $\mathrm{N}$ & - & $\leq 20000$ & - & - \\
\hline $\mathrm{Na}$ & - & - & $10750 \pm 180$ & $(10300-10700)$ \\
\hline $\mathrm{Mg}$ & - & - & $1.05 \pm 0.21$ & $(0.74-0.79)$ \\
\hline $\mathrm{Al}$ & $39090 \pm 90$ & - & $36600 \pm 200$ & $(35800-38500)$ \\
\hline Si & $290100 \pm 500$ & - & $281600 \pm 2500$ & $(261000-292300)$ \\
\hline $\mathrm{s}$ & - & $3600 \pm 1300$ & - & - \\
\hline $\mathrm{Cl}$ & - & - & $9080 \pm 910$ & $(9000-9600)$ \\
\hline $\mathrm{K}$ & $18110 \pm 60$ & - & $17000 \pm 1000$ & $(14600-16600)$ \\
\hline $\mathrm{Ca}$ & $55430 \pm 20$ & - & $52000 \pm 2400$ & $(51200-56000)$ \\
\hline Sc & - & - & $7.098 \pm 0.068$ & $7.10(6.90-7.21)$ \\
\hline v & - & - & $77.7 \pm 3.2$ & $77.7(65.0-80.7)$ \\
\hline $\mathrm{Cr}$ & $\cdot$ & - & $149.4 \pm \pm 3.5$ & $149(125-161)$ \\
\hline $\mathrm{Mn}$ & $865 \pm 7$ & - & $809.9 \pm 9.2$ & $777(728-801)$ \\
\hline $\mathrm{Fe}$ & $39000 \pm 600$ & - & $36920 \pm 3400$ & $(35300-37800)$ \\
\hline Co & - & - & $11.73 \pm 0.04$ & $12.1(11.2-12.7)$ \\
\hline $\mathrm{Ni}$ & $30.2 \pm 1.8$ & - & - & $31.0(27.0-34.0)$ \\
\hline $\mathrm{Cu}$ & $88 \pm 16$ & - & $\cdot$ & $72.2(68.1-75.2)$ \\
\hline $\mathrm{Zn}$ & $492 \pm 23$ & - & $438.4 \pm 3.6$ & $439(423-452)$ \\
\hline As & - & - & $65.0 \pm 0.9$ & $50.0(2.4-60.0)$ \\
\hline $\mathrm{Se}$ & - & - & $2.245 \pm 0.037$ & $(2.30-3.78)$ \\
\hline $\mathrm{Rb}$ & $70.5 \pm 5.8$ & - & $66.4 \pm 2.1$ & $74.2(68.6-77.0)$ \\
\hline Sr & $293.0 \pm 1.7$ & - & $279.0 \pm 4.4$ & $291(277-303)$ \\
\hline Mo & - & - & $2.30 \pm 0.60$ & $(1.30-2.60)$ \\
\hline $\mathrm{Ag}$ & - & - & $2.043 \pm 0.041$ & $(1.30-2.60)$ \\
\hline $\mathrm{Cd}$ & - & $10.47 \pm 0.56$ & $9.1 \pm 1.5$ & $11.0(10.0-12.0)$ \\
\hline $\mathrm{Sn}$ & - & - & $\leq 18$ & \\
\hline $\mathrm{Sb}$ & - & - & $(3.222 \pm 0.050) \times 10^{-3}$ & $3.62(3.20-3.95) \times 10^{-3}$ \\
\hline Cs & - & - & $4.593 \pm 0.028$ & $4.9(4.1-5.4)$ \\
\hline $\mathrm{Ba}$ & - & - & $248 \pm 21$ & $289(276-310)$ \\
\hline $\mathrm{La}$ & - & - & $35.4 \pm 0.6$ & $31.9(30.0-35.5)$ \\
\hline $\mathrm{Ce}$ & - & - & $53.47 \pm 0.80$ & $60.3(58.2-65.0)$ \\
\hline Sm & - & - & $6.24 \pm 0.09$ & $5.58(5.40-6.35)$ \\
\hline Eu & - & - & $1.246 \pm 0.068$ & $1.16(1.12-1.30)$ \\
\hline $\mathrm{Au}$ & - & - & $0.0361 \pm 0.0019$ & $(0.03-0.04)$ \\
\hline $\mathrm{Hg}$ & - & - & $1.448 \pm 0.074$ & $(0.06-1.72)$ \\
\hline $\mathrm{Pb}$ & $140 \pm 10$ & - & - & $120(112-132)$ \\
\hline Th & - & - & $7.090 \pm 0.075$ & $7.04(6.85-7.20)$ \\
\hline
\end{tabular}

${ }^{a}$ Uncertainties are $1 \sigma$ counting statistics of samples and standards 
Table 3. - Elemental Concentrations for Selected Bivalve Samples (concentrations based on dry weight)

\begin{tabular}{|c|c|c|c|c|c|c|c|}
\hline \multirow{2}{*}{$\begin{array}{l}\text { Species } \\
\text { Site }\end{array}$} & \multicolumn{2}{|c|}{ Mytilus edulis } & \multirow{2}{*}{$\begin{array}{l}\text { Mytilus californianus } \\
\text { MW1M029 }\end{array}$} & \multicolumn{4}{|c|}{ Crassostrea virginica } \\
\hline & $\mathrm{M} 2 \mathrm{~N} 0086^{\mathrm{a}}$ & MW1M048 & & MW1Y030 & MW1Y044 & MW1Y068 & MW1Y073 \\
\hline Element & $n=6^{b}$ & $\mathrm{n}=2$ & $n=2$ & $n=2$ & $n=2$ & $\mathrm{n}=2$ & $\mathrm{r}=2$ \\
\hline $\mathrm{H} \quad(\mathrm{mg} / \mathrm{kg})$ & $64200 \pm 1000^{c}$ & $67000 \pm 2000$ & $67600 \pm 200$ & $70800 \pm 400$ & $64200 \pm 200$ & $64400 \pm 400$ & $72000 \pm 400$ \\
\hline $\mathrm{B} \quad(\mathrm{mg} / \mathrm{kg})$ & $38.5 \pm 0.9$ & $41.5 \pm 0.8$ & $40.4 \pm 0.7$ & $21.6 \pm 0.3$ & $39.8 \pm 1.8$ & $34.9 \pm 1.9$ & $18.5 \pm 0.8$ \\
\hline C $(\mathrm{mg} / \mathrm{kg})$ & $430000 \pm 30000$ & $360000 \pm 10000$ & $430000 \pm 40000$ & $470000 \pm 100000$ & $490000 \pm 120000$ & $0500000 \pm 30000$ & $350000 \pm 13000$ \\
\hline$N \quad(\mathrm{mg} / \mathrm{kg})$ & $74000+25000$ & $86000 \pm 4000$ & $101000 \pm 4000$ & $70000 \pm 4000$ & $57000 \pm 4000$ & $84000 \pm 5000$ & $108000 \pm 12000$ \\
\hline $\mathrm{Na}(\mathrm{mg} / \mathrm{kg})$ & $59500 \pm 7500$ & $46600+200$ & $42000 \pm 200$ & $22200 \pm 100$ & $50200+2400$ & $48600 \pm 200$ & $22200 \pm 100$ \\
\hline $\mathrm{Mg}(\mathrm{mg} / \mathrm{kg})$ & $7300 \pm 1100$ & $6780 \pm 210$ & $6420 \pm 190$ & $3800 \pm 120$ & $7000 \pm 450$ & $7590 \pm 450$ & $4070 \pm 120$ \\
\hline Al $(\mathrm{mg} / \mathrm{kg})$ & $905 \pm 140$ & $648 \pm 7$ & $956 \pm 9$ & $291 \pm 4$ & $649 \pm 7$ & $1588 \pm 14$ & $168 \pm 3$ \\
\hline $\mathrm{Si}(\mathrm{mg} / \mathrm{kg})$ & $2400 \pm 300$ & $2100 \pm 300$ & $1300 \pm 400$ & $800 \pm 400$ & $2400 \pm 500$ & $7000 \pm 400$ & $\leq 700$ \\
\hline $\mathrm{P} \quad(\mathrm{mg} / \mathrm{kg})$ & $9200 \pm 400$ & $8900 \pm 400$ & $12600 \pm 500$ & $7200 \pm 300$ & $7500 \pm 500$ & $6300 \pm 300$ & $7600 \pm 400$ \\
\hline $\mathrm{S} \quad(\mathrm{mg} / \mathrm{kg})$ & $21800 \pm 2000$ & $20600 \pm 800$ & $21700 \pm 800$ & $12400 \pm 500$ & $18300 \pm 1000$ & $12800 \pm 500$ & $11600 \pm 600$ \\
\hline $\mathrm{Cl}(\mathrm{mg} / \mathrm{kg})$ & $103700 \pm 3600$ & $84500 \pm 500$ & $74800 \pm 400$ & $40300 \pm 200$ & $87600 \pm 500$ & $88100 \pm 500$ & $38800 \pm 200$ \\
\hline $\mathrm{K} \quad(\mathrm{mg} / \mathrm{kg})$ & $12200 \pm 200$ & $11000 \pm 1000$ & $13700 \pm 1000$ & $10300 \pm 600$ & $15300 \pm 1000$ & $11800 \pm 1000$ & $9600 \pm 600$ \\
\hline $\mathrm{Ca}(\mathrm{mg} / \mathrm{kg})$ & $5400 \pm 400$ & $6600 \pm 500$ & $10300 \pm 500$ & $7100 \pm 400$ & $14000 \pm 800$ & $8100 \pm 800$ & $16400 \pm 600$ \\
\hline Sc $(\mu g / \mathrm{kg})$ & $150 \pm 10$ & $115.6 \pm 0.5$ & $246.0 \pm 1.0$ & $52.9 \pm 0.2$ & $145.8 \pm 0.6$ & $297.4 \pm 0.1$ & $76.3 \pm 0.4$ \\
\hline$V \quad(m g / k g)$ & $2.0 \pm 0.5$ & $1.9 \pm 0.2$ & $2.6 \pm 0.2$ & $1.7 \pm 0.1$ & $9.3 \pm 0.3$ & $4.2 \pm 0.3$ & $\leq 0.6$ \\
\hline $\mathrm{Cr} \quad(\mathrm{mg} / \mathrm{kg})$ & $1.74 \pm 0.07$ & $4.48 \pm 0.03$ & $1.80 \pm 0.02$ & $0.81 \pm 0.03$ & $1.60 \pm 0.03$ & $2.52 \pm 0.03$ & $1.39 \pm 0.03$ \\
\hline $\mathrm{Mn}(\mathrm{mg} / \mathrm{kg})$ & $26.1 \pm 1.1$ & $13.8 \pm 0.9$ & $17.6 \pm 1.0$ & $11.5 \pm 0.6$ & $15.8 \pm 1.0$ & $54.2 \pm 1.2$ & $23.4 \pm 0.6$ \\
\hline $\mathrm{Fe}(\mathrm{mg} / \mathrm{kg})$ & $557 \pm 20$ & $557 \pm 3$ & $620 \pm 3$ & $209 \pm 1$ & $492 \pm 3$ & $1060 \pm 5$ & $230 \pm 2$ \\
\hline Co $(\mu \mathrm{g} / \mathrm{kg})$ & $538 \pm 11$ & $369 \pm 2$ & $641 \pm 2$ & $329 \pm 1$ & $465 \pm 3$ & $856 \pm 4$ & $761 \pm 3$ \\
\hline $\mathrm{Ni}(\mathrm{mg} / \mathrm{kg})$ & $3.2 \pm 0.1$ & $\leq 1.5$ & $\leq 1.4$ & $2.6 \pm 0.5$ & $\leq 1.9$ & $2.7 \pm 0.7$ & $9.4 \pm 1.2$ \\
\hline $\mathrm{Cu}(\mathrm{mg} / \mathrm{kg})$ & $7.0 \pm 0.6$ & $15.8 \pm 0.9$ & $9.4 \pm 0.7$ & $104 \pm 4$ & $97 \pm 5$ & $75 \pm 3$ & $317 \pm 16$ \\
\hline $\mathrm{Zn}(\mathrm{mg} / \mathrm{kg})$ & $131 \pm 1$ & $117 \pm 1$ & $143 \pm 1$ & $1449 \pm 9$ & $1462 \pm 9$ & $2354 \pm 18$ & $5766 \pm 35$ \\
\hline As $(\mathrm{mg} / \mathrm{kg})$ & $11.0 \pm 0.6$ & $8.1 \pm 0.2$ & $8.0 \pm 0.3$ & $6.3 \pm 0.2$ & $34.7 \pm 0.5$ & $16.6 \pm 0.4$ & $4.6 \pm 0.2$ \\
\hline $\mathrm{Se}(\mathrm{mg} / \mathrm{kg})$ & $2.54 \pm 0.05$ & $2.82 \pm 0.16$ & $2.72 \pm 0.02$ & $2.58 \pm 0.02$ & $2.86 \pm 0.02$ & $2.62 \pm 0.40$ & $3.68 \pm 0.02$ \\
\hline B $\quad(\mathrm{mg} / \mathrm{kg})$ & $467 \pm 8$ & $420 \pm 14$ & $398 \pm 10$ & $209 \pm 7$ & $392 \pm 20$ & $340 \pm 12$ & $190 \pm 10$ \\
\hline $\mathrm{Rb}(\mathrm{mg} / \mathrm{kg})$ & $6.95 \pm 0.15$ & $6.41 \pm 0.08$ & $5.37 \pm 0.10$ & $4.26 \pm 0.08$ & $4.95 \pm 0.14$ & $5.98 \pm 0.16$ & $2.83 \pm 0.15$ \\
\hline $\mathrm{Sr} \quad(\mathrm{mg} / \mathrm{kg})$ & $65 \pm 3$ & $48 \pm 2$ & $83 \pm 4$ & $41 \pm 10$ & $86 \pm 6$ & $56 \pm 3$ & $59 \pm 4$ \\
\hline $\mathrm{Zr} \quad(\mathrm{mg} / \mathrm{kg})$ & $2.2 \pm 1.0$ & $\leq 2$ & $\leq 3$ & $\leq 2$ & $2.0 \pm 0.9$ & $\leq 3$ & $\leq 2$ \\
\hline Mo (mg/kg) & $1.6 \pm 0.4$ & $\leq 2.4$ & $\leq 3$ & $\leq 1.4$ & $\leq 2$ & $3.8 \pm 0.5$ & $\leq 2$ \\
\hline $\mathrm{Ag}(\mu \mathrm{g} / \mathrm{kg})$ & $80 \pm 10$ & $1710+20$ & $1250 \pm 20$ & $3780 \pm 40$ & $3380 \pm 40$ & $2840 \pm 40$ & $5850 \pm 60$ \\
\hline $\mathrm{Cd}(\mathrm{mg} / \mathrm{kg})$ & $1.9 \pm 0.4^{\mathrm{d}}$ & $0.5 \pm 0.4$ & $0.5 \pm 0.5$ & $2.7 \pm 0.4$ & $0.5 \pm 0.4$ & $1.8 \pm 0.4$ & $7.8 \pm 0.4$ \\
\hline$S_{n}(\mathrm{mg} / \mathrm{kg})$ & $0.17 \pm 0.03$ & $\leq 7$ & $1.46 \pm 0.07$ & $0.60 \pm 0.06$ & $0.45 \pm 0.07$ & $\leq 0.44$ & $0.68 \pm 0.10$ \\
\hline Sb $(\mu \mathrm{g} / \mathrm{kg})$ & $37 \pm 3$ & $50 \pm 2$ & $23 \pm 2$ & $11 \pm 2$ & $18 \pm 3$ & $22 \pm 3$ & $\leq 20$ \\
\hline I $\quad(\mathrm{mg} / \mathrm{kg})$ & $13 \pm 3$ & $\leq 10$ & $\leq 10$ & $\leq 5$ & $\leq 10$ & $\leq 12$ & $\leq 6$ \\
\hline Cs $(\mu g / \mathrm{kg})$ & $69 \pm 5$ & $54+2$ & $35 \pm 2$ & $32 \pm 3$ & $32 \pm 4$ & $92 \pm 4$ & $\leq 0.03$ \\
\hline $\mathrm{Ba}(\mathrm{mg} / \mathrm{kg})$ & $8.4 \pm 2.1$ & $4.1 \pm 0.9$ & $8.0 \pm 0.8$ & $5.7 \pm 0.8$ & $\leq 10$ & $10.6 \pm 2.0$ & $10.0 \pm 2.0$ \\
\hline Ia $(\mu \mathrm{g} / \mathrm{kg})$ & $520 \pm 80$ & $382 \pm 100$ & $1040 \pm 50$ & $190 \pm 10$ & $360 \pm 20$ & $1360 \pm 30$ & $180 \pm 10$ \\
\hline $\mathrm{Ce}(\mathrm{mg} / \mathrm{kg})$ & $0.92 \pm 0.07$ & $0.720 \pm 0.012$ & $1.59 \pm 0.020$ & $0.285 \pm 0.008$ & $0.880 \pm 0.014$ & $2.514 \pm 0.019$ & $0.314 \pm 0.013$ \\
\hline $\operatorname{Sm}(\mu g / \mathrm{kg})$ & $55 \pm 2$ & $81+2$ & $196 \pm 3$ & $414 \pm 2$ & $93 \pm 3$ & $288 \pm 4$ & $51 \pm 2$ \\
\hline Eu $(\mu \mathrm{g} / \mathrm{kg})$ & $20.3 \pm 1.1$ & $16.1 \pm 0.4$ & $30.7 \pm 0.5$ & $10.6 \pm 0.1$ & $19.9 \pm 0.5$ & $62.3 \pm .1$ & $8.8 \pm 0.7$ \\
\hline Hf $(\mu \mathrm{g} / \mathrm{kg})$ & $80 \pm 7$ & - & - & - & - & - & - \\
\hline $\mathrm{Au}(\mu \mathrm{g} / \mathrm{kg})$ & $313 \pm 23$ & $66.8 \pm 6.5$ & $4.9 \pm 0.9$ & $16.5 \pm 0.6$ & $5.4 \pm 1.4$ & $3.9 \pm 0.8$ & $29.0 \pm 0.7$ \\
\hline$H g(\mu g / k g)$ & $158 \pm 24$ & $225.0 \pm 6.6$ & $84 \pm 6$ & $98 \pm 6$ & $81 \pm 8$ & $149 \pm 8$ & $96 \pm 1$ \\
\hline $\mathrm{Pb} \quad(\mathrm{mg} / \mathrm{kg})$ & $4.6 \pm 0.4$ & $13.1 \pm 1.0$ & $2.1 \pm 1.0$ & $\leq 1.8$ & $\leq 2$ & $\leq 2$ & $\leq 2$ \\
\hline Th $(\mu \mathrm{g} / \mathrm{kg})$ & $122 \pm 9$ & $128 \pm 2$ & $221+2$ & $44 \pm 2$ & $239 \pm 3$ & $333 \pm 3$ & $34 \pm 2$ \\
\hline
\end{tabular}

a Site Identification -

M2N0086 - Narraganset Bay, RI

MW1M048 - Dorchester Bay, MA

MW1M029 - San Diego Harbor, CA

MW1Y030 - Galveston Harbor, TX

MW1Y044 - Fort Johnson, SC

MW1Y068 - Pascagoula Bay, MI

MW1Y073 - Baltimore Harbor, MD

$b_{n}$ designates the number of replicate samples analyzed

Uncertainties are $1 \sigma$ sample standard deviation

dError includes additional uncertainty due to the uncertainty of the subtracted blank 
Table 4. Elemental Concentrations for NS\&T 1985 Benthic Surveillance Sediment Samples ${ }^{a}$

\begin{tabular}{|c|c|c|c|c|c|c|}
\hline $\begin{array}{l}\text { Sample } \\
\text { Site }\end{array}$ & $\mathrm{BS} 1 S 001^{\mathrm{b}}$ & BS1S010 & BS1S013 & BS1S019 & $\mathrm{BS} 1 \mathrm{~S} 022$ & BS $1 S 028$ \\
\hline \multicolumn{7}{|l|}{ Element } \\
\hline $\mathrm{Na}$ & $26610+330$ & $29220 \pm 380$ & $30350+340$ & $11560 \pm 190$ & $39440 \pm 490$ & $19720 \pm 340$ \\
\hline $\mathrm{Mg}$ & $10200 \pm 630$ & $19260 \pm 920$ & $20810 \pm 920$ & $7590 \pm 490$ & $21070 \pm 1000$ & $12170 \pm 830$ \\
\hline $\mathrm{Al}$ & $66200 \pm 0.035$ & $77320 \pm 410$ & $7476 \pm 360$ & $41720 \pm 350$ & $68370 \pm 520$ & $62110+370$ \\
\hline $\mathrm{Si}$ & $307000 \pm 4200$ & $205500 \pm 4900$ & $264300 \pm 4200$ & $356700 \pm 4700$ & $228900 \pm 5200$ & $250000 \pm 6600$ \\
\hline $\mathrm{Cl}$ & $6100 \pm 140$ & $9500 \pm 200$ & $3860 \pm 180$ & $2320 \pm 90$ & $56220 \pm 600$ & $23720 \pm 550$ \\
\hline $\mathrm{K}$ & $22500 \pm 1100$ & $\leq 3800$ & $\leq 4000$ & $20400 \pm 900$ & $26700 \pm 1500$ & $25500 \pm 1300$ \\
\hline $\mathrm{Ca}$ & $23400 \pm 1600$ & $26700 \pm 1800$ & $35900 \pm 2200$ & $10200 \pm 1000$ & $31500 \pm 2100$ & $44300 \pm 1000$ \\
\hline $\mathrm{Sc}$ & $9.546 \pm 0.091$ & $16.47 \pm 0.16$ & $11.74 \pm 0.11$ & $5.335 \pm 0.051$ & $11.80 \pm 0.11$ & $17.70 \pm 0.17$ \\
\hline V & $58.3 \pm 3.0$ & $108.0 \pm 3.8$ & $92.0 \pm 3.5$ & $44.6 \pm 2.5$ & $95.2 \pm 4.0$ & $112.6 \pm 3.4$ \\
\hline $\mathrm{Cr}$ & $35.7 \pm 1.0$ & $82.3 \pm 1.9$ & $36.5 \pm 0.9$ & $41.5 \pm 1.0$ & $56.5 \pm 1.3$ & $114.3 \pm 2.7$ \\
\hline $\mathrm{Mn}$ & $365.6 \pm 5.0$ & $631.4 \pm 7.9$ & $662.2 \pm 8.4$ & $276.6 \pm 4.2$ & $551.2 \pm 7.0$ & $1070 \pm 15$ \\
\hline $\mathrm{Fe}$ & $18970 \pm 180$ & $45510 \pm 420$ & $35540 \pm 330$ & $16740 \pm 160$ & $37530 \pm 350$ & $54630 \pm 510$ \\
\hline Co & $4.98 \pm 0.02$ & $16.35 \pm 0.06$ & $12.81 \pm 0.05$ & $7.92 \pm 0.03$ & $11.34 \pm 0.04$ & $36.64 \pm 0.13$ \\
\hline $\mathrm{Zn}$ & $49.72 \pm 0.42$ & $163.6 \pm 1.4$ & $76.30 \pm 0.65$ & $55.54 \pm 0.47$ & $155.3 \pm 1.3$ & $365.0 \pm 3.0$ \\
\hline As & $4.24 \pm 0.28$ & $16.77 \pm 0.48$ & $2.66 \pm 0.37$ & $6.84 \pm 0.38$ & $10.44 \pm 0.46$ & $20.81 \pm 0.71$ \\
\hline $\mathrm{Se}$ & $\leq 0.07$ & $0.312 \pm 0.028$ & $\leq 0.10$ & $\leq 0.07$ & $\leq 0.10$ & $1.56 \pm 0.05$ \\
\hline $\mathrm{Rb}$ & $62.5 \pm 1.1$ & $41.7 \pm 2.0$ & $50.2 \pm 2.0$ & $63.3 \pm 1.4$ & $108.6 \pm 2.3$ & $134.6 \pm 3.6$ \\
\hline $\mathrm{Sr}$ & $284.6 \pm 4.4$ & $413.1 \pm 5.1$ & $420.2 \pm 5.2$ & $214.4 \pm 3.2$ & $173.1 \pm 4.3$ & $184.7 \pm 6.3$ \\
\hline Mo & $3.45 \pm 0.43$ & $4.86 \pm 0.59$ & $4.44 \pm 0.79$ & $2.06 \pm 0.31$ & $4.58 \pm 0.56$ & $5.46 \pm 0.68$ \\
\hline $\mathrm{Ag}$ & $\leq 0.05$ & $0.401 \pm 0.024$ & $\leq 0.08$ & $\leq 0.04$ & $\leq 0.10$ & $0.208 \pm 0.040$ \\
\hline $\mathrm{Cd}$ & $\leq 6$ & $\leq 9$ & $\leq 8$ & $\leq 5$ & $\leq 9$ & $\leq 12$ \\
\hline $\mathrm{Sn}$ & $\leq 9$ & $\leq 13$ & $\leq 15$ & $\leq 9$ & $\leq 15$ & $\leq 24$ \\
\hline $\mathrm{Sb}$ & $0.476 \pm 0.0 .025$ & $2.708 \pm 0.048$ & $0.143 \pm 0.025$ & $0.515 \pm 0.019$ & $0.635 \pm 0.029$ & $1.397 \pm 0.051$ \\
\hline Cs & $2.481 \pm 0.015$ & $2.541 \pm 0.016$ & $2.632 \pm 0.017$ & $2.457 \pm 0.015$ & $8.331 \pm 0.048$ & $8.337 \pm 0.049$ \\
\hline $\mathrm{Ba}$ & $463 \pm 25$ & $425 \pm 30$ & $428 \pm 23$ & $667 \pm 17$ & $662 \pm 27$ & $453 \pm 36$ \\
\hline La & $29.5 \pm 0.5$ & $22.0 \pm 0.4$ & $23.3 \pm 0.4$ & $34.7 \pm 0.6$ & $39.2 \pm 0.7$ & $57.3 \pm 1.0$ \\
\hline $\mathrm{Ce}$ & $48.12 \pm 0.73$ & $37.50 \pm 0.57$ & $38.24 \pm 0.58$ & $51.28 \pm 0.77$ & $63.71 \pm 0.96$ & $91.0 \pm 1.4$ \\
\hline $\mathrm{Sm}$ & $5.90 \pm 0.08$ & $4.79 \pm 0.07$ & $4.48 \pm 0.06$ & $5.58 \pm 0.08$ & $6.81 \pm 0.09$ & $10.68 \pm 0.15$ \\
\hline Eu & $1.344 \pm 0.073$ & $1.397 \pm 0.076$ & $1.273 \pm 0.070$ & $1.151 \pm 0.063$ & $1.425 \pm 0.078$ & $2.15 \pm 0.12$ \\
\hline $\mathrm{Au}$ & $0.005 \pm 0.0007$ & $0.0246 \pm 0.0019$ & s0.006 & $0.0096 \pm 0.0009$ & $0.0114 \pm 0.0016$ & $0.0285 \pm 0.0021$ \\
\hline $\mathrm{Hg}$ & $\leq 0.10$ & $0.824 \pm 0.029$ & $\leq 0.11$ & $0.172 \pm 0.019$ & $0.272 \pm 0.013$ & $0.608 \pm 0.051$ \\
\hline Th & $10.37 \pm 0.12$ & $5.23 \pm 0.06$ & $6.39 \pm 0.07$ & $7.64 \pm 0.08$ & $12.37 \pm 0.13$ & $13.54 \pm 0.15$ \\
\hline
\end{tabular}

${ }^{a}$ Concentrations in $\mathrm{mg} / \mathrm{kg}$ dry weight; uncertainities are $1 \sigma$ counting statistics of samples and standards

bsite Identification

BS1S001 - Dana Point, CA

¿S1S010 - Elliott Bay, WA

BS1S013 - Nisqually Reach, WA

BS1S019 - Mississippi River Delta, MI

BS1S022 - Corpus Christi, TX

BS1S028- Chesapeake Bay, MD 
also unable to obtain copper results, since copper alloys with the platinum fusion crucible leading to a high systematic error ( $\pm 45 \%$ ).

Lead results were not reported by XRF due to the interference with arsenic; the arsenic $\mathrm{K}_{\alpha}$ line with the lead $\mathrm{L}_{\beta}$ line. A direct overlap correction could not be made due to the possible loss of arsenic during fusion.

\section{CONCLUSIONS}

The sequential analysis procedure which was evaluated and applied in this work to bivalve samples is an efficient approach towards the accurate determination of approximately half of the elements in the periodic table, and included many of the elements important for environmental and marine studies. of course, this list of elements is very dependent on their concentrations and may not be feasible in all samples of this matrix. However, only slight modifications should be needed to optimize the determinations in these marine tissues. Undoubtedly, with more effort, in particular epithermal activation, reirradiations and added radiochemical steps, the list of elements could be further increased to include elements of concern such as silicon, palladium, platinum, and bismuth.

Considerable additional work is needed to design a similar sequential analysis procedures for the sediment samples. In particular, improvements in sample preparation methods prior to the XRF analysis need to be made to avoid the problems observed in this work. However, the application of XRF to the instrumental analysis of these complex samples may still be limited by matrix problems such as micro-inhomogeneities.

Nonetheless, the analysis scheme described above has provided much useful information on a great number of elements in the marine tissues as well as in the sediments. The developing database on the samples from U.S. coastal and eustuarine waters in conjunction with ongoing Specimen Banking programs will provide us with a measurement yardstick for reference in future years.

\section{ACKNOWLEDGEMENT}

The authors acknowledge the assistance of Gunnar G. Lauenstein in the coordination of the Specimen Banking activities for the NS\&T Program of NOAA. We acknowledge the cooperation and assistance of the following individuals in the collection of the samples: Donald Phelps (U.S. EPA Narragansett), Sandy Freitas (Battelle New England Marine Laboratory), Andy Lissner (Pacific Northwest Laboratory), Gary Wolff (Texas A \& M University) Robert C. Clark, Jr. (National Marine Fisheries Northwest and Alaska Fisheries Center), Peter Hanson (National Marine Fisheries Southeast Fisheries Center), and Vincent Zdanowicz (National Marine Fisheries Northeast Fisheries Laboratory). We acknowledge the assistance of Kevin Diamond in the homogenization and preparation of the bivalve specimens from the NS\&T program and Lavern Baker (Battelle-PNL) for assistance in the XRF-BFP analyses. This work was supported in part by the Ocean Assessments Division, NOAA, the Office of Health Research, Office of 
Research and Development, U.S. Environmental Protection Agency, and by the U.S. Department of Energy under contract DE-AC06-76RLO 1830.

\section{REFERENCES}

[1] Zeisler, R., Stone, S. F., and Sanders, R. W. (1988), Sequential Analysis of 44 Trace Elements in Marine Bivalves, submitted to Anal. Chem.

[2] Lauenstein, G. G., Schantz, M. M., Wise, S. A., Zeisler, R. (1986), Specimen Banking in the National Status and Trends Program: Development of Protocols and First Year Results, Oceans " 86 Conference Record, IEEE, New York, NY, 586-589.

[3] Wise, S. A. and Zeisler, R. (1984), The Pilot Environmental Specimen Bank Program, Environ. Sci. Technol. 18, 302A-307A.

[4] Zeisler, R., Harrison, S. H., and Langland, J. K. (1983), Cryogenic Homogenization of Biological Tissues, Anal. Chem. 55, 2431-2434.

[5] Stone, S. F. and Zeisler, R. (1984), Evaluation of Biological Samples for Specimen Banking and Biomonitoring by Nuclear Methods, Proc. 5th Conf. on Nuclear Procedures in Environment and Energy Technology, J.R. Vogt, Ed., NTIS U.S. Dept. Energy, Springfield, VA, CONF-840408, 801-812.

[6] Schantz, M. M., Chesler, S. N., Koster, B. J., and Wise, S. A., (1988), Analytical Methods for the Determination of Organic Contaminants in Marine Sediments and Tissues, In: These Proceedings.

[7] Sleater, G. A. (1986), XRF Analysis of Marine Sediments (NOAA/NBS Specimen Bank) by Automated Borate Fusion, In: Technical Activities 1986, Center for Analytical Chemistry, NBSIR 86-3486, National Bureau of Standards, pp 150-151.

[8] Becker, D. A. (1986), Determination of Silicon by Fast Neutron Activation Analysis, In: Technical Activities 1986, Center for Analytical Chemistry, NBSIR 86-3486, National Bureau of Standards, pp 41-42.

[9] Certificate of Analysis, Standard Reference Material 1566, Oyster

Tissue, (1979), National Bureau of Standards, Gaithersburg, MD 20899, USA.

[10] Okamoto, K. and Fuwa, K. (1984), Certificate for NIES Certified Reference Material No. 6, Mussel, National Institute for Environmental Studies (NIES), Yatabe-machi, Tsukuba, Ibaraki, 305, Japan.

[11] International Atomic Energy Agency (IAEA) Certified Reference Material SD-N-1/2, (1985), Musee Oceanographique, 98000 Monaco.

[12] Currie, L. A. (1968), Limits for Qualitative Detection and Quantitative Determination, Anal. Chem. 40, 586-593. 
[13] Gladney, E.S., Burns, C.E., Perrin, D.R., Roelandts, I., Gills, T.E. (1984), 1982 Compilation of Elemental Concentration Data for NBS Biological, Geological, and Environmental Standard Reference Materials, NBS Spec. Publ. 260-88, U.S. Government Printing Office, Washington, DC, $231 \mathrm{pp}$. 


\title{
SECTION 8
}

\section{IMPROVED ANALYTICAL METHODOLOGY FOR THE DETERMINATION OF PCBS AND PESTICIDES IN HUMAN LIVER SPECIMENS}

\author{
Reenie M. Parris, Stephen N. Chesler, and Stephen A. Wise \\ Center for Analytical Chemistry \\ National Bureau of Standards \\ Gaithersburg, MD 20899
}

\begin{abstract}
SUMMARY
An analytical method is described which was developed for the determination of low $\mathrm{ng} / \mathrm{g}$ levels of selected individual polychlorinated biphenyl (PCB) congeners and chlorinated organic pesticides in human liver specimens from the Environmental Specimen Bank at the National Bureau of Standards (NBS). Two liquid chromatographic fractionations are utilized to remove analytical interferences and to separate the analytes of interest into two fractions prior to quantification by high resolution gas chromatography with electron capture detection.
\end{abstract}

\section{INTRODUCTION}

As part of the Environmental Specimen Banking program sponsored in part by U. S. Environmental Protection Agency, NBS has been involved with the sampling, processing, storage and analysis of human liver samples since 1980. This project is part of a continuing effort to archive and characterize several types of environmental samples for future retrospective analyses for both inorganic and organic components. Detailed protocols on the collection and storage of these specimens have been described previously [1] .

Prior to the development of the analytical methodology described in this paper, organic analyses at NBS of these human liver specimens focused on the determination of selected chlorinated pesticides using classical column chromatography on Florisil as a pre-separation step [2]. The methods used previously have been modified to include individual PCB congeners as analytes, to utilize more efficient and reproducible liquid chromatographic preseparation techniques, and to separate the species of interest into two fractions for the analytical measurements. The five individual PCB congeners selected as analytes are among those currently used by many researchers as marker compounds for the identification and quantification of PCB contamination. The liver specimens were also analyzed for the determination of seven chlorinated pesticides. The analytical scheme consists of extraction of the sample, two liquid chromatographic fractionation steps, and quantification by capillary gas chromatography with electron capture detection. 


\section{II . EXPERIMENTAL SECTION}

\section{A. Sample Collection and Preparation}

The samples analyzed were collected in 1984 in Seattle, Washington. The liver specimens were frozen within one hour of autopsy and shipped to and stored in the NBS specimen bank at liquid nitrogen vapor temperatures $\left(-150^{\circ} \mathrm{C}\right)$. Prior to analysis, the liver specimens (150 g) were cryogenically homogenized in a Teflon disk mill [3]. Aliquots of this frozen liver particulate homogenate were transferred to Teflon storage jars and were stored at liquid nitrogen vapor temperature [1]. A flow diagram is shown in Figure 1 for the analytical procedure used for the analysis of the human liver specimens for the determination of selected $\mathrm{PCB}$ and chlorinated pesticide analytes.

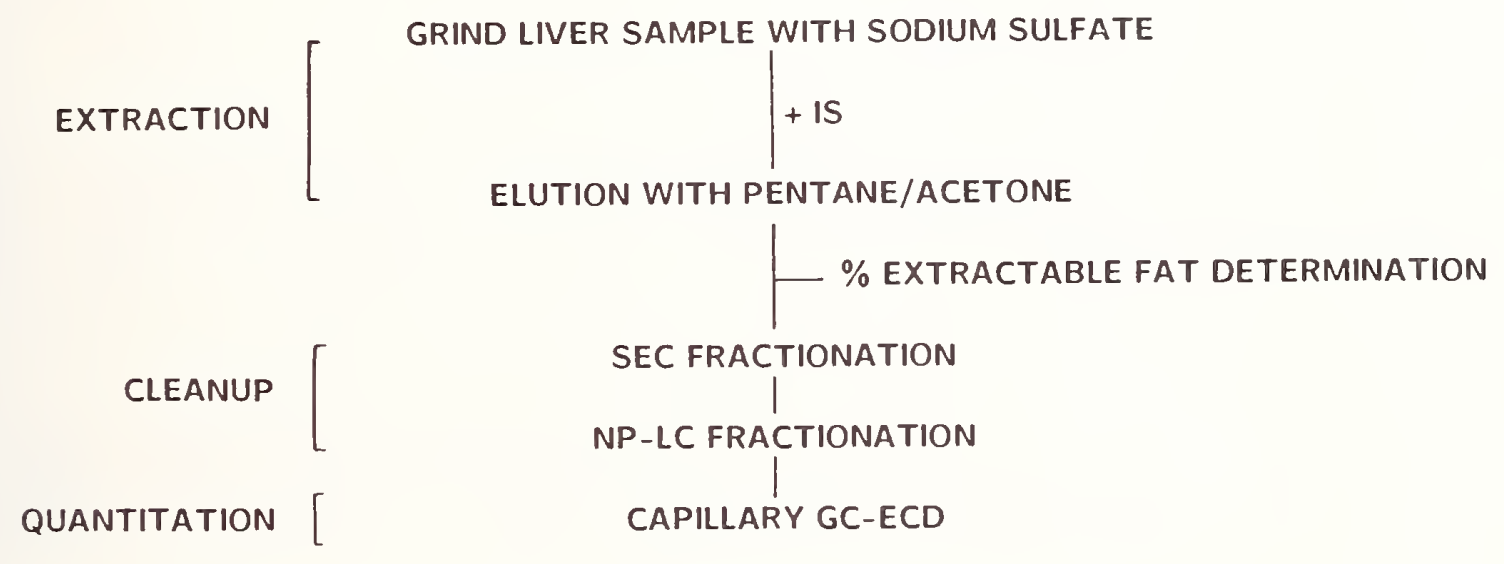

Figure 1. Flow diagram of the analytical procedure

\section{B. Sample Extraction}

Each weighed sample $(2.5 \mathrm{~g})$ was ground with precleaned anhydrous sodium sulfate $(100 \mathrm{~g})$ at room temperature in a mortar with pestle. This mixture was transferred to a glass column $(20 \mathrm{~mm}$ i.d. x $360 \mathrm{~mm})$ equipped with a Teflon stopcock at the lower end. An aliquot containing known masses of the internal standards (IS) was pipetted onto the top of the column. The internal standards used were PCB 103 [4], PCB 198, and deuterated-4,4'-DDT $\left(\mathrm{d}_{8}\right)$. These IS's were not significantly present in the samples and had appropriate LC and GC elution zones. This mixture was then eluted with $200 \mathrm{~mL}$ of $2: 1$ ( $\mathrm{v}: \mathrm{v}$ ) pentane/acetone. The rate of flow was adjusted so that about $6 \mathrm{~h}$ were required for the extraction. The extract was concentrated to approximately $20 \mathrm{~mL}$ in a rotary evaporator, transferred to a centrifuge tube, and reduced to $1 \mathrm{~mL}$ with a stream of precleaned nitrogen gas. Methylene chloride ( $5 \mathrm{~mL}$ ) was then added to the extract. A typical set of samples consisted of six liver samples, two aliquots of liver samples that had been analyzed in the previous set, two aliquots of gravimetrically prepared calibration solutions, and one aliquot of hexane. Each sample was spiked with the internal standards, extracted, fractionated, and analyzed as shown in Figure 1 . 


\section{Percent-Extractable Components Determination}

The $\mathrm{w} / \mathrm{w}$ percent of the liver extracted as defined by the following formula was determined for each liver extract. This is often called "percent extractable fat". A $90 \mu \mathrm{L}$ aliquot of known mass of the extract was transferred to a tared foil pan. The methylene chloride was allowed to evaporate at room temperature $(l \mathrm{~h})$ and the mass of the remaining residue was determined.

$\begin{aligned} & \text { extractable } \\ & \text { components }\end{aligned}=\frac{100 \times \mathrm{M} 2 \times \mathrm{E}}{\mathrm{M} 1 \times \mathrm{L}}$

where: $M 1$ = initial mass of aliquot

M2 = mass of aliquot residue after solvent evaporation

$\mathrm{L}=$ mass of liver extracted

$\mathrm{E}=$ mass of total extract

\section{Size Exclusion LC Fractionation}

The remainder of the extract was filtered with a precleaned $0.5 \mu \mathrm{m}$ glass microfilter (disposable unit), and evaporatively concentrated to $600 \mu \mathrm{L}$. To remove most lipid and other large molecular weight components from this complex liver extract matrix, the extract was fractionated on a preparative-scale size exclusion column $(2.5 \mathrm{~cm}$ i.d. $x 60 \mathrm{~cm})$. The column material was a divinylbenzene-styrene copolymer with pore size of $100 \AA$ and particle size of $10 \mu \mathrm{m}$. With methylene chloride as the mobile phase, the fraction containing the PCBs and chlorinated pesticides was collected according to previously calibrated retention zones. The volume of the fraction was reduced to $400 \mu \mathrm{L}$ after the solvent was changed to hexane.

\section{E. Aminosilane LC Fractionation}

The entire fraction was injected onto a normal phase aminosilane semipreparative column $(7.9 \mathrm{~mm}$ i.d. x $300 \mathrm{~mm})$. Two fractions were collected according to previously determined retention zones. Initially, the mobile phase was 1008 hexane and Fraction I which contains the PCBs and two pesticides (4,4'-DDE and hexachlorobenzene) was collected. The mobile phase was changed to $1: 20$ (v:v) methylene chloride/hexane and Fraction II was collected which contains the remaining pesticides of interest (4,4'-DDT, 2,4'-DDT, heptachlor epoxide, transnonachlor, 4,4'-DDD and dieldrin). The volume of each fraction was reduced to $150 \mu \mathrm{L}$ prior to GC analysis.

\section{F. Gas Chromatographic Analyses}

For the gas chromatographic analyses, $1.5 \mu \mathrm{L}$ aliquots of each fraction were injected into a gas chromatograph equipped with an electron capture detector and an immobilized nonpolar fused silica column ( $30 \mathrm{~m} \times 0.25 \mathrm{~mm} \times 0.25$ $\mu \mathrm{m}$ film thickness). A split mode of injection was used with helium as the carrier gas. 


\section{RESULTS AND DISCUSSION}

Typical chromatograms of Fraction I and II from the analysis of a human liver sample are shown in Figures 2 and 3 . The PCBs are identified according to the Ballschmiter-Zell numbering scheme [4]. A range of results from 24 samples for each analyte is listed in Table 1. The concentrations of the PCBs ranged from 0.5 to $30 \mathrm{ng} / \mathrm{g}$ of wet liver tissue and concentrations of chlorinated pesticides ranged from 1 to $400 \mathrm{ng} / \mathrm{g}$ wet liver tissue.

\section{CONCLUSIONS}

By including these liquid chromatographic fractionation steps in our procedure, low $\mathrm{ng} / \mathrm{g}$ levels of selected $\mathrm{PCB}$ congeners and chlorinated pesticides in human liver tissue can be determined because 1) many matrix components that could interfere with the quantitative analysis and/or foul the analytical system are removed, 2) analytes can be separated into several fractions which precludes coelution of some components during the analytical measurement step and 3) sample contamination and exposure during the analysis is minimized. These LC procedures are also less labor intensive than most classical column sample pre-treatments and are automatable.

\section{ACKNOWLEDGEMENTS}

The authors acknowledge the cooperation and assistance of Dr. V. F. Garry, University of Minnesota, Minneapolis, Dr. N. K. Mottet, University of Washington, Seattle, and Mrs. D. Kenny, Harborview Medical Center, Seattle, for the careful collection of the liver samples. We acknowledge the assistance of W. F. Kline, K. A. Fitzpatrick, and G. Harrington in the homogenization and preparation of the liver samples.

\section{REFERENCES}

[1] Zeisler, R., Harrison, S. H., and Wise, S. A., Eds., (1983), The Pilot National Environmental Specimen Bank - Analysis of Human Liver Specimens, NBS Spec. Publ. 656, U. S. Government Printing Office, Washington, DC, $135 \mathrm{pp}$.

[2] Kline, W. F., Allen, C. F., Chesler, S. N., Hilpert, L. R., and Wise, S. A., (1983), Development of Analytical Methodology for the Determination of Organochlorine Compounds in Human Liver Samples, In: The Pilot National Environmental Specimen Bank - Analysis of Human Liver Specimens, R. Zeisler, S. H. Harrison, and S. A. Wise, Eds., NBS Spec. Publ. 656, U. S. Government Printing Office, Washington, DC, pp 91-97.

[3] Zeisler, R., Langland, J. K., and Harrison, S. H. (1983), Cryogenic Homogenization of Biological Tissues, Anal. Chem. 55, 2431-2434. 


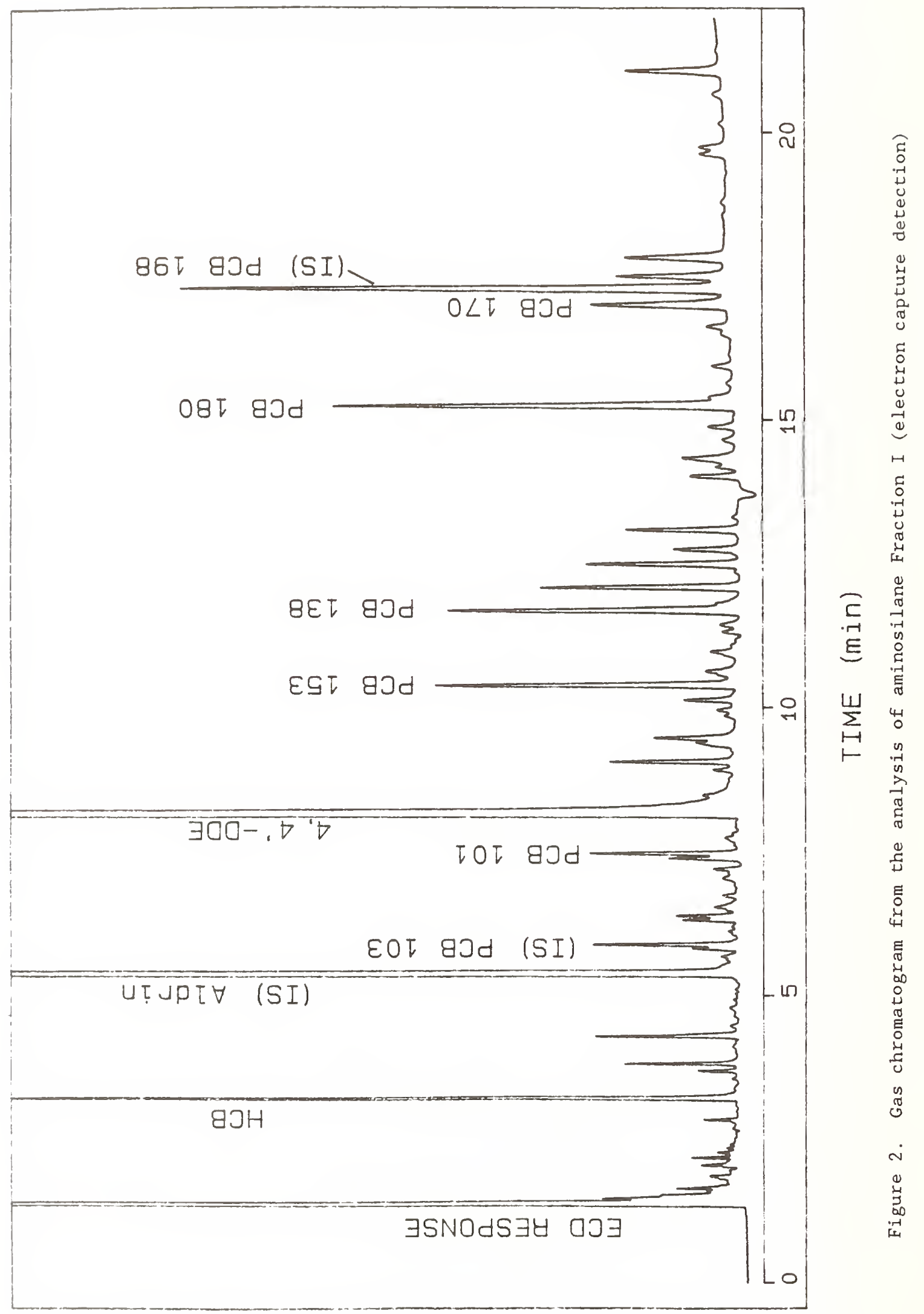




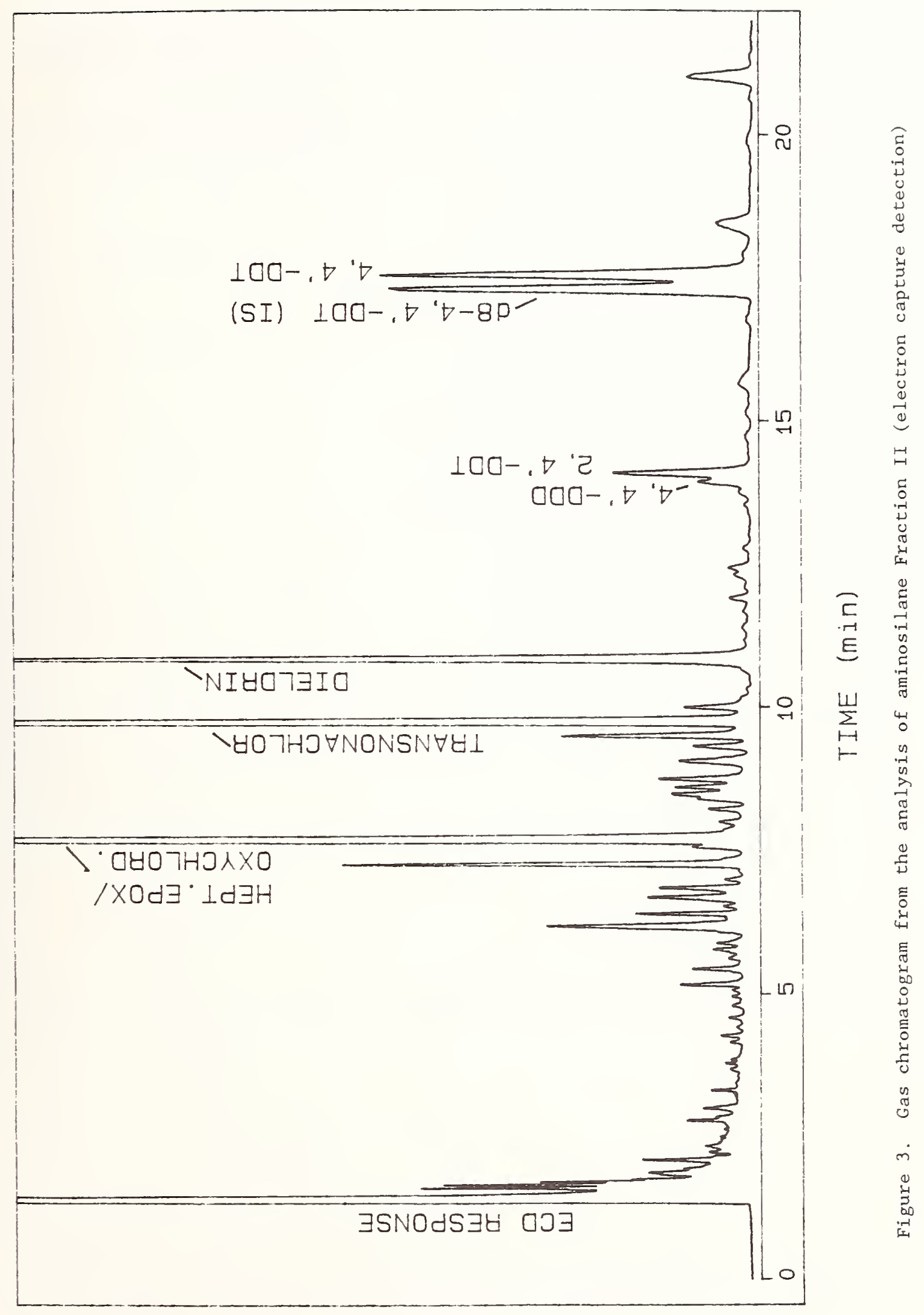


Table 1. Range of Concentrations of Selected PCBs and Pesticides in 24 Human Liver Samples

\begin{tabular}{|c|c|c|}
\hline Compound & $\begin{array}{l}\text { Analyte Concen } \\
\mathrm{ng} / \mathrm{g} \text { liver tiss }\end{array}$ & $\begin{array}{l}\text { ntration } \\
\text { sue (wet) }\end{array}$ \\
\hline $\begin{array}{l}\text { PCB } 10 \\
\left(2,2^{\prime}, 4,5,5^{\prime} \text {-pentachlorobiphenyl) }\right.\end{array}$ & $11.1-$ & -8.3 \\
\hline $\begin{array}{l}\text { PCB } 138 \\
\left(2,2^{\prime}, 3,4,4^{\prime}, 5^{\prime} \text {-hexachlorobiphenyl) }\right.\end{array}$ & $3.4-$ & -29 \\
\hline $\begin{array}{l}\text { PCB } 153 \\
\left(2,2^{\prime}, 4,4^{\prime}, 5,5^{\prime} \text {-hexachlorobiphenyl) }\right.\end{array}$ & $4.6-$ & -29 \\
\hline $\begin{array}{l}\text { PCB } 170 \\
\left(2,2^{\prime}, 3,3^{\prime}, 4,4^{\prime}, 5 \text {-heptachlorobiphenyl) }\right.\end{array}$ & $0.9-$ & -11 \\
\hline $\begin{array}{l}\text { PCB } 180 \\
\left(2,2^{\prime}, 3,4,4^{\prime}, 5,5^{\prime} \text {-heptachlorobiphenyl) }\right.\end{array}$ & $2.4-$ & -20 \\
\hline Hexachlorobenzene & $1-$ & -30 \\
\hline $4,4^{\prime}-\mathrm{DDE}$ & $32-$ & -400 \\
\hline Heptachlor epoxide/oxychlordane & $6.7-$ & -42 \\
\hline Transnonachlor & $2.0-$ & -14 \\
\hline Dieldrin & $3.6-$ & -17 \\
\hline $4,4^{\prime}-\mathrm{DDD}$ & 1.8 & -130 \\
\hline $4,4^{\prime}-\mathrm{DDT}$ & 1.4 & -250 \\
\hline \& Extractable Components & $2.4-$ & -6.48 \\
\hline
\end{tabular}


[4] Ballschmiter, K. and Zell, M., (1980) Analysis of Polychlorinated Biphenyls (PCB) by Glass Capillary Gas Chromatography, Fresenius. Z. Anal. Chem. 302, 20-31. 


\title{
SECTION 9
}

\author{
THE DETERMINATION OF TRACE ELEMENTS IN HUMAN LIVERS
}

\author{
Rolf Zeisler, Robert R. Greenberg, and Susan F. Stone \\ Center for Analytical Chemistry \\ National Bureau of Standards \\ Gaithersburg, MD 20899 \\ USA
}

\section{INTRODUCTION}

Since 1980, the pilot National Environmental Specimen Bank (NESB) program at the National Bureau of Standards (NBS) has examined the collection, processing, storage, and analysis of human livers [1]. Sampling protocols, handling procedures and analytical methods have been developed and implemented taking into consideration the requirements for valid analytical results. Sampling and handling included the use of clean-room technology, specific clean implements and packaging materials made from titanium and Teflon, and flash-freezing and preservation of the tissues at liquid nitrogen temperature. More than 500 human liver specimens have been collected and banked from several locations in the U.S. since the pilot program began, representing all age groups above age fourteen. A representative portion of the samples included in the bank has been analyzed to provide data for real time monitoring, determination of long term stability, and evaluation of today's analytical capabilities.

Initially, a combination of four techniques provided a comprehensive data set for 36 human livers. However, several key trace elements were not detectable in all samples or insufficient data was obtained from a particular analytical technique. Frequently, analyses had to be repeated to detect low levels or to confirm results. This expensive approach needed improvement to reduce the amount of sample required and to limit the number of techniques and analytical steps required. In addition, the naturally occurring levels of several pollutant trace elements were approximately one order of magnitude lower than previously reported, thus requiring more sensitive analytical procedures. Since NAA had been used for the determination of most of the above elements, on individual $1 \mathrm{~g}$ (fresh weight) samples, further expansion of NAA and lowering of its detection limits could effectively achieve this goal. Therefore, we modified the instrumental NAA procedures and added radiochemical separation procedures that would provide the additional sensitivity and precision required.

\section{EXPERIMENTAL SECTION}

\section{A. Sample Preparation}

Human liver specimens were selected from the 1982 and 1984 collections of the pilot NESB program. The samples were obtained from the NESB storage in the form of aliquots of cryogenically homogenized liver specimens [2]. These homogenates, stored at liquid nitrogen temperature in Teflon jars, consisted of 
5 to $7 \mathrm{~g}$ of fresh material in the form of a finely divided powder. Before analysis, the selected aliquots were freeze-dried at $-5{ }^{\circ} \mathrm{C}$ and 1 pascal until stable weight was reached. Water loss ranged between 70 and $80 \%$, and the individually determined results were used to correct analytical values to a fresh weight basis. Portions of the freeze-dried material, weighing typically $250 \mathrm{mg}$ (equivalent to $1 \mathrm{~g}$ fresh weight), were then pressed into $13 \mathrm{~mm}$ diameter pellets with a Perkin-Elmer $\mathrm{KBr}$ pellet press. Control materials (NBS SRM 1577a, Bovine Liver) and primary standards (multi-element solutions on Whatman 42 filter paper) were pressed into similar pellets. The pellets were individually sealed in acid cleaned linear polyethylene film for irradiation. The pellets were re-packaged in a similar manner for counting and re-irradiation. Pelletizing greatly facilitates the handling of the samples, and to date, no contamination from the pellet press has been observed in numerous analyses of biological materials with even lower trace element concentrations, e.g., milk powder, and rice and wheat flour.

\section{B. Neutron Activation Analysis}

The instrumental NAA procedures followed the general principles that were outlined previously [3]. A sequential analysis scheme, consisting of several irradiation, decay and counting cycles for each sample, provides optimum information from each individual sample. All irradiations were performed in the pneumatic tube facilities RT3 and RT4 of the NBS research reactor. For the analyses done with modification B (see below), we utilized the higher fluence rates available at the upgraded 20 MW research reactor of the NBS [4].

All counting was done on high resolution, high efficiency gamma spectrometers (typically $1.9 \mathrm{keV}$ FWHM for $1332 \mathrm{keV}$ and $25 \%$ relative efficiency). The gamma spectra contained 8192 data channels with $0.40 \mathrm{keV} / \mathrm{channel}$ (1st and 2nd counts) or $0.25 \mathrm{keV} /$ channel ( $3 \mathrm{rd}$ and $4 \mathrm{th}$ counts) resolution. The spectra were accumulated with Nuclear Data 6000 Series MCA's and the data were stored on disk for automatic processing. Pileup and live time corrections in the 1 st and 2nd counts were done from a $100 \mathrm{~Hz}$ pulser peak stored with the spectral data; for the other counts, ADC live times were taken and pileup corrections were calculated from a calibration curve.

To improve the detection limits in INAA, a Compton suppression system was used for some counts. It consists of a central Ge(Li)-detector surrounded by a sodium iodide scintillator with internal sample position, and a Harshaw NC-26R Compton suppressor analyzer [5]. This system is particularly effective with these samples during the 3 rd count where a more than 20 fold reduction in the background under the $559 \mathrm{keV}$ line of arsenic can be achieved. We have dedicated two ADCs for the simultaneous acquisition of the Compton suppressed spectra along with the normal data. Random coincidence suppression of the As, $\mathrm{Cd}$, and $\mathrm{Cr}$ counts were estimated by comparison of the intensities of single line emitting nuclides, such as $\mathrm{Zn}-65$, in both spectra. The necessary correction, between two and ten percent, was determined individually for each sample spectrum.

The analysis scheme that was applied to the first set of human liver samples [1], and the revised scheme that was used during this investigation are illustrated in Figure 1. Modification A was applied to the 1982 set of human 


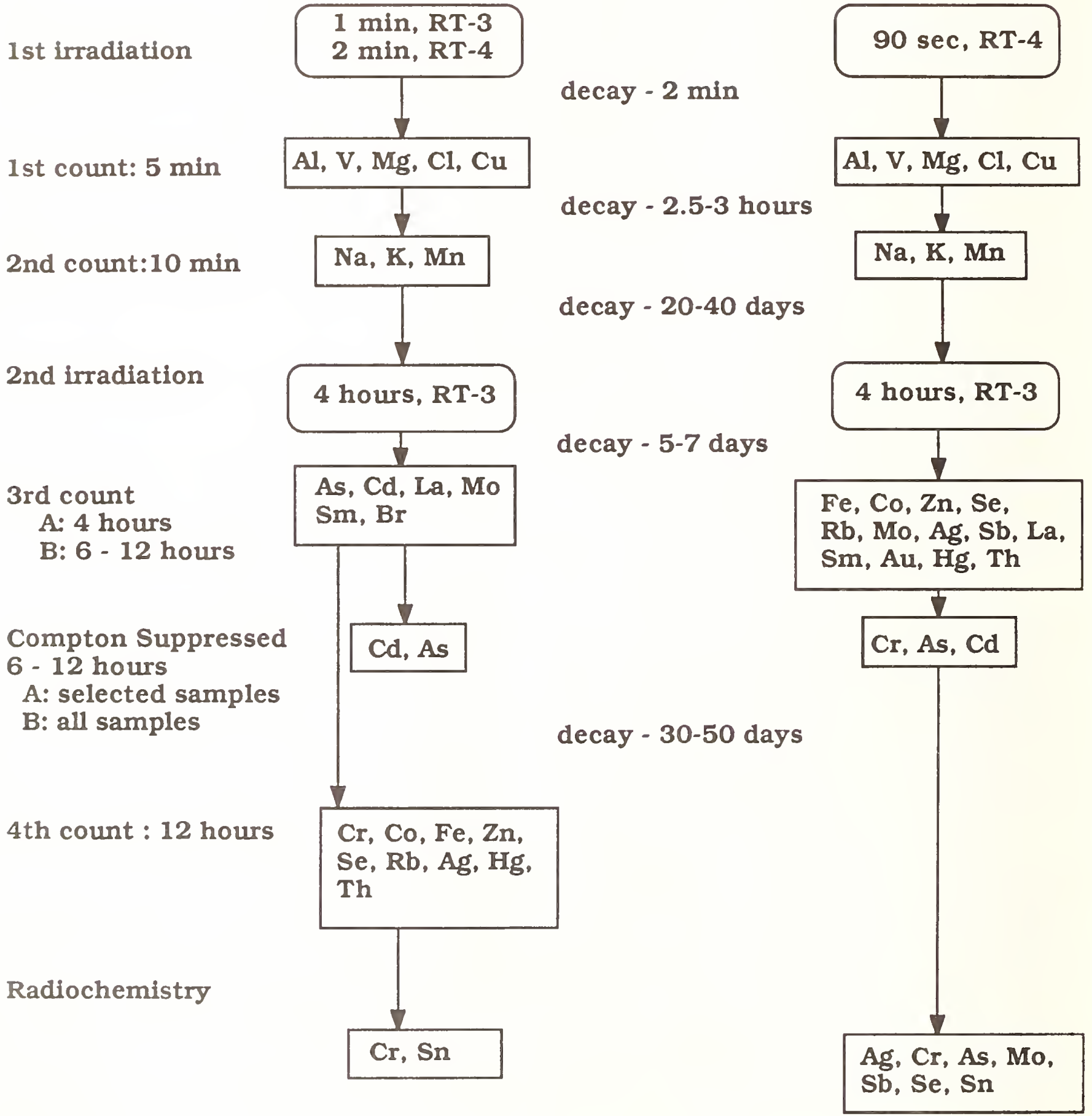

Figure 1. Flow chart for the irradiation, decay and counting cycles of the activation analysis procedures (Modification A for the 1982 set of human livers, Modification B for the 1984 set) 
livers, modification B to the 1984 set. In modification A, no changes were made to the irradiation cycles. The improvements were focused on lowering the detection limits during count 3 by implementing Compton suppression, and evaluating a radiochemical step for long-lived nuclides to be implemented after count 4. The simultaneous irradiation of at least six samples in each rabbit resulted in greatly varying sensitivity for arsenic because of the relatively short half life $\left(\mathrm{T}_{\frac{1}{2}}=26.3 \mathrm{~h}\right)$ of its radionuclide. This drawback was eliminated in modification $B$, where only two to three samples were irradiated at a time, thus providing practically equal sensitivity for the determination of arsenic in each sample after a 6 to 7 day decay. The radiochemical separation in modification A provided results for chromium and tin. However, silver and antimony were not considered. To include these elements, and further lower the detection limit for arsenic, a different separation was used in modification $B$.

\section{Radiochemical Procedures}

Following the completion of the instrumental assays, radiochemical procedures were added to obtain better sensitivity for several low level trace elements. In modification A, efforts were focused on combining existing procedures for the determination of chromium [6] and tin [7]. In modification $B$, more elements were included in an adapted group separation [10] for counting after 9 to 10 days of decay.

For the radiochemical separation, the samples were digested after the addition of appropriate carriers, using a stepwise addition of an appropriate combination of acids in several steps. Evaporating the solutions to dryness was avoided to prevent loss of selenium and chromium. In modification A, a liquid/liquid extraction of the $\operatorname{Cr}(V I)$ tribenzylamine (TBA) complex in chloroform was used for the specific separation of this element [6]. Following the separation, the chloroform was evaporated and the chromium taken up in $15 \mathrm{~mL}$ of concentrated $\mathrm{HNO}_{3}$ and $\mathrm{H}_{2} \mathrm{SO}_{4}$ (1:1) for counting.

The aqueous phase was then used for the separation of tin by liquid/liquid extraction of $\mathrm{SnI}_{4}$ in toluene. Before this could be accomplished, all chloride was eliminated by adding concentrated $\mathrm{HNO}_{3}$ and gently heating for 48 hours. The residual organic material (TBA) was digested with $\mathrm{H}_{2} \mathrm{SO}_{4} / \mathrm{HNO}_{3}$ and $\mathrm{H}_{2} \mathrm{O}_{2}$ by heating in a Teflon beaker. The solution was then adjusted to approximately $208 \mathrm{H}_{2} \mathrm{SO}_{4}$. A mixture of $10 \mathrm{~mL}$ of $5 \mathrm{~mol} / \mathrm{L} \mathrm{KI}$ and $20 \mathrm{~mL}$ toluene were added to extract the $\mathrm{SnI}_{4}$. The tin was back-extracted from the organic phase with $20 \mathrm{~mL}$ of $5 \% \mathrm{Na}_{2}$ EDTA solution. The tin-containing solution was counted after 12 hours, allowing for the buildup of $\mathrm{In}-113 \mathrm{~m}$, and the $392 \mathrm{keV}$ gamma line was used for quantitation.

In modification $B$, the $3 r d$ count was a compromise, achieving some additional sensitivity with the Compton suppression; however, this action gives up the usual advantage for nuclides with half-lives greater than 70 hours, which commonly are counted after longer decay periods. This was done to obtain sufficient sensitivity for arsenic in the radiochemical separation step that follows the instrumental assay. Samples were digested as described above and then submitted to a previously described group separation on an inorganic ion exchange column prepared from hydrated manganese dioxide (HMD, Carlo Erba) [7]. 
The HMD had been preconditioned with phosphoric acid to minimize the retention of radioactive phosphorus which causes excessive bremsstrahlung background. In addition to the previously investigated elements, $\mathrm{Cr}$, As, Se, Mo, Ag, and $\mathrm{Sb}$, it was found that the retention of $\mathrm{Sn}$ is quantitative from $1 \mathrm{~mol} / \mathrm{L} \mathrm{HNO}_{3}$. After washing with $1 \mathrm{~mol} / \mathrm{L} \quad \mathrm{HNO}_{3} / 0.0025 \mathrm{~mol} / \mathrm{L} \mathrm{H}_{3} \mathrm{PO}_{4}$, the $\mathrm{HMD}$ column was counted immediately on a gamma spectrometer and in some cases a second time after additional decay.

\section{RESULTS AND DISCUSSION}

A major part of this work was to determine up to 30 elements for baseline studies in human livers collected during 1982 and 1984. The ranges of elemental concentrations found in the sixty selected specimens are summarized in Table 1. As discussed above, improved INAA and RNAA procedures were implemented to lower detection limits and to include additional elements. The significant improvements in detection limits achieved for the low level trace elements $\mathrm{Cr}, \mathrm{As}, \mathrm{Ag}, \mathrm{Sn}$, and $\mathrm{Sb}$ are summarized in Table 2. These detection limits represent the element concentrations at which, with $95 \%$ probability, a sample with the given concentration would generate a detectable signal [8]. The lower detection limits permitted the determination of the aforementioned elements in all 1984 specimens.

In Figure 2, the data obtained for arsenic in the 1984 human liver specimens are summarized. The plotted data are ranked according to increasing values and are compared to "best" regional values [9]. The figure illustrates the improvements in the analytical procedures. The Compton suppression lowers the detection limits to the naturally occurring levels, but this is still insufficient for about 50\% of the actual concentrations. The value of RNAA is clearly established at these levels. The comparison of RNAA with INAA at the higher levels shows good agreement between both procedures, re-affirming the quantitativeness of the separation procedure. It should be noted that the recent literature data [9] are an order of magnitude lower than previously reported values [10].

When this procedure is applied to specimen bank samples, only one additional technique is needed. Voltammetry complements the activation analysis measurements in an ideal way by providing results for $\mathrm{Ni}, \mathrm{Cu}, \mathrm{Cd}$, and $\mathrm{Pb}$. Most of the values for these elements in Table 1 were obtained by this technique [11]. This combination of the two techniques significantly reduces the amount of sample needed as well as analytical effort spent. The second technique would also serve to estimate the quality of the results. Since INAA results are not affected by the matrix and interferences are known and correctable, the comparison of $\mathrm{Cu}$ and $\mathrm{Cd}$ results would allow a reasonable assessment of the quality of the results. If there is good agreement between the two techniques for those two elements, it can be assumed that the quality of the rest of the results is good. This highly efficient approach will be useful in the future by providing more results on human livers, without sacrificing the quality of the analytical data. 
Table 1. Ranges of Trace Element Concentrations in Selected Human Liver Specimens

\begin{tabular}{|c|c|c|c|c|}
\hline \multirow[b]{2}{*}{ Element } & \multicolumn{2}{|c|}{1982 Collection } & \multicolumn{2}{|c|}{1984 Collection } \\
\hline & Low & High & Low & High \\
\hline $\mathrm{Na}$ & 720 & 2265 & 750 & 2140 \\
\hline Mg & 81.5 & 171 & 104 & 246 \\
\hline $\mathrm{Al}$ & 0.525 & 2.22 & 0.29 & 7.31 \\
\hline $\mathrm{Cl}$ & 1019 & 2418 & 984 & 1980 \\
\hline $\mathrm{K}$ & 1645 & 3942 & 1330 & 3090 \\
\hline Sc & 0.000096 & 0.00093 & 0.00028 & 0.00051 \\
\hline V & $\leq 0.016$ & $\leq 1.05$ & 0.011 & 0.026 \\
\hline $\mathrm{Cr}$ & $\leq 0.01$ & 0.18 & 0.01 & 0.12 \\
\hline Mn & 0.608 & 1.964 & 0.742 & 2.152 \\
\hline $\mathrm{Fe}$ & 73.22 & 441.3 & 38.6 & 915 \\
\hline Co & 0.026 & 0.059 & $\leq 0.017$ & 0.074 \\
\hline $\mathrm{Ni}$ & 0.0027 & 0.037 & 0.0029 & 0.036 \\
\hline $\mathrm{Cu}$ & 3.62 & 17.2 & 2.60 & 23.8 \\
\hline $\mathrm{Zn}$ & 29.3 & 103 & 36.97 & 99.87 \\
\hline As & $\leq 0.001$ & 0.0268 & 0.0022 & 0.0203 \\
\hline $\mathrm{Se}$ & 0.327 & 0.631 & 0.348 & 0.838 \\
\hline $\mathrm{Rb}$ & 1.74 & 8.07 & 2.701 & 8.930 \\
\hline Mo & 0.241 & 1.41 & 0.332 & 1.41 \\
\hline $\mathrm{Ag}$ & $\leq 0.003$ & 0.0347 & 0.00086 & 0.0341 \\
\hline $\mathrm{Cd}$ & 0.28 & 6.05 & 0.440 & 3.268 \\
\hline Sn & --- & -- & 0.050 & 2.420 \\
\hline $\mathrm{Sb}$ & $\leq 0.0008$ & 0.0122 & 0.0013 & 0.0772 \\
\hline Cs & 0.0012 & 0.019 & 0.0079 & 0.0146 \\
\hline $\mathrm{La}$ & $\leq 0.008$ & 0.417 & 0.0017 & 0.0191 \\
\hline $\mathrm{Ce}$ & $\leq 0.01$ & 0.52 & $\leq 0.022$ & 0.086 \\
\hline $\mathrm{Sm}$ & $\leq 0.0009$ & 0.0154 & $\leq 0.0003$ & 0.0033 \\
\hline $\mathrm{Au}$ & --- & --- & $\leq 0.00008$ & 0.06164 \\
\hline $\mathrm{Hg}$ & -- - & -- - & 0.0423 & 0.329 \\
\hline $\mathrm{Pb}$ & 0.138 & 0.926 & 0.23 & 1.03 \\
\hline Th & -- & - . & $\leq 0.002$ & 0.0047 \\
\hline
\end{tabular}


Table 2. Limits of Detection [8] $(\mu \mathrm{g} / \mathrm{kg})$ for Seven Critical Elements

\begin{tabular}{|c|c|c|c|c|c|c|}
\hline \multirow[b]{2}{*}{ Element } & \multicolumn{3}{|c|}{ MODIFICATION A } & \multicolumn{3}{|c|}{ MODIFICATION B } \\
\hline & $\begin{array}{c}\text { INAA } \\
\text { Normal }\end{array}$ & $\begin{array}{c}\text { INAA } \\
\text { Suppressed }\end{array}$ & RNAA & $\begin{array}{c}\text { INAA } \\
\text { Normal } \\
\end{array}$ & $\begin{array}{c}\text { INAA } \\
\text { Suppressed }\end{array}$ & RNAA \\
\hline $\mathrm{Cr}$ & 10 & 4 & 0.5 & 40 & 15 & 1.0 \\
\hline As & 30 & 5 & - & 10 & 5 & 1.0 \\
\hline $\mathrm{Se}$ & 6 & $-a$ & - & 35 & $-a$ & 0.5 \\
\hline Mo & 25 & 20 & - & 45 & 30 & $40^{b}$ \\
\hline $\mathrm{Ag}$ & 4 & $-a$ & - & 40 & $-a$ & 0.7 \\
\hline $\mathrm{Sn}$ & 300 & 200 & 10 & 3000 & 2000 & 30 \\
\hline 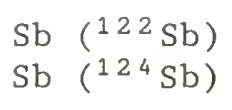 & 3 & 0.8 & - & 2 & 0.7 & 0.06 \\
\hline \multicolumn{7}{|c|}{$\begin{array}{l}{ }^{a} \text { Due to coincident gamma lines, } \mathrm{Ag} \text { and } \mathrm{Se} \text { are not included. } \\
{ }^{\mathrm{b}} \text { The } 739 \mathrm{keV} \text { line of } 99 \mathrm{Mo} \text { was used to avoid an additional decay period } \\
\text { required for the }{ }^{99} \mathrm{Mo}-99 \mathrm{~m} \text { Tc equilibrium to be established. }\end{array}$} \\
\hline
\end{tabular}




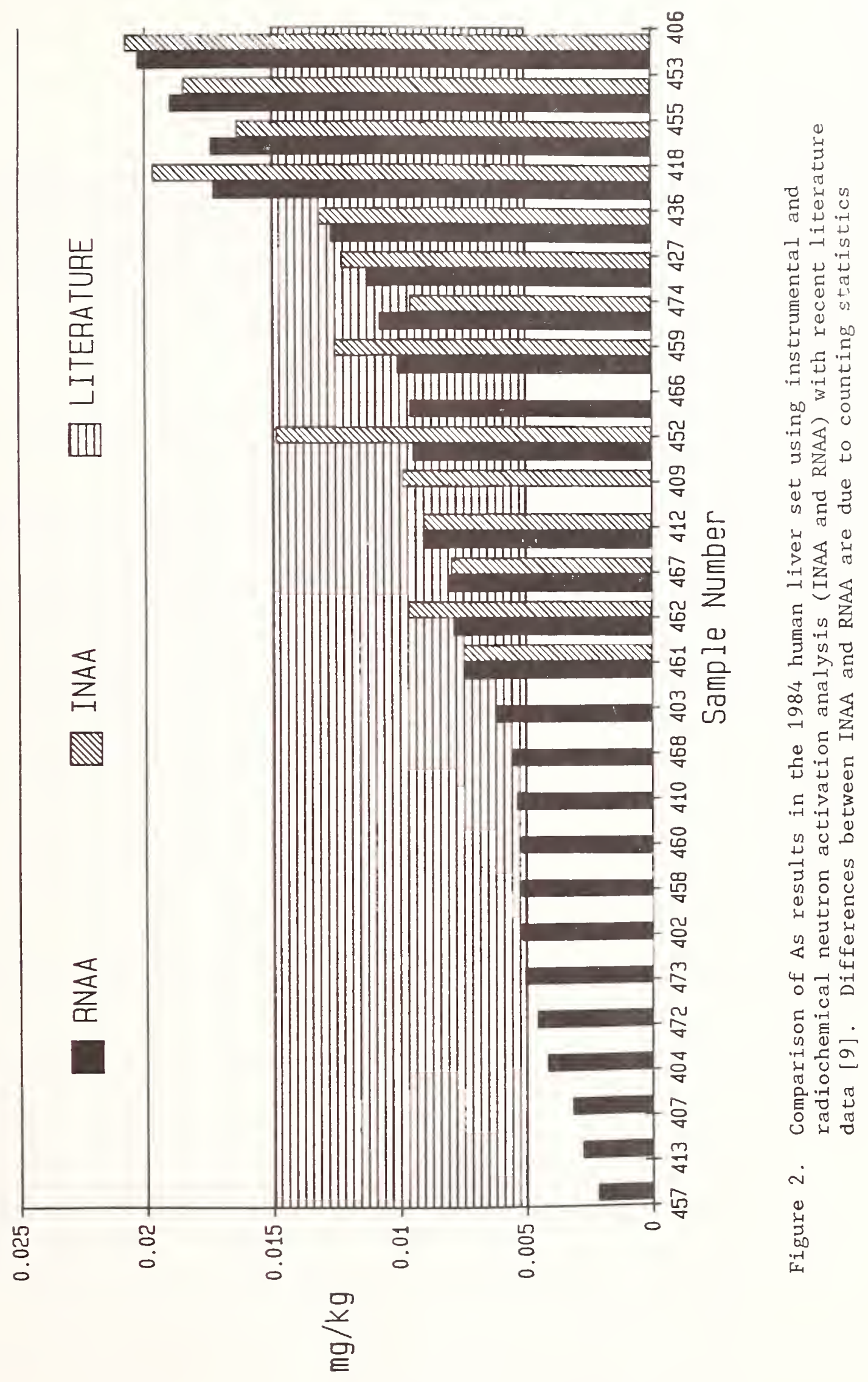




\section{ACKNOWLEDGEMENTS}

The authors acknowledge the cooperation and assistance of Dr. V. F. Garry, University of Minnesota, Minneapolis, Dr. N. K. Mottet, University of Washington, Seattle, and Mrs. D. Kenny, Harborview Medical Center, Seattle, for the careful collection of the liver samples. We acknowledge the assistance of W. F. Kline, K. A. Fitzpatrick, and G. Harrington in the homogenization and preparation of the liver samples.

\section{REFERENCES}

[1] Wise, S. A., and Zeisler, R. (1984), The Pilot Environmental Specimen Bank Program, Environ. Sci. Tech. 18, 302A-307A.

[2] Zeisler, R., Langland, J. K., and Harrison, S. H., (1983), Cryogenic Homogenization of Biological Tissues. Anal. Chem. 55, 2432-2434.

[3] Greenberg, R. R., Fleming, R. F., and Zeisler, R. (1984), High Sensitivity Neutron Activation Analysis of Environmental and Biological Standard Reference Materials. Environ. Intern. 10, 129-136.

[4] Becker, D. A., and Williamson, T. (1985), Characterization of the NBSR at 20 MW, Nat. Bur. Stand. (U.S.) Tech. Note 1217, 120-129.

[5] J. R. Vogt and R. Zeisler (1983), A Compton Suppression System for Background Reduction and Improved Sensitivity, Nat. Bur. Stand. (U.S.) Tech. Note $1178,154-159$.

[6] Greenberg, R. R. and Zeisler, R., A Radiochemical Procedure for Ultratrace 'Determination of Chromium in Biological Materials, J. Radioanal. Nucl. Chem., in press.

[7] Greenberg, R. R. (1986), Elemental Characterization of the National Bureau of Standards Milk Powder Standard Reference Material, Anal. Chem. $58,2511-2516$.

[8] L. A. Currie (1968), Limits for Qualitative Detection and Quantitative Determination. Anal Chem. 40, 586-593.

[9] Iyengar, G. V. (1985), Concentrations of 15 Trace Elements in Some Selected Adult Human Tissues and Body Fluids of Clinical Interest from Several Countries: Result from a Pilot Study for the Establishment of Reference Values, Berichte der KFA Jülich - Nr. 1974, 156 pp.

[10] Iyengar, G. V., Kollmer, W. E., Bowen, H. J. M. (1978), The Elemental Composition of Human Tissues and Body Fluids, Verlag Chemie, Weinheim/New York, $151 \mathrm{pp}$.

[11] Stoeppler, M. and Ostapczuk, P. (1986), Report of Analysis, Nuclear Research Center (KFA) Jülich, 1986. 


\title{
SECTION 10
}

\section{NATIONAL AIR MONITORING PROGRAM NATIONAL PARTICULATE NETWORK}

\author{
Stanley F. Sleva and Dennis Shipman \\ Monitoring and Data Analysis Division \\ Office of Air Quality Planning and Standards \\ U.S. Environmental Protection Agency \\ Research Triangle Park, North Carolina 21771 \\ USA
}

\section{INTRODUCTION}

Section 110 of the Clean Air Act [1] (CAA) requires ambient air quality monitoring and data reporting for purposes of State Implementation Plans (SIPs). The Environmental Protection Agency (EPA) promulgated regulations in August 1971, for the preparation, adoption and submittal of SIPs under Section 110 of the Act [2]. Included in these regulations were requirements for States to establish and operate ambient air monitoring networks and to report the data to EPA. These data were to be used for such purposes as evaluation of national control efforts, tracking attainment and maintenance of the National Ambient Air Quality Standards (NAAQS), reevaluation of the NAAQS, development of national control policies and strategies, and the preparation of national trends in ambient air quality.

In the mid-70's, several critical reviews [3-6] of environmental monitoring programs identified major deficiencies in several aspects of the existing monitoring systems. A Standing Air Monitoring Work Group (SAMWG) was formed to review and provide recommendations to overcome these deficiencies. The group was composed of representatives of EPA, State and local agencies. After an extensive and comprehensive review of the monitoring program, SAMWG issued an air strategy report which called for the revision of the 1971 monitoring regulations [5]. The suggested revisions would, in effect, correct the major shortcomings of the existing air monitoring programs and would also respond to requirements of Section 319 of the 1977 CAA.

The Environmental Protection Agency in May 1979 promulgated air monitoring and reporting regulations which significantly revised the previous regulations as recommended by SAMWG [7].

\section{HIGHLIGHTS OF THE 1979 REGULATIONS}

Briefly, the major elements of the revised regulations are the following [8]:

1. Provides for fixed and movable monitoring sites.

2. Establishes uniform monitoring criteria.

3. Requires that reference or equivalent methods be used. 
4. Imposes an annual network review.

5. Requires public reporting of an air quality index daily.

6. Provides for the quarterly reporting of all NAMS data and the annual summary reporting of SLAMS data.

III. TYPES OF MONITORING STATIONS

Three types of stations are provided for in the regulations. Each is designed to serve different needs and must be established according to different reporting, siting, and instrumentation requirements.

State and Local Air Monitoring Stations (SLAMS)

SLAMS consist of a carefully planned network of fixed monitoring stations whose size and distribution is largely determined by the needs of State and local air pollution con-trol agencies to meet their respective SIP requirements. These stations are the backbone of the ambient monitoring program relative to State Implementation Plan (SIP) activities. To ensure quality data, the SLAMS are required to meet the following:

a. Each site must meet network design criteria and criteria for instrument exposure and sample inlet design.

b. Each SLAMS network must include a quality assurance program.

c. All sampling methods and equipment must meet EPA reference or equivalent requirements.

d. Acceptable data validation and recordkeeping procedures must be followed.

In addition, data from the SLAMS must be summarized and reported annually to EPA.

\section{National Air Monitoring Stations (NAMS)}

The NAMS are a subset of the SLAMS network with emphasis being given to urban and multi-source areas. In effect, they are the key SLAMS with emphasis on areas of maximum concentration and high population density. NAMS, like SLAMS, must conform to EPA siting criteria and operate according to quality assurance procedures that equal or exceed EPA's minimum specifications. The NAMS differ from the SLAMS in that:
a. NAMS must use continuous automated instruments for gaseous pollutants.
b. A minimum number of NAMS must be established in specified urbanized areas.


c. NAMS data must be reported to EPA on a quarterly basis.

d. Adherence to quality assurance, siting and probe criteria must be achieved two years earlier than for SLAMS.

Special Purpose Monitoring (SPM)

Special Purpose Monitoring stations provide for special studies needed by the State and local agencies to support SIPs and other air program activities. SPMs are not permanently established and thus, can be adjusted easily to accommodate to changing needs and priorities. SPMs can be used to supplement the fixed monitoring network as circumstances require and resources permit.

\section{UNIFORM MONITORING CRITERIA}

The monitoring stations of the SLAMS and NAMS must adhere to the uniform monitoring criteria described in the regulation. These criteria cover quality assurance, monitoring methods, network design, and probe siting.

The quality assurance program consists of two functions. One function is the assessment of the quality of the data through precision and accuracy estimates. This function must be adhered to explicitly. The second function is the control and improvement of the quality of the data and is described in general terms. Each state is allowed to develop a quality control system appropriate for its situation.

Criteria were established for the monitoring methods that must be used for all SLAMS and NAMS. Each station must use reference or equivalent methods which are designated by EPA. Exceptions to the requirements may be allowed for unique circumstances where it can be proven that the method to be used will essentially provide the same results as an approved reference or equivalent method. It is further required that except for TSP, only continuous instruments be operated at the NAMS.

Procedures for the design of the monitoring networks to meet specified monitoring objectives are provided. Spatial scales of representativeness are included as a means of providing a useful system for classifying stations as well as to serve as a physical basis of defining sample station characteristics. The spatial scales of representativeness that are most important are microscale, middle, neighborhood, urban, and regional scale.

After selecting the general location of a monitoring station, a decision must also be made about the specific siting of the instrument probe of sampler inlet. In order to ensure consistency in this decision making process, probe siting criteria that must be followed were incorporated into the regulations. Pollutant specific criteria for the horizontal and vertical probe placement of the sampling probe, its spacing from obstructions and roads, as well as probe material and pollutant sample residence time are provided. Recognizing that some stations may not meet the probe siting requirements while still producing acceptable data, a waiver provision for such stations may be obtained. For 
NAMS, the requests are to be forwarded to the Administrator, for SLAMS to the Regional Administrator.

\section{OTHER FEATURES}

Three other items of major importance in the regulations are the annual network review, the reporting of the Pollutant Standard Index (PSI) daily, and air monitoring data reporting requirements.

In order to ensure optimal use of monitoring resources as well as meet changing data needs, the regulations require that the SIP monitoring plan provide for an annual review of the state network. Furthermore, if the annual review indicates that a change in the monitoring system is called for, the state must develop and implement a schedule for modifying the system.

In response to Section 319 of the Act, the regulations also contain a requirement that states report a uniform air quality index to the general public daily. By January 1, 1981, urban areas greater than 500,000 population were required to begin reporting, and by January 1, 1983, all urban areas exceeding 200,000 individuals. As of September 1986, over 100 urban areas were using the PSI.

Air quality data reporting for NAMS must be done on a quarterly basis. Under the requirements of the regulations, validated data must be submitted to EPA within 120 days of the end of the calendar quarter.

Data collected from SLAMS must be summarized annually, certified by the state senior air pollution control officer, and submitted to EPA by July 1 .

In line with congressional requirements, EPA reviews most of its environmental regulations at five year intervals. Therefore, in 1984 EPA, state, and local agencies started a review of the Part 58 air monitoring regulations. In March 1986, revisions to the regulations were promulgated. The revisions were relatively minor resulting in the adoption of the 1980 census as a basis for determination of the NAMS network size, minor modifications to the number of required total suspended particulate (TSP) samplers and sulfur dioxide $\left(\mathrm{SO}_{2}\right)$ monitors according to population size and pollution levels. In addition, some changes in the quality assurance program were made.

Table 1 illustrates the changes in the number of state and local agency air monitors which have taken place between 1977 and 1986 . Overall, the number of monitors has decreased from 9459 in 1977 to 4645 in 1986 for a total reduction of 51 percent. Nitrogen dioxide $\left(\mathrm{NO}_{2}\right)$ and $\mathrm{SO}_{2}$ bubblers and TSP samplers have decreased while continuous monitoring of Ozone $\left(\mathrm{O}_{3}\right)$, Carbon Monoxide ( $\mathrm{CO}), \mathrm{NO}_{2}$ and $\mathrm{SO}_{2}$ remained very stable, 1846 continuous monitors in 1977 versus 1842 monitors in 1986. Table 2 shows the yearly change in the total of SLAMS monitors. The largest changes occurred in 1979 and 1980, a drop of 1530 between 1978 versus 1979 and 1616 between 1979 and 1980. Since 1981, the network has stabilized and the number of monitors is expected to remain close to these levels for the next several years. 
Table 1. Comparison by Pollutant of National Air Monitoring Stations 1977 vs. 1986

\begin{tabular}{lrrr} 
& & \multicolumn{2}{c}{1986} \\
\cline { 3 - 4 } Pollutant & 1977 & SLAMS & NAMS \\
\hline Total Suspended Particulate Matter & 3987 & 2396 & 638 \\
Sulfur Dioxide & 2382 & 547 & 218 \\
$\quad$ Continuous & 600 & 541 & 218 \\
$\quad$ Bubbler & 1782 & 6 & --- \\
Carbon Monoxide & 470 & 447 & 113 \\
Nitrogen Dioxide & 1588 & 252 & 57 \\
$\quad$ Continuous & 234 & 238 & 57 \\
$\quad$ Bubbler & 1324 & 14 & -- \\
Ozone & 542 & 616 & 214 \\
Lead & 490 & 416 & 105 \\
$\quad$ Total & 9459 & 4674 & 1345 \\
& & & \\
\hline *Include NAMS & & & \\
\hline
\end{tabular}

Table 2. National Summary of SLAMS Monitors

\begin{tabular}{cccc}
\hline Year & NAMS & SLAMS & TOTAL \\
\hline 1977 & -- & -- & 9459 \\
1978 & -- & -- & 8800 \\
1979 & -- & -- & 7350 \\
1980 & -- & -- & 5734 \\
1981 & 1277 & 3655 & 4932 \\
1982 & 1354 & 3478 & 4832 \\
1983 & 1351 & 3412 & 4763 \\
1984 & 1347 & 3377 & 4724 \\
1985 & 1344 & 3330 & 4674 \\
1986 & 1345 & 3300 & 4645 \\
\hline
\end{tabular}

\section{NATIONAL PARTICULATE NETWORK}

Currently, at the national level the closest approach to any type of air quality monitoring specimen banking program would be the National Particular Network (NPN). The network is based on the hi-volume sampling (hi-vol) method for particulate matter in the atmosphere. The current network can be traced back to a 1953 cooperative program between the U.S. Public Health Service and 
17 state and local health departments to sample for the protein content of airborne particulate matter [10]. Figure 1 shows the approximate location of the original network. These particulate samples were sufficiently large to allow additional chemical analyses to be added to the original scope of the program. The additional analyses included determinations for acetone or benzene soluble organics, radioactivity, chlorides, fluorides, nitrates, sulfates and 23 metals. Sampling equipment and central laboratory services were provided by the U.S. Public Health Service's Sanitary Engineering Center in Cincinnati, Ohio while state and local organizations provided the personnel for particulate matter sample collection and site operation. As the years passed, additional communities elected to participate in the program expanding it by 66 sampling sites by 1956. Some of these additional sites operated on an every other year or every third year basis. During the early years of operation, the principal objectives for the network were as follows:

1. Determine the extent and nature of air pollution.

2. Study trends in the levels of various atmospheric contaminants.

3. Investigate the relationships between air pollution and socioeconomic, geographic, topographic, meteorological and other factors.

On January 1, 1957, this program was officially named the National Air Sampling Network. Between 1957 and 1961, the network was expanded to 250 stations. Approximately 140 were scheduled to sample every other year leaving 110 operating annually; therefore, about 180 stations were operating during a given year [11]. These operating sites were to collect samples on a randomized biweekly preset schedule. In 1967, the network was renamed the National Air Surveillance Network (NASN). By 1968, the network had grown to about 350 sites, about half of which also operated every year [12]. In December of 1970, the U.S. Environmental Protection Agency (EPA) was formed from several other Federal Programs. The NASN was taken over and has been administered by EPA since that date. During the early 1970's, the sampling frequency for the NASN stations was changed to one sample every 12 th day instead of one biweekly sample and the NASN size remained stable. However, during the $70^{\prime} \mathrm{s}$, the number of TSP hi-vol samplers operated by state and local agencies grew to approximately 3000. The next principal change to the NASN occurred in 1981, when the National Filter Analysis Network was reevaluated and reduced in size to 167. The network was renamed the National Particulate Network (NPN) in 1984. The NPN consisted of 167 sites, 16 of which were rural or background sites, 17 located in vicinity of coking operations to measure benzo[a]pyrene (BaP) and the remaining 134 sites located in urban settings which generally had a population of 150,000 or greater. Since that time, approximately 30 sites have been added to the network for a special study. Some of these sites will be discontinued at the conclusion of the study in 1987 and the resulting network will be approximately 175 sites. Figure 2 shows the approximate locations of the current network. 


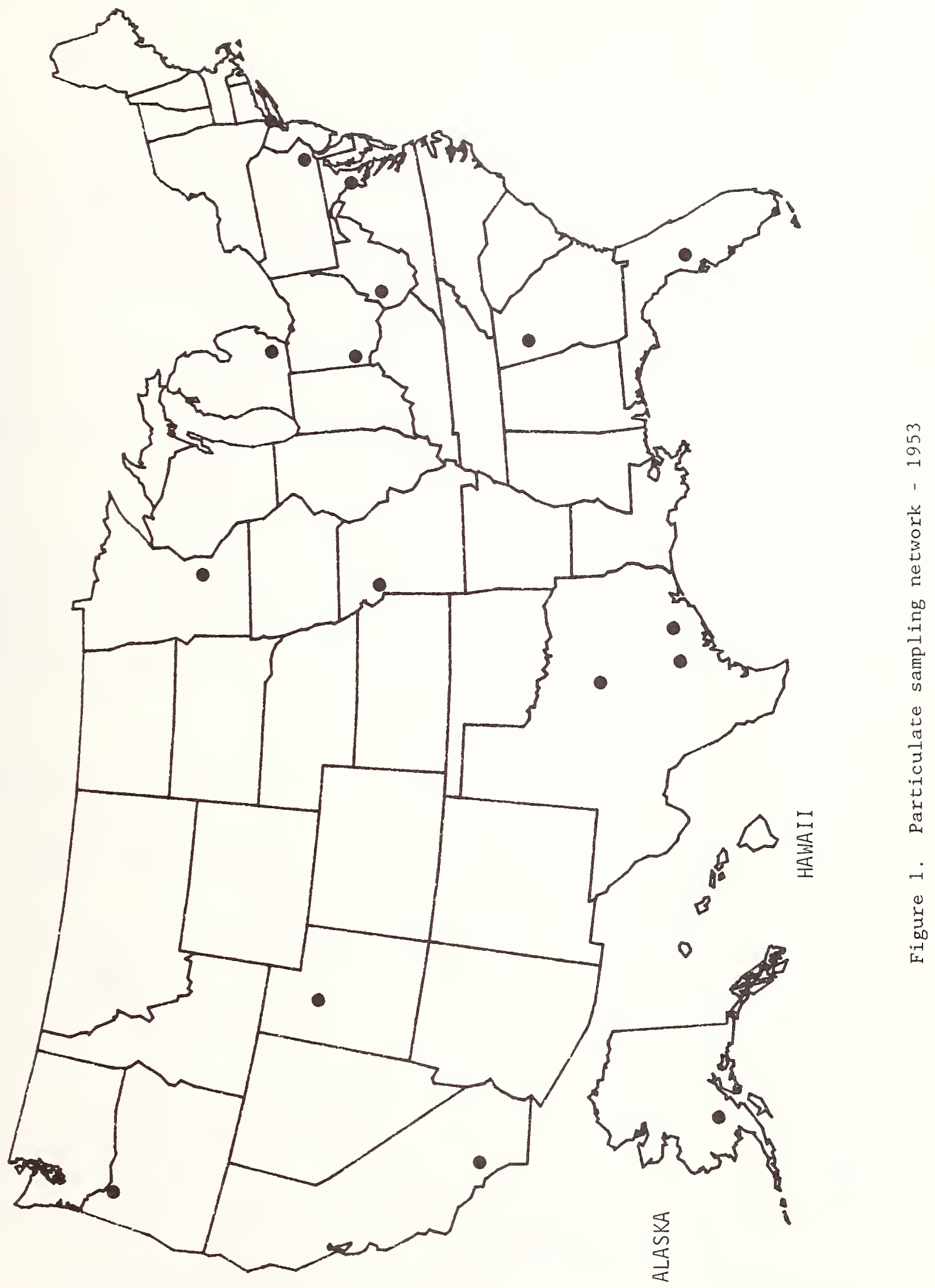




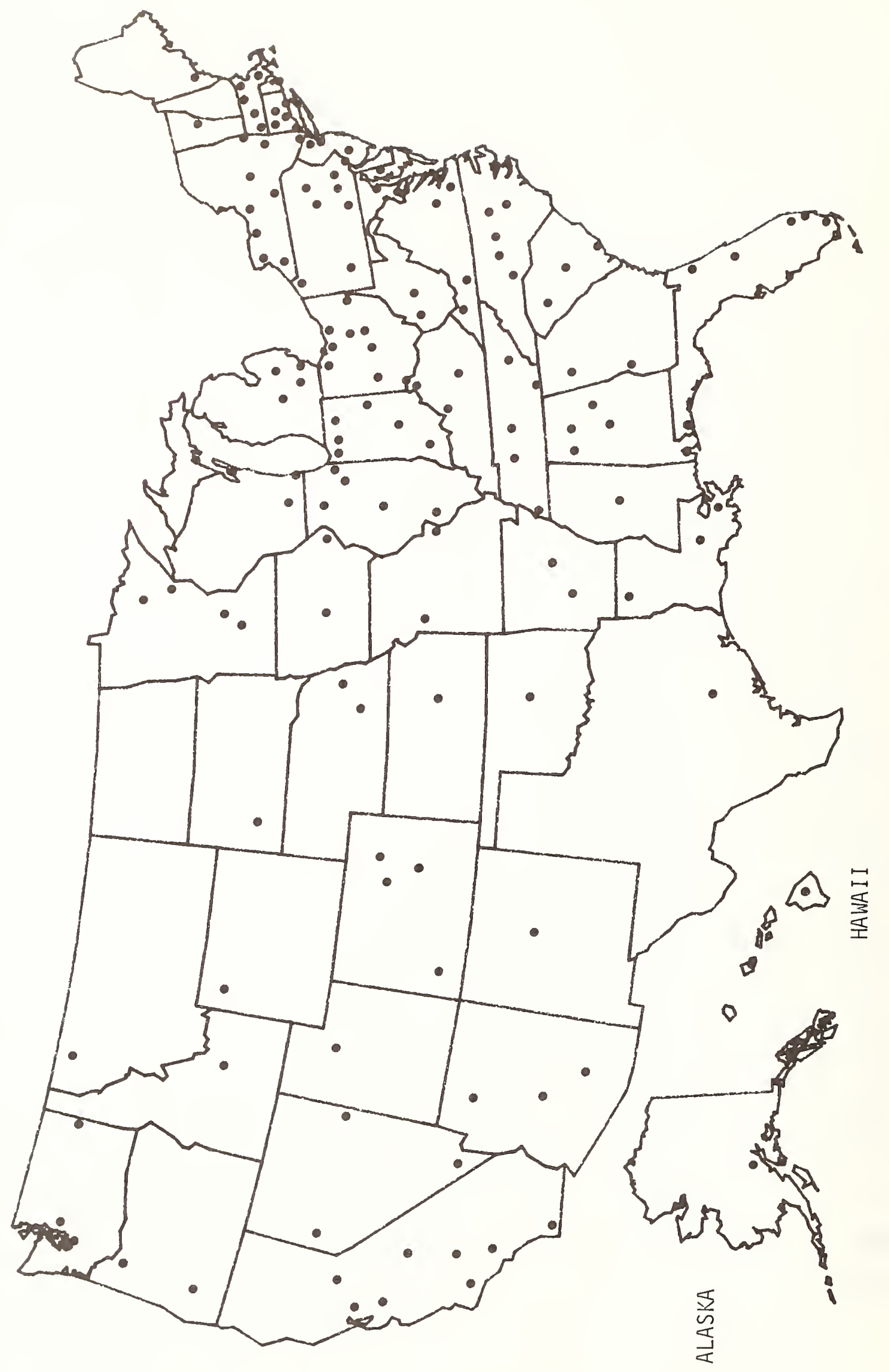

O 
Over the years the pollutants measured have changed, as have analytical methods. Currently, the filters are reanalyzed for arsenic (As), chromium $(\mathrm{Cr})$, cobalt ( $\mathrm{Co}$ ), barium ( $\mathrm{Ba}$ ), beryllium (Be), cadmium ( $\mathrm{Cd}$ ), copper ( $\mathrm{Cu}$ ), iron $(\mathrm{Fe})$, manganese (Mn), molybdenum (Mo), nickel ( $\mathrm{Ni}$ ), lead ( $\mathrm{Pb}$ ), vanadium $(\mathrm{V})$, and zinc $(\mathrm{Zn})$. The filters from 60 of the sites are also analyzed for benzo(a)pyrene $(\mathrm{BaP})$. The differences in pollutants measured were influenced by varying data needs as well as problems with analytical methods, emerging technology, etc.

From the beginning of the NASN program in 1953 until 1982, the unused portion of filters from all stations participating in the program were stored (banked) by the Federal Agency to provide for future retrospective analyses. However, because of storage space availability and funding levels, beginning in 1982, filters are banked for a period of 10 years and then removed from the bank.

It is believed that metal constituents of TSP collected on these filters will remain stable for relatively long periods of time; however, organics and many inorganic compounds are known to decompose over time; therefore, no retrospective analysis for substances other than metals is contemplated. While EPA banks filters only for a period of 10 years, each state and local government agency has its own policy and there may be some of which have filters banked from specific monitoring locations for periods of 20 to 30 years.

\section{REFERENCES}

[1] Clean Air Act as Amended August 1977, Section 110(a)(2)(c), 42 U.S.C. $7410(a)(2)(c)$.

[2] Requirements for Preparation, Adoption, and Submittal of Implementation Plans," Federal Register 36 (158), 15486 (August 14, 1971).

[3] Environmental Monitoring, (1977), A Report to the U.S. Environmental Protection Agency from the Study Group on Environmental Monitoring, National Academy of Sciences, Washington, DC.

[4] A Report to the President and the Congress, National Advisory Committee on Oceans and Atmosphere, Sixth Annual Report, Washington, DC, June 30 , 1977.

[5] Air Monitoring Strategy for State Implementation Plans, EPA-450/2-77-010, U.S. Environmental Protection Agency, Research Triangle Park, N.C., 27711, June 1977.

[6] Environmental Quality, The Eight Annual Report of the Council on Environmental Quality, September 1976.

[7] Air Programs: Ambient Air Quality Monitoring, Data Reporting, and Surveillance Provisions, Federal Register 44 (92), 27558 (May 10, 1979). 
[8] Hoffman, A. J., Sleva, S. F., and Cox, W. M. (1979), "Revised Air Quality Surveillance Requirements for State Implementation Plans, J. Air Poll. Control Assoc. 29, 7, 704-707.

[9] Air Programs: Ambient Air Quality Monitoring, Data Reporting, and Surveillance Provisions," Federal Register 51 (53):9582 (March 19, 1986).

[10] Air Pollution Measurements of the National Air Sampling Network, U.S. Department of Health, Education, and Welfare, Public Health Service, Cincinnati, Ohio, 1958.

[11] Air Pollution Measurements of the National Air Sampling Network, Analyses of Suspended Particulates, 1957-1961, U.S. Department of Health, Education and Welfare, Public Health Service, Cincinnati, Ohio, 1962.

[12] Air Quality Data for 1968 from the National Air Surveillance Networks and Contributing State and Local Networks, U.S. Environmental Protection Agency, Research Triangle Park, N.C., 1972.

[13] Air Quality Data for Metals 1970 through 1974 from the National Air Surveillance Networks and Contributing State and Local Networks, U.S. Environmental Protection Agency, Research Triangle Park, N.C., 1972. 


\section{SECTION 11}

\section{CHEMICALS IN INDOOR AIR}

Istvan Gebefūgi and Friedhelm Korte Gesellschaft für Strahlen- und Umweltforschung mbH

Institut für Ökologische Chemie

D-8042 Neuherberg

FEDERAL REPUBLIC OF GERMANY

\section{INTRODUCTION}

The hygienic importance of air contamination in workplaces has been commonly known for decades. For the protection of workers, maximum concentration limits have been fixed for chemicals whose impact can be damaging to one's health. The so-called maximum workplace concentration values ("MAK"-values) were established. They are valid for the surrounding air at industrial workplaces. Although there is a total body exposure, additional detailed precautions, such as the wearing of gloves and protective clothing or instructions not to eat in the workplace, provide for the highest possible safety.

But there are also burdens in other confined spaces where no handling of chemicals takes place. The substances responsible for this are summed up by the expression "indoor chemicals" and defined as non-occupationally introduced chemicals in confined spaces. In contrast to industrial chemical burdens which are restricted by the above mentioned maximum workplace concentration values, indoor chemicals are up to now not subject to limit regulations. The importance of this lack of regulations is outlined by the fact that people in well industrialized countries spend more than $80 \%$ of their time in confined spaces. The formaldehyde burden in a chipboard factory for instance, is regulated for the workers in the production units by maximum workplace concentration values, but not so for the secretaries in the offices. In schools and homes, where the chipboards can emit formaldehyde, the maximum workplace concentration regulations are not valid and not reasonable. (To complete the picture, it should be mentioned that there exists a recommendation by the German federal health agency saying that in indoor spaces and recreation rooms the formaldehyde concentration in the air should not be above $0.1 \mathrm{ppm}$, approximately a tenth of the maximum workplace concentration value.)

Chemicals can come into indoor air from many different sources. Passive exposure can take place by intake from outside, contamination of the housing ground, building materials with residues, but also household furnishings. Active contamination, e.g., caused by man himself can arise by habits such as smoking as well as the use of household chemicals, sprays, moth deterrents, cleansing, and polishing agents, etc. 


\section{INITIAL INDOOR POLLUTION RESEARCH}

The Institute for Ecological Chemistry of the GSF was asked in 1974 to conduct measurements of halogenated phenols in a home, since it was suspected that these substances, ingredients in some wood protection products, caused symptoms of illness in one of the inhabitants. In the investigated room, the proportion of wood to the remaining surface was $1: 3$. The wood, as the proprietor stated, had been treated according to instructions with a wood protection agent. This product contains, like many others, about $6 \%$ pentachlorophenol (PCP) [1].

First of all, PCP concentrations in the air as well as in nontreated walls, carpets, furniture, etc. were determined. The resulting air concentration of PCP varied between 50 and $100 \mu \mathrm{g} / \mathrm{m}^{3}$. The air analyses were repeated half a year and one year later. The PCP values detected then, were lower and varied between 0.6 and $1.7 \mu \mathrm{g} / \mathrm{m}^{3}$. For these concentration differences, no explanation could be found at first. Incorrect measurements with deviation values higher than a power of ten could be at least considered as improbable, since multiple measurements had been made. In the house concerned, about 20 serial investigations had been made, which agreed with the above mentioned concentration range. In the same house, a flat with a separate entry, which had no wooden parts, by simultaneous measurements showed no PCP content. When the medical symptoms indicating that the illness possibly correlated with the PCP content in the house grew stronger, it was deemed necessary to make comparative measurements in another building. This, we thought, might lead to an understanding of the great variations of PCP content in the air.

As a model room for this study, a closed hall (swimming baths, $6 \times 12 \mathrm{~m}$ ) was selected. The walls and the ceiling were wood panelled yielding a treated wooden surface around $210 \mathrm{~m}^{2}$. The swimming baths were furnished with a heat pump so that no outdoor air could get in. The condensed water of the heat pump was available for analytical investigations.

The wood in the hall had been treated according to instructions with another wood protection product that has about the same PCP content as the one used in the above mentioned house. Inside the room, air temperature, humidity and air exchange could be held constant for a certain time. Two investigations of four weeks each were carried out. The results can be interpreted to indicate that at least humidity is an important factor affecting the PCP concentration in the indoor air.

\section{SUMMARY OF THE FIELD AND MODEL STUDIES}

Detectable PCP and TCP values in non-treated samples lead to the conclusion that after treatment with wood protection products containing pentachlorophenol, a contamination of all objects within a confined space is inevitable. The values measured in plaster, wood and in other objects vary between $0.2-26.0 \mathrm{mg} / \mathrm{kg}$ for $(P C P)$ and $0.4-5.5 \mathrm{mg} / \mathrm{kg}$ for 2,3,4,6-tetrachlorophenol (TCP). Consequently, they are contamination sources by themselves. In addition, it is sure that PCP, TCP and other chlorinated attendant substances in wood protection products are transported in the air. The model studies 
proved a certain correlation between PCP air contamination and humidity. However, by knowing the room temperature and the humidity content, the concentration values cannot be predicted (see Figure 1).

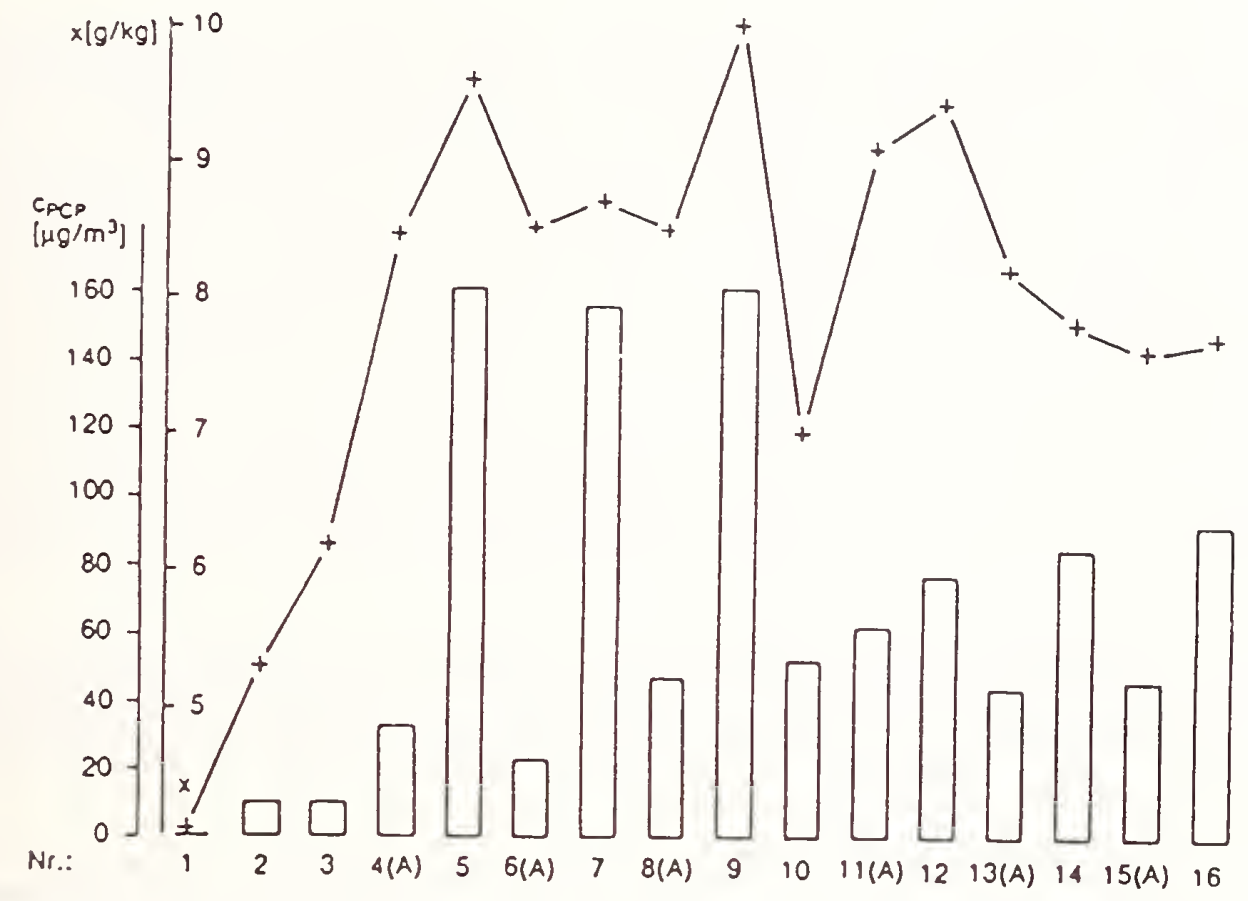

Figure 1. Correlation between air humidity and PCP-concentrations in a model experiment

The humidity can be considered as a type of "solvent" for PCP, so that the variations in PCP values can be explained as the result of varying extraction yields. It can be stated as a fact, however, that the vapor emission and uptake in the system influences these variations. Increasing the temperature causes an increase in the diffusion velocity of pentachlorophenol.

For a better ranking of the data from the field and model studies, case studies were carried out on selected objects. The aim was to determine clearly the contamination and to detect by close analysis as well as by model experiments the paths of non-industrial exposition in confined spaces.

\section{CASE STUDIES}

For the case studies, private households were selected where a massive use of material protection agents containing pentachlorophenol and lindane had taken place. In the most part, information was available about ways, amount, and time of application. The two chemicals mentioned above served as model substances for these studies because of their wide spread use and their sensitive analytical characteristics. The well-known and highly toxic 
impurities of technical pentachlorophenol, i.e., polychlorinated dibenzodioxins and dibenzofurans, were also intended to be included in the study.

\section{A. Case A}

Family A lives in a wood house which the family has been renovating mostly in a 'do-it-yourself' style since 1975. In the course of those efforts, about 200 L of wood protection products containing pentachlorophenol and lindane had been applied not only to the beams, walls (outside and inside), and doors, but also to a great part of the furniture, too. Shortly after application of the chemical agents, all four members of the family complained of being ill. Skin rashes, headaches, concentration weakness, and hair loss were the symptoms. These complaints have been growing stronger until the present time, especially with one person.

Since regular wood protection products contain about $6 \%$ pentachlorophenol and about $1.5 \%$ lindane, nearly $12 \mathrm{~kg}$ pentachlorophenol and $3 \mathrm{~kg}$ lindane had been used within this house. All inhabitants claimed that the symptoms mentioned disappeared during longer absence from the house, e.g., on holidays.

In spite of the wood samples' high content of pentachlorophenol and lindane (beams of the atelier and living room), only small concentrations were detected in the air. If the risk assessment in this flat would have been made only according to the air concentration values, one must have had to qualify the concentrations as harmless.

The textiles out of this flat, however, were all highly contaminated. Since these textiles consisted mainly of clothing and bed linen, i.e., substances worn close to the skin, it was confirmed that uptake of the chemical does not only take place via inhalation but via direct skin contact, especially after a longer time following application. The blood samples taken for comparison showed relatively low values.

\section{B. Case B}

In this case, the application of the wood protection product had taken place in 1976. No detailed information about the amount or type of the product could be provided. The blood investigation had been made at a time when none of the six members of the family lived any longer in the contaminated flat. An air measurement was not carried out.

The wood samples in this case showed high contents of pentachlorophenol and lindane too. A strong contamination of the whole home had occurred. House dust and textile samples showed high pentachlorophenol values. In this case also, the conclusion was that exposure to the chemical was due to direct skin contact. Accordingly, high pentachlorophenol values could be detected in the blood. 


\section{Cases C, D, AND E}

These three cases also showed the same findings. The air samples were very low contamination; often the chemicals were not even detectable in the room air.

The wood samples as the indoor sources of the chemicals often showed high concentrations of pentachlorophenol and lindane even after ten years. A spreading around in the whole flat had taken place. Apparently, the biocidal active agents accumulate strongly on wood and cotton (case E).

In contrast, the concentrations on mixed tissues and pure synthetics are about a factor of 10 lower. A risk assessment with the help of blood samples should not be recommended based on our investigations since broad variations did not provide a relevant correlation to the concentrations in indoor spaces.

\section{MODEL EXPERIMENTS FOR INVESTIGATING THE BEHAVIOR OF PENTACHLOROPHENOL AND LINDANE IN CONFINED SPACES}

To verify the observed high contamination of textiles, model experiments were performed [2,3]. Boxes the size of $50 \times 50 \times 50 \mathrm{~cm}$ served as model rooms. They were made of untreated pinewood, the bottom covered by a $2 \mathrm{~mm}$ aluminum sheet and the top consisting of a $0.50 \mathrm{~cm}$ thick glass plate the size of $50 \times 50$ $\mathrm{cm}$.

Into the model room six cotton strips were inserted. Onto the side walls the active agents PCP and lindane had been applied under reproducible conditions. An air exchange rate of about 1.6 was arranged. The temperature was $20{ }^{\circ} \mathrm{C}$, the relative humidity $45 \%$. These circumstances are the standard for a not specifically heat insulated flat. As can be seen from Figure 2, pentachlorophenol and lindane accumulate on the cotton. For pentachlorophenol, an increase of up to $24.8 \mu \mathrm{g} / \mathrm{g}$ cotton can be observed after 225 hours. After that time an equilibrium seems to have been established. This equilibrium concentration of pentachlorophenol on cotton amounts to about $20 \mu \mathrm{g} / \mathrm{g}$. For lindane, saturation is established after only 70 hours with an equilibrium concentration of about $6 \mu \mathrm{g} / \mathrm{g}$ cotton.

The concentration profile of both substances in the air escaping from the box is contrary. The PCP concentration is rising for about 50 hours to a value of $430 \mathrm{ng} / \mathrm{m}^{3}$, and then decreases to below $100 \mathrm{ng} / \mathrm{m}^{3}$. The lindane concentration in the air escaping the box is higher than that of PCP; although, the concentration on the cotton is lower.

\section{ANALYSIS OF THE TOXIC IMPURITIES IN SAMPLES OF WOOD, HOUSE DUST, AND TEXTILES}

In four cases, samples of wood, house dust, and textiles were analyzed for chlorinated dibenzodioxins and dibenzofurans. In all cases, highly chlorinated dibenzodioxins and dibenzofurans could be identified definitely in the wood. The concentrations are at the low ppb level. In three cases, these compounds 


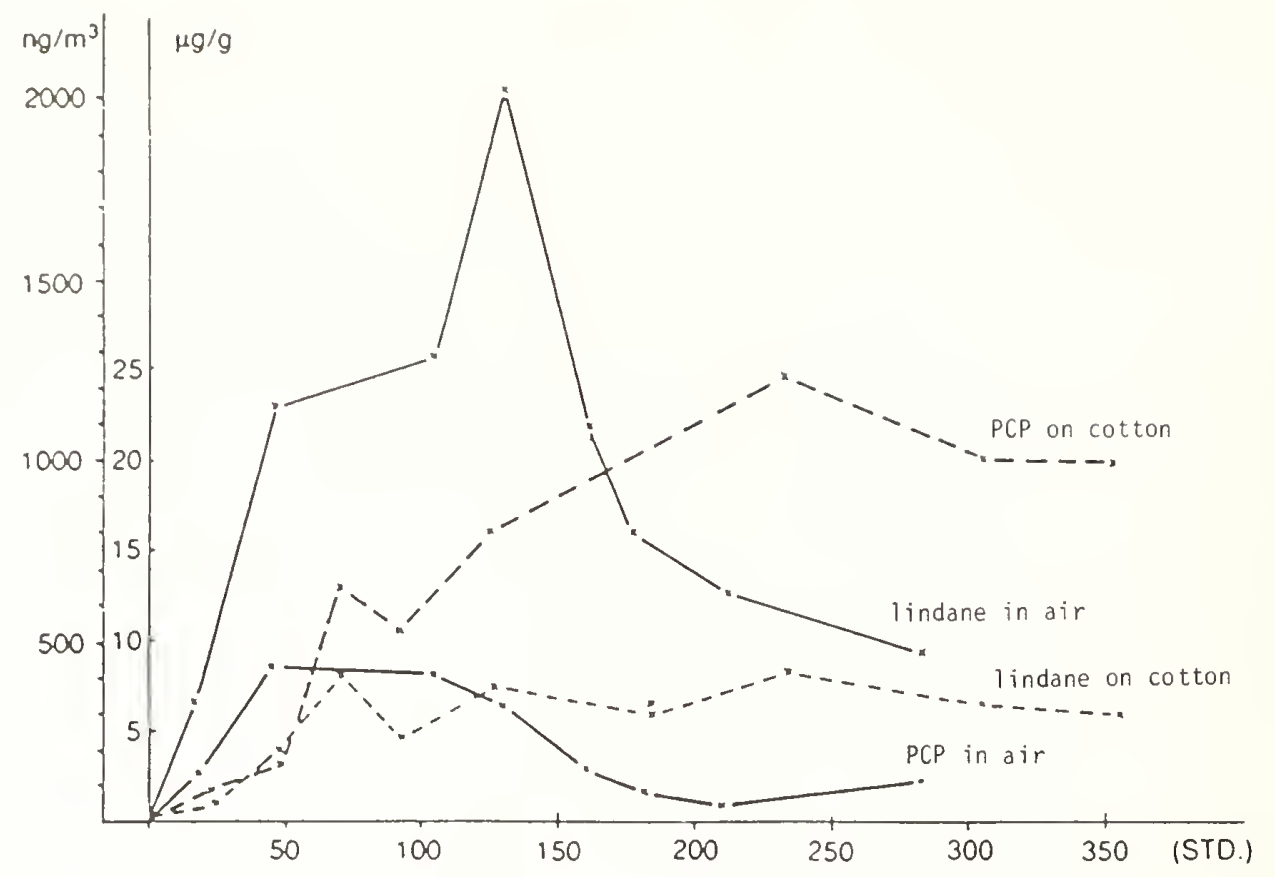

Figure 2. Lindane and pentachlorophenol accumulation on cotton surface

could also be found in the house dust. These compounds also seem to be spread via air in the treated homes [4]. In the textiles analyzed, the concentrations were below the detection level. The results of these analysis are listed in Table 1.

\section{CONCLUSIONS}

As a result of the case and model studies, it can be concluded that in indnor spaces, chemicals which are less volatile than $10^{-2}$ mbar, accumulate on surfaces, especially textiles. The contamination of persons staying indoors takes place not only directly via air (inhalation). Skin contact with contaminated surfaces can lead to a significant additional burden. The so-called total body intake of the chemicals in indoor spaces is possibly more relevant than inhalation. The results of the case studies seem to confirm this. By analyzing PCP impurities, a contamination of house dust with octachlorodibenzodioxin could be detected. Therefore, a contamination of inhabitants in rooms treated with wood protection products with toxic impurities of PCP could be classified as probable. 
Table 1. Pentachlorophenol, Lindane, Chlorinated Dibenzodioxin and Dibenzofuran in Samples of Wood, Dust, and Textiles

\begin{tabular}{lcccc}
\hline & $\begin{array}{c}\text { OCDD } \\
(\mathrm{ng} / \mathrm{g})\end{array}$ & $\begin{array}{c}\text { OCDF } \\
(\mathrm{ng} / \mathrm{g})\end{array}$ & $\begin{array}{c}\text { PCP } \\
(\mu \mathrm{g} / \mathrm{g})\end{array}$ & $\begin{array}{c}\text { Lindane } \\
(\mu \mathrm{g} / \mathrm{g})\end{array}$ \\
\hline Wood 1: & 10.5 & 32.8 & 826.0 & -- \\
Dust 1: & -- & -- & 1.46 & -- \\
Textile 1: & -- & -- & 1.20 & -- \\
Wood 2: & ++ & ++ & 376.0 & 12.5 \\
Dust 1: & 4.2 & 8.7 & 16.2 & 2.4 \\
Textile 2: & -- & -- & 2.3 & 0.89 \\
Wood 3: & 71.0 & -- & 8.4 & 3.62 \\
Dust 3: & ++ & ++ & 7.0 & -- \\
Textile 3: & -- & -- & 3.26 & 1.1 \\
Wood 4: & 27.8 & 45.0 & -- & 15.3 \\
Dust 4: & -- & -- & -- & 8.4 \\
Textile 4: & -- & -- & -- & 2.6 \\
\hline
\end{tabular}

\section{REFERENCES}

[1] Gebefügi, I., Parlar, H., and Korte, F. (1979), Occurrence of Pentachlorophenol in Enclosed Environments, Ecotox. Environ. Safety 3, $269-300$.

[2] Gebefügi, I. and Korte, F. (1984), Indoor Contamination of Household Articles Through Pentachlorophenol and Lindane, Indoor Air 4, 317-322.

[3] Ruh, C., Gebefügi, I., and Korte, F. (1984), The Indoor Biocide Pollution, Occurrence of Pentachlorophenol and Lindane in Homes, Indoor Air 4, 309-315.

[4] Gebefügi, I. (1986), Chemikalienbelastung in Innenräumen, Arcus Review for Architecture and Science 4, 172-176. 
SECTION 12

\title{
BANKING OF ATMOSPHERIC PARTICULATE MATTER SAMPLES FOR LONG-TERM MONITORING OF ATMOSPHERIC POLLUTION AND RELATED REFERENCE MATERIAL AT THE NATIONAL INSTITUTE FOR ENVIRONMENTAL STUDIES
}

\author{
Yoshinari Ambe, Hitoshi Mukai, and Kensaku Okanoto \\ Division of Chemistry and Physics \\ National Institute for Environmental Studies (NIES) \\ Yatabe-Machi, Tsukuba, Ibaraki 305 \\ JAPAN
}

\section{INTRODUCTION}

The idea of environmental specimen banking can be applied to many kinds of environmental samples including atmospheric samples [1,2]. The distinguishing characteristics of atmospheric samples compared to other environmental samples are: (1) high variability, both spatial and temporal, which presents a problem for representability of the sample, (2) the amount of matrix is high and the concentration of pollutant is low, therefore, large volume sampling and highly sensitive analytical methods are needed, and (3) reactions with light, oxidants, container walls, etc., which lead to sample handling problems.

Of the three phases of atmospheric samples --- gas, rain, and particulate matter ---, the storage of gaseous samples is most difficult from a practical standpoint because it not only requires a large space for storage, but there are also many problems with the sample stability, e.g., reactions with other components, adsorption on the container wall, etc.

We selected atmospheric particulate matter samples collected on filters as a most promising sample for specimen banking related to atmospheric pollution. Using these samples, we started a small pilot specimen banking program a few years ago to systematically collect samples and preserve them for future retrospective analysis. In addition to particulate matter, rain and snow samples were collected although not so systematically, and are also stored in the bank.

Parallel to the banking program, a storage study on the stability of benzo[a]pyrene in the atmospheric particulate matter on the filter is in progress. It was revealed that a part of the benzo[a]pyrene in the samples disappeared during storage. In connection with the above program, we prepared an environmental reference material for the analysis of particulate matter which is representative of vehicle exhaust particles. The outline of the preparation of this reference material is presented in this paper.

\section{PILOT PROGRAM FOR BANKING ATMOSPHERIC PARTICULATE MATTER SAMPLES AT NIES}

The atmospheric particulate matter samples stored in the bank for a long time can be used for the following purposes: 
1. To monitor the occurrence of new pollutants especially new man-made chemicals in the atmosphere.

2. To analyze old samples by future improved analytical techniques.

3. To record a more precise trend of long-term air pollution by simultaneously analyzing a series of samples.

4. To repeat analysis of past samples when any problems occurs in the future.

5. To analyze retrospectively presently unnoticed atmospheric pollutants.

The following are the conditions needed for the stored samples to be available for the above mentioned uses $[1,2]$.

1. The relevant constituents in the samples at the time of sampling should be preserved both qualitatively and quantitatively for several decades.

2. The samples to be stored should be meaningful as indicators of change in the environment.

3. The origin and the history of the samples should be well recorded.

In order to realize an effective and appropriate banking program for atmospheric particulate matter samples, the following items should be studied.

1. Relating to Sample Collection

a. Sampling sites (distribution, height)

b. Sampling time and duration

c. Sampling method

i. Sampler (high volume sampler, low volume sampler, Andersen sampler)

ii. Filter (membrane, glass fiber, quartz fiber, metal, etc.)

d. Sample amounts

e. Sample transportation

2. Relating to Sample Storage
a. Sample size
b. Container (size, form, material)
c. Light condition
d. Humidity
e. Temperature
f. Atmosphere (air, other gases)
g. Pretreatment 
h. Storage room

i. Storage duration

3. Relating to Storage Management

\section{a. Registration system}

b. Storage room capacity

i. Amounts of samples

ii. Replacement of samples

c. Countermeasures for accidents (stoppage of electricity, fire, earthquake, and other natural disasters)

After having considered the problems mentioned above and the preliminary results of the storage experiment described in the next chapter, a small pilot program for long-term storage of atmospheric particulate matter samples was initiated at the National Institute for Environmental Studies (NIES) in Japan in 1983. The purpose of this program was to examine the availability and usefulness of stored samples for monitoring long-term changes of atmospheric pollution by retrospective analysis of stored sample materials.

For organic substances in the atmospheric particulate matter other than polycyclic aromatic hydrocarbons ( $\mathrm{PAH}$ ), the information on the long-term stability is very scanty. Some estimates, however, on the stability may be possible from considerable other information, such as chemical characteristics, chemical structure, stability in short-term storage, etc. Though storage at $-20{ }^{\circ} \mathrm{C}$ is not always the perfect condition to preserve organic substances, this condition of storage was selected mainly for practical reasons. As the concentrations of heavy metals and other elements, other than volatile ones like $\mathrm{Hg}$, are considered to be stable for a long time, the stored filter samples can be used to monitor the pollution by such substances. The outline of this program is as follows (Figure 1).

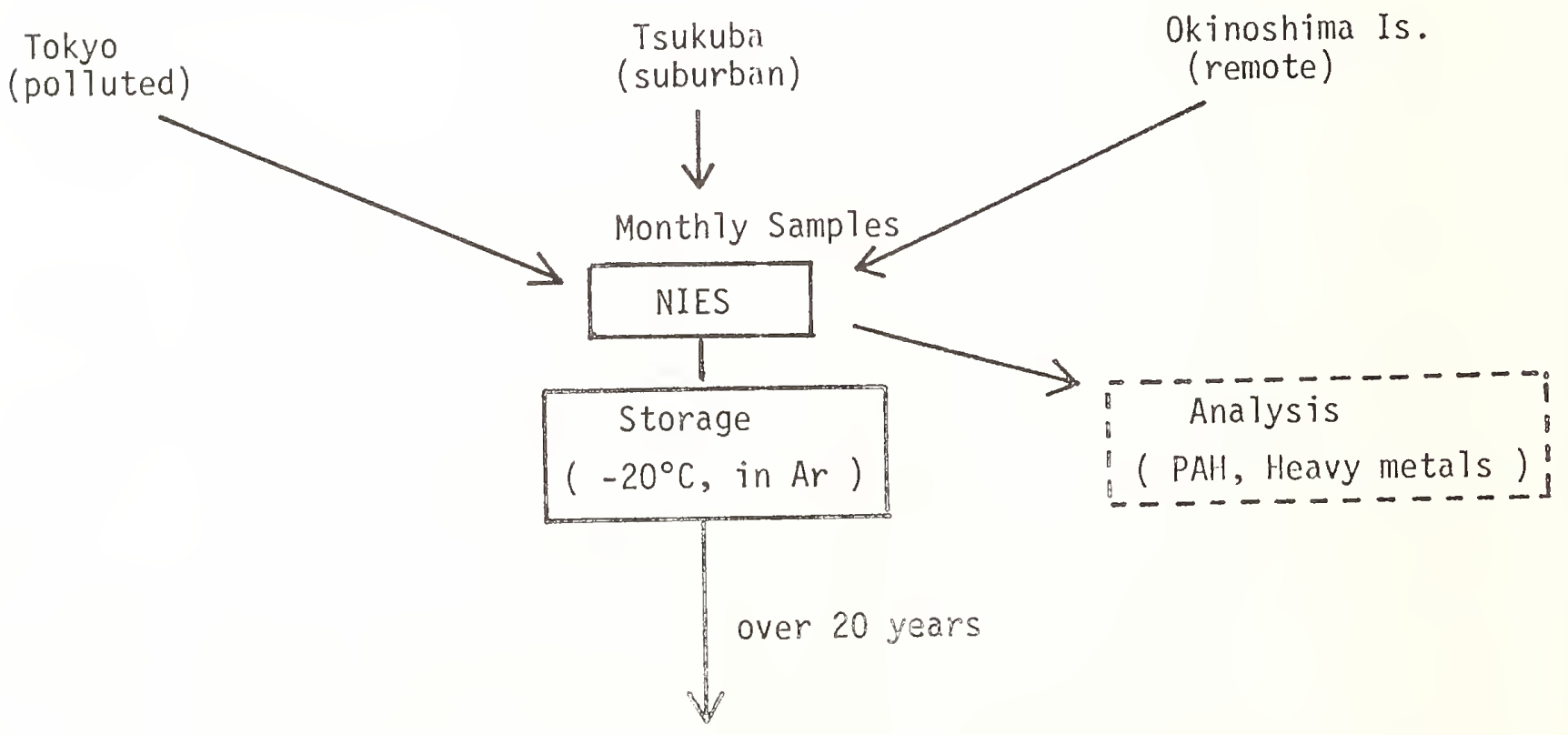

Figure 1. Banking program of atmospheric particulate matter samples 


\section{A. Sample Collection}

Atmospheric particulate matter is collected using a high volume air sampler on a quartz fiber filter on the first day of each month at Tsukuba, a suburban area which is located $50 \mathrm{~km}$ northeast of Tokyo.

At Okinoshima Island, which is a rural and remote area lying in the Japan Sea as shown in Figure 2, samples are collected at the top of a mountain (300 m high) for a month on a filter with low volume air samplers. Sampled filters are sent by mail to Tsukuba where storage facilities exist.

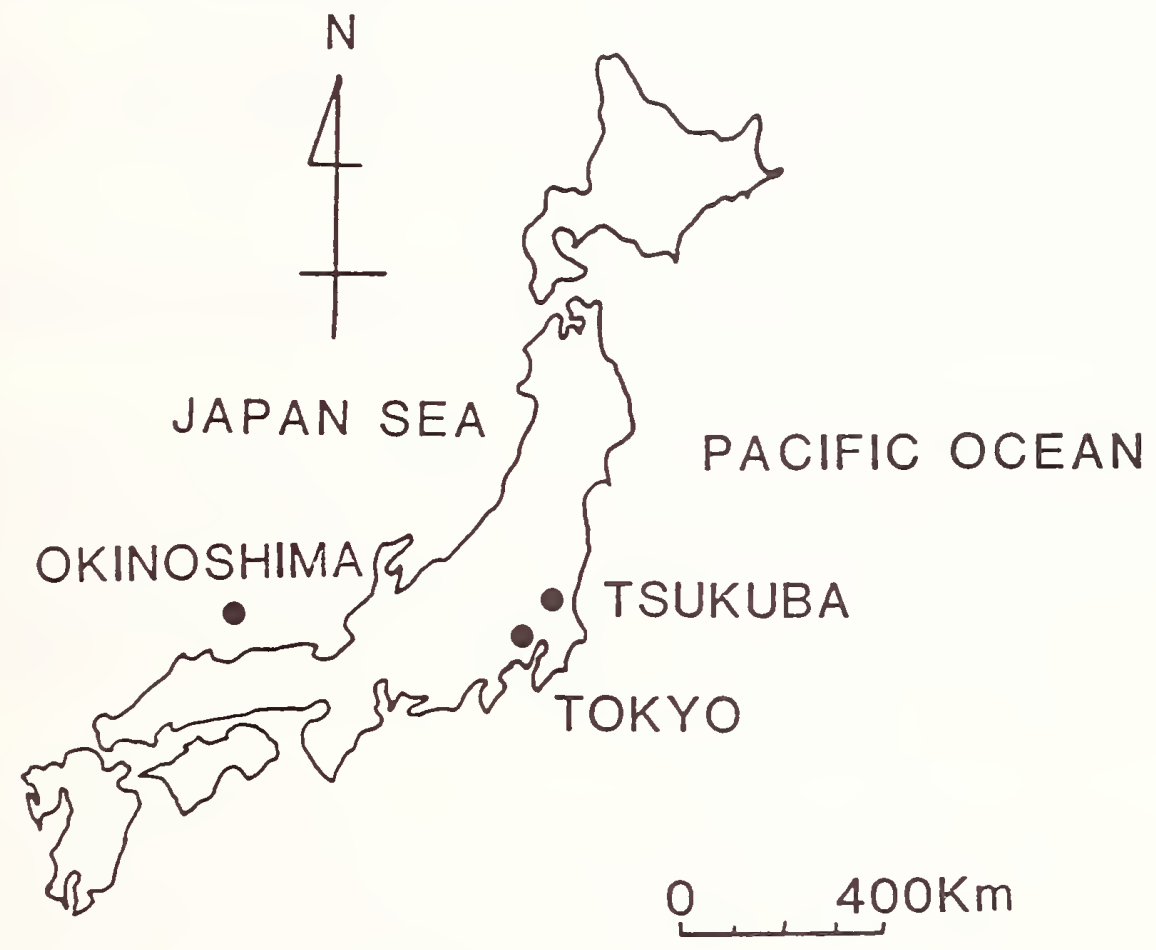

\section{Sampling Locations}

Figure 2. Sampling locations

Samples are also collected in a highly polluted urban area in Tokyo using high volume air samplers. This sampling program is planned to continue for 20 years and the number of sampling sites is expected to increase in the near future.

\section{B. Storage of Collected Samples}

Prior to storage, the collected sample filters are registered and a part of the sample is used to determine $\mathrm{PAH}$, heavy metals, and other pollutants for real-time monitoring of atmospheric pollution. The major part of the sample is placed on a stainless steel plate $(20 \mathrm{~cm} \times 25 \mathrm{~cm})$ and stored in a airtight stainless steel plate box $(30 \mathrm{~cm} \times 30 \mathrm{~cm} \times 50 \mathrm{~cm})$ filled with argon gas to 
prevent oxidation. The container box is placed in the $-20{ }^{\circ} \mathrm{C}$ storage room to store for a long period as an environmental sample bank.

C. Sample Registration And Management

All the necessary information on each sample such as the characteristics of the sample, sampling conditions, and storage conditions are recorded on a card and stored in a personal computer.

\section{Storage of Rainwater And Snow Samples}

In addition to atmospheric particulate matter, rain water, and snow samples, which are occasionally collected from various regions, are also stored at $-20{ }^{\circ} \mathrm{C}$ condition. Polypropylene bottles and glass bottles are used as containers for these samples.

\section{STABILITY OF BENZO[A]PYRENE IN THE STORED ATMOSPHERIC PARTICULATE MATTER SAMPLES}

Information on the stability of pollutants in the atmospheric samples during long-term storage over months is scanty. However, as to the stability of $\mathrm{PAH}$ (polycyclic aromatic hydrocarbons) in atmospheric particulate matter on the filters during sampling, several studies have indicated that some degradation of PAH occurs on the filters presumably affected by UV-radiation, $\mathrm{NO}_{3}, \mathrm{O}_{3}$ and other oxidants in the atmosphere [3-8]. Tomingas [3] reported that nearly $50 \%$ of benzo[a]pyrene collected on glass fiber filters disappeared after one year's storage at room temperature.

These results suggest that protection from such factors is necessary for long-term storage of $\mathrm{PAH}$ in atmospheric particulate matter. In this study, an experiment was conducted on the long-term stability of benzo[a]pyrene, as a representative $\mathrm{PAH}$ in the atmospheric particulate matter on the sampling filter, under several storage conditions to examine the suitability of the storage method.

\section{A. Experimental Section}

\section{Samples}

Atmospheric particulate matter was sampled at the roadside near Shijuku Gyoen Park, Tokyo in June, 1982. The road had heavy vehicular traffic and a high content of particulate matter and $\mathrm{PAH}$ derived from vehicle exhaust gas was expected in the samples. Samples were collected on four sheets of quartz glass fiber filter (Palliflex 2500 QAOT) and the air was sampled for $70 \mathrm{~h}$ using four sets of high volume air samplers simultaneously which were set side by side. Sampling was repeated twice to prepare two series of sample filters having different contents of particulate matter and benzo[a]pyrene.

From one sheet of sampled filter $(20 \mathrm{~cm} \times 25 \mathrm{~cm}), 12$ pieces of small discs ( $5 \mathrm{~cm}$ diameter) were cut out as analytical samples using a stainless steel punch. 


\section{Analytical Procedure}

The analytical sample filter disc was folded and dissected into $5 \mathrm{~mm}$ wide strips with stainless steel scissors and put into a $10-\mathrm{mL}$ centrifuge tube. After adding $10 \mathrm{~mL}$ of acetonitrile and extracting ultrasonically for 15 minutes, the solvent was centrifuged for $7 \mathrm{~min}$ (300 rpm). The extracted benzo[a]pyrene in the supernatant solvent was determined by HPLC coupled with a fluorescence detector under the following conditions [9-12]:

\section{Instrument: HPLC (Waters 700A)}

Column: $\quad \mu$-Bondapak $\mathrm{C}_{18}$ (i.d. $1 / 8$ in. $\mathrm{x} 1 \mathrm{ft.}$ )

Solvent: acetonitrile/water $80 / 20$

Flow Rate: $\quad 2.0 \mathrm{~mL} / \mathrm{min}$

Detector: fluorescent detector (Hitachi 10LC) (excitation wavelength $366 \mathrm{~nm}$, fluorescence emission wavelength $403 \mathrm{~nm}$ )

The analytical result was expressed as benzo[a]pyrene weight per weight (ppm) of atmospheric particulate matter. The weight was made constant in the room with 508 relative humidity and a temperature of $20{ }^{\circ} \mathrm{C}$.

\section{$\underline{\text { Storage Experiment }}$}

The experiment was designed to check the effects of temperature and oxygen on the stability of benzo[a]pyrene in the samples during storage under the following four conditions:

(1) $+20{ }^{\circ} \mathrm{C}$ in air

(2) $+20{ }^{\circ} \mathrm{C}$ in argon gas

(3) $-20{ }^{\circ} \mathrm{C}$ in air

(4) $-20{ }^{\circ} \mathrm{C}$ in argon gas

The sample filters were placed on a stainless steel plate $(20 \mathrm{~cm} \times 25 \mathrm{~cm}$ ) and placed in airtight stainless steel boxes $(30 \mathrm{~cm} \times 30 \mathrm{~cm} \times 50 \mathrm{~cm}$ ) filled with air or argon gas and stored in the $20{ }^{\circ} \mathrm{C}$ or the $-20{ }^{\circ} \mathrm{C}$ storage room. Twelve pieces of analytical sample filter discs were stored under each of the four conditions and two discs each were programmed to be taken out from each container to measure benzo[a]pyrene after 6 months, 1 year, 2 years and 4 years from the start of the experiment. The determination was repeated twice for each analytical sample disc and two series of samples with different benzo[a]pyrene content, which were sampled at different times, were used in this experiment.

Since the similarity of the stored samples at the start of the experiment is essential for the comparison of the analytical results at a later date to determine whether a change in the samples has occurred, the homogeneity of the distribution of benzo[a]pyrene in the sample filters was examined prior to the storage experiment. 


\section{B. Results And Discussions}

\section{Recovery of Analysis and Blank Test}

The recovery of benzo[a]pyrene in this analytical method was examined by adding a small amount of benzo[a]pyrene solution on the filters and analyzing by the same procedure. The percent of recovery was above $92 \%$ for each run. The blank value of the filter for benzo[a]pyrene was $0.0 \mathrm{ppm}$.

Distribution of Particulate Matter and Benzo[a]pyrene Concentration on the Sampled Filter

The coefficient of variance of the weights of particulate matter of 12 analytical sample discs cut from one sheet of filter was 1.48 and that of benzo[a]pyrene was $4.5 \%$, both showing nearly homogeneous distribution on the filter. The concentrations of benzo[a]pyrene on four sheets of filters were approximately equal as shown in Table 1. This also gave a reliable homogeneity in the samples at the time of the start of the experiment.

Table 1. Comparison of the Concentration of Benzo[a]pyrene in the Simultaneously Sampled Four Filters. Sampling was Repeated Twice (1st and 2nd run)

\begin{tabular}{cll}
\hline Sampler No. & 1st run & 2nd run \\
\hline 1 & $5.2 \mathrm{ppm}$ & $8.4 \mathrm{ppm}$ \\
2 & 5.2 & 8.6 \\
3 & 5.4 & 8.2 \\
4 & 5.2 & 8.7 \\
Mean & $5.3 \mathrm{ppm}$ & $8.5 \mathrm{ppm}$ \\
C.v. & 2.98 & 2.28 \\
\hline
\end{tabular}

\section{Storage Experiment}

Table 2 summarizes the analytical results of benzo[a]pyrene concentration in the atmospheric particulate matter at the time of the start of the experiment, after 6 months, 1 year, 2 years, and 4 years, for each series of samples stored under each of four storage conditions. The duplicate analysis for each disc agreed within $\pm 2 \%$. The trends of changes expressed as percentage of the initial values (100\%) are illustrated in Figure 3. The two series of samples tested gave nearly similar results, both decreasing in their benzo[a]pyrene concentrations according to the storage conditions.

The average rate of decrease of benzo[a]pyrene during the test period (4 years) was higher for the samples stored at $20{ }^{\circ} \mathrm{C}$ decreasing to about $35 \%$ of the initial value. The samples in $-20{ }^{\circ} \mathrm{C}$, on the other hand, were both reduced on the average by $12 \%$ of the initial values. Thus, the effect of the difference of temperature was significant. The difference of the atmosphere in 


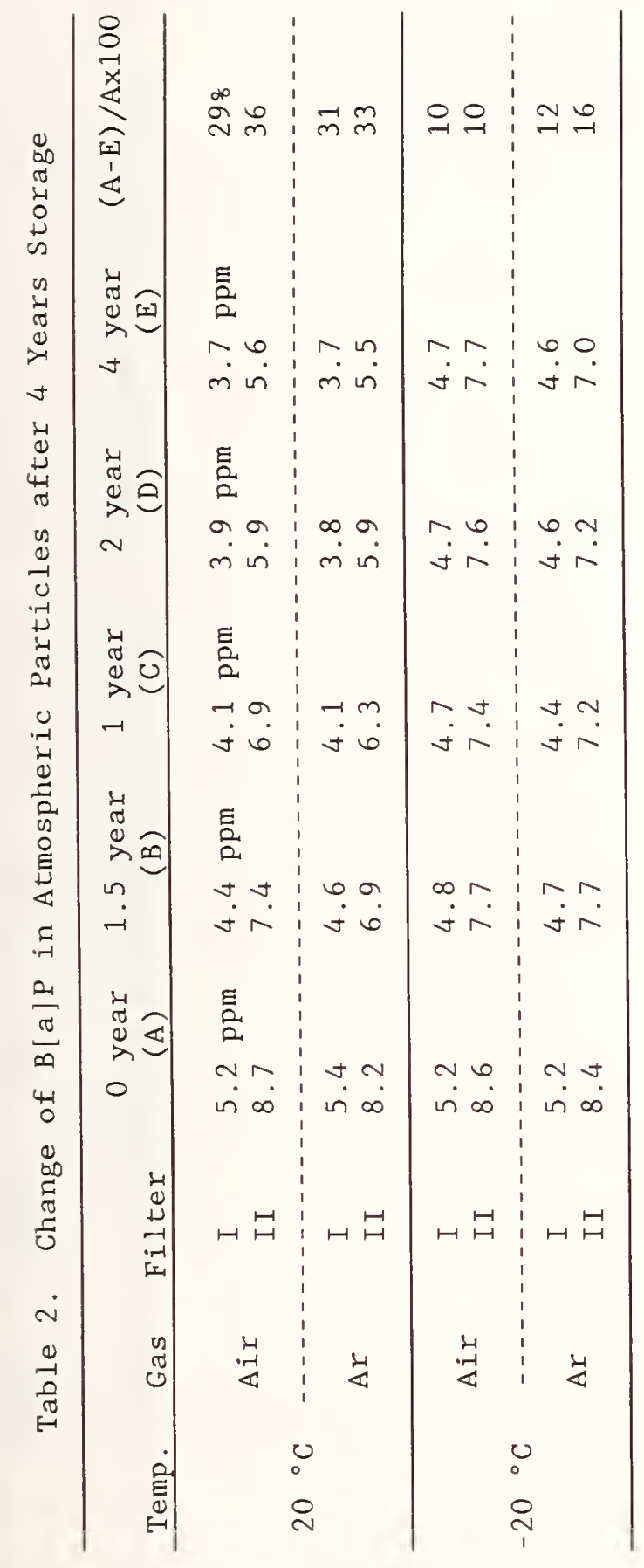




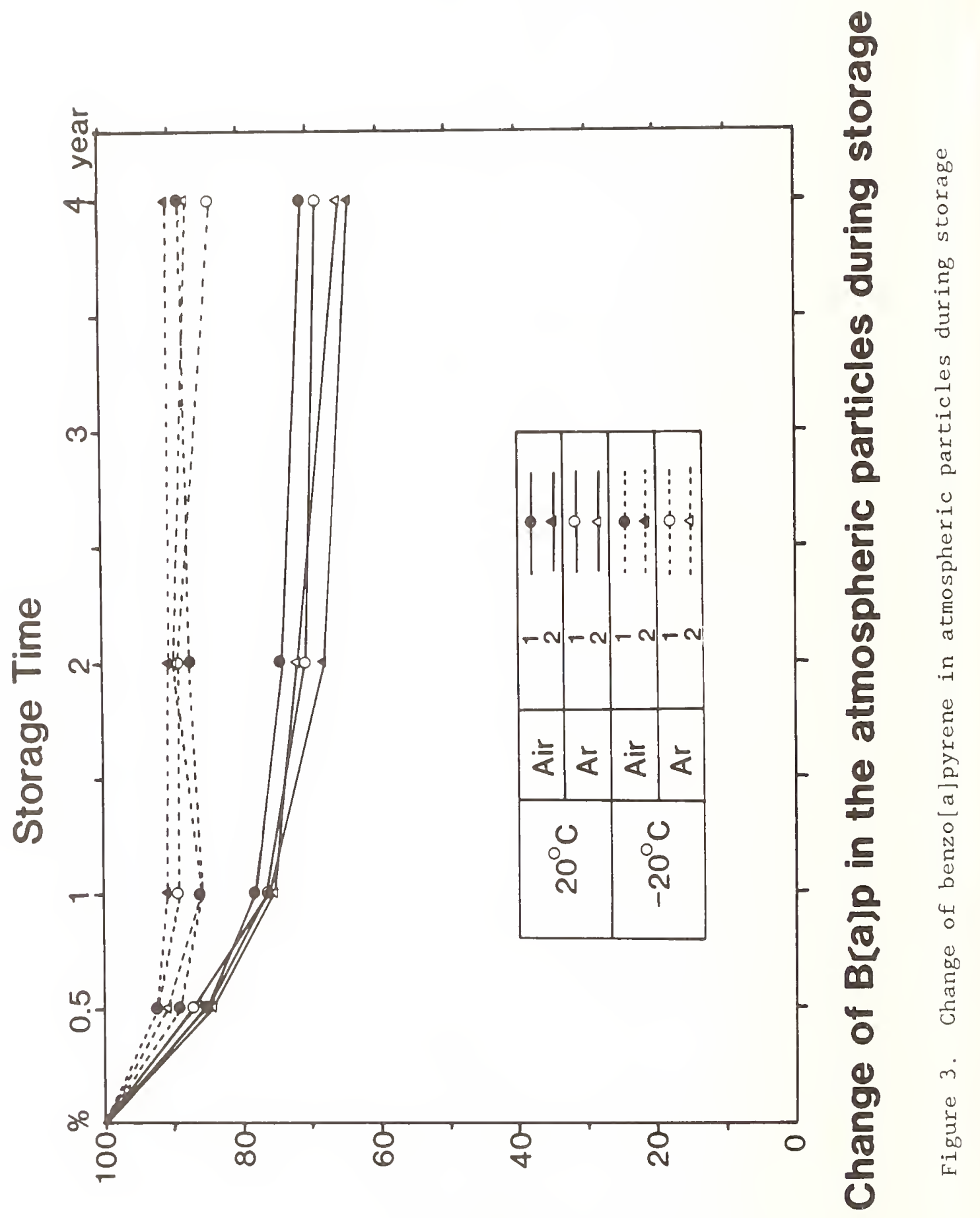


the storage box did not show any remarkable effect in this experiment; but, a problem still remains as to whether the substitution of air by argon gas was complete or not; further studies are needed.

The reasons for the decrease of benzo[a]pyrene in this experiment cannot be explained adequately. The box was closed and dark inside, no effect of light can be considered to have occurred. From these differences in the behavior of benzo[a]pyrene in the different temperature conditions, it is proposed that some bacteriological or chemical reactions may have occurred other than the decomposition by the reaction with oxygen or oxidants, assuming that none of the benzo[a]pyrene could escape by evaporation.

A rapid decrease in the initial stage is remarkable for the storage both at $20{ }^{\circ} \mathrm{C}$ and $-20{ }^{\circ} \mathrm{C}$. The difference between the rate of decrease during the first 6 months and that of the following periods is remarkable as shown in Figure 3, which shows that in the first 6 months' storage the rate of decrease was approximately twice that in the next 6 months and during the following 1 year the rate of decrease became almost zero under the $-20{ }^{\circ} \mathrm{C}$ condition, whereas under the $20{ }^{\circ} \mathrm{C}$ condition the concentration still decreased by several percent. These results suggest that benzo[a]pyrene in atmospheric particulate matter consists of an easily changeable part and stable part at $-20{ }^{\circ} \mathrm{C}$.

The experiment is still going on and the final results will be obtained after one or two additional years. From the results obtained so far, it was concluded that the storage method applied in our storage program does not preserve the sample completely, but as the rate of reduction of benzo[a]pyrene after 6 months is quite low, at least $80 \%$ of the initial amount is expected to be preserved after 20 years storage and the samples can be utilized for a retrospective analysis.

As to other organic substances in the atmospheric particulate material, the information on the long-term preservability is very limited, and similar experimental studies will be needed to increase the usefulness of the stored samples.

\section{PREPARATION OF ENVIRONMENTAL REFERENCE MATERIAL "VEHICLE EXHAUST PARTICULATES"}

The National Institute for Environmental Studies (NIES) has prepared several kinds of environmental reference materials. One of the newest ones is "NIES No. 8 Vehicle Exhaust Particulates," which will be of use as a reference for the analysis of elemental composition of atmospheric particulate matter samples. In spite of increasing demand for various types of reference materials of atmospheric particulate matter in many areas of environmental sciences, the availability of such reference materials has been limited to only the three Standard Reference Materials issued by the U.S. National Bureau of Standards (SRM 1648, "Urban Particulate Matter" for trace element; SRM 1649, "Urban Dust Organics; " and SRM 1650, "Diesel Particulate Matter" for organics), probably because of the difficulty in the collection of sufficient amounts of material. Under these circumstances, the preparation of a new type of atmospheric particulate reference material, which is closely related to 
automobiles pollution problems, has been undertaken at NIES in cooperation with Keio University.

\section{A. Sample Collection and Preparation}

The material used for this reference material was collected from electrostatic precipitators in huge ventilators connected to a highway tunnel. The electrostatic precipitators were placed behind moving cloth filters and the contribution from pavement material and soil was small in the collected samples. About $7 \mathrm{~kg}$ of the material was used for the preparation of this reference material.

During preparation procedures, special care was taken when handling such a large amount of potentially hazardous material. Because this material readily produced a dust cloud and had an irritating smell of gasoline, it was treated under wet conditions whenever possible, for safe operation with respect to occupational health and danger of explosion.

After examining three methods to prepare a homogeneous and easy-to-handle material safely, a "paste-granule" method was adopted making a paste with ethanol. About $300 \mathrm{~g}$ of the material and 1 liter of $35 \%$ ethanol were mixed well in a 10-L polyethylene container. After repeating this mixing procedure for the remaining samples, all mixtures were combined together in a large polyethylene tray, mixed again, and air-dried for 2 weeks.

The material was transferred to aluminum trays, dried in an air-oven at $60{ }^{\circ} \mathrm{C}$ for about 5 days and crushed into fine powder in polyethylene bags with a wooden hammer. After passing though a $2 \mathrm{~mm}$ nylon screen, the powder was mixed again in a 30-L polyethylene bottle by rolling it on a ball-mill apparatus. The mixed powder was packaged into small gas bottles ( $7 \mathrm{~g}$ each).

\section{B. Homogeneity Assessment}

A homogeneity test of the final product was performed by acid-dissolution followed by inductively coupled plasma emission and atomic absorption analyses. Six bottles were randomly selected from the lot of 1000 bottles and 5 aliquots (about $300 \mathrm{mg}$ each) were taken from each bottle (total 30 samples).

For the elements $\mathrm{Ca}, \mathrm{Al}, \mathrm{Na}, \mathrm{K}, \mathrm{Zn}, \mathrm{Mg}, \mathrm{P}, \mathrm{Pb}, \mathrm{Sr}, \mathrm{Cu}, \mathrm{Cr}, \mathrm{Ni}, \mathrm{V}$, Co and $\mathrm{Cd}$, variations between bottles were not significant. For Fe, Ti, and Mn on the other hand, between-bottle variations were significant, though the reason for this inhomogeneity is not clear.

\section{Sample Dissolution}

Certified values for this reference material are issued based on analyses of the entire samples. Decomposition procedures, therefore, should be designed to achieve complete dissolution of the material. 
The dissolution procedure used at NIES was as follows:

Weigh $300 \mathrm{mg}$ of the sample into a Teflon PTFE 100-mL beaker. Add $5 \mathrm{~mL}$ of concentrated nitric acid, cover with a Teflon PTFE watch glass and heat at $160{ }^{\circ} \mathrm{C}$ for $3 \mathrm{~h}$ on a hot-plate. After cooling, add $5 \mathrm{~mL}$ of perchloric acid and heat at $180^{\circ} \mathrm{C}$ for $8 \mathrm{~h}$ with the cover on. After washing the inside of the beaker with distilled water, add another $5 \mathrm{~mL}$ of perchloric acid and continue to heat at $200{ }^{\circ} \mathrm{C}$ for $8 \mathrm{~h}$ with the cover on, until the contents become a yellow clear solution. Remove the Teflon cover and add $5 \mathrm{~mL}$ of hydrofluoric acid to dissolve the small amount of remaining residues. Heat the contents at $200{ }^{\circ} \mathrm{C}$ to near dryness. After cooling, add a small volume of warm distilled water and $0.5 \mathrm{~mL}$ of nitric acid, transfer the contents quantitatively to a 50-mL polypropylene bottle and dilute it 100-fold with distilled water. Thus, $300 \mathrm{mg}$ of sample is diluted to $30 \mathrm{~g}$ of solution.

\section{Certified Values for Vehicle Exhaust Particulates Reference Material}

The initial stage of this certification process requires analytical data for the various elements to be obtained by independent and established analytical techniques. At NIES, the analyses of the vehicle exhaust particulate reference material were carried out by atomic absorption spectrometry, flame emission spectrometry, inductively coupled plasma emission spectrometry and spectrophotometry. Collaborative studies on the elemental analysis of the Vehicle Exhaust Particulate sample have been performed by 20 participating laboratories. The analytical data obtained by isotope dilution mass spectrometry, neutron activation analysis and spectrofluorimetry and by the above mentioned techniques were provided by the collaborating laboratories.

Table 3 shows the certified and reference values for NIES Vehicle Exhaust Particulates reference material. The certified values are based on results of determinations by at least three independent analytical techniques. Technical considerations and statistical outlier tests were first applied and the certified value is the mean of the acceptable values. Certified values are provided for $\mathrm{Al}, \mathrm{As}, \mathrm{Ca}, \mathrm{Cd}, \mathrm{Co}, \mathrm{Cr}, \mathrm{Cu}, \mathrm{K}, \mathrm{Mg}, \mathrm{Na}, \mathrm{Ni}, \mathrm{Pb}, \mathrm{Sb}, \mathrm{Sr}, \mathrm{V}$ and $\mathrm{Zn}$, while reference values are reported for $\mathrm{Ag}, \mathrm{Br}, \mathrm{Ce}, \mathrm{Cs}$, Eu, La, Lu, Mo, P, Rb, $\mathrm{Sc}, \mathrm{Se}, \mathrm{Sm}$ and Th. The elemental composition of NIES Vehicle Exhaust Particulates CRM is considered typical of automobile emission particulates. The NIES Vehicle Exhaust Particulates CRM is available in bottles containing $7 \mathrm{~g}$ on request from NIES [13]. 
Table 3. Analytical Values for NIES Certified Reference Material No. 8 "Vehicle Exhaust Particulates"

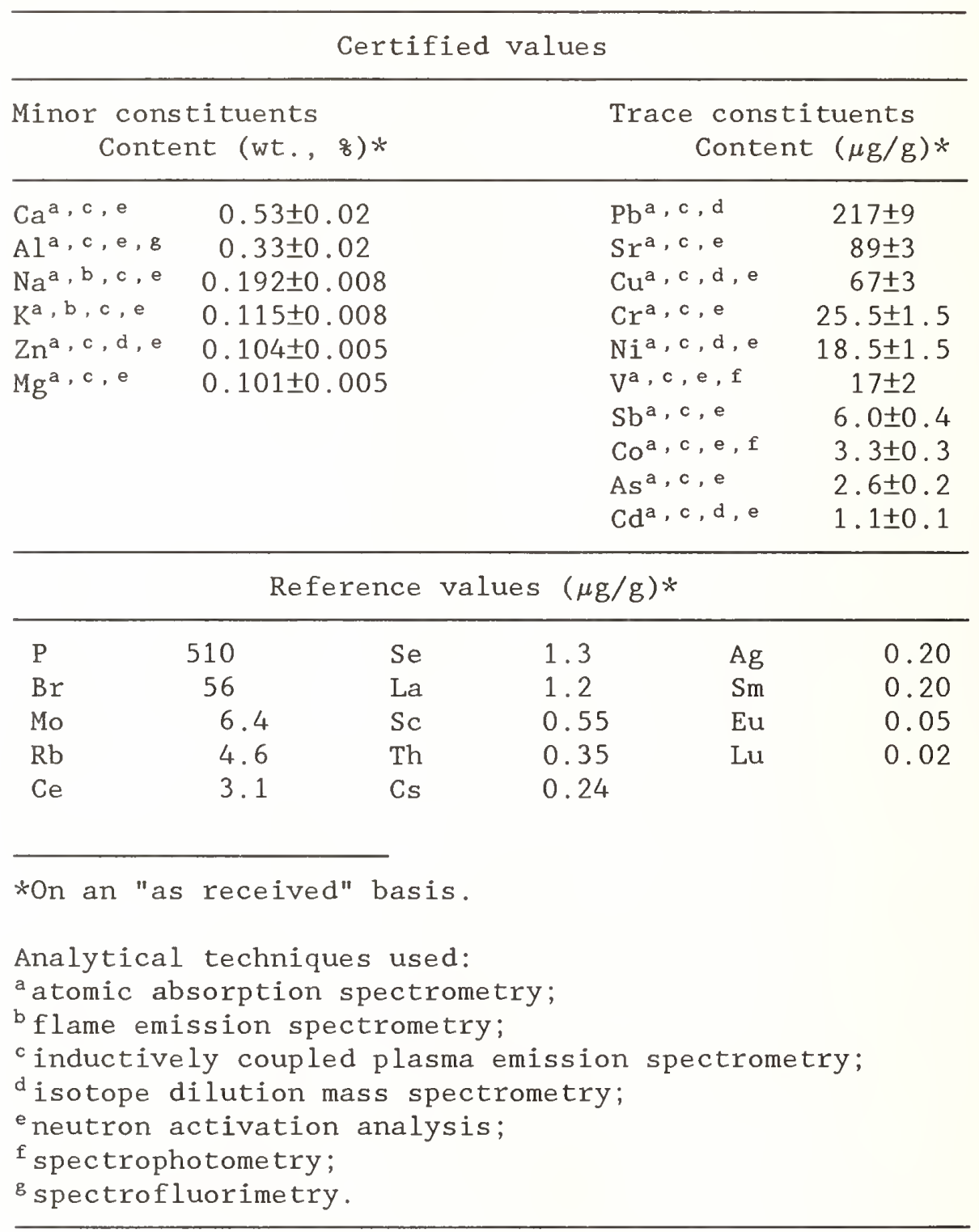

\section{REFERENCES}

[1] Luepke, N. P., Ed. (1979), Monitoring Environmental Materials and Specimen Banking, Martinus Nijhoff Publishers, The Hague, 591 pp.

[2] Lewis, R. A., Stein, N., and Lewis, C. W., Ed. (1984), Environmental Specimen Banking and Monitoring as Related to Banking, Martinus Nijhoff Publishers, Boston, MA, 358 pp. 
[3] Tomingas, R. (1979), Remarks on the Sampling Procedures for Polycyclic Aromatic Hydrocarbons from the Atmosphere, Fresenius. Z. Anal. Chem. 297, 97-101.

[4] Peters, J. and Siefert, B. (1980), Losses of Benzo[a]pyrene Under the Conditions of High Volume Sampling, Atmos. Environ. 14, 117-119.

[5] Grosjean, D., Fung, K., and Harrison, J. (1983), Interactions of Polycyclic Aromatic Hydrocarbons with Atmospheric Pollutants, Environ. Sci. Tech. 17, 673-679.

[6] Cimberle, M. R., Bottino, P., and Valerio, F. (1983), Decomposition of Benzo[a]pyrene Deposited on Glass Fiber Filters and Exposed to Sunlight, Chemosphere 12, 317-324.

[7] Nikolaou, K., Masclet, P., and Mouvier, G. (1984), Sources and Chemical Reactivity of Polynuclear Aromatic Hydrocarbons in the Atmosphere, Sci. Total Environ. 32, 103-132.

[8] Galasyn, J. F.., Horing, J. F., and Soderberg, R. H. (1984), The Loss of PAH from Quartz Fiber High Volume Filters, J. Air Pollut. Control Assoc. $34,57-59$.

[9] Fox, M. A. and Staley, S. W. (1976), Determination of Polycyclic Aromatic Hydrocarbons in Atmospheric Particulate Matter by High Pressure Liquid Chromatography with Fluorescence Technique, Anal. Chem.48, 992-998.

[10] Matsushita, H., Arashiya, K., and Handa, T. (1975), Simple Microanalysis of Benzo[a]pyrene in Air Suspended Particulates Using Ultrasonic Extraction, Bunseki Kagaku 25, 264-268.

[11] Das, B. S. and Thomas, G. H. (1978), Fluorescence Detection in High Performance Liquid Chromatographic Determination of Polycyclic Aromatic Hydrocarbons, Anal. Chem. 50, 967-973.

[12] May, W. E., Chelser, S. N., Hertz, H. S., and Wise, S. A. (1982), Analytical Standards and Methods for the Determination of Polynuclear Aromatic Hydrocarbons in Environmental Samples, Inter. J. Environ. Anal. Chem. 12, 259-275.

[13] Okamoto, K. (1987), A New Certified Reference Material, Vehicle Exhaust Particles, Anal. Sci. 3, 191-192. 
SECTION 13

\title{
ANALYSIS OF PAH IN AIR SAMPLES OBTAINED BY LONG- AND SHORT-TERM PROCEDURES
}

\author{
J. Jacob, G. Grimmer, K.-W., Naujack, and G. Dettbarn \\ Institute for Environmental Carcinogens \\ D-2070 Grosshansdorf \\ FEDERAL REPUBLIC OF GERMANY
}

\section{INTRODUCTION}

When the pilot phase of the German Environmental Specimen Bank was started, the terrestrial and aquatic environment were represented by various kinds of specimens. However, the matrix air was not addressed mainly for technical reasons, since no adequate and reliable sampling procedures seemed to be available at that time. It was expected that broad basic studies had to be carried out before air samples could become a regular matrix for the bank.

One of the goals of specimen banking is to correlate human diseases with pollution, and one of the best known examples for this is human lung cancer. According to a study of the Department of Epidemiology and Statistics of the American Cancer Society about $83 \%$ of the lung cancers in the United States may be attributed to tobacco smoking, and there are some strong indications that air pollution also plays an important role as a risk factor for this disease. It can be expected that emissions, at least from coal combustion and from vehicles, contribute considerably to the carcinogenesis in the human lung. There are various classes of compounds that might be responsible for this such as polycyclic aromatic hydrocarbons ( $\mathrm{PAH}$ ), nitroaromatics, thiaarenes, asbestos, etc. As a result of these emissions, the importance of air as a matrix for an environmental specimen bank is obvious.

At least as far as $\mathrm{PAH}$ are concerned, there are various problems associated with air sampling related to the volatility of the lower-boiling compounds, which may result in re-evaporation of already collected compounds from the filter, and to the sensitivity of some $\mathrm{PAH}$ against $\mathrm{NO}_{\mathrm{x}}$, ozone, sulfur dioxide, and other photooxidants resulting in irreversible destruction. These reactions form compounds which are possibly even more biologically active than the original $\mathrm{PAH}$, such as nitro-PAH, ketones, aldehydes, peroxides and quinones, about which we know very little at the moment - analytically as well as biologically.

In this paper some preliminary data are presented on the different PAHconcentrations as found after long-term and short-term sampling.

\section{EXPERIMENTAL SECTION}

Air sampling was performed with commercially available instruments. For sample sizes of $15 \mathrm{~m}^{3} / \mathrm{h}$, a LIB-instrument was used equipped with glass fiber filters of $113 \mathrm{~cm}^{2}$ and $500 \mathrm{~cm}^{2}$ surface possessing a separation degree of 99.998\% for particles with a diameter of 0.3-0.5 $\mu \mathrm{m}$. For sample sizes of 2-2.3 
$\mathrm{m}^{3} / \mathrm{h}$ a small filter instrument Derenda $\mathrm{GS} / 050 / 3$ with a $12.5 \mathrm{~cm}^{2}$ filter was used. To check the volatility of PAH, a subsequent Porapak PS filter was used. The clean up is schematically represented in Figure 1.

Filter, extracted with toluene + internal standard

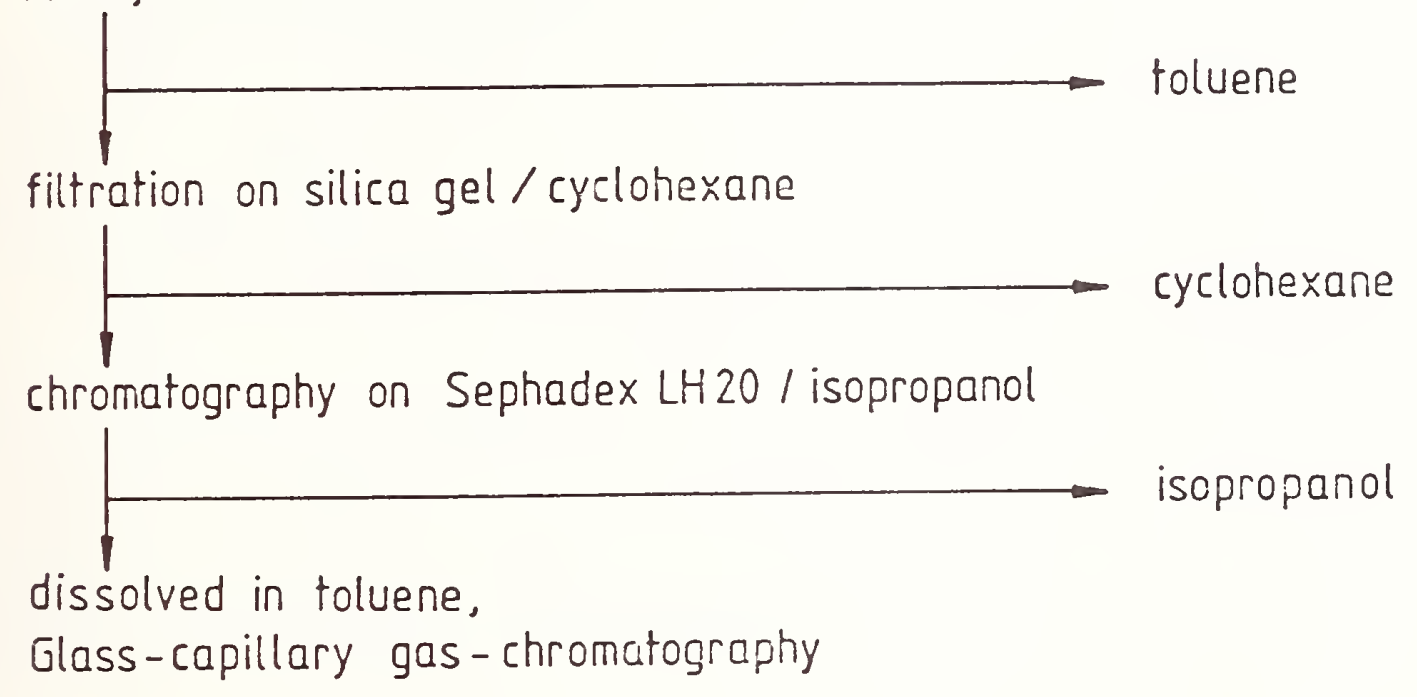

Figure 1. Schematic representation of the PAH-profile analysis of air suspended matter

\section{RESULTS AND DISCUSSION}

A first set of results was obtained from an urban area predominantly polluted by domestic and industrial heating, a coke plant and to a lesser extent by vehicle exhaust. Two samples were collected in parallel: the first was obtained after a $24 \mathrm{~h}$ collecting period using one filter for a total of 326 $\mathrm{m}^{3}$ air equal to $13.6 \mathrm{~m}^{3} / \mathrm{h}$. The second sample consisted of 24 subsamples each obtained after one hour collecting during the same period. In this experiment, between 11 and $13 \mathrm{~m}^{3} / \mathrm{h}$ air passed through each of the filters. In Figures 2 and 3, the time dependence of various PAH concentrations are shown. All compounds follow the same trend despite the different chemical reactivities which can be expected for the various PAH. (Note: No specifically low values for benz[a]anthracene or dibenz[a,h]anthracene were found, although both are sensitive anthracenoid structures.)

A first maximum appears between 6 and 7 o'clock a.m., followed by a second one at 9 a.m.; these maxima may be attributed to the morning rush hours. A huge maximum then is observed at $5 \mathrm{p} . \mathrm{m}$. and there is also a maximum at about 12 a.m. 


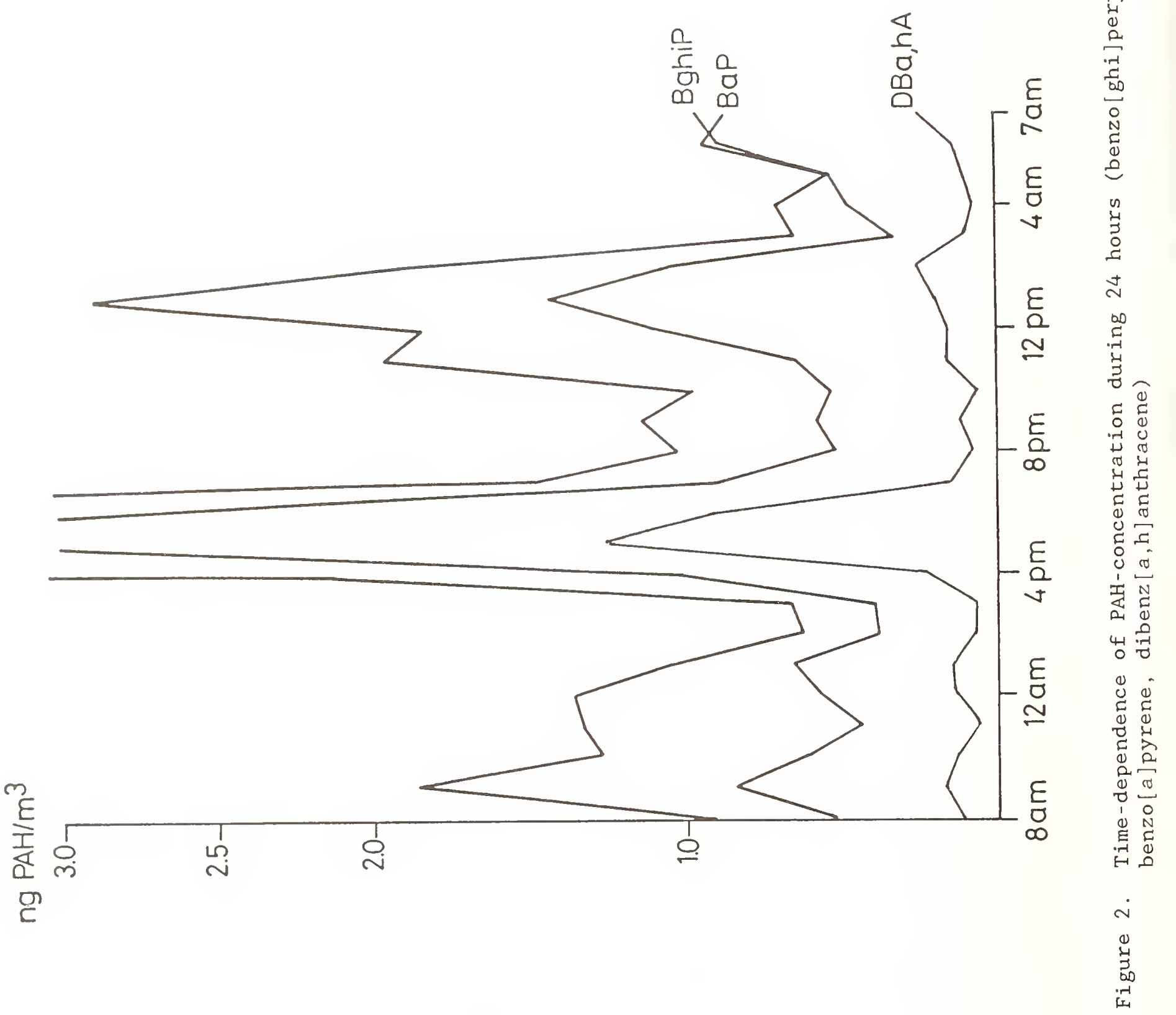




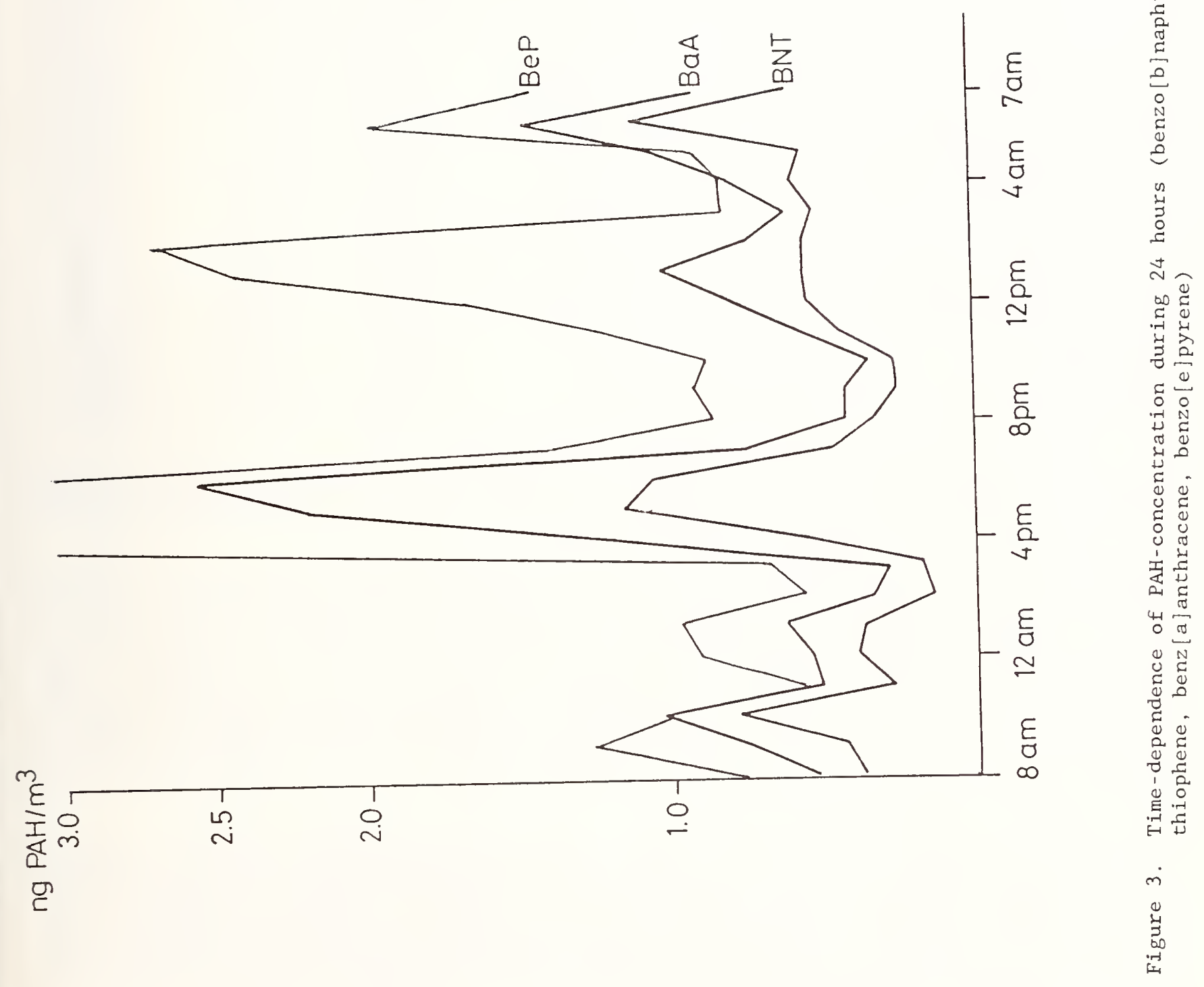


Of greater interest is the comparison of the sum of the 24 single onehour samples and the long-term sample $(24 \mathrm{~h})$. On the basis of a $100 \%$ separation for the short-term (one hour) collection, which is not completely realistic for the low-boiling compounds, a significant decrease of the recoveries for the lower-boiling compounds was observed, as shown in Table 1.

Table 1. PAH Profiles on Air Particulate Filters (ng $\mathrm{PAH} / \mathrm{m}^{3}$ )

\begin{tabular}{|c|c|c|c|c|}
\hline $\begin{array}{c}\text { Sample } \\
\text { Volume }\left(\mathrm{m}^{3}\right)\end{array}$ & b.p. $\left({ }^{\circ} \mathrm{C}\right)$ & $\begin{array}{c}1 \\
24 \times 1 \mathrm{~h} \\
277.16 \\
\end{array}$ & $\begin{array}{r}2 \\
1 \times 24 h \\
326.39 \\
\end{array}$ & $\begin{array}{l}\text { Yield } 2 \\
\text { Rel. to } 1 \\
\end{array}$ \\
\hline Fluoranthene & 384 & 1.31 & 0.50 & 38.28 \\
\hline Pyrene & 394 & 1.12 & 0.33 & 29.58 \\
\hline Benzo[b] naphtho[d,2-1] thiophene & 430 & 0.52 & 0.15 & 28.88 \\
\hline Benz [a] anthracene & 438 & 0.85 & 0.31 & 36.58 \\
\hline Chrysene + Thiphenylene & $441 / 439$ & 2.69 & 0.86 & 31.98 \\
\hline Benzofluoranthenes $[b+j+k]$ & 480 & 3.55 & 2.83 & 79.78 \\
\hline Benzo[e]pyrene & 493 & 1.63 & 1.17 & $71.8 \%$ \\
\hline Benzo[a]pyrene & 496 & 0.91 & 0.67 & 73.68 \\
\hline Indeno $[1,2,3$-cd ] pyrene & --- & 1.40 & 1.09 & 77.98 \\
\hline Dibenz $[\mathrm{a}, \mathrm{h}]$ anthracene & --- & 0.21 & 0.22 & $104.8 \%$ \\
\hline Benzo[ghi]perylene & 500 & 1.73 & 1.60 & 92.58 \\
\hline Anthanthrene & --- & $<0.16$ & 0.16 & 100.08 \\
\hline Coronene & 525 & 0.75 & 0.74 & 98.78 \\
\hline
\end{tabular}

When the recoveries of the various PAH are plotted against their boiling points a linear curve is obtained which, however, seems to depend on the total amount of PAH collected on the filter (Figure 4).

From the data, it may be predicted that compounds with boiling points above $480{ }^{\circ} \mathrm{C}$ can be collected quantitatively and compounds boiling below about $340{ }^{\circ} \mathrm{C}$ such as dibenzothiophene, phenanthrene, and anthracene cannot be collected at all by this commonly used filter system. The curves do not indicate any chemical conversion of the $\mathrm{PAH}$ investigated, if they do not already decompose within the first hour. The re-evaporation can also be demonstrated by adding a Porapak PS filter following to the glass fiber filter as demonstrated in Table 2 .

It was demonstrated that the air flow velocity onto the filter significantly influences the $\mathrm{PAH}$ concentration separated by a particle filter system. Although only two measurements have been made, one may conclude with caution that the lower-boiling $\mathrm{PAH}$ are more affected than the higher-boiling ones. This is shown in Figure 5, in which two air flow velocities have been used, $7.6 \mathrm{~cm} / \mathrm{s}$ and $52.6 \mathrm{~cm} / \mathrm{s}$. Both samples have been taken at identical times and at identical locations. 


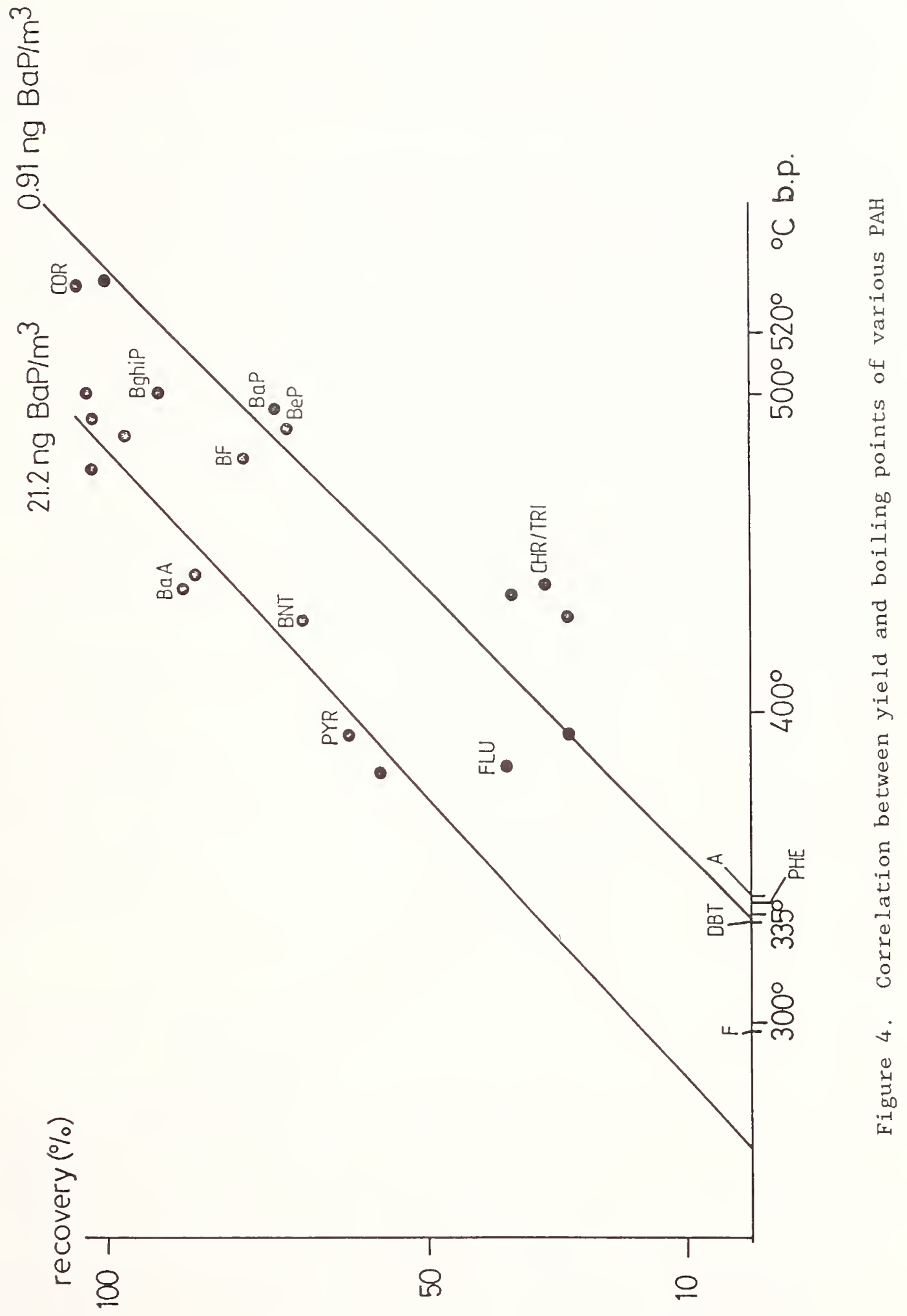


Table 2. PAH-Profiles Collected on a Glass Fiber Filter and a Subsequent Porapak PS Filter (ng $\mathrm{PAH} / \mathrm{m}^{3}$ )

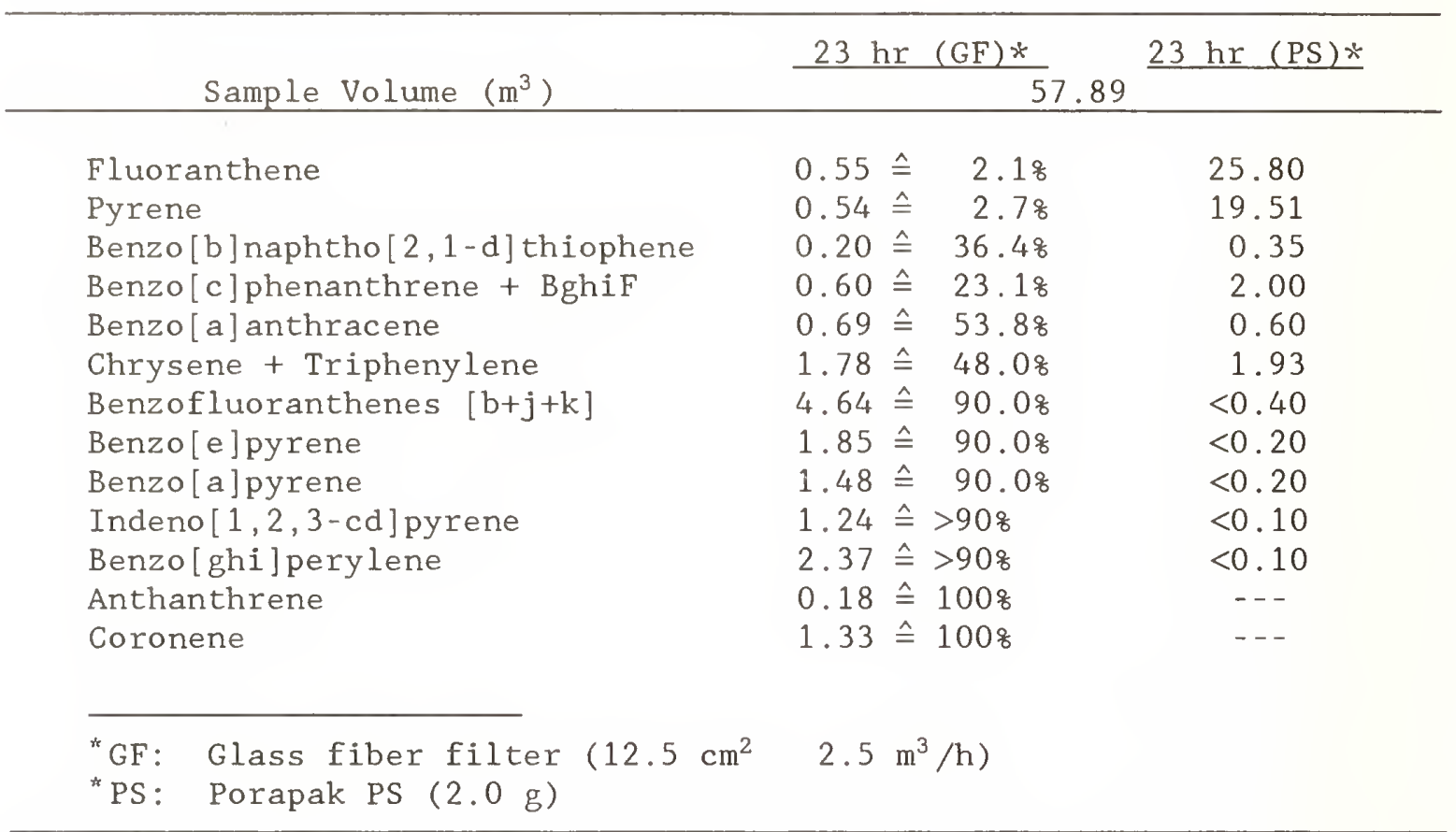

ng PAH/m

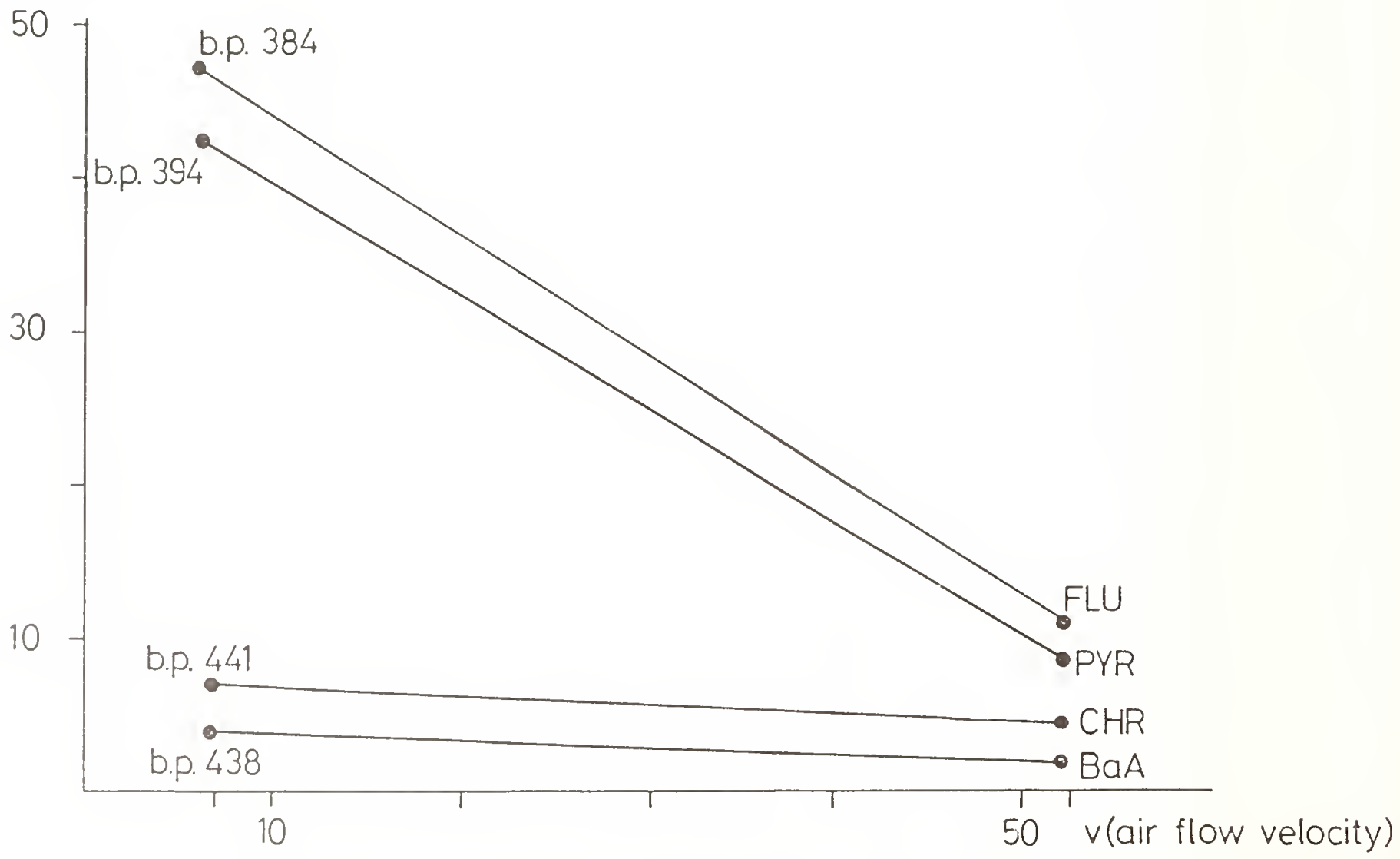

Figure 5. Dependence of the yield on the air flow velocity 
Slopes of the curves are comparable for compounds with similar boiling points. The slopes approach zero for $\mathrm{PAH}$ with boiling points of about $450{ }^{\circ} \mathrm{C}$. Unfortunately, results were less consistent in samples linked predominantly to vehicle traffic.

Very sensitive compounds such as cyclopenta[cd]pyrene and anthanthrene are significantly reduced in concentration when compared to more stable compounds such as benzo[e]pyrene and coronene. The ratio $24 \mathrm{x} 1 \mathrm{~h} / 1 \mathrm{x} 24 \mathrm{~h}$ is abnormally high for cyclopenta[cd]pyrene and anthanthrene when compared to PAH having the same boiling points, as shown in Table 3 which compares long- and short-term sampling at a car parking area. At this location, which is predominantly or almost entirely polluted by vehicle exhaust, a comparative experiment with sampling times of $24 \times 1 \mathrm{~h}$ and $1 \times 24 \mathrm{~h}$ has been repeated three times, and the results were very disappointing (Table 4).

Table 3. PAH-Profiles on Glass Fiber Filters (ng $\mathrm{PAH} / \mathrm{m}^{3}$ )

\begin{tabular}{lccr}
\hline \multicolumn{1}{c}{$\begin{array}{c}\text { Sample } \\
\text { Volume }\left(\mathrm{m}^{3}\right)\end{array}$} & $\begin{array}{c}1 \\
24 \times 1 \mathrm{~h}\end{array}$ & $\begin{array}{c}2 \\
1 \times 24 \mathrm{~h}\end{array}$ & $\begin{array}{r}\text { Yield 2 } \\
\text { Rel. to }\end{array}$ \\
& 328.17 & 329.05 & 1 \\
\hline Fluoranthene & 43.32 & 7.39 & 17.08 \\
Pyrene & 36.19 & 6.44 & $17.8 \%$ \\
Benzo[b]naphtho[2,1-d] thiophene & 1.87 & 1.20 & 64.28 \\
Cyclopenta[cd]pyrene & 6.72 & 0.40 & 6.08 \\
Benz[a] anthracene & 3.60 & 2.29 & 63.68 \\
Chrysene + Thiphenylene & 8.08 & 4.58 & 56.28 \\
Benzofluoranthenes [b+j+k] & 9.58 & 5.73 & 59.88 \\
Benzo[e]pyrene & 4.55 & 2.47 & 54.38 \\
Benzo[a]pyrene & 3.45 & 1.76 & 51.08 \\
Indeno[1,2,3-cd]pyrene & 2.80 & 1.69 & 60.48 \\
Benzo[ghi]perylene & 5.53 & 3.17 & 57.38 \\
Anthanthrene & 0.87 & 0.25 & 28.78 \\
Coronene & 3.22 & 1.58 & $49.1 \%$
\end{tabular}

Air flow velocity: $7.6 \mathrm{~cm} / \mathrm{s}$

Although, the recoveries of the lower boiling compounds are significantly reduced, the higher-boiling compounds generally were not found to be in the 100 r range but rather in the 50\%-range. Table 4 also gives the absolute amounts of benzo[a]pyrene. The atmospheric conditions were different in all three experiments and they might be responsible for the great variations, especially for the low concentrations of benzo[a]pyrene and benz[a]anthracene in the second experiment. On the other hand, no correlation between $\mathrm{NO}_{\mathrm{x}}, \mathrm{SO}_{2}$, and ozone levels, which were measured simultaneously (not shown in Table 4), and the PAH-profile could be observed. Until further systematic experiments have been carried out, these data cannot be interpreted satisfactory. However, from the information available, one may question whether the concentrations of benzo[a]pyrene and other PAH measured in air, as reported in the literature, 
Table 4. PAH-Profiles Recorded at a Vehicle-Exhaust Polluted Location Three Independent Experiments During Different Days). Yields Calculated from 1 × $24 \mathrm{~h}$ Sampling

\begin{tabular}{lccc}
\hline & $1 *$ & $2 *$ & $3 * *$ \\
\hline Fluoranthene & 16 & 22 & 17 \\
Pyrene & 13 & 19 & 18 \\
Benzo[b] naphtho[2,1-d] thiophene & 11 & 30 & 64 \\
Benzo[a] anthracene [b+j+k] & 11 & 28 & 64 \\
Benzofluoranthenes [b]pyrene & 20 & 51 & 60 \\
Benzo[e]pyone & 23 & 45 & 54 \\
Benzo[a]pyrene & 29 & $(18)$ & 54 \\
Indeno[1,2,3-cd]pyrene & 50 & 65 & 60 \\
Benzo[ghi]perylene & 47 & 41 & 57 \\
Coronene & 67 & 42 & 49 \\
Absolute Benzo[a]pyrene (ng/m $\left.{ }^{2}\right)$ & 1.7 & 4.2 & 4.6 \\
& & & \\
*Filter surface $113 \mathrm{~cm}^{3} ; * * f i l t e r$ & surface $500 \mathrm{~cm}^{2}$. &
\end{tabular}

are a reliable basis for any meaningful conclusions. It could well be that most of these data are underestimating the actual PAH-concentrations in the matrix air.

\section{CONCLUSIONS}

1. During long-term sampling, there is a considerable re-evaporation of the lower boiling PAH collected on glass fiber filters after $24 \mathrm{~h}$ and even earlier. This problem can be overcome by using a subsequent Porapak PS filter. The effect depends on:

- the absolute amount of $\mathrm{PAH}$ collected on the filter, and

- the air flow velocity.

The effect can be neglected for $\mathrm{PAH}$ boiling above $480 \quad{ }^{\circ} \mathrm{C}$ (benzofluoranthenes), but data for pyrene and fluoranthene have to be regarded with great caution. They might not be very reliable. Hence, in general, short-term and low-volume sampling should be preferred and the air flow velocity onto the filter should be less than $8 \mathrm{~cm} / \mathrm{s}$.

2. In places which are predominantly polluted by vehicle exhaust emission, hitherto unidentified effects influence the recoveries and the profiles of $\mathrm{PAH}$ collected on glass fiber filters. Various reasons may be responsible for this among which sunlight-catalyzed reactions are the most probable ones. Further basic and systematic investigations are required to understand these detrimental effects. Long-term sampling, however, cannot be recommended for the active collection of the matrix air. 
SECTION 14

TRENDS AND EFFECTS OF ENVIRONMENTAL CONTAMINANTS DETERMINED FROM ANALYSIS OF ARCHIVED WILDLIFE SAMPLES

\author{
J. E. Elliott, R. J. Norstrom, S. W. Kennedy and G. A. Fox \\ Canadian Wildlife Service \\ National Wildlife Research Centre \\ Ottawa, K1A $0 \mathrm{H} 3$ \\ CANADA
}

\title{
I. INTRODUCTION
}

Most developed countries introduced measures during the past 20 years to control the release of persistent toxic chemicals to the environment. However, chemical inputs continue from manufacturing, waste dumpsites, transport accidents, ocean dumping, incineration and open uses especially in developing countries. Substantial amounts of chemicals such as the polychlorinated biphenyls (PCBs), persisting mainly from previous usage, continue to cycle through the environment [1].

Agencies in some countries have established programs to monitor persistent contaminants in the environment. A number of cooperative international monitoring projects have also been established over the past two decades [2-4]. The storage of environmental samples for future use, or specimen banking, is a natural complement to environmental monitoring [5]. Environmental agencies in a number of countries now operate specimen banks $[6,7]$.

This paper will briefly discuss current specimen banking activities by Canadian federal agencies working in the Great Lakes. We will then discuss the use of samples from the National Specimen Bank of the Canadian Wildlife Service (CWS) to determine both levels and effects of environmental contaminants in the Great Lakes and the Gulf of St. Lawrence.

\section{SPECIMEN BANKING BY CANADIAN AGENCIES IN THE GRFAT LAKES}

The three Canadian agencies involved in monitoring environmental contaminant levels in the North American Great Lakes also operate specimen banks. The Canadian Wildlife Service maintains the most comprehensive bank largely in support of its monitoring programs [8,9].

The Canadian Department of Fisheries and Oceans monitors contaminant levels in larger predatory fish such as Lake Trout (Salvelinus namaycush) and Coho Salmon (Oncorhynchus kisutch) in the Great Lakes [10]. Homogenized aliquots of whole fish, invertebrates and plankton are archived at $-80{ }^{\circ} \mathrm{C}$ [11]. Other fish samples are stored in chemical fixatives. Information on samples in the bank is on computer.

The National Water Research Institute of Environment Canada maintains a bank of Great Lakes sediment samples [12]. Surficial sediments were collected 
from locations throughout the Great Lakes, homogenized, freeze-dried, aliquotted and stored at room temperature.

The specimen banks operated by Canadian agencies in the Great Lakes are not formally coordinated as in the Federal Republic of Germany's Environmental Specimen Banking project [13]. However, coordination of effort is maintained by direct contact among the scientists involved, by the federal government Great Lakes Water Quality Program Working Group, and via committee structures of the International Joint Commission (IJC) which oversees the monitoring of contaminants in the Great Lakes [4].

\section{MONITORING CANADIAN WILDLIFE}

Our monitoring of environmental contaminants in Canadian wildlife samples is often designed to meet two complementary objectives: 1) determination of levels and trends in the environment using wildlife as indicator organisms and 2 ) assessment of the effects of chemicals on wildlife health. Here we discuss the use of archived Herring Gull (Larus argentatus) eggs to determine trends of organic contaminants in the North American Great Lakes. The second objective is pursued at both the population and subcellular levels and examples are presented using banked samples.

\section{A. Monitoring Trends in Contaminant Residues}

Biological and chemical surveillance of Great Lakes Herring Gulls has been part of the IJC Great Lakes Surveillance Program since 1974. Two geographically separated colonies from each lake and colonies on connecting channels are monitored annually [14]. The Herring Gull is a useful indicator of persistent, lipophilic contaminant levels in the Great Lakes. It is a colonial species which feeds mainly on aquatic food chains. Upon reaching breeding age, the Herring Gull is a year-round resident in the Great Lakes. Seasonal movements between lakes and changes in diet can confound interpretation of Herring Gull residue data. A bioenergetics based model has been developed to aid data interpretation $[15,16]$.

Until 1986, we collected and analyzed ten individual eggs from each monitor colony. Statistical analysis of ten years' accumulated data showed that a strategy of pooling samples would reduce analytical costs and still provide a reliable estimate of mean residue levels and trends [17,18]. We continue to collect, process and bank individual Herring Gull eggs. In this way, we shall always have the option for individual analyses should the trends in pooled sample means require greater statistical treatment. We have established a schedule of annual pooled analyses for most colonies with each lake and connecting channel receiving individual analyses on a rotating schedule, i.e., every five years.

Since the Herring Gull program began in 1974, the number of chemicals reported on a routine basis has increased considerably. Also, methodological changes and improvements have rendered some of the earlier data of questionable value. We decided in 1982 to do a comprehensive retrospective analysis of Herring Gull eggs from the specimen bank in order to determine temporal trends 
for a variety of chemicals. We searched our specimen bank records to locate colonies where adequate numbers of Herring Gull eggs had been collected and archived regularly since the early 1970s. We selected two locations, Scotch Bonnet Island in Lake Ontario and Big Sister Island in Lake Michigan. We prepared 50 gram pools of Herring Gull egg homogenate for each year and analyzed the pools for a variety of contaminants. The stability of organochlorine residues in stored Herring Gull eggs has been demonstrated $[19,9]$.

Figure 1 shows contaminant trends for three of the major chlorinated organics (PCBs, DDE, oxychlordane) found in Herring Gull eggs from Lake Ontario and Lake Michigan. Declining trends are evident for PCBs and DDE. Oxychlordane remained relatively constant throughout the study period. The higher levels of chlordane derived compounds in Lake Michigan reflect the more agricultural nature of the drainage basin. Both lakes are also surrounded by large urban populations and extensive industrial developments, accounting for high PCB concentrations.

The controls imposed in Canada and the U.S. in the 1970s on use and disposal of PCBs and many organochlorine pesticides presumably account for the declining concentrations of PCBs and DDE in Herring Gull eggs. Oxychlordane is the major metabolite of cis and trans-chlordane, the main components of technical chlordane. Chlordane was used extensively in North America after the restrictions on DDT, and controls were only imposed in the late 1970s. Ongoing use of chlordane as a termiticide and atmospheric deposition from long range transport from areas of broader use may also contribute to the relatively constant levels of this chemical.

Figure 1 also shows trends for a tetrachloro dibenzo-dioxin (TeCDD) congener, 2378-TeCDD, also from analysis of the archived samples from Scotch Bonnet and Big Sister Islands. Among the dioxin congeners, only 2378-TeCDD levels in Lake Ontario Herring Gull eggs from the early 1970 s were significantly elevated over levels from Lake Michigan [20]. This indicated that the dioxin source to Lake Ontario contained predominantly 2378-TeCDD. 2,4,5-T was manufactured in the Niagara Falls area for many years and is probably the origin of most of the $2378-\mathrm{TeCDD}$ in Lake Ontario.

\section{B. Monitoring Contaminant Effects on Biochemical State}

Impaired reproduction observed in a variety of Great Lakes colonial water birds during the 1960 s and 1970 s has been related to chemical contaminants [14]. With the exception of some species in the Green Bay area of Lake Michigan [21,22], productivity of colonial water birds is now thought to be normal throughout the Great Lakes [23,24]. Although contaminant concentrations have decreased at least in Herring Gulls, levels are still much higher than found elsewhere in Canada [25]. The focus is now on possible sublethal effects on Great Lakes wildlife.

Chronic exposure to the polyhalogenated aromatic (PHA) compounds including the biphenyls (PCBs), dioxins (PCDDs) and furans (PCDFs) produces a suite of toxic effects in most species studied [26]. Among those effects, induction of hepatic microsomal aryl hydrocarbon hydroxylase (AHH) activity has been 

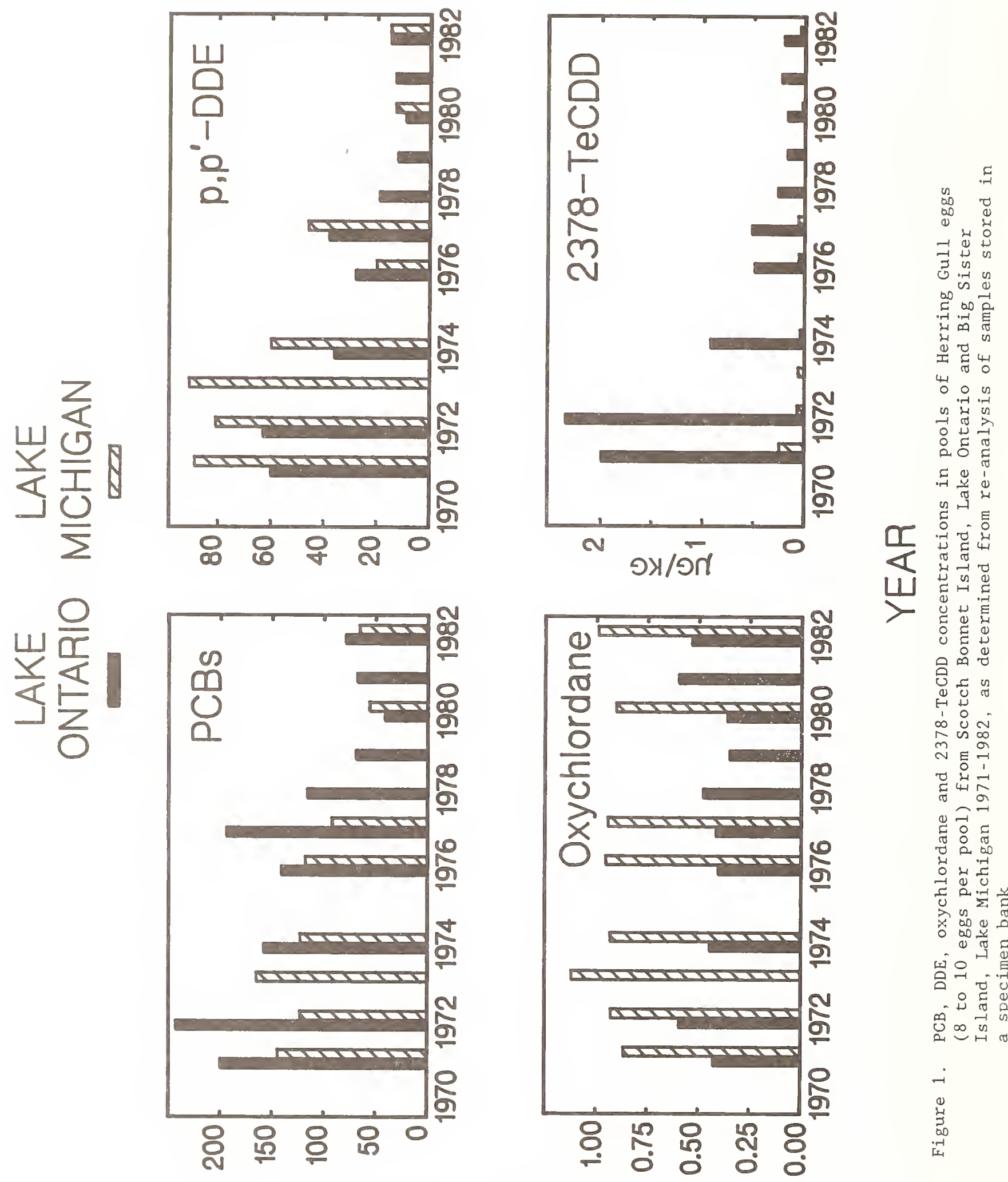

on

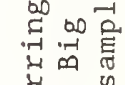

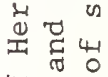

㟧 00

n

농

تี

?

$\frac{0}{4}$

式若

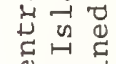

岂

0 足

吕

प्र

两

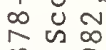

N $E \stackrel{\circ}{-1}$

돈

तै

긍

ते

강

ป क.

ते

- $4 \pi$

됨음 훙

- 요

㟔 $\infty \vec{v}$ 的

$\perp H$ I $\exists M \perp \exists M$ SY/OW 
investigated in wild species and proposed for monitoring of birds [27,28] and fish (Spies et al. 1982). Many PHA congeners have been shown to disrupt the heme biosynthetic pathway [30]. Disruption of the pathway by PHAs causes a change in the normal "porphyrin pattern" resulting in elevated levels of highly carboxylated porphyrins (HCPs) in tissues and excreta. In a recent paper, Koss et al. [31] showed that livers of pike, Esox lucius, from the Rhine River contained much higher HCP levels than livers of pike from the less polluted River Lahn. Livers of adult Herring Gulls collected in 1985 from the Great Lakes had much higher HCP levels than in Herring Gulls or other avian species collected from more pristine sites [32]. In an earlier study, Herring Gull chicks collected from the Great Lakes in 1974 had total porphyrin levels which correlated with exposure to PHAs [33].

Livers from prefledged Herring Gull chicks, collected in 1974 from two Great Lakes colonies, were re-analyzed in 1985 for porphyrins. HCPs in some Herring Gull chick samples from Scotch Bonnet Island, Lake Ontario were ten times higher than any of the samples from Port Colborne, Lake Erie (Figure 2). A six month study of porphyrin stability in rat liver homogenate frozen at $-20{ }^{\circ} \mathrm{C}$ showed no apparent degradation of HCPs $[34,35]$.

Methods of sample collection and preservation for study of biochemical or histological effects of contaminants may differ from those required for measuring contaminant levels. Collection protocols can be designed to meet different objectives; however, many samples, including the bulk of our CWS National Specimen Bank have been collected for chemical analyses. Such samples can still be used for measuring biochemical effects in the form of levels and patterns of stable metabolites such as porphyrins.

\section{Correlating Contaminant Residue Trends With Population State}

Northern Gannet (Sula bassanus) populations in the Gulf of St. Lawrence declined during the late 1960s and early 1970s [36]. Adult and juvenile birds and eggs were collected on a number of occasions from 1968 to 1976 at Bonaventure Island ( $\left.4830^{\prime} \mathrm{N} 6409^{\prime} \mathrm{W}\right)$ and stored in the CWS specimen bank. Analysis of those samples showed high levels of DDE and other organochlorine contaminants. In 1984, we collected more eggs at the colony and retrieved a subset of the eggs from the specimen bank. We analyzed those eggs for organochlorines using current analytical methodology.

One objective of the study was to reassess the role of chemicals in the gannet reproductive decline using a more extensive organochlorine database. The data strongly suggests that high levels of DDE and thin eggshells were associated with the period of reduced reproductive success [37,38].

We also saw an opportunity to determine organochlorine trends in the Gulf of St. Lawrence ecosystem using the gannet as an indicator seabird species [17]. The St. Lawrence River drains a highly industrialized, heavily populated region of North America. The Gulf of St. Lawrence also receives drainage water from four surrounding maritime provinces. Long range atmospheric transport from the North American mainland is a further source of airborne chemical contaminants to the gulf. 


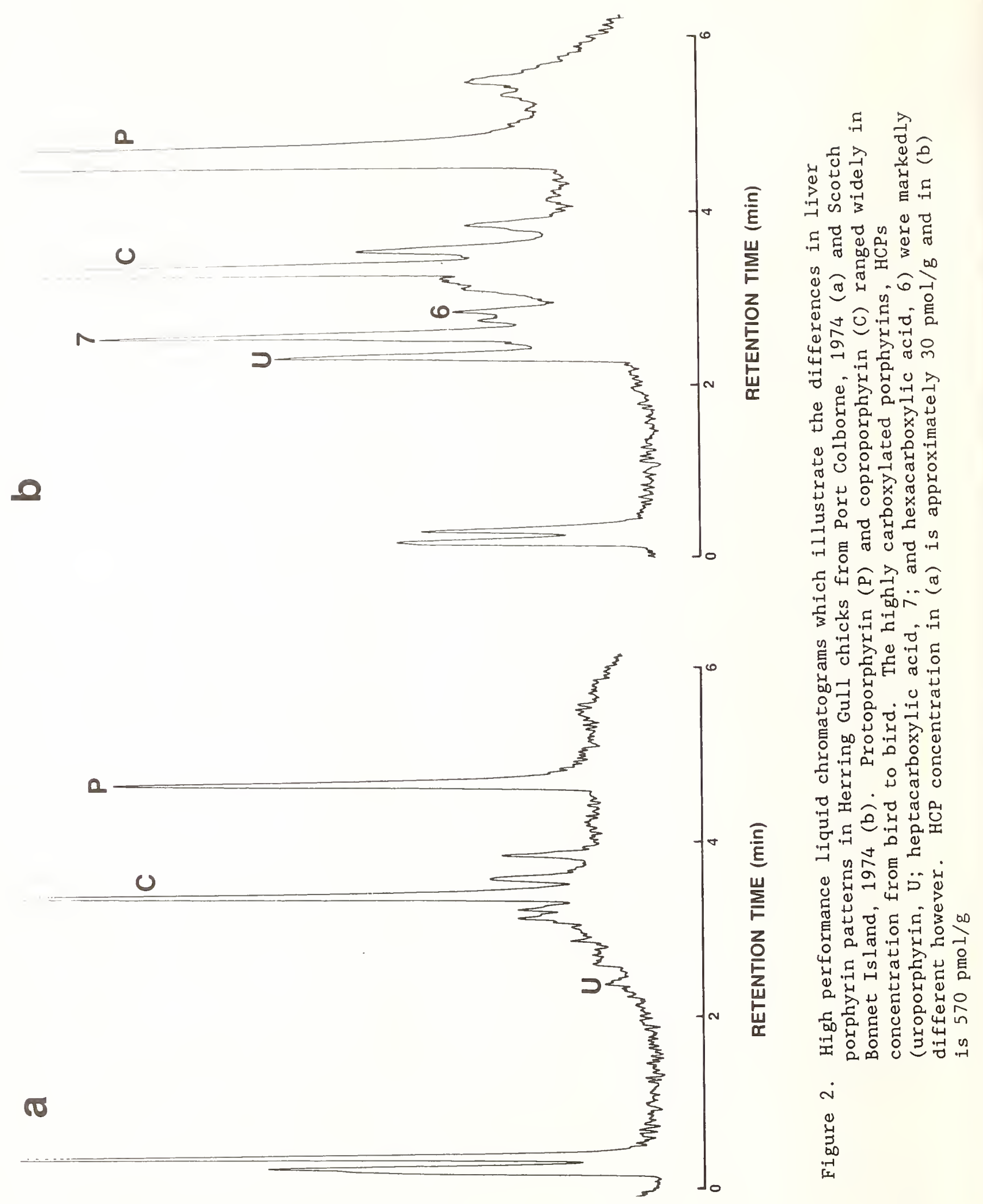


Figure 3 shows trends of DDE, PCBs, $\alpha-\mathrm{HCH}$ and oxychlordane in gannet eggs from Bonaventure Island. Only random samples of the eggs laid were used for trend assessment. Eggs that failed to hatch were also re-analyzed from some years in order to determine difference in contaminant levels between those eggs and samples of eggs laid random from the same year [37].

DDE levels declined significantly throughout the study period. Aerial application of DDT to control forest insects around the Gulf of St. Lawrence stopped in 1969. Legislative controls on DDT use in Canada and the U.S. came into effect the following year. Declining DDE levels in gannet eggs from the gulf are probably the result of reduced DDT input from both regional and wider North American sources.

PCB levels also decreased in gannet eggs during the course of the study but at a slower rate than DDE. Re-analysis of PCBs from specimen bank samples has been particularly useful: Analytical methods used in 1969 seriously under-estimated PCB levels which resulted in the appearance of a flat or increasing trend for PCBs in gannet eggs from 1969 to 1976 [39].

With the exception of heptachlor epoxide, chlordane-related isomers were not measured routinely in wildlife samples prior to 1976. The re-analysis of archived samples provides a trend picture for this group of compounds. Oxychlordane concentrations in gannet eggs were constant throughout the period 1969 to 1976, paralleling the situation in Great Lakes Herring Gulls. This does not reflect increasing Canadian usage during that time frame. However, the decrease in oxychlordane by 1984 would appear to follow 1978 restrictions on use in Canada.

$\mathrm{HCH}$ residues were not routinely measured in our wildlife samples until 1978. Although not statistically significant ( $p<0.05$, regression test) levels of $\alpha-\mathrm{HCH}$ increased with time as indicated in archived gannet eggs. We could find no published data on $\mathrm{HCH}$ trends with which to compare our results. Increasing levels in the Atlantic coastal environment are possible as a result of long range transport from areas of continued use [40].

\section{SUMMARY}

A specimen bank can be a valuable addition to an environmental monitoring program. Canadian agencies involved in monitoring wildlife, fish and water in the Great Lakes ecosystem currently maintain specimen banks.

The Canadian Wildlife Service has been monitoring environmental contaminant levels in Great Lakes Herring Gulls since the early 1970s. Remains of these and other samples are routinely archived. Series of Herring Gull eggs collected from 1971 to 1982 at colonies in Lakes Ontario and Michigan were analyzed for a broad suite of contaminants. PCB and DDE levels in Herring Gull eggs declined substantially at both colonies. Oxychlordane levels remained constant in Herring Gull eggs at both colonies throughout the study period. 2378-TeCDD levels declined at both locations. 

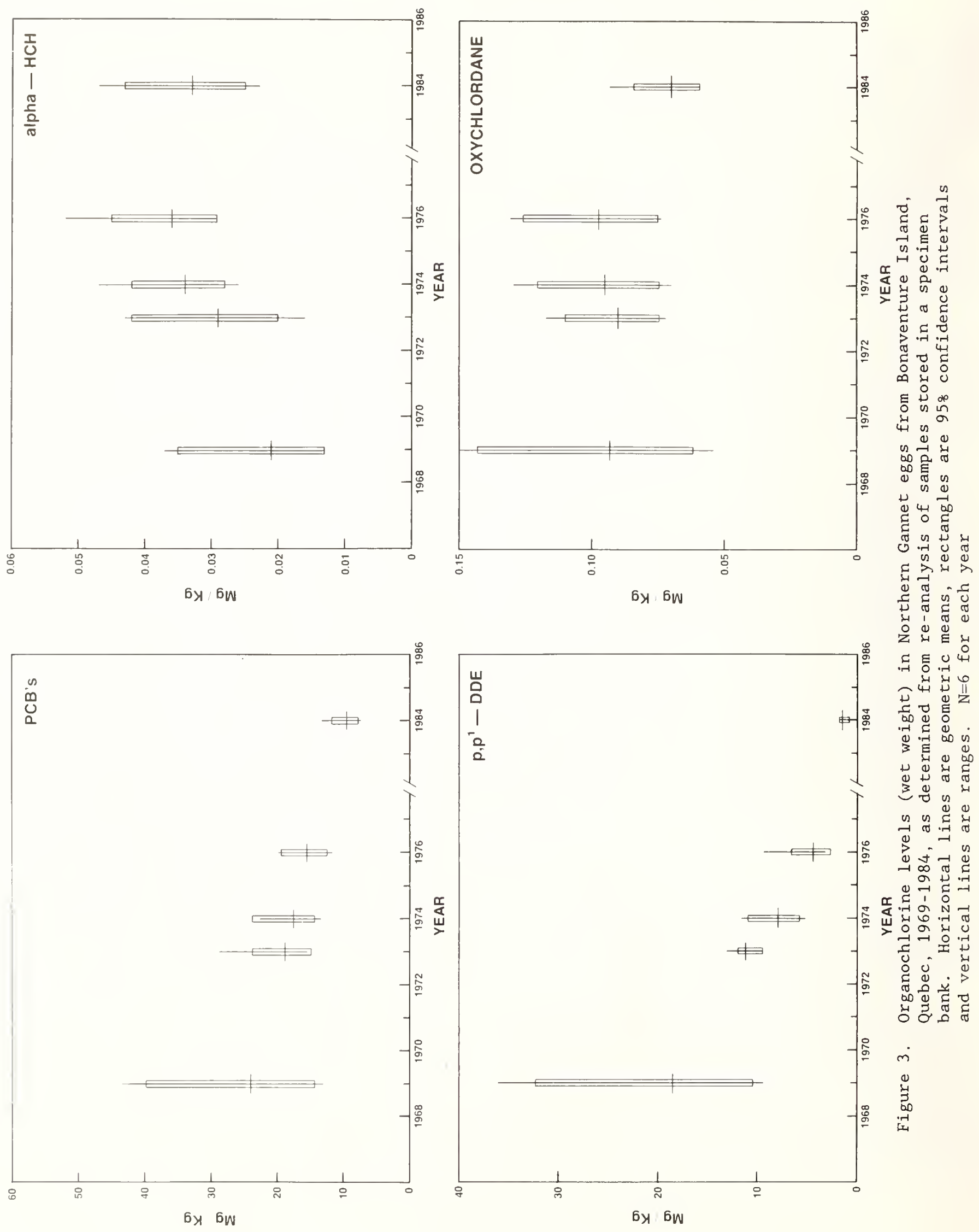
Increased liver levels of highly carboxylated porphyrins have been measured in wildlife from environments heavily contaminated with polyhalogenated aromatic hydrocarbons (PAHs). Measurement of tissue porphyrin levels is a promising tool for monitoring biochemical effects of PHAs.

Analysis of Northern Gannet eggs from the Canadian Wildlife Service specimen bank showed trends in organochlorine residues from 1969 to 1984 in the marine ecosystem of the Gulf of St. Lawrence. Levels of DDE and PCBs declined throughout the study period. Oxychlordane levels remained quite constant while $\alpha-\mathrm{HCH}$ levels increased throughout the study.

\section{v. ACKNOWLEDGEMENTS}

We gratefully acknowledge the late, Y. Ouellette, for his careful reorganization of the specimen bank samples and records. H. Won, M. Simon and M. Mulvilhill performed the chemical analysis.

\section{REFERENCES}

[1] Eisenreich, S. J., Looney, B. B., and Thornton, J. D. (1981), Airborne Organic Contaminants in the Great Lakes Ecosystem, Environ. Sci. Technol. $15,30-38$.

[2] International Council for the Exploration of the Sea (1977), The ICES Coordinated Monitoring Programmes, 1975 and 1976, Cooperative Research Report No. 72, Charlottenlund, Denmark, $27 \mathrm{pp}$.

[3] Organization for Economic Cooperation and Development (1980), Chemical Trends in Wildlife, Paris, $249 \mathrm{pp}$.

[4] International Joint Commission (1985), 1985 Report on Great Lakes Water Quality, Great Lakes Water Quality Board Report to the International Joint Commission, Windsor, Ontario.

[5] Luepke, N. -P. (1979), Monitoring Environmental Materials and Specimen Banking, Martinus Nijhoff Publishers, The Hague, 591 pp.

[6] Lewis, R. A., Stein, N., and Lewis, C. W. (1984), Environmental Specimen Banking and Monitoring as Related to Banking, Martinus Nijhoff Publishers, The Hague, $358 \mathrm{pp}$.

[7] Wise, S. A. and Zeisler, R., Eds., (1985), International Review of Environmental Specimen Banking, NBS Spec. Publ. 706, U.S. Government Printing Office, Washington, DC, 54 pp.

[8] Elliott, J. E. (1984), Collecting and Archiving Wildlife Specimens in Canada, In: Environmental Specimen Banking and Monitoring as Related to Banking, R. A. Lewis, N. Stein, and C. W. Lewis, Eds., Martinus Nijhoff Publishers, Boston, MA, pp 45-66. 
[9] Elliott, J. E. (1985), Specimen Banking in Support of Monitoring for Toxic Contaminants in Canadian Wildlife, In: International Review of Environmental Specimen Banking, S. A. Wise and R. Zeisler, Eds., NBS Spec. Publ. 706, U. S. Government Printing Office, Washington, DC, pp 4-12.

[10] Shear, H. (1984), Contaminants Research and Surveillance - A Biological Approach, In:' Toxic Contaminants in the Great Lakes, J. O. Nriagu and M. S. Simmons, Eds., John Wiley and Sons, Inc., New York, NY.

[11] Hyatt, W. H., Fitzsimons, J. D., Keir, M. J., and Whittle, D. M. (1984), Great Lakes Biological Tissue Archive Studies, Canadian Technical Report of Fisheries and Aquatic Sciences, No. 1497, Burlington, Ontario, 58 pp.

[12] Bourbonniere, R. A., Van Sickle, B. L., and Mayer, T. (1986), The Great Lakes Sediment Bank, I. National Water Research Institute, Environment Canada, Burlington, Ontario.

[13] Boehringer, U. R. (1985), The Environmental Specimen Banking Project of the Federal Republic of Germany, In: International Review of Environmental Specimen Banking, S. A. Wise and R. Zeisler, Eds., Nat. Bur. Stand. Spec. Publ. 706, U.S. Government Printing Office, Washington, DC, pp 13-21.

[14] Mineau, P., Fox, G. A., Norstrom, R. J., Weseloh, D. V., Hallett, D. J., and Ellenton, J. A. (1984), Using the Herring Gull to Monitor Levels and Effects of Organochlorine Contamination in the Canadian Great Lakes, In: Toxic Contaminants in the Great Lakes, J. O. Nriagu and M. S. Simmons, Eds., John Wiley and Sons, Inc., New York, NY, pp 425-452.

[15] Norstrom, R. J., Clark, T. P., Jeffrey, D. A., Won, H. T., and Gilman, A. P., (1986a), Dynamics of Organochlorine Compounds in Herring Gulls (Larus argentatus): I. Distribution and Clearence of ${ }^{14} \mathrm{C}$ DDE in Freeliving Gulls, J. Environ. Toxicol. Chem. 5, 41-48.

[16] Norstrom, R. J., Clark, T. P., Kearney, J. P., and Gilman, A. P. (1986b), Herring Gull Energy Requirements and Body Constituents in the Great Lakes, Ardea 72, 11-32.

[17] Gilbertson, M., Elliott, J. E., and Peakall, D. B. (1987), Seabirds as Indicators of Marine Pollution, In: The Uses of Birds, A. W. Diamond and F. Filion, Eds., ICBP Technical Publication, Cambridge.

[18] Struger, J. and Collins, B. T., A Statistical Evaluation of the Great Lakes Herring Gull Monitoring Program, Canadian Wildlife Service, Ottawa, (manuscript in preparation).

[19] Norstrom, R. J. and Won, H. T. (1985), Long-term Preservation of Egg and Tissue Homogenates for Retrospective Determination of Organochlorine Compounds: Freezing Versus Freeze Drying, J. Assoc. Off. Anal. Chem. $68(1), 129-135$. 
[20] Norstrom, R. J. (1986), Long-Term Trends of PCDD and PCDF Contamination in the Great Lakes, Presented at the 6th Internat. Symp. on Dioxins and Related Compounds, Fukuoka, Japan, Sept. 16-19, 1986.

[21] Hoffman, D. J., Rattner, B. A., Sileo, L., Docherty, D., and Kubiak, T. J. (1987), Embryotoxicity, Teratogenicity, and Aryl Hydrocarbon Hydroxylase Activity in Forster's Terns on Green Bay, Lake Michigan, Environ. Res. 42, 176-184.

[22] Kubiak, T. J., Harris, H. J., Smith, L. M., Stalling, D. L., Schwartz, T. R., Trick, J. A., Sileo, L., Docherty, D. E., and Erdman, T. C., Microcontaminants and Reproductive Impairement of the Forster's Tern on Green Bay, Lake Michigan - 1983, U.S. Fish and Wildlife Service, East Lansing, Michigan, manuscript in preparation.

[23] Weseloh, D. V., personal communication.

[24] Weseloh, D. V., Mineau, P., Teeple, S. M., Blokpoel, H., and Ratcliff, B. (1986), Colonial Waterbirds Nesting in Canadian Lake Huron in 1980, Canadian Wildlife Service, Progress Notes, No. 165, 28 pp.

[25] Canadian Wildlife Service, unpublished data.

[26] Poland, A. and Knutson, J. C. (1982), 2,3, 7,8-Tetrachlorodibenzo-p-Dioxin and Related Halogenated Aromatic Hydrocarbons: Examination of the Mechanism of Toxicity, Ann. Rev. Pharmacol. Toxicol. 22, 517.

[27] Ellenton, J. A., Brownlee, L. J., and Hollebone, B. R. (1985), Aryl Hydrocarbon Hydroxylase Levels in Herring Gull Embryos from Different Locations on the Great Lakes, Environ. Toxicol. Chem. 4, 615-22.

[28] Peakall, D. B., Norstrom, R. J., Rahimtula, A. D., and Butler, R. D. (1986), Characterization of Mixed-function Oxidase Systems of the Nestling Herring Gull and Its Implications for Bioeffects Monitoring, Environ. Toxicol. Chem. 5, 379-85.

[29] Spies, R. B., Felton, J. S., and Dillard, L. (1982), Hepatic MixedFunction Oxidases in California Flatfishes are Increased in Contaminated Environments and by Oil and PCB Ingestion, Mar. Biol. 70, 117-127.

[30] Marks, G. S. (1985), Exposure to Toxic Agents: The Heme Biosynthetic Pathway and Hemoproteins as Indicator, CRC Crit. Rev. Toxicol. 15(2), 151-179.

[31] Koss, G., Schuler, E., Arndt, B., Seidel, J., Seubert, S., and Seubert, A. (1986), A Comparative Toxicological Study on Pike (Esox lucius L.) from the River Rhine and the River Lahn, Aquat. Toxicol. 8, $1-9$. 
[32] Kennedy, S. W., Fox, G. A., Norstrom, R. J., and Wigfield, D. C., Porphyria in Herring Gulls: A Biochemical Response to Chemical Contamination of Great Lakes Food Chains, Canadian Wildlife Service, Ottawa, (manuscript in preparation).

[33] Gilbertson, M. and Fox, G. A. (1977), Pollutant-associated Embryonic Mortality of Great Lakes Herring Gulls, Environ. Pollut. 12, 211-16.

[34] Kennedy, S. W. (1986), Porphyria in Great Lakes Herring Gull: A Biochemical Indicator of Polyhalogenated Aromatic Hydrocarbon Exposure, Canadian Wildlife Service Report, Ottawa.

[35] Kennedy, S. W., Wigfield, D. C., and Fox, G. A. (1986), Tissue Porphyrin Pattern Determination by High-Speed High-Performance Liquid Chromatography, Anal. Biochem. 157, 1-7.

[36] Nettleship, D. N. (1976), Gannets in North America: Present Numbers and Recent Population Changes, Wilson Bull. 88(2), 300-13.

[37] Elliott, J. E., Norstrom, R. J., and Keith, J. A., Organochlorines and Eggshell Thinning in Northern Gannets (Sula bassanus) from Eastern Canada, 1968-1984, Environ. Pollut., in press.

[38] Chapdelaine, G., Laporte, P., and Nettleship, D. N., Population, Productivity and DDT Contamination Trends of Northern Gannets (Sula bassanus) at Bonaventure Island, Quebec, 1967-1984, Can. J. Zoo., in press.

[39] Turle, R., Norstrom, R. J., and Won, W. T. (1986), Quality Assurance as Applied to Long Term Monitoring and Specimen Banking, In: These Proceedings.

[40] Tanabe, S., Tatsukawa, R., Kawano, M., and Hidaka, H. (1982), Global Distribution and Atmospheric Transport of Chlorinated Hydrocarbons HCH (BHC) Isomers and DDT Compounds in Western North Pacific, Easter Indian and Antarctic Oceans, J. Oceanograph. Soc. Japan. 38, 137-148. 


\title{
SECTION 15
}

\section{WILDLIFE AS AN INDICATOR FOR ENVIRONMENTAL CONTAMINANTS \\ IN MONITORING SYSTEMS}

\author{
Jasper Holm \\ Staatliches Veterinäruntersuchungsamt \\ D-3300 Braunschweig \\ FEDERAL REPUBLIC OF GERMANY
}

\section{INTRODUCTION}

The government Veterinary Research Institute in Braunschweig is responsible for the hygienic control in foods of animal origin. The controlled area, in the east of Lower Saxony, comprises extensive agriculture, integrated heavy industry as well as the mining of toxic metals, and includes various power stations. Thus, the environmental chemicals such as the toxic metals and organochlorine residues in the human food chain are of great importance.

Within the last 10 years we have established an efficient cause-oriented system for monitoring the contaminants, using wildlife to indicate the residues, in the terrestrial ecosystems where also the production areas for human consumption are to be found. The advantages of this indication method are as follows :

1. Wildlife are directly confronted in their natural habitat with single or multiple pollutants all the year round. Therefore, the accumulation of different pollutants may follow the emission levels of their home ranges.

2. Wildlife seem to have a higher degree of contamination than farm animals [1-3]. Regional differences, therefore, can be observed more easily. The food chain of wildlife and the ruminants may have parallels thus giving us some information about the contamination degree in cattle and the human food chain.

\section{ACTIVITIES OF THE FIRST RESEARCH PROGRAM}

As a first step a research program was carried out, sponsored by the Ministry of Public Health in Bonn, where the levels of contamination in game had to be determined. Five differently structured regions, each with an area of $1500 \mathrm{~km}^{2}$, were selected in the east of Lower Saxony where different levels of contamination could be expected. The regional classification was programmed on the basis of previous data obtained from other indicators (fish and cattle). In Table 1 the influence of contamination to be expected is outlined. These areas are outlined on the map shown in Figure 1.

The selection of the indicators (roe deer, red deer, wild boar, hare, nearly 1500 animals) used in this study was made in accordance with different criteria (distribution, living area, biotop, nutrition) as summarized in 
Table 1. Different Contaminations ${ }^{a}$ to be Expected in 5 Regions in the East of Lower Saxony

\begin{tabular}{|c|c|c|c|}
\hline REGION & CONTAMINATION & EMISSIONS & AGRICULTURE \\
\hline 1. Lüchow-Dannenberg & Low & $\begin{array}{c}\text { No Industries, } \\
\text { Low Traffic }\end{array}$ & $\begin{array}{c}\text { Grain and Cattle } \\
\text { Production } \\
\text { Forestry }\end{array}$ \\
\hline $\begin{array}{l}\text { 2. Braunschweig } \\
\text { 3. Göttingen } \\
\text { 4. Helmstedt - Wolfsburg }\end{array}$ & Middle & $\begin{array}{c}\text { Industry and } \\
\text { Traffic Emissions }\end{array}$ & $\begin{array}{c}\text { Grain and Cattle } \\
\text { Production } \\
\text { Forestry }\end{array}$ \\
\hline 5. Goslar - Osterode & High & $\begin{array}{c}\text { Mining-Industry } \\
\text { Emissions }\end{array}$ & $\begin{array}{l}\text { Forestry } \\
\text { Cattle }\end{array}$ \\
\hline
\end{tabular}

Table 2. Questionnaires were sent out to the hunters asking for details of animals killed (species, sex, date killed, age, and weight) and for information

Table 2. Criteria for Bioindicators in Monitoring Studies

\begin{tabular}{|c|c|c|c|c|}
\hline CRITERIA & ROE DEER & RED DEER & WILD BOAR & HARE \\
\hline & $\begin{array}{c}\text { Capreolus } \\
\text { Capreolus L. }\end{array}$ & $\begin{array}{l}\text { Cervus } \\
\text { Elaphus L. }\end{array}$ & $\underset{\text { Sus }}{\text { Sorofa L. }}$ & $\begin{array}{c}\text { Lepus } \\
\text { Europaeus } P .\end{array}$ \\
\hline Distribution & $\begin{array}{l}\text { West } \\
\text { Europe } \\
\text { Near East } \\
\text { Iran }\end{array}$ & $\begin{array}{c}\text { West, South } \\
\text { East } \\
\text { Europe, Asia } \\
\text { North Africa }\end{array}$ & Eurasia & $\begin{array}{c}\text { West } \\
\text { Europe To } \\
\text { Ural }\end{array}$ \\
\hline \multirow[t]{2}{*}{$\begin{array}{c}\text { Living } \\
\text { Area }\end{array}$} & $\begin{array}{l}\text { q } 25-30 \mathrm{HA} \\
\text { o } 25-40 \mathrm{HA}\end{array}$ & $\begin{array}{l}5 \mathrm{Km} \text { and } \\
\text { more }\end{array}$ & To $250 \mathrm{HA}$ & $\begin{array}{l}94-10 \mathrm{HA} \\
0^{\prime \prime} 30-38 \mathrm{HA}\end{array}$ \\
\hline & FOREST & FOREST & FOREST & AGRICULTURAL \\
\hline Biotop & $\begin{array}{c}\text { Agricultural } \\
\text { Area }\end{array}$ & & $\begin{array}{c}\text { Agricultural } \\
\text { Area }\end{array}$ & $\begin{array}{c}\text { Area } \\
\text { Forest }\end{array}$ \\
\hline Nutrition & $\begin{array}{c}\text { Herbivore } \\
\text { Selecting } \\
\text { Concentrates }\end{array}$ & $\begin{array}{l}\text { Herbivore } \\
\text { Prefering } \\
\text { Roughages }\end{array}$ & Omnivore & $\begin{array}{c}\text { Herbivore } \\
\text { Selecting } \\
\text { Green } \\
\text { Grasses }\end{array}$ \\
\hline According $t$ & $\begin{array}{l}\text { to Ellenberg } \\
\text { Hofmann (19 } \\
\text { Müller ( } 198 \\
\text { Schneider }\end{array}$ & $\begin{array}{l}\text { 977), Fradrich } \\
\text { 8), Krautforst } \\
\text {, Raesfeld und } \\
978 \text { ) }\end{array}$ & $\begin{array}{l}\text { und Fradrich } \\
(1975) \text {, Meynha } \\
\text { Vorreyer (197 }\end{array}$ & $\begin{array}{l}973) \\
d t(1978), \\
)\end{array}$ \\
\hline
\end{tabular}




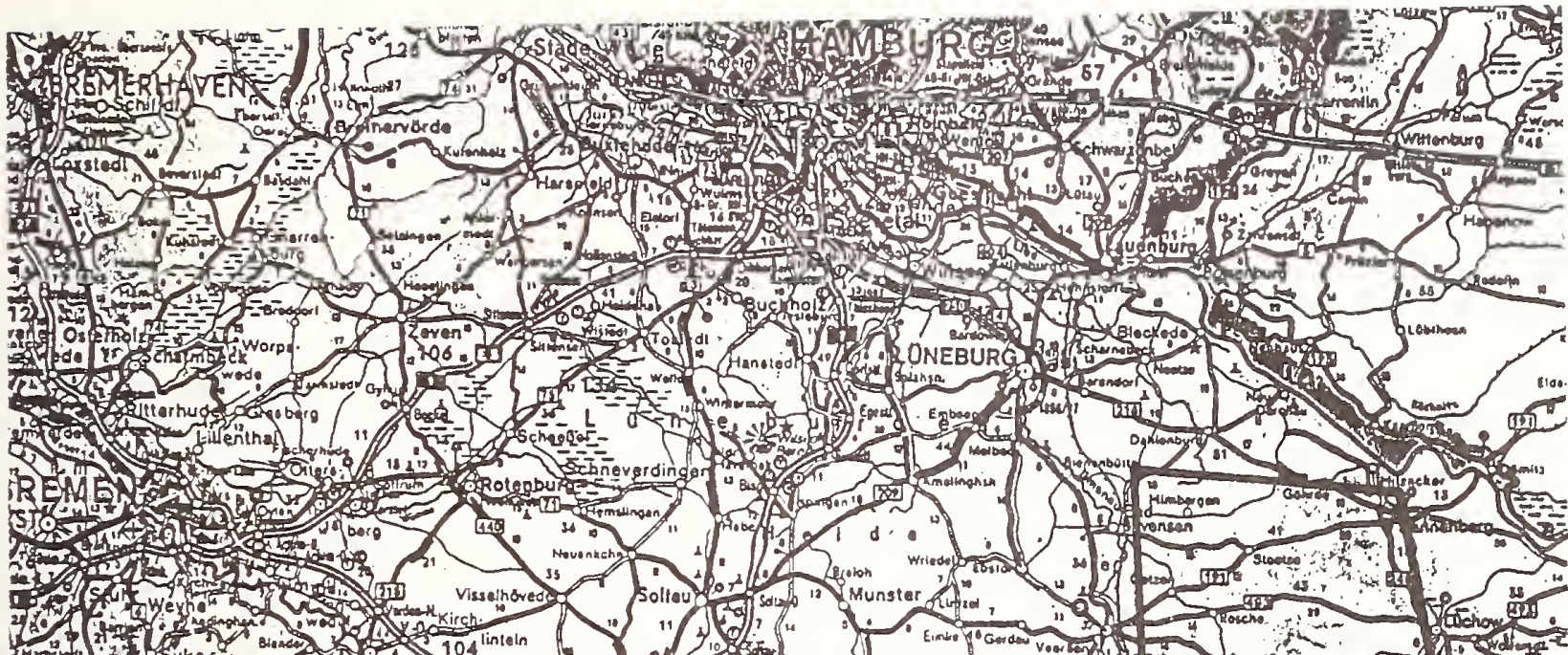

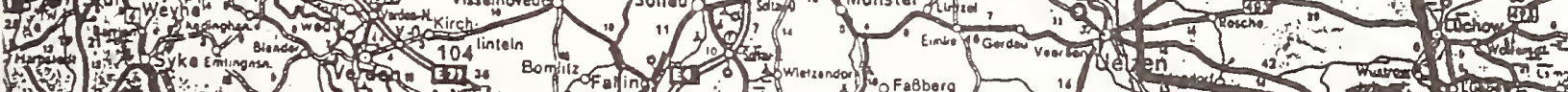
15.

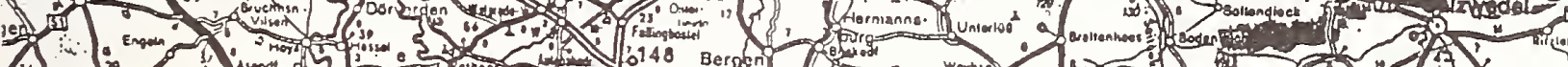
20.4. (1)

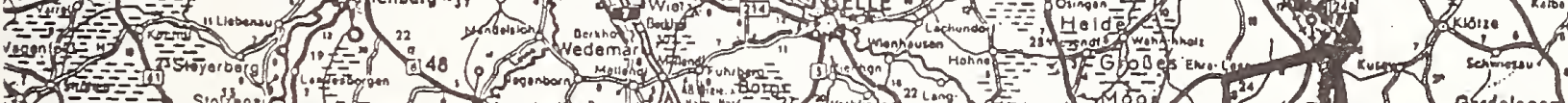
T. I) Ikenp po

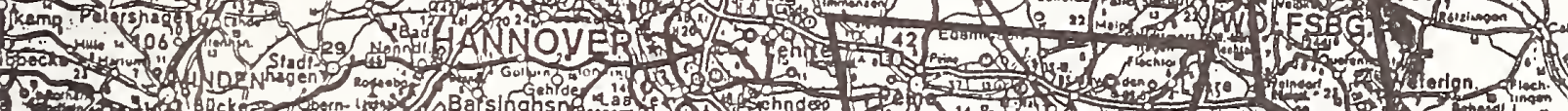

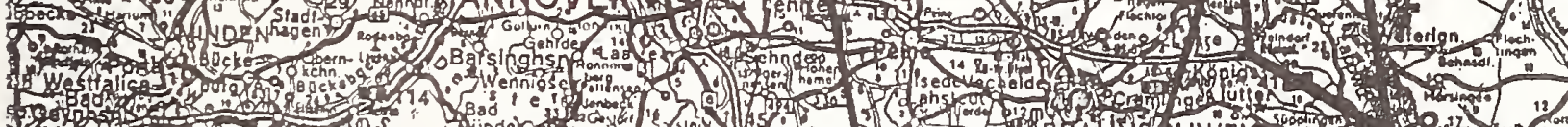
Fon.

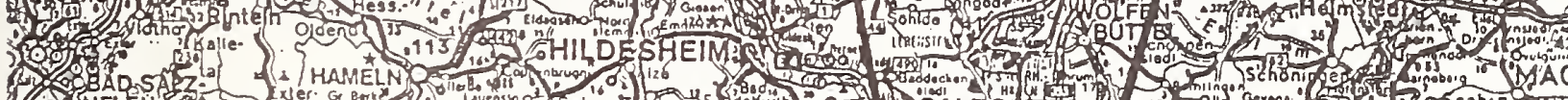

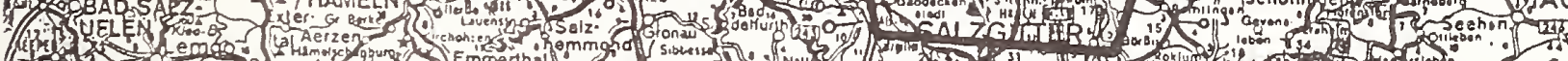

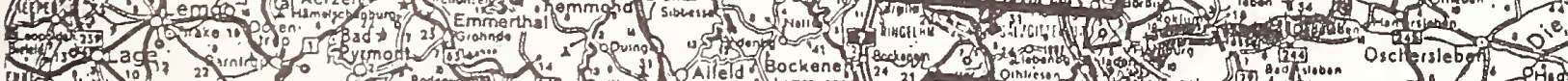

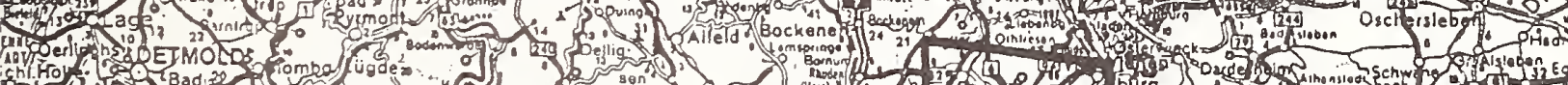

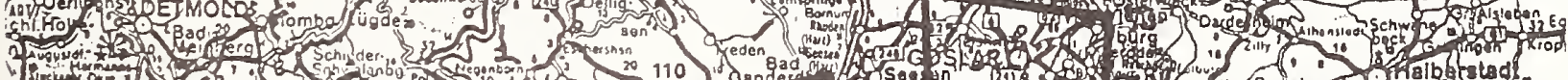
HAguth 19.1. a PA

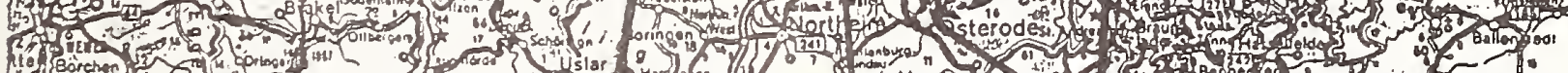

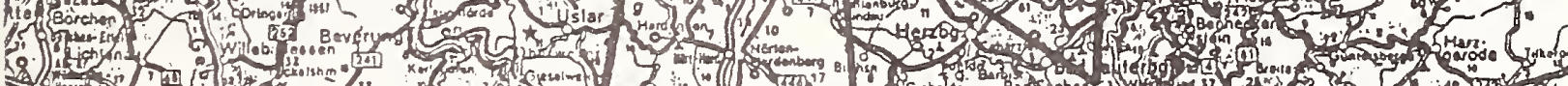
1.20) T.

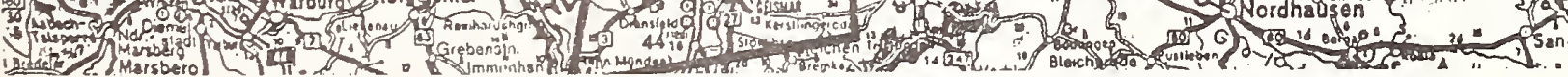

Figure 1. Regions for monitoring activities with wildlife in the east of Lower Saxony 
on the vegetation and other parameters of the region of origin. The analysis data (20,000 for lead, cadmium, mercury, and arsenic from liver, kidney, muscle, and hair) and 8,000 for the chlorinated hydrocarbons (body fat) were stored with the questionnaire data in an IBM 4341-2 computer with an SPSS statistical packet ( $\operatorname{Rel} 9$ ) [4]. The results of this study have been reported previously $[5,6]$ and are described briefly below.

1. The lead content increases from roe deer, red deer, wild boar to hare. Regional differences can be seen from 1 : 3 for roe and 1 : 12 for hare in low, middle, and high contaminated areas. The percentage frequency distribution of the lead content in liver confirms the results as shown in Figure 2 .

2. The cadmium content in the kidney is 57 times higher than in the liver. The lowest cadmium content can be found in red deer (see Figure 3). The hare, especially, demonstrates very high differences of the regional cadmium contamination. Mercury contamination is fairly high in wild boar and hare. Regional contaminations can be observed in areas of high agricultural production.

3. The regional differences of chlorinated hydrocarbons are fairly restricted (see Figures 4 and 5). Wild boar, in particular, have a somewhat higher DDT content (sum frequency function of random sample values for DDT), while hare have a lower PCB content in their body fat (Sum frequency function of random sample values for PCB).

Kleminger [7] defined the bioindicators in more detail in this project. He suggested selecting roe deer and hare for bioindication. Hares showed an excellent accumulation especially for toxic metals, but unfortunately they have disappeared in many ecosystems in Europe. Therefore, we decided to give roe deer the preference within the activities of the Environmental Specimen Bank [3]. The advantages are their widespread distribution, their high population densities, their easy availability, the relatively small home ranges they live in, and finally roe deer serve as man's food. During the hunting season of 1983/84 nearly 700,000 roe deer were killed in Germany.

When we calculated the residue contents of different wildlife species from the point of view of their influencing parameters (age, area of origin, etc.), we observed certain difficulties in the data set having a too high range of contamination. An example is shown in Figure 6 which shows the toxic metal contents in liver and kidney of roe deer in different areas of Lower Saxony. Figure 6 summarizes the lead and cadmium content of liver and kidney in different age groups in areas with low, middle and high contamination. Although we know that animals from areas with high contamination should also have the highest cadmium contents, the diagram indicates otherwise. One reason is the different numbers within the age groups, so that the age parameter overlaps the region of origin parameter. 
groups with

low and middle contamination
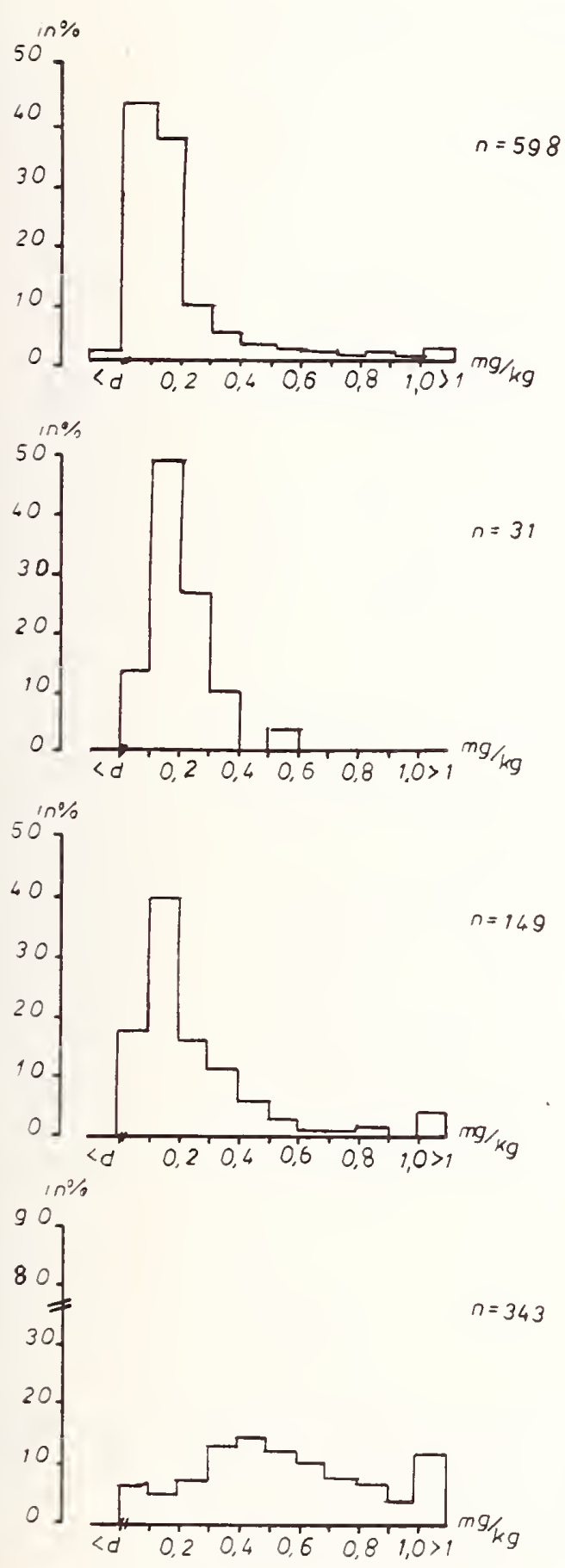

wild boar

hare

$d=$ detection limit

mean value in $\mathrm{mg} / \mathrm{hg}$ wet weight

Figure 2. Percentage frequency distribution of lead content in liver of various wildlife groups with

high contamination $n=116$
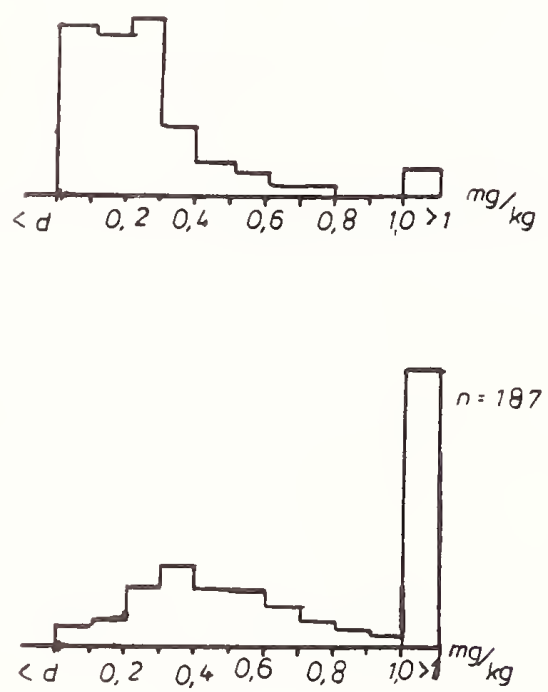

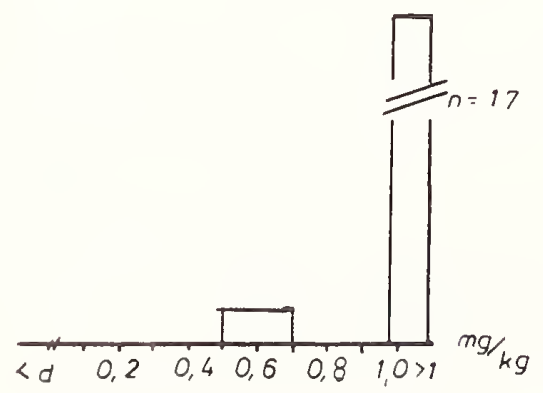


groups with

low and middle contamination
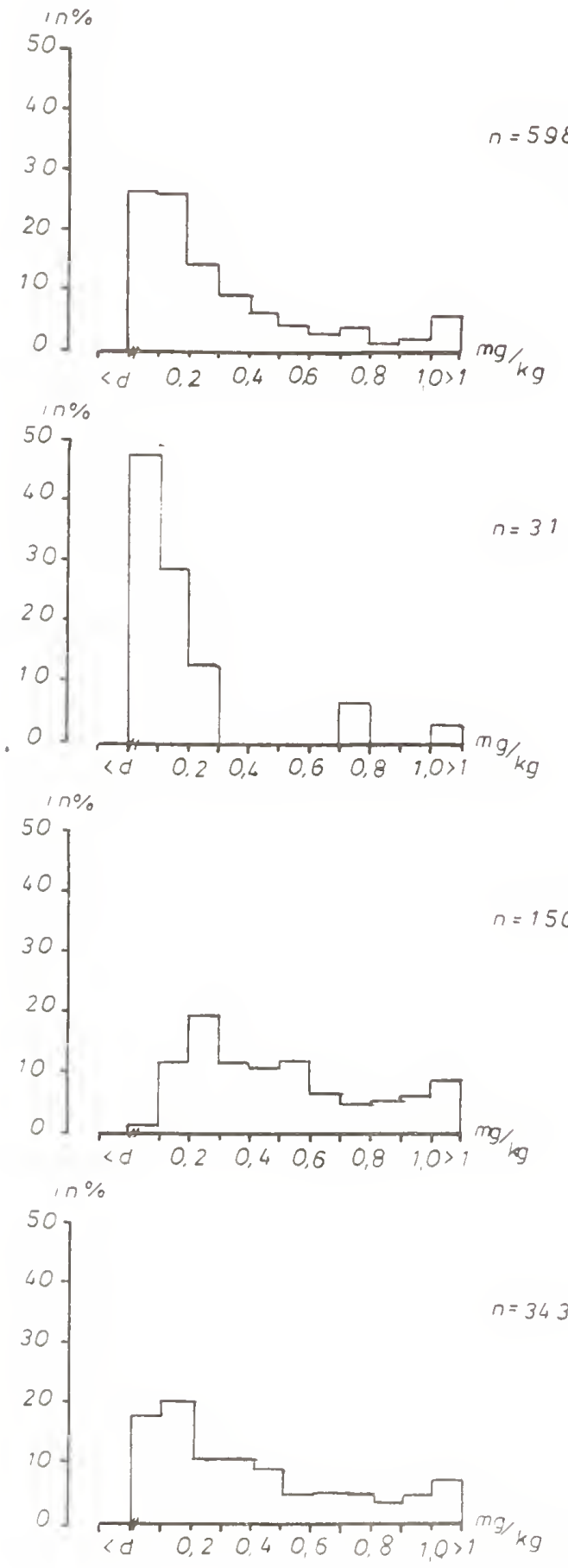

$d=$ detection $l, m i t$

mean value in $\mathrm{mg} / \mathrm{hg}$ wet weight groups with

high contamination

roe deer

red deer

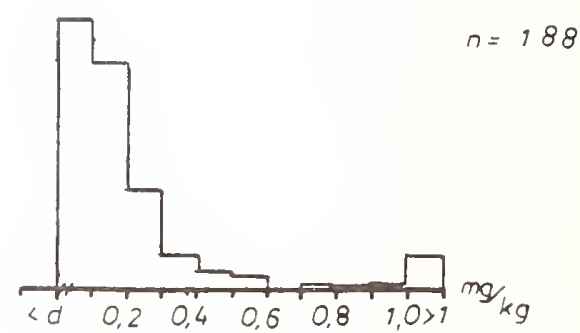

wild bogr

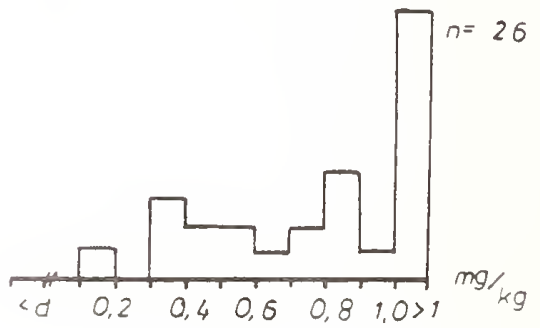

hare

$n=17$

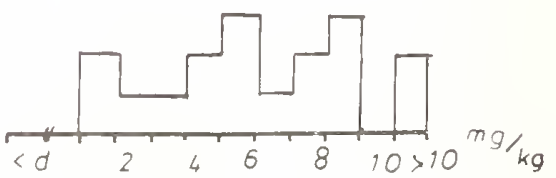

Figure 3. Percentage frequency distribution of cadmium content in liver of various wildlife 


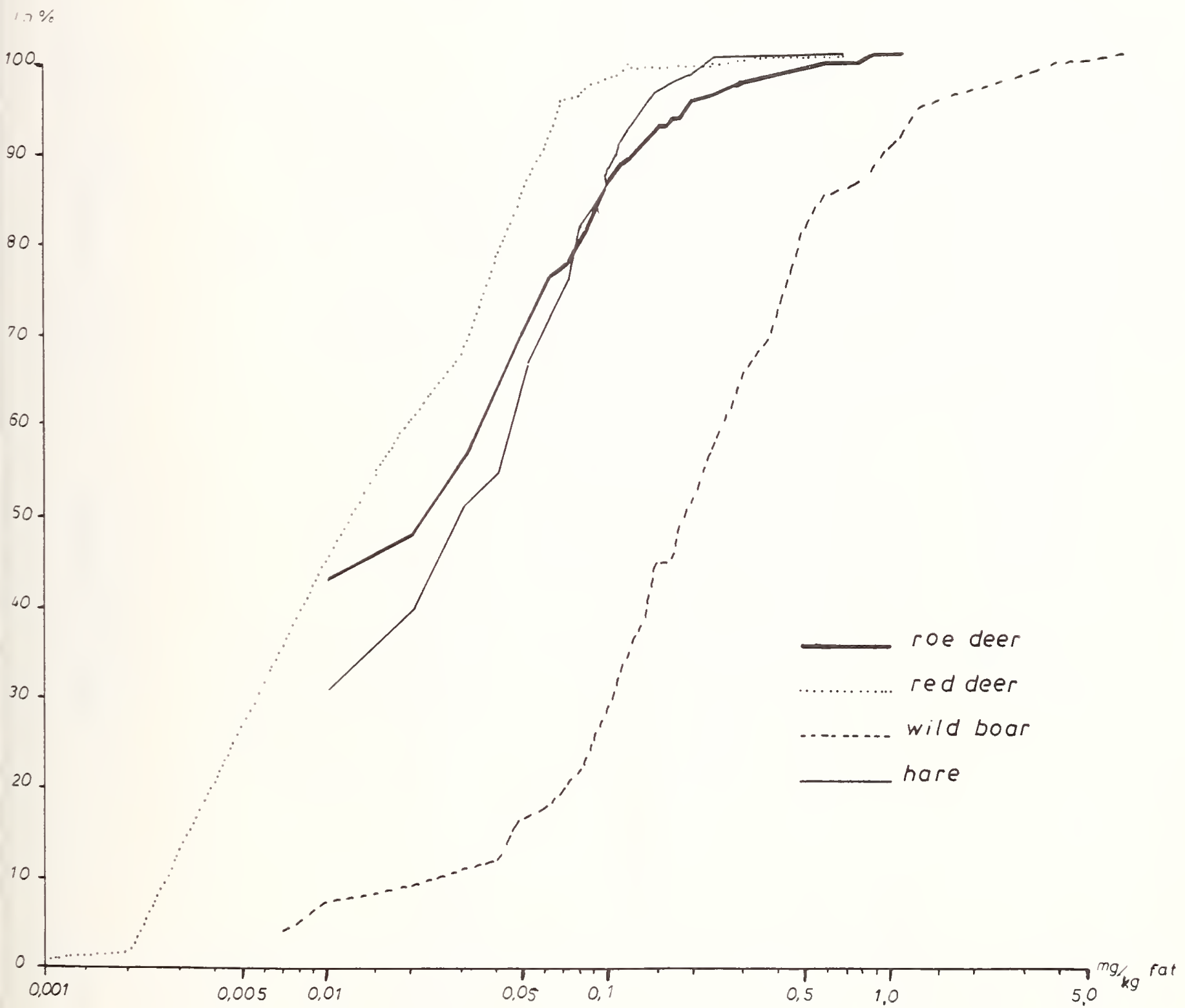

Figure 4. Sum frequency function of random sample values for DDT in various wildlife 


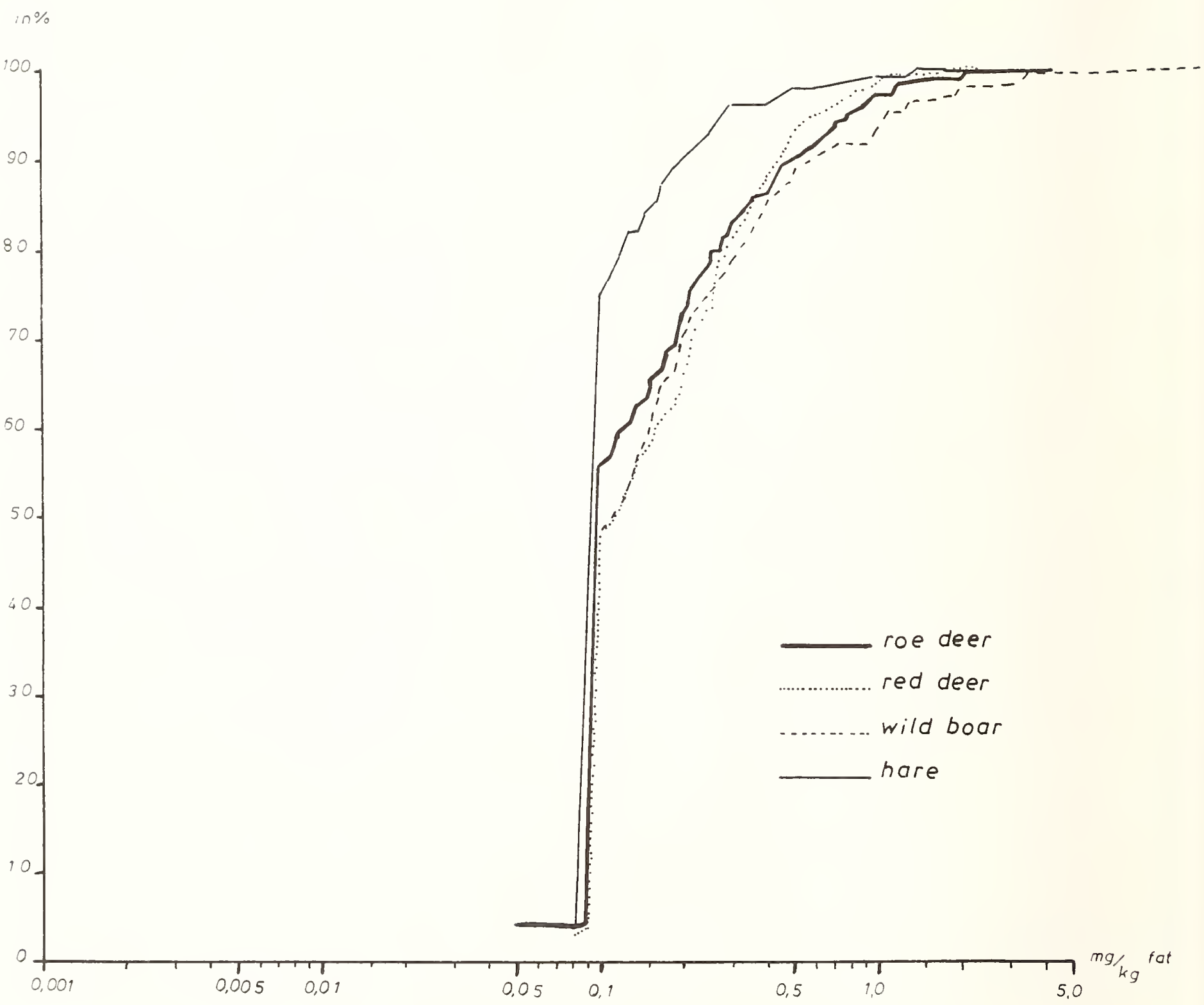

Figure 5. Sum frequency function of random sample values for $P C B^{\prime} s$ in various wildlife 

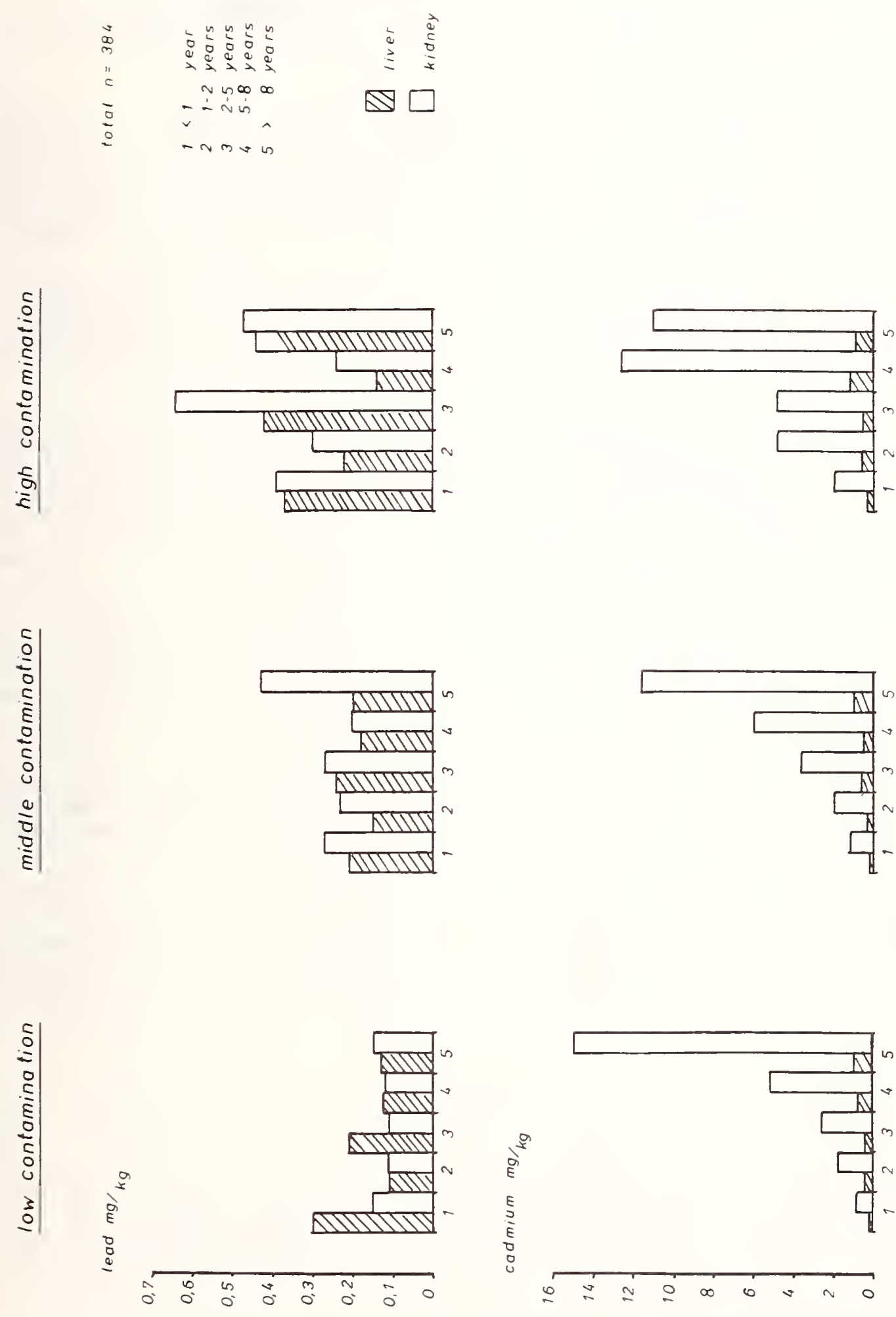

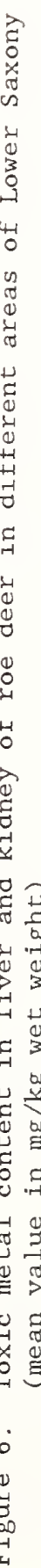


III. WORKING MODEL FOR THE BIOINDICATOR ROE IN THE ENVIRONMENTAL SPECIMEN BANK

\section{A. Sampling}

The reasons for taking roe into the Specimen Bank have been outlined. Since the areas we took the samples from within the first research program were relatively large, we now decided to limit the areas to three forestries having a size of only 8,000 hectare each. In addition, the age was limited by choosing yearlings which represent the largest group within a hunting season.

These decisions were supposed to limit the influence of the parameters "region" and "age" so as to enable us to observe the contamination range of the indicator more exactly. Thus, we hope to stabilize the indicator for trend analyses in the Specimen Bank.

One main problem to be solved is the correct sampling of organs for the Specimen Bank. Since the chlorinated hydrocarbons were taken on a priority list of studies for the Specimen Bank, the question of organotropy should be solved for these contaminants. Of further interest are also the toxic metals and other relevant elements. In order to establish the best accumulation, we chose the liver, kidney and brain, which, along with the body fat, will be checked for a period of two years in the three forestries involved.

The hunters were trained to collect liver and kidney samples not contaminated by shot, vegetation, or intestinal injury. The samples are collected at the forestry stations in freeze packs and the fresh material is sent immediately to the Veterinary Institute in Braunschweig. After the organs have been inspected and prepared they are frozen to a temperature of $-80{ }^{\circ} \mathrm{C}$. The liver is subdivided for pesticide and metal analyses, and the necessary amounts are reserved for the Specimen Bank in Jülich. The right kidney is reserved totally for Jülich, where already more than 130 organs have been collected and deep frozen.

The analysis work is carried out after homogenization. A sophisticated clean up of the samples is used prior to analysis by capillary gas chromatography. The determination of 15 elements is performed by inductively coupled plasma (ICP) spectroscopy after wet digestion.

\section{B. Chlorinated Hydrocarbons}

The mean values for chlorinated hydrocarbons in 19 yearlings from the forestry in Braunschweig are listed in Table 3. We observed a significantly higher contamination with chlorinated hydrocarbons in the liver than in the kidney. Furthermore, the range of contamination seems to be rather narrow. The main $\mathrm{CH}$ components to be found in the liver are $\alpha$-BHC, $\beta$-BHC, $\tau-\mathrm{BHC}$ and 4,4'-DDE. The PCB's are mentioned in Table 3 that now are controlled in the human food chain. We observed significantly higher contents for PCB 52, 138, 153 compared with the other components. 
Table 3. Chlorinated Hydrocarbons ${ }^{a}$ in Organs of One Year old Roebucks from the Forest Near Braunschweig

\begin{tabular}{|c|c|c|c|c|}
\hline \multirow{2}{*}{$\begin{array}{c}\text { Chlorinated } \\
\text { Hydrocarbons }(\mathrm{CH})\end{array}$} & \multicolumn{2}{|c|}{ Liver } & \multicolumn{2}{|c|}{ Kidney } \\
\hline & Mean & Std. Dev. & Mean & Std. Dev. \\
\hline$\alpha-B H C$ & 0.304 & 0.24 & 0.025 & 0.01 \\
\hline$\beta-\mathrm{BHC}$ & 0.245 & 0.18 & 0.130 & 0.05 \\
\hline $\boldsymbol{\gamma}-\mathrm{BHC}$ & 0.086 & 0.04 & 0.100 & 0.09 \\
\hline$\sigma-\mathrm{BHC}$ & 0.024 & 0.02 & ND & - \\
\hline $\mathrm{HCB}$ & 0.054 & 0.04 & 0.033 & 0.02 \\
\hline $4,4^{\prime}-\mathrm{DDE}$ & 0.154 & 0.17 & 0.038 & 0.03 \\
\hline $4,4^{\prime}-\mathrm{DDD}$ & 0.061 & 0.03 & ND & - \\
\hline $4,4^{\prime}-\mathrm{DDT}$ & 0.014 & 0.01 & ND & - \\
\hline Heptachlor & ND & - & ND & - \\
\hline Trans HCEP & ND & - & ND & - \\
\hline OCS & 0.009 & 0.02 & ND & - \\
\hline PCB 28 & 0.018 & 0.02 & 0.022 & 0.02 \\
\hline PCB 52 & 0.035 & 0.03 & 0.041 & 0.02 \\
\hline PCB 101 & 0.013 & 0.01 & ND & - \\
\hline PCB 138 & 0.073 & 0.04 & 0.024 & 0.01 \\
\hline PCB 153 & 0.076 & 0.04 & 0.025 & 0.01 \\
\hline PCB 180 & 0.030 & 0.02 & 0.017 & 0.01 \\
\hline $\begin{array}{l}\text { a Mean values in } \\
\text { ND }=\text { Not Detecta }\end{array}$ & fat, $\mathrm{N}$ & & & \\
\hline
\end{tabular}

\section{Trace Elements}

The trace element determination by ICP created difficulties since the detection limits of some elements are high. Therefore, the ICP method for element determination in mammals is also criticized, because the contents are partly too low. In the last two years, we have developed a digestion method with high tissue concentration and a suitable aspirator.

In Table 4 the elements and their limits of detection are summarized. From $\mathrm{Ca}$ to $\mathrm{Zn}$ the concentration in liver and kidney in roebucks is well over the detection limit; however, from $\mathrm{Al}$ to $\mathrm{V}$ the determination may become difficult, and $\mathrm{Pb}, \mathrm{Sb}, \mathrm{Tl}$ are not detectable by this method. Liver and kidney seem to have different abilities for accumulating the elements.

\section{CONCLUSION}

The results demonstrate that the liver might be the organ from roe deer to be sampled and stored in the Specimen Bank. The organ offers enough material for multiple analysis of different contaminants. The distribution of the elements and the chlorinated hydrocarbons is very homogeneous, so that subsampling of this organ is possible. The accumulation of the contaminants seems to be higher than in the kidney. 
Table 4. Limits of Detection for Elements Determined by ICP

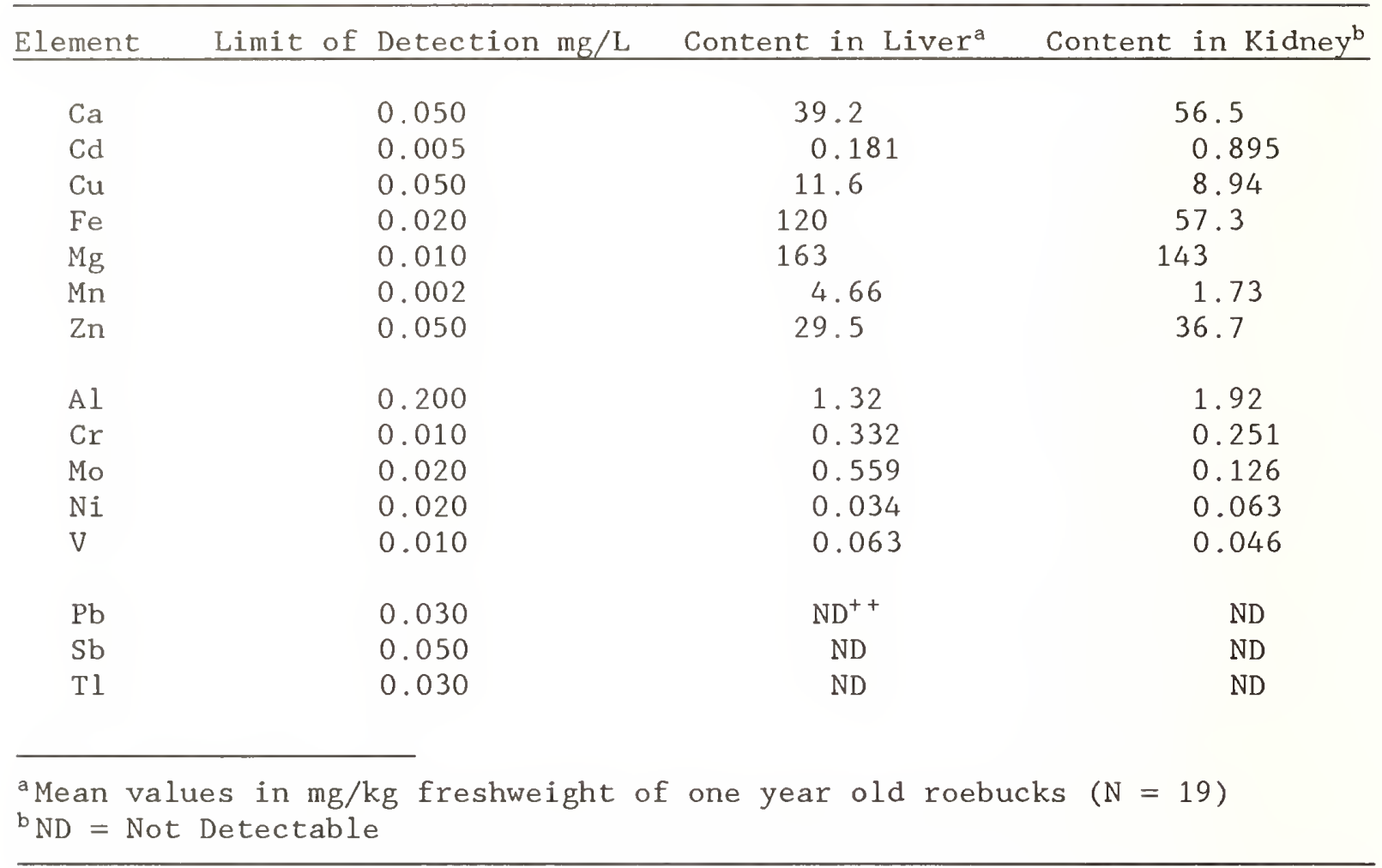

\section{REFERENCES}

[1] Hecht, H. (1986), Unterschiede im Schwermetallgehalt bei Haus- und Wildschweinen und ihre Ursachen, Mitteilungsblatt der Bundesanstalt für Fleischforschung Nr. 92, 6962-6970.

[2] Holm, J. (1985), Uberwachungsmodelle für Umweltkontaminanten in Form von Monitoringsystemen, Fleischwirtsch. 65, 1405-1407.

[3] Müller, P. (1985), Cadmium-Konzentrationen bei Rehpopulationen (Capreolus capreolus) und deren Futterpflanzen, Zeitschrift für Jagdwissenschaft 31 , $146-153$.

[4] Holm, J. (1983), Aufbau eines ursachenorientierten Monitoring-Systems für Schadstoffbelastungen beim Wild, Problemstellung und Aufbau des MonitoringSystems, Fleischwirtsch. 63, 1764-1766.

[5] Holm, J. (1984), Belastungen von wild mit Schwermetallen aus unterschiedlich strukturierten Herkunftsgebieten, Fleischwirtsch. 64, 613-619.

[6] Holm, J. (1984), Belastungen von Wild mit chlorierten Kohlenwasserstoffen aus unterschiedlich strukturierten Herkunftsregionen, Fleischwirtsch. 64, 970-973. 
[7] Kleiminger J. (1983), Untersuchungen über die Eignung von freilebenden Wildarten als Bioindikatoren zur Erfassung von flächenhaften Schwermetallkontaminationen in Niedersachsen, Hannover vet. med. Diss.

[8] Kleiminger J. and Holm, J. (1985), Aufbau eines ursachenorientierten Monitoring-Systems für Schadstoffbelastungen beim Wild, Wahl eines geeigneten Bioindikators für die Anzeige von Schadstoffen, Fleischwirtsch. 65, 394-399. 


\title{
SECTION 16
}

\section{REGIONAL MONITORING OF POLLUTANTS WITH HONEY BEES}

\author{
Jerry J. Bromenshenk \\ Department of Zoology \\ University of Montana \\ Missoula, Montana 59812 \\ USA
}

\section{INTRODUCTION}

Identification and mitigation of problems associated with hazardous chemicals is a worldwide concern. Vast quantities of toxic chemicals are produced, transported, and used throughout the world. There are opportunities for entry of these materials into the environment at each stage in their existence. Anthropogenic materials are continually moved across natural and political boundaries by man, or by physical and biological processes [1]. Contaminants end up in air, soil, water, and eventually in living organisms. Monitoring programs are needed to detect serious environmental contamination before critical or irreversible damage has been sustained [2].

Effective monitoring of this myriad of substances is confounded by our lack of knowledge about the potential hazards. Often, we are unable to predicate the consequences of chronic exposure to mixtures of chemicals, understand mechanisms of action, identify indirect as well as direct effects, or determine the assimilative capacity of ecosystems [3].

We can detect incredibly small quantities of many substances, but their hazard to man, other organisms, and ecosystems is largely unknown. Improved measurement procedures do not necessarily increase our ability to extrapolate to biological effects. Environmental protection is a biologically oriented goal: the protection of life. Attainment of that objective can only be determined by assessing biological parameters [4]. Although considerable research has been conducted to develop biologically oriented monitoring capability, only a few examples of dedicated ongoing biomonitoring programs exist, and few have any legal status.

\section{BIOMONITORING AND SPECIMEN BANKING}

We define biomonitoring as any biologically based measurement of environmental quality. Bioindicators like the miner's canary, some lichens, and certain aquatic invertebrates, generally display rapid, unambiguous responses such as presence or absence, avoidance, or death. Usually, indicator organisms are particularly sensitive to changes in environmental conditions. They often are not well suited for long-term monitoring. For example, the death of the miner's canary provides an immediate warning of toxic gases but yields no further information. 
Ideally, a monitor organism, unlike an indicator, should be relatively hardy so that responses can be assessed over extended periods of time. In addition, a biomonitor should possess one or more readily quantified parameters that can be related to pollution exposure levels and any environmental effects.

Specimen banking provides extended monitoring capability over time. Deferred analysis provides a means of retrospectively examining environmental problems as we become aware of them or as new techniques are made available for investigation [5]. Specimen banking often emphasizes sampling and analyses of environmental scavengers, organisms that accumulate or concentrate chemicals.

This perspective turns our attention to biological receptors and essential issues such as bioavailability and bioeffects, rather than merely quantifying amounts of specific contaminants in air, soil, or water.

As specimen banking moves from pilot phases to established programs, fiscal commitments must be made, since most specimen banks rely upon cold storage facilities. Loss of adequate funding would jeopardize current activities and all preceding efforts. Maintenance of cold storage places a high priority on long-term undertakings.

Real-time biomonitoring programs in the United States, and presumably other countries, are frequently subjected to unpredictable fluctuations in funding, justification being that sampling efforts can be temporarily reduced or suspended. This on-off approach has seriously hampered development of biomonitoring techniques, establishment of long-term monitoring programs, and our ability to follow environmental trends.

Protection of human health and the environment requires not only a commitment to monitoring and banking programs, but also requires further chemical, toxicological and ecological research, development of control technologies, hazard assessments, improved data management, and international cooperation [1-3]. Unfortunately, the cost of these activities precludes testing and monitoring all potentially toxic chemicals [1].

This underscores the importance of specimen selection and the need to link specimen banking and real-time monitoring, especially if we bank materials to assess potential environmental problems that may transpire in the future. Our ability to store samples is limited. Materials selected for banking should be indicative of properties valued by humans, especially those pertaining to welfare and health. Samples must be ecologically and chemically meaningful as well as representative of environmental conditions [1-3,5].

These issues received considerable attention at the 1978 and 1982 international workshops on banking and environmental monitoring. A variety of organisms were recommended for environmental monitoring. The actual species or set of species selected is dependent on monitoring objectives, the aforementioned issues, and site-specific considerations [2,3]. 


\section{HONEY BEES AND REAL-TIME MONITORS}

Following the 1978 international workshop, the U.S. Environmental Protection Agency (EPA) sponsored a pilot investigation of the feasibility of using honey bees (Apis mellifera) for monitoring and banking. The pilot study built upon work initiated in 1974 at the University of Montana (UM). In 1982, investigators from the quantitative ecology and statistics divisions of Pacific Northwest Laboratories (PNL) joined the UM and the EPA in a cooperative research effort. By 1985, we were using honey bees in application modes to determine exposure levels, identify sources, and map the distribution of trace elements and radionuclides.

Beekeepers have long associated bee mortalities with exposure to industrial effluents. One of the earliest damage awards resulted from a 1912 legal suit filed by a beekeeper against a lead and silver work located on the Rhein [6]. In 1972, Debackere [7] noted that honey bees could serve as pollution indicators in a review of air pollution, bee mortalities, toxicity data, and transfer of various industrial chemicals to pollen, nectar, water, and bees. Shortly thereafter, studies appeared that focused on developing the biomonitoring potential of bees [8-48].

A bee colony contains thousands of forager bees. They forage relatively large areas ( $7 \mathrm{~km}^{2}$ or more, assuming they fly $1.5 \mathrm{~km}$ from the hive). During each flight, a bee may sample up to 350 flowers and may undertake more than 100 trips per day [49]. Thus, it is not surprising that bees provide spatially integrated and averaged samples of their forage area $[11,31,41,46,47]$.

Honey bees return to their hives with nectar, honeydew, pollen, resin, and water. They sometimes 'mistake' dusts and powders for pollen [10] and caulking materials for resin [50]. Their bodies may be contaminated by air pollutants while flying or by contacting dusty surfaces. Electrostatic charges on the surface of the bee may play a role in the gathering of small particulates [47]. Pollutant uptake into body tissues may occur from ingestion, inhalation, or absorption through the exoskeleton [7]. Contamination of nectar and pollen may occur via direct contact with chemicals in the ambient air, from wind resuspended soils, or by transfer through plant tissues from soil or water. Control of hive temperature and humidity by fanning to promote air circulation and the spreading and evaporation of water constitutes other potential mechanisms for the introduction of contaminants into bee systems [7,10,31,41,46,47]. Bees encounter contaminants in or on air, water, soil, or plants, effectively providing multi-media monitoring $[46,47]$.

\section{MONITORING POLLUTANTS BY RESIDUES IN BEES AND BEE PRODUCTS}

Extensive studies have been made on pesticides and their effects on bees. A complete review of the pesticide literature is beyond the scope of this paper. The Agricultural Act of 1970 authorized the U.S. federal government to indemnify bee losses due to the use of registered and approved pesticides. Documentation of losses required proof of pesticide exposure, usually based on chemical analysis of dead and dying bees [49]. Although this program no longer exists, it generated well-developed procedures for determining pesticide 
residues in bee tissues as well as other indicators of poisoning such as reduced brain cholinesterase levels [51].

A three year Italian study combined bee mortality data analysis of pesticide residues to identify pesticide pollution in the province of Forli. In orchards where bee mortalities were highest, bees, larvae, and honey contained $17.0,1.64$, and $1.68 \mathrm{ppm}$ of dithiocarbamates, respectively, as well as residues of DDT/DDE and organophosphates [33].

Pesticides can be monitored with bees even when dosages are below toxic levels. In eastern Montana, we found trace levels of the DDT/DDD/DDE chlorinated hydrocarbon complex in forager bees collected live at all 14 apiaries sampled in 1975 and 7 of 11 apiaries sampled in 1976 [18]. These apiaries were located on rangeland near alfalfa fields where DDT application had been banned ten years earlier.

In addition to pesticides, radioactive and trace elements, especially heavy metals, have been monitored using bees, honey, or bee-collected pollen. Investigators at Cornell University, USA [10] examined 47 elements in honey bought from groceries and collected from bee colonies near underground zinc mines, a major highway, and an industrial area in Niagara County, New York. They found elevated levels of several chemicals from automobile exhausts and industries. Honey processed in a galvanized metal extractor had elevated levels of zinc, while high levels of tin were thought to have come from processing or storage in metal containers. In another study, Cornell researchers examined 16 elements in honeys from around the globe. Concentrations of iron varied from 5.8 to $183 \mathrm{ppm}$, zinc from 2.0 to $172 \mathrm{ppm}$, while chromium and nickel levels paralleled the concentration of iron in some samples. Variations in elemental concentrations were thought to be a result of leaching from metal containers, industrial pollution, or naturally occurring variations in soil geochemistry [24]. In another study, they found that pollen collected by bees foraging on asters growing on a New York fly ash dump contained high concentrations of selenium [14]. A post-closure investigation of a nuclear reprocessing plant did not discern any measurable amounts of beta or gamma emitting elements in honey, pollen, propolis, or water [19]. Nor could any significant increase in gamma-radiation be detected in honey collected within $16 \mathrm{~km}$ of the Three-Mile Island nuclear power plant after an accidental release of radioactive materials in March 1979 [25].

For many years, honey bees have been utilized as a constant surveillance monitoring system of radioactive waste disposal sites at Los Alamos National Laboratory in New Mexico, USA. Hakonson and Bostick successfully used bees to determine the bioavailability of radioactive tritium, 137-cesium, and plutonium. Concentrations of these radionuclides in bees closely followed fluctuations of radionuclides in other components of the surrounding environment. Tritiated water was most readily transferred to hive components, including honey, but there appeared to be discrimination against transfer of 137-cesium to honey [12]. This research led to the establishment of a monitoring network of bee colonies, which is maintained at potentially contaminated areas at the Laboratory. As an example, honey samples from 1980 contained low levels of 7-beryllium, 137-cesium, tritium, and 22-sodium, and undetectable levels of 
mercury, 238-plutonium, and 239-plutonium. One sample from a hive near a waste stream outfall had detectable levels of uranium [31].

In a cage feeding experiment, uranium uptake by bees was investigated using syrup spiked with an uranium tracer. Highest uranium concentrations were found in the bees themselves with lower levels in comb, larvae, and honey [26]. Another caged bee study examined tritium kinetics in honey bee colonies. Bees were fed tritium and measurements made of rates of uptake and depuration. An attempt was made to model the results and apply them to field situations. The model was not satisfactory, probably because accurate predictions of stack releases were impossible due to variable wind patterns in complex terrain and time-dependent variations in tritium releases [39].

At Los Alamos, the highest concentrations of tritium, cesium, and uranium occurred in the bees themselves. Investigators at the Oak Ridge National Laboratory, Tennessee, USA, also placed bees near waste disposal sites. Bees foraging for pollen or nectar showed little evidence of radioactive contamination, but water brought back to the hive for evaporative cooling provided a mechanism for radionuclide transfer to colony components [43].

Our ongoing research includes deploying bees at other USA facilities near radioactive waste disposal sites (in ponds or buried), nuclear reprocessing plants, and nuclear power plants. Our initial results indicate that bees can be used to monitor an array of radionuclides, including 137-cesium, tritium, 60-cobalt, 51-chromium, and 65-zinc. Significantly elevated levels of gamma emitting radiation was observed in adult bees, but not necessarily pollen or brood. At one site, 137-cesium found in pollen was transported to hives by pollen foraging bees, but not by nectar or water gatherers [51].

In Pennsylvania, USA, lead levels in honey bees were compared to those of wildflowers frequented by the bees. Flowers from a site located along a highway contained an acreage of $13.6 \mathrm{ppm}$ lead; flowers from the control site $0.2 \mathrm{ppm}$. Lead concentrations in bees were $28.1 \mathrm{ppm}$ near the highway and 1.4 for the control site. Analysis of bee legs revealed concentrations of lead in excess of $50 \mathrm{ppm}$, which suggest pollen as a more likely route of accumulation than nectar [30].

European researchers also have used bees to monitor inorganic elements. Honey was obtained from 18 locations near Stolberg/Rheinland, FRG, where the air contains high concentrations of lead and cadmium. Honey samples had 0.016$0.8 \mathrm{ppm}$ lead and 0.009-0.125 ppm cadmium. A sample of pollen, one of beeswax and two samples of propolis had considerably higher levels of lead and cadmium than honey: $2.1 \mathrm{ppm}$ lead, $0.322 \mathrm{ppm}$ cadmium; $6.2 \mathrm{ppm}$ lead, $0.103 \mathrm{ppm}$ cadmium; and $41 \mathrm{ppm}$ lead, $0.327 \mathrm{ppm}$ cadmium, respectively. A correlation was found between lead and cadmium in honey and in dust $(r=0.76, r s p .0 .50)$ [45]. In West Berlin, a study of 2600 urban colonies was initiated to monitor heavy metals. Lead concentrations in honey varied from $0.02-1.8$ ppm [37]. A Dutch investigation found wide variations in the lead and cadmium contents of honeys attributable to species of plant foraged, geographic region, and whether honey was derived from nectar or honeydew. Average lead and cadmium levels were somewhat higher for honeydew honey than floral honey: $0.89 \mathrm{ppm}$ lead and 0.018 
ppm cadmium versus $0.31 \mathrm{ppm}$ lead and $0.014 \mathrm{ppm}$. A sample of honey from California contained $0.76 \mathrm{ppm}$ lead and $0.016 \mathrm{ppm}$ cadmium [36].

In a Bulgarian study, pollen and honey collected near two copper mills contained higher than normal levels of copper, zinc, and phosphorus. Hive samples from various regions, including agricultural areas, also displayed widely varying levels of manganese, cobalt, iron, sodium, calcium, and potassium. Trace element content of pollen was 2 to 3 times higher than that of honey [9]. In a Great Britain study of nineteenth century copper mining region, bee-collected pollen contained elevated levels of manganese, zinc, copper, and lead and reflected those of stream sediments. Using the published data, we computed coefficients of variation ( $C V^{\prime} s$ ) for within site variation due to colony specific differences in metal concentrations. For duplicate samples of pollen from six colonies per site, $\mathrm{CV}^{\prime}$ s ranged from 4.3 to $81.2 \%$. The authors concluded that differences in trace element uptake by each species of plant would account for much of the variability [34].

A study conducted during summer and winter in an industrial region near Saarbrucken, FRG, examined the bees themselves, rather than pollen or honey. Bees displayed levels of cadmium ranging from 0.4 to $3.1 \mathrm{ppm}$ and lead from 2.6 to $69.1 \mathrm{ppm}[35]$.

These findings are consistent with our own studies near smelters in western Montana, coal-fired power plants in eastern Montana, in rural, urban, and industrial zones of the Puget Sound region of Washington, and in agricultural and semi-arid desert regions of eastern Washington and central Idaho $[8,16-18,20,22,23,28,29,32,40,42,46-48]$. We mapped widespread distribution (over thousands of square kms) of arsenic, cadmium, and fluoride based on concentrations of contaminants in bees. We also detected widely varying levels of lead, copper, zinc, nickel, titanium, strontium, bromine, iron, rhodium, aluminum, and manganese. Levels of most of these chemicals in pollen approximated those in bees, except for fluoride which was much higher in bees. sontaminant levels in pollen displayed greater temporal and colony specific variability than concentrations in bees. CV's for arsenic and cadmium in bees averaged about $20 \%$ and were dependent on time of year, proximity to source, and other factors [47].

Several authors have suggested that bees concentrate or biomagnify certain elements. This is clearly evident for air-or water-borne fluoride. Fluoride levels in bees usually exceeded those of air, water, or pollen by one or more orders of magnitude $[17-18,22,23,28,42,47]$. In a study of an aluminum reduction facility, fluoride content of bees provided a means of statistically distinguishing more differences in exposure levels among sites than did calcium formate plates (static air monitors). In addition, decreasing fluoride levels in bees over a period of several years provided evidence that curtailment of emissions as evidenced by improved air quality was mirrored by bees. Partial correlation analysis suggested that the bees accumulated substantial amounts of fluoride from the air, while pollen and plant blossoms (sources of nectar and pollen) contributed considerably less fluoride than air [42]. 


\section{CHOICE OF COLONY COMPONENT FOR MONITORING}

During our 12 years of research with honey bees, we have examined a wide array of trace and radioactive elements in forager bees, nurse bees, pupae, pollen, honey, and wax. We have chosen the forager bee as the primary sample unit. Contaminant concentrations in forager bees tend to be equal to or greater than levels in nurse bees, pollen, or wax and usually are higher than levels in honey. Forager bees are the oldest bees in a colony (longest exposure time), are easy to obtain, and provide a temporally and spatially integrated sample of air, soil, water, and vegetation [47]. Pollutant concentrations in bees display less within colony, between colony, and temporal variability than levels in pollen or wax.

Other investigators have chosen honey for their primary sample unit, probably due to the potential of ingestion of toxic chemicals by humans. However, concentrations of toxic pollutants generally are lower in honey than in bees or pollen and, to the best of our knowledge, reported values usually are not thought to constitute a hazard to consumers.

Pollen constitutes another potential means of transfer of toxic chemicals to human. In recent years, pollen has been marketed as a 'health food'. We found that concentrations of toxic elements such as arsenic, cadmium, and lead in pollen collected near smelters often exceeds safety standards for other food products (unpublished data). However, most pollen sold in US stores is collected from rural areas, few people eat pollen, and those who do usually ingest small quantities. It seems unlikely that human exposures to toxic substances in pollen would exceed acceptable health safety guidelines.

We have found bee-collected pollen useful for providing information about levels of hazardous chemicals in or on plants. Combining this knowledge with microscopic identification of plant species yields information about the specific areas and plants foraged and helps pinpoint the locality of the pollutant source.

Beeswax offers a possibility of providing a historic record of pollutant exposure, since the comb in a hive may be many years old. We found that concentrations of heavy metals varied widely in wax sampled from different places within the same hive. The amounts appeared to be dependent on the age of the wax, i.e., new wax contained lower levels than old. We are unaware of any practical way of accurately determining the age (days-years) of wax in existing hives.

Propolis has seldom been analyzed for environmental contaminants. Altmann [45] found 20 times more lead in propolis than in pollen and a 50-fold increase over honey, cadmium valves in propolis approximated those for pollen, but were higher than those for honey. Bees use propolis to seal and waterproof their nest cavities or hives. It is made from saps and gums exuded by trees. Propolis may have value for averaging samples from woody plants, but it is a difficult substance to collect and handle because of its adhesive nature. Also, it is composed of an indeterminate number of substances and has no specific chemical formula [50]. 


\section{EXPOSURE AND EFFECTS MONITORING WITH HONEY BEES}

Examining chemical residues in a biological receptor such as a honey bee in order to detect and follow spatial and temporal trends in contaminant levels is often referred to as exposure or concentration monitoring. Addressing the consequences of exposures to these substances requires a different approach, which we term effects monitoring. Ideally, effects monitoring can be linked with exposure monitoring and correlated by dose response information. With honey bees it is possible to combine these functions. The individual bee is susceptible to hard such as poisoning and can be a sensitive indicator, while the colony functions as a monitor, since it is remarkably adaptive and capable of surviving all but the most severe pollution insults [46]. Effects monitoring can provide an early warning of pollutant induced perturbations and provides information about the nature and severity of the impacts to bees, to the products they provide, and most importantly to the pollination of croplands and natural ecosystems.

It is hoped that exposure and effects monitoring with bees can be used to reveal the presence of chemicals detrimental to human health. In 1982, we were the first to identify such an area. A commercial beekeeper reported severe bees losses near an inoperable copper smelter. The bees and pollen contained extremely high levels of arsenic and other toxic metals. Four years later, a study by the EPA and the Center for Disease Control (CDC) found unacceptably high levels of arsenic in the hair and urine of children living in the area foraged by the bees. Relocation of families to reduce health risk is now being considered [46].

We have developed specialized procedures for exposure and effects monitoring. A particularly promising technique is the use of mini-hives and colonies. Each consists of a small box containing a queen and usually less than $0.5 \mathrm{~kg}$ (4-5 thousand) bees. Mini-hives are easy to manage and transport and are inexpensive. They are useful for effects monitoring because we are able to quickly and accurately make measurements that normally are time consuming and difficult using full-size hives and colonies. For exposure monitoring, mini-hives allow us to inexpensively fill voids in sampling grids, provide additional replication, and place bees where risk of loss is high.

\section{EXPOSURE MONITORING PROTOCOLS}

Well documented and standardized monitoring protocols are essential to data quality and comparability. Slight changes in procedures may significantly affect results. For example, we found that fluoride levels in bees vacuumed from frames inside the hive were approximately one-half those of bees collected at the hive entrance [18]. What constitutes a representative sample varies with the chemicals of interest and component examined. As few as 25 bees may be adequate to provide a representative sample for heavy metals in a colony. On the other hand, a study conducted near a nuclear power plant indicated that only a few in several hundred pollen pellets contained detectable amounts of cesium. The non-uniform distribution of cesium was thought to reflect individual bee foraging patterns relative to localized sources [personal communication, L. Cadwell, Pacific Northwest Laboratories]. 
Avoiding inadvertent contamination of field collected samples requires specialized procedures. We clean the front of the hive, block the entrance with a polycarbonate shield or fiberglass screen, and aspirate incoming bees directly into sample storage bags. Pollen is collected by entrance mounted traps, made of relatively inert materials such as polycarbonate plastic, teflon or stainless steel. Traps are precleaned, attached to hives, and left in place for 4-6 hours. Pollen is poured from the traps directly into storage bags. Bee and pollen samples are quick frozen in the field. All sampling equipment is acid washed and kept in dust-proof containers until use. Sample storage bags are presealed with a perforated closure that is torn from the bag at the time of sampling. After sampling, the bags are immediately resealed.

Chain of custody is documented by a permanent identification number on each bag, a sample label card which is completed when the sample is collected, and field and laboratory chain-of-custody logs containing serially numbered, tracking sheets.

In the laboratory, samples are freeze or oven-dried $\left(45^{\circ} \mathrm{C}\right.$ ) and ground or cryogenically fractionated into a fine powder. Preparation for analysis varies according to chemicals of interest. For heavy metal analysis, we utilized sealed-vessel, high pressure digestions in high purity nitric acid.

Accuracy, precision, and completeness of field and laboratory parameters are addressed by statistical evaluation of a matrix of collated, quantifiable parameters. Quality assurance is provided by adherence to written protocols and corrective action as needed. Data quality criteria include replicate samples, collocation of bee hives with conventional instrumentation such as high volume air samplers, field blanks, standardized siting, sampling, and analysis, performance and systems audits, interfield and laboratory comparison studies, internal and external quality control checks, control charts, traceability of samples, standards, and instruments, regularly scheduled preventative maintenance of facilities and equipment, certified reference materials, standard additions, our own standard bee tissues, spiked samples, consistency of reporting units (e.g., ppm dry weight), standardized data formats, data analysis, validation, and reporting. Our procedures and results from statistical assessments of data quality have been published [46-48]. Detailed protocols for field sampling, laboratory methods, and quality assurance are available from the UM.

\section{BEES AND SPATIAL MONITORS}

To the best of our knowledge, every reported investigation of honey bees as environmental monitors has concluded that bee colonies are well suited to this task. Bees are particularly valuable as self-sustaining, multi-media samplers of large geographical areas. We know of no other way of costeffectively acquiring such spatially integrated environmental samplers.

To fully realize this potential, we need to do more the merely report concentrations of specific chemicals in bees or bee collected materials. We have found a relatively new statistical approach called kriging [47] to be useful for mapping pollutant distributions. Kriging uses a weighted moving 
average technique in which point estimates or block averages are calculated for a specified grid. Factors such as proximity of observations to points or areas of interest, the "structure" of observations, and systematic drift or trends are taken into account. Two and three-dimensional contour maps can be derived from grid estimates, while confidence bands for individual isopleths can be obtained from the collection confidence intervals for kriging estimates [47].

Using this technique, we were able to map widespread distributions over thousands of $\mathrm{km}^{2}$ for many elements. Our kriging maps generally show dispersion patterns similar to isopleth maps derived from modeling of soil or air concentrations, but reveal discernible patterns over larger areas, implying longerrange transport. We also have been able to identify pollution "hot spots" and can partition chemicals to different point sources.

Combining kriging with preliminary observations can yield exact estimates of the needed sampling intensity for low or high resolution monitoring for spatial pattern. Factors needed are block size estimates, grid spacing, and the size of the multiplicative standard deviation (because data is log transformed). Interrelating these factors with the variagram model enables us to predict the outcome of various proposed sampling scenarios and to recommend site specific sampling strategies (high spacing and numbers).

Sampling intensity (space between hive locations) is dependent on the purpose of the monitoring and the desired degree of definition of spatial patterns. Sampling intensity also depends on expected values for contaminants. Greatest accuracy is usually desired in high impact areas where high and rapidly changing concentrations of pollutants engender regulatory, health, and environmental concern. In contrast, for routine screening of areas where relatively low contaminant values are expected, low resolution and relatively high percentage errors data still provides informative maps. Hive spacing can be far apart where low resolution data with a relatively high percentage of error is acceptable. For highest resolution, we recommend at least one hive in each unit of foraging range, approximately $7 \mathrm{~km}^{2}$ throughout the area of interest.

\section{COMMENTS AND CONCLUSIONS}

Honey bees of the same species, Apis mellifera, thrive as managed colonies or as wild colonies throughout the world. Beekeeping is practiced over a greater portion of the earth's surface than any other branch agriculture, and other types of agriculture depend on bees. Bees are not only kept in rural and agricultural areas, but also in cities. Highest honey yields are obtained from Australia, North America, and parts of South America; whereas $83 \%$ of the hives and 908 of world's beekeepers are found in Europe, Asia, and Africa. Worldwide, approximately 52 million colonies of bees are kept in nearly all areas where people reside [49-50]. This provides an in-place, potential global monitoring network.

Moreover, our experience indicates that this form of monitoring is less expensive than most other approaches. From a relatively few sample locations, it is possible to use bees to search for and map environmental contaminants 
over large geographical areas with a reliable degree of resolution. Since bees gather materials over a range of several kilometers, hive placement is less critical than, for example, a high volume air sampler, which requires electrical power and should be a specified distance above the ground and away from buildings or trees. Furthermore, sampling can be successfully performed by beekeepers. Thus, we believe that this monitoring approach could be employed even in countries or regions lacking electrical power or access to sophisticated monitoring instruments.

To determine how bees can most effectively contribute to monitoring needs, particularly in terms of integrating information obtained with decision-making and regulatory processes will require continued investigation. However, it should be apparent that the function of bees as self-sustaining, multi-media spatial monitors ideally complements the temporal advantages of specimen banking. Combining a powerful, real-time, spatial analysis monitor with longterm temporal analysis capability should maximize information return. Thus, we believe honey bees should be seriously considered for incorporation into specimen banking programs.

\section{ACKNOWLEDGEMENTS}

Our successful development of honey bees as environmental monitors has been a cooperative research effort, funded primarily by the U.S. EPA, the U.S. DOE, and the UM. Dr. John M. Thomas, PNL, was responsible for the statistical design and evaluation of field and laboratory investigations. Dr. Eric $M$. Preston, Project Officer, U.S. EPA, is credited with recognizing the significance of such a tool and laying the groundwork for this work. Janet $\mathrm{L}$. Gudatis, Stan R. Carlson, and Mark L. Dewart were principal contributors to the field and laboratory research at UM. Jeanne C. Simpson and Mary Ann Simmons, PNL, conducted the kriging, which added a critical component of the sophistication of this approach. Finally, much of the work was performed with the assistance of several hundred of the beekeepers of the Pacific Northwest states.

It is hoped that the work that has been carried out in many nations of the world can be coordinated and intensified in the future.

The opinions expressed in this paper reflect the views of the author and are not necessarily those of any sponsoring agency.

\section{XI . REFERENCES}

[1] Wise, S. A. and R. Zeisler, Eds. (1985), International Review of Environmental Specimen Banking, NBS Spec. Publ. 706, U.S. Government Printing Office, Washington, DC, $62 \mathrm{pp}$.

[2] Luepke, N.-P., Ed. (1979), Monitoring Environmental Materials and Specimen Banking, Martinus Nijhoff Publishers, The Hague, 591 pp. 
[3] Lewis, R. A., Stein, N., and Lewis, C. W., Eds. (1984), Environmental Specimen Banking and Monitoring as Related to Banking, Martinus Nijhoff Publishers, The Hague, 358 pp.

[4] Orians, G. (Chair) (1980), Report of the Ecology Committee of the Scientific Advisory Board of the EPA, U.S. Environmental Protection Agency, Washington, DC.

[5] States, J., Burns, T., and Hinds, T. (1984), The Environmental Monitoring of "Emergent Properties" as Related to Specimen Banking, In: Environmental Specimen Banking and Monitoring as Related to Banking, Martinus Nijhoff Publishers, Boston, MA, pp 228-251.

[6] Steche, W. (1975), Industrial Development and Its Effects on Beekeeping, Apiacata $10,3,119-124$.

[7] Debackere, M. (1972), Industrial Air Pollution and Apiculture, Vlamm, Imbersblad 6, 145-155.

[8] Bromenshenk, J. J. and Carlson, C. E. (1975), Impact on Insect Pollinators, In: Air Pollution and Metropolitan Woody Vegetation, W.H. Smith and L.S. Dochinger, Eds., Yale University Printing Service, New Haven, Connecticut, pp 26-28.

[9] Shabanov, M. and Ibrishimov, N. (1975), Assessment of Trace Elements in the Environment on the Basis of Honeybee Foraging Activity, Acta Microbiologica, Virologica, and Immunologica 21, 105-108.

[10] Tong, S. C., Morse, R. A., Bache, C. A., and Lisk, D. J. (1975), Elemental Analysis of Honey as an Indicator of Pollution, Arch. Environ. Health $30,329-332$.

[11] Toshkov, A. S., Shabanov, N. M., and Ibrishimov, N. I. (1975), Attempts to Use Bees to Prove Impurities in the Environment, C.R. Acad. Bulg. Sci. $27,677-702$.

[12] Hakonson, T. E. and Bostick, K. W. (1976), Availability of Environmental Radioactivity to Honeybee Colonies at Los Alamos, J. Environ. Qual. 5(3), 307-310.

[13] Bortitz, S. and Reuter, F. (1977), Untersuchungen uber den Fluorgehalt von Bluten in Bebieten mit bienengefahrdenden Immissionen, Archiv fur Gartenbau 25(5), 247-255.

[14] De Jong, D., Morse, R. A., Gutenmann, W. H., and Lisk, D. J. (1977), Selenium in Pollen Gathered by Bees Foraging on Fly Ash-Grown Plants, Bull. of Envrion. Contamin. Toxicol. 18(4), 442-444.

[15] Kirkham, M. E. and Corey, J. C. (1977), Pollen as Indicator of Radionuclide Pollution, J. Nuclear Agricult. Biol. 6(3), 71-74. 
[16] Bromenshenk, J. J. (1978), Yet Another Job for Busy Bees, The Sciences $18(6), 12-15$.

[17] Bromenshenk, J. J. and Gordon, C. C. (1978), Terrestrial Insects Sense Air Pollution, In: Proceedings of the Fourth Joint Conference on Sensing of Environmental Pollutants, November 6-11, 1977, New Orleans, Louisiana, American Chemical Society, Washington, DC, 5 pp.

[18] Bromenshenk, J. J. (1978), Investigation of the Impact of Coal-Fired Power Plant Emissions Upon Insects, Entomological Studies in the Vicinity of Colstrip, Montana, In: The Bioenvironmental Impact of a Coal-Fired Power Plant, Third Interim Report, Colstrip, Montana, December, 1978, U.S. Environmental Protection Agency, Corvallis Environmental Research Laboratory, Corvallis, Oregon, EPA-600/3-78-021: 140-212.

[19] Gilbert, M. D. and Lisk, D. J. (1978), Honey as an Environmental Indicator of Radionuclide Contamination, Bull. Environ. Contamin. Toxicol. 19(11), 32-34.

[20] Bromenshenk, J. J. (1979), Monitoring Environmental Materials and Specimen Banking Using Terrestrial Insects with Particular Reference to Inorganic Substances and Pesticides, In: Monitoring Environmental materials and Specimen Banking, N.-P. Luepke, Ed., Martinus Nijhoff Publishers, The Hague, pp 132-155.

[21] Canteneur, R. (1978), L'Abeille et son Utilitie dans la Detection Des Pollutions, La Sante de L'Abeille, December, 159-163.

[22] Bromenshenk, J. J. (1979), Honey Bees and Other Insects as Indicators of Pollution Impact from the Colstrip Power Plants, In: The Bioenvironmental Impact of a Coal-Fired Power Plant, Fourth Interim Report, Colstrip, Montana, December 1978, E.M. Preston and T.L. Gullet, Eds., U.S. Environmental Protection Agency, Corvallis Environmental Research Laboratory, Corvallis, Oregon, EPA-600/3-79-044: 215-239.

[23] Bromenshenk, J. J. (1980), Accumulation and Transfer of Fluoride and Other Trace Elements in Honey Bees Near the Colstrip Power Plants, In: The Bioenvironmental Impact of a Coal-Fired Power Plant, Fifth Interim Report, Colstrip, Montana, April 1980, E.M. Preston and D.W. O'Guinn, Eds., U.S. Environmental Protection Agency, Corvallis Environmental Research Laboratory, Corvallis, Oregon, EPA-600/3-80-052: 72-95.

[24] Morse, R. A. and Lisk, D. J. (1980), Elemental Analysis of Honeys from Several Nations, American Bee Journal, 522-523.

[25] Morse, R. A., Van Campen, D. R., Gutenmann, W. H., Lisk, W. H., and Collision, C. (1980), Analysis of Radioactivity in Honeys Produced Near Three-Mile Island Nuclear Power Plant, Nutrition Reports International $22,319-321$. 
[26] Gladney, M. D., Curtis, D. B., Perrin, D. R., Owens, J. W., and Goode, W. E. (1980), Nuclear Techniques for the Chemical Analysis of Environmental Materials, LA-8192-MS Informal Report, Los Alamos National Laboratory.

[27] Romanow, L. R. (1980), Effects of an Air Pollutant, Solid Rocket Fuel Exhaust on the Honey Bee Apis mellifera and Other Insects, MS Thesis, North Carolina State University, Raleigh, North Carolina, 78 pp.

[28] Bromenshenk, J. J. (1981), Fluoride and Arsenic Concentrations in Honey Bees Near Colstrip, In: The Bioenvironmental Impact of a Coal-Fired Power Plant, Sixth Interim Report, Colstrip, Montana, August 1980, E.M. Preston and D.W. O'Guinn, Eds., U.S. Environmental Protection Agency, Corvallis Environmental Research Laboratory, Corvallis, Oregon, EPA-600/3-81-007, 210-227.

[29] Bromenshenk, J. J. and Rice, P. M. (1982), Air Pollutants and Plant Fertilization, Proceedings of the Tenth Pollination Conference, Carbondale, Illinois, 10, 95-101.

[30] Pratt, C. R. and Sikorski, R. S. (1982), Lead Content of Wild Flowers and Honeybees Apis mellifera Along a Roadway, Possible Contamination of a Simple Food Chain, Proceedings of the Pennsylvania State Academy of Sciences 56(2), 151-152.

[31] Wallwork-Barber, M. K., Ferenbaugh, R. W., and Gladney, E. S. (1982), The Use of Honey Bees as Monitors of Environmental Pollution, American Bee Journal 12, 770-772.

[32] Bromenshenk, J. J., Dewart, M. L., and Thomas, J. M. (1983), Pollution Monitoring Using Networks of Honey Bees, VI Congress Mondial Pour La Quality de L'Air, May 16-20, Paris, Presentation des Posters 6, 155-158.

[33] Celli, G. (1983), L'apa Come Insetto Test Della Salute di un Territorio, $L^{\prime}$ apicoltore Moderno 75, 133-140.

[34] Free, J. B., Williams, I. H., Pinsent, R. J. F. H., Townshed, A., Basi, M. S., and Graham, C.L. (1983), Using Foraging Honeybees to Sample an Area for Trace Metals, Environ. Intern. 9, 9-12.

[35] Hoffel, I. and Muller, P. (1983), Schwermetallruckstande in Honigbienen (Apis mellifica L.) in Einem Okosystem (Saarbrucken), Forum StatdteHygiene 34, 191-193.

[36] Kerkvliett, J. D. (1983), Lood-en Cadmiumgehaltes van Honig, Maandschr. Bijent. 85 (10), 251-253.

[37] Kulike, H. and Voget, M. (1983), Bienenhonig als biologischer Indikator fur die Blei- und Cadmium-Immission aus der Luft, Allg. dt. Imkerzty $17(10), 323-324$.

[38] Lilley, W. (1983), Bee Miners Join British Columbia Gold Hunt, American Bee Journal 123(9), 635-637. 
[39] White, G. C., Hakonson, T. E., and Bostick, K. W. (1983), Fitting a Model of Tritium Uptake by Honey Bees to Data, Ecological Modeling 18, 241.

[40] Bromenshenk, J. J., Thomas, J. M., and Simpson, J. C. (1984), Biomonitoring Using Honeybees, Battelle Pacific Northwest Laboratories, Annual Report for 1983 on Interagency and Other Research, p. 20-21.

[41] Crane, E. (1984), Bees, Honey and Pollen as Indicators of Metals in the Environment, Bee World 65(1), 47-49.

[42] Dewart, M. L. (1984), Pollution Monitoring in the Flathead Valley with Honey Bees, M. S. Thesis, University of Montana, Missoula, MT, 22 pp.

[43] Eldridge, J. S., Stegnar, P., Oakes, T. W., and Teasley, N. A., Jr. (1984), The Use of Bioindicator Organisms and Specialized Analysis Techniques in a Program of Environmental Survelliance, Health Physics 47(1), $118-119$.

[44] Terzic, L., Terzic, V., Krunic, M., and Brajokovic, M. (1984), Honey Bee Poisoning Caused by Arsenic from Copper Smelter Smoke, Acta Veterinaria, Beograd 34(1), 57-62.

[45] Altmann, G. (1985), Belastung von Blutenhonig mit Schwermetallen und Ihre Herkunft, Apidologie 16(3), 197-198.

[46] Bromenshenk, J. J. (1985), Monitoring Air Pollution, More Work for Honeybees, Western Wildlands 11(3), 27-32.

[47] Bromenshenk, J. J., Carlson, S. R., Simpson, J. C., and Thomas, J. M. (1985), Pollution Monitoring in Puget Sound with Honey Bees, Science $227(4687), 632-634$.

[48] Bromenshenk, J. J. and Preston, E. M. (1986), Public Participation in Environmental Monitoring, Environ. Monit. Assess. 6, 35-37.

[49] Dadant and Sons (1975), The Hive and the Honey Bee, Revised Edition, Journal Printing Company, Carthage, IL, 740 pp.

[50] Morse, R. A. and Hooper, T. (1985), The Illustrated Encyclopedia of Beekeeping, E. P. Dutton, Inc., New York, NY, 432 pp.

[51] Barker, R. J., Lehner, Y., and Kunzmann, M. R. (1978), The Constancy of Cholinesterase Activity in Adult Honeybees, Journal of Apicultural Research 17(4), 173-175.

[52] Cronn, R. C. and Bromenshenk, J. J. (1986), Monitoring Contaminants with Honey Bees at the INEL, FY-1986 Annual Report to the Idaho DOE Operations Office, U.S. Department of Energy, Idaho Falls, Idaho, 7 pp. 


\title{
QUALITY ASSURANCE AS APPLIED TO LONG-TERM MONITORING OF CHEMICAL RESIDUES AND SPECIMEN BANKING
}

\author{
R. Turle, R. J. Norstrom, and H. T. Won \\ Wildlife Toxicology and Surveys Branch \\ Canadian Wildlife Service \\ Environment Canada \\ Ottawa, K1A OE7 \\ CANADA
}

\section{INTRODUCTION}

The main purpose of long-term monitoring of toxic chemical residues is to establish changes in concentration with respect to time. The analytical chemist may not be concerned with identifying the physical sources of the contaminants or to interpret the trends in terms of biological effects, populations, etc., but the chemist is charged with producing analytical results that are accurate, precise and comparable to previous results, that is, results without bias with respect to the true value, however obtained. The reasons for this are obvious; compounds may be mis-identified and trends in the levels of contaminants may be mis-interpreted. Also, it may not be possible to see the effects of regulatory action on chemicals entering the environment, if imprecisior masks changes in actual levels.

Because of this need to produce accurate data, the chemist is very concerned with Quality Assurance (QA) and all that it entails. Two successful aspects of the QA program of the Canadian Wildlife Service (CWS) long-term monitoring studies have been the ability to retrieve samples from a specimen bank and the use of reference materials. The retrieval of samples ensures that the analyst can determine levels of compounds that he was unable to determine in the past and, perhaps as importantly, ensures that changes in methods are not obscuring long-term trends. The establishment of reference materials enables a direct comparison between methods, analysts and laboratories over a long time frame.

In this paper we discuss the changes in methodology for organochlorine insecticides (OCs) and polychlorinated biphenyls (PCBs) over a 15 year period and compare the results of the original analysis and the re-analysis of samples retrieved from the CWS National Specimen Bank. The National Specimen Bank has been described previously [1], and in another paper in this volume [2]. The criteria used to assess results based on reference materials developed by CWS will also be discussed.

\section{METHODOLOGY CHANGES IN OC AND PCB ANALYSIS}

In the $1960^{\prime} \mathrm{s}$, there was an increasing concern with the effects of organochlorine insecticides in the environment and especially with their effects on avian reproduction [3]. At that time, projects were in effect in 
the Canadian Wildlife Service to measure the levels of the then commonly used organochlorine insecticides given in Table 1.

Table 1. Pesticides Determined in Canadian Wildlife in 1968

\begin{tabular}{ll}
\hline lindane & heptachlor \\
heptachlor epoxide & aldrin \\
kelthane & DDE \\
dieldrin & DDD \\
o, $\mathrm{p}^{\prime}$-DDT & $\mathrm{p}, \mathrm{p}^{\prime}$-DDT \\
methoxychlor & endrin \\
tedion & \\
\hline
\end{tabular}

To place the situation in its analytical context, we must examine the methods in use at that time. The analytical technique of choice was the gas chromatograph equipped with packed columns and electron capture detectors, which were then exceedingly troublesome. In about late 1968, a concern was being expressed about the industrial chemicals known as PCBs. As a consequence it was decided that some effort should be made to determine the levels of PCBs in Canadian wildlife tissues [4]. Analysts of that era realized that these mixtures could interfere with the analysis of DDT and its metabolites. Thus, methods were developed to separate PCBs from the organochlorine pesticides.

In the first procedure used by CWS contractors [5], it is likely that any PCBs would have interfered with the DDT determination, because the method lacked a column clean-up and separation step. It was regarded as a major innovation when it became physically possible to separate PCBs from OCs using a Florisil column [6]. This was achieved using hexane as an eluant to remove PCBs and then followed by 208 ether:hexane to remove most of the OC pesticiderelated residues. Only DDE proved difficult to separate from PCBs. During the following years, interest in PCBs remained high and resulted in considerable improvement in analytical methodology as shown in Table 2. Also during this period of time new analytes such as technical BHC (hexachlorocyclohexane isomers), mirex and chlordane-related compounds were added into the method.

Perhaps in looking back to 1969 we should realize how difficult it was to quantitate PCBs from a chromatogram given the packed column technology of that era. It was extremely difficult to decide which peaks to choose for quantitation and what they represented. Indeed, at that time little was known about the composition of the individual Aroclors [4]. It is only recently that all of the PCB congeners have been synthesized and the relative response factors on an electron capture detector determined [7]. Quantitation was then based on averaging peaks 8 and 10 of either Aroclor 1254, as shown in Figure 1, or Aroclor 1260 [8]. For most wildlife samples Aroclor 1260 was used for comparison as this appeared to be the best visual match of peaks. This was found to be as accurate as averaging all major peaks. Peaks 8 and 10 turned out to be good choices, since they were composed mainly of $2,4,5,2^{\prime}, 4^{\prime}, 5^{\prime}$-hexachlorobiphenyl and $2,3,4,2^{\prime}, 4^{\prime}, 5^{\prime}$-hexachlorobiphenyl respectively [9]. These two isomers (IUPAC No. 153 and 138 [10]), are major constituents of both Aroclor 
Table 2. Changes in CWS Analytical Methodology for PCBs 1968-1986

1968 Chemical separation from OCs based on removal of aromatics by nitration. Quantitation based on packed column chromatograms.

1969 Florisil column separation introduced.

1970 Carbon-celite filtering at $-70{ }^{\circ} \mathrm{C}$ to improve clean-up.

1972 Alumina-celite filtering.

197428 water deactivation of Florisil.

1976 Quantitation based on 1:1 mixture of Aroclors 1254 and 1260 .

1979 Introduction of glass capillary GC columns. Quantitation based on specific peaks for Aroclor 1254, Aroclor 1260 and $1: 1$ mixture of the two.

1981 Fused silica capillary GC columns.

1982 Mini-column Florisil clean-up.

1986 Specific PCB congener analysis introduced.

1254 and 1260, and the PCB levels obtained were therefore not particularly sensitive to the proportion of these Aroclors in environmental samples.

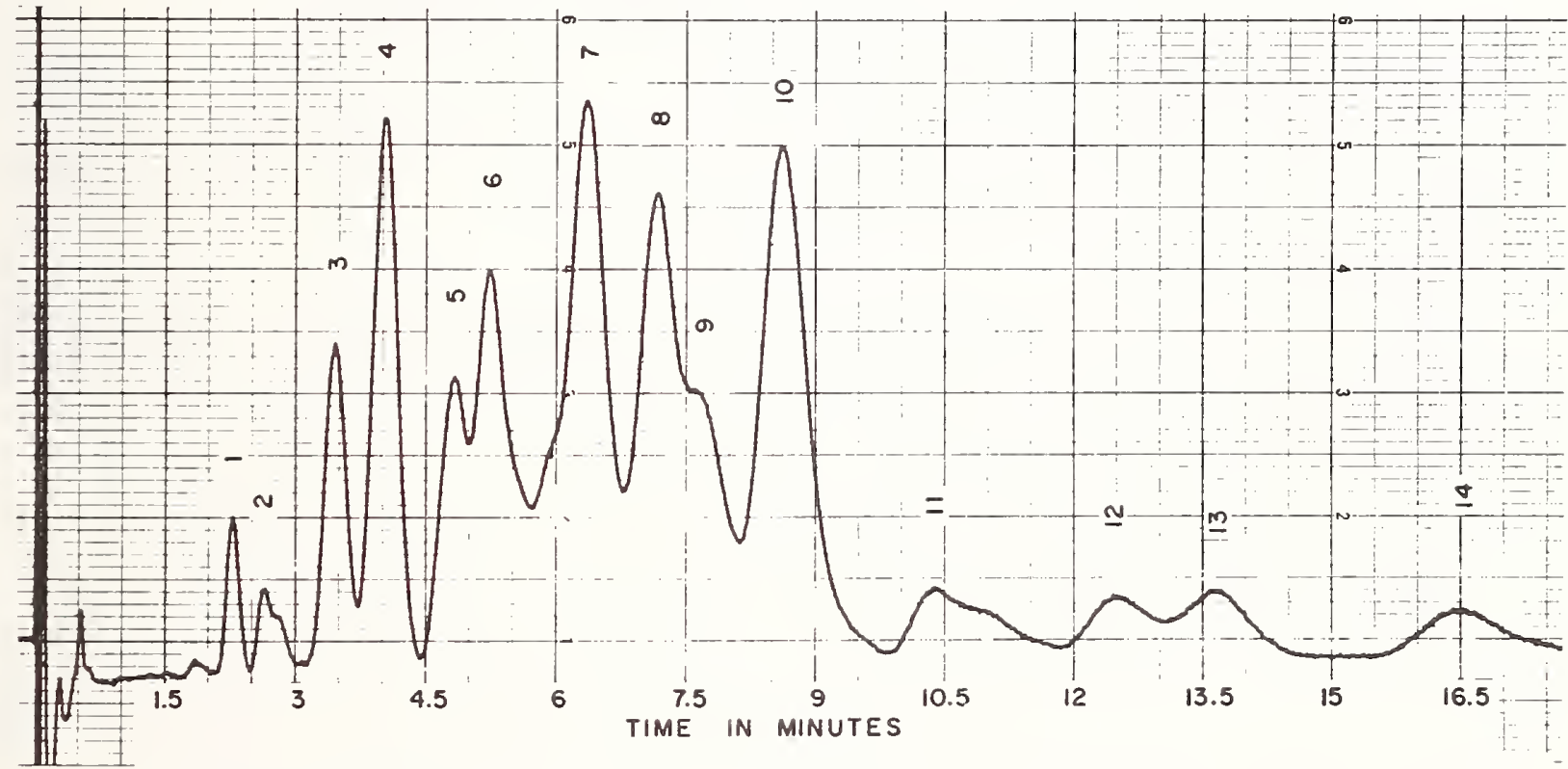

Figure 1. Standard of Aroclor 1254, EC detection, chromatographed on a $6^{\prime} \times 1 / 8 " \mathrm{OD}, 6 \% \mathrm{QF}-1$ and $4 \%$ SE30 on Chromosorb $\mathrm{W}$ (AW) column at $190^{\circ}, \mathrm{N}_{2}$ flow of $40 \mathrm{~mL} / \mathrm{min}$. Reproduced with permission of L.M. Reynolds from Ontario Research Foundation Report 68-18

From about 1976 a $1: 1$ mixture of Aroclor 1254 and 1260 was used for calibration. On a $60 \mathrm{~m} \mathrm{DB}-5$ fused silica column (Figure 2), congener 138 was used for calculation of total $\mathrm{PCB}$ content because it corresponded to peak 10 in the packed column analysis and the results obtained were therefore comparable 


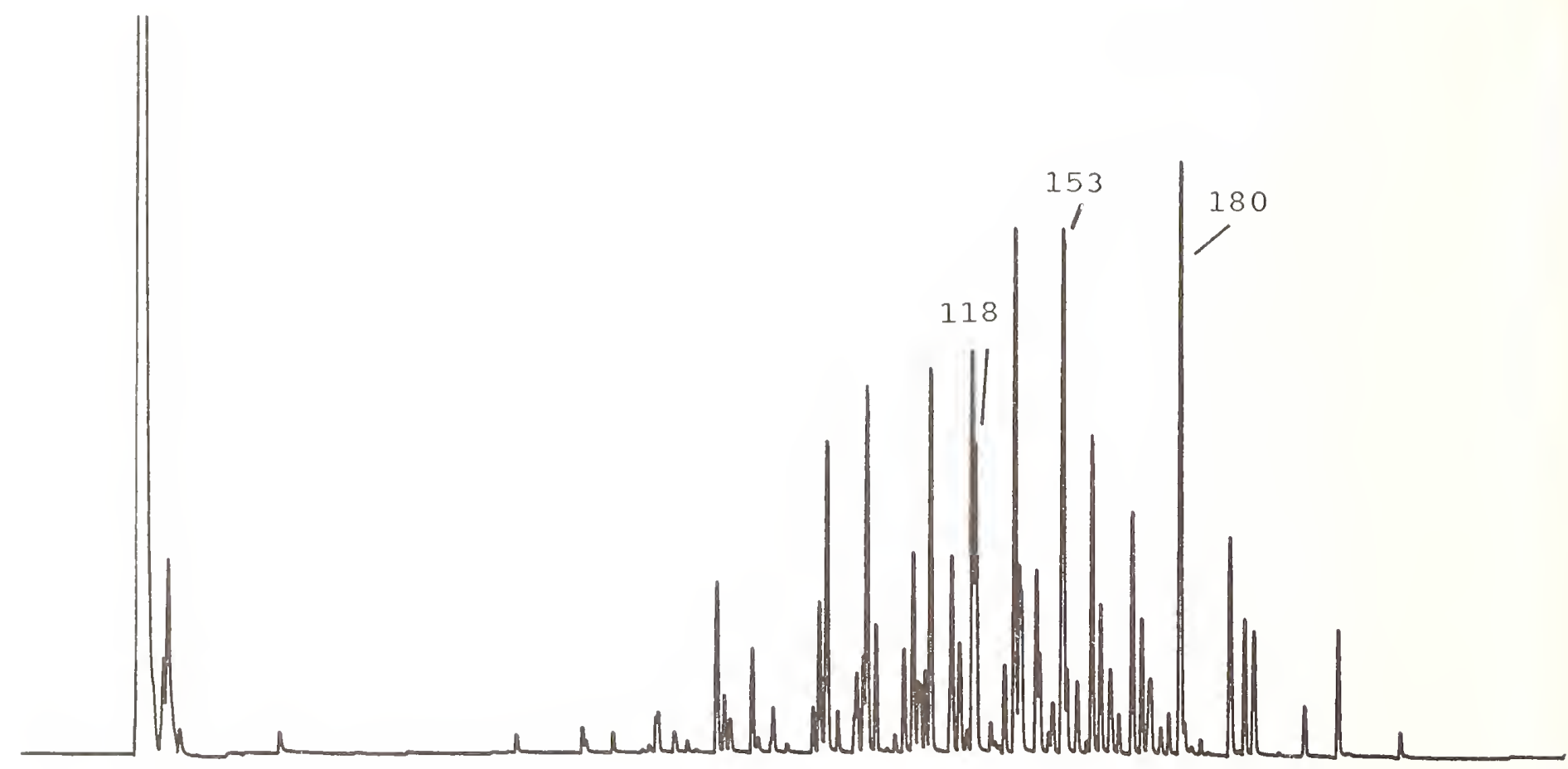

Figure 2. A 1:1 mixture of Aroclors 1254 and 1260, chromatographed on a 60m DB-5 fused silica capillary column, EC detection, initial temperature $100^{\circ}$ for $2 \mathrm{~min}$, then $10^{\circ} / \mathrm{min}$. to $150^{\circ}$, then $3 \% / \mathrm{min}$ to $300^{\circ}$, the carrier velocity $25 \mathrm{~cm} / \mathrm{sec}$

to those obtained prior to the introduction of capillary columns. Congeners 118 and 180 can be used to estimate the Aroclor 1254 and Aroclor 1260 levels, respectively, because these congeners are unique to each Aroclor [11].

\section{CASE STUDY: ANALYSIS OF GANNET EGGS 1969 - 1984}

Results obtained over the period 1969-1976, were compared with analyses on the samples retrieved from the specimen bank and re-analyzed in our own labs in 1984 [12]. The condition of storage of these samples varied from $-10^{\circ}$ to$40^{\circ}$, depending on the period. The results obtained from ten Gannet (Sula bassanus) eggs collected and analyzed in 1969 are given in Table 3. The results of the re-analysis of six 1969 egg samples are shown in Table 4. As has been noted the number of analytes has greatly increased. The original and re-analysis of the samples for the determination of DDE and PCB are compared in Figures 3 and 4 for the years 1969 to 1976. 
Table 3. Analysis of Gannet Eggs from Bonaventure Island 1969 [12] (10 analyses of 10 eggs)

\begin{tabular}{|c|c|c|c|}
\hline \multirow[t]{2}{*}{ Residue } & \multicolumn{3}{|c|}{ Result (mg/kg wet weight) } \\
\hline & Mean & $95 \% \mathrm{CI}$ & Range \\
\hline DDE & 14.5 & $12.3-17.1$ & $10.0-20.6$ \\
\hline dieldrin & 0.500 & $0.415-0.603$ & $0.365-0.818$ \\
\hline heptachlor epoxide & 0.058 & $0.044-0.076$ & $0.029-0.099$ \\
\hline Aroclor $1260^{\circ}$ & 5.11 & $3.81-6.87$ & $1.81-8.57$ \\
\hline \&fat & 4.54 & & \\
\hline swater & 84.2 & & \\
\hline
\end{tabular}

Table 4. Re-analysis of 1969 Gannet Eggs, Bonaventure Island [12] ( 6 analyses of 6 eggs)

\begin{tabular}{|c|c|c|c|}
\hline \multirow[t]{2}{*}{ Residue } & \multicolumn{3}{|c|}{ Result (mg/ $\mathrm{kg}$ wet weight) } \\
\hline & Mean & $958 \mathrm{CI}$ & Range \\
\hline DDE & 18.5 & $10.6-32.3$ & $9.5-35.8$ \\
\hline DDT & 1.67 & $0.703-3.95$ & $0.687-3.93$ \\
\hline $\mathrm{DDD}$ & 0.811 & $0.524-1.26$ & $0.416-1.48$ \\
\hline dieldrin & 0.641 & $0.452-0.911$ & $0.467-1.04$ \\
\hline heptachlor epoxide & 0.029 & $0.019-0.043$ & $0.019-0.053$ \\
\hline Mirex & 0.030 & - & $0.030-0.030$ \\
\hline$\alpha-\mathrm{HCH}$ & 0.021 & $0.013-0.035$ & $0.013-0.037$ \\
\hline$\beta-\mathrm{HCH}$ & 0.006 & $0.003-0.010$ & $0.004-0.013$ \\
\hline$\gamma-\mathrm{HCH}$ & 0.003 & $0.002-0.005$ & $0.002-0.005$ \\
\hline oxychlordane & 0.093 & $0.061-0.143$ & $0.052-0.154$ \\
\hline trans-chlordane & 0.021 & $0.014-0.031$ & $0.015-0.039$ \\
\hline cis-chlordane & 0.240 & $0.163-0.353$ & $0.158-0.385$ \\
\hline cis-nonachlor & 0.173 & $0.130-0.230$ & $0.125-0.250$ \\
\hline$\overline{\mathrm{HCB}}$ & 0.075 & $0.045-0.125$ & $0.044-0.128$ \\
\hline Aroclor $1254: 1260$ & 23.9 & $14.3-39.9$ & $13.1-43.4$ \\
\hline \&fat & 4.44 & & \\
\hline 8water & 83.0 & & \\
\hline
\end{tabular}




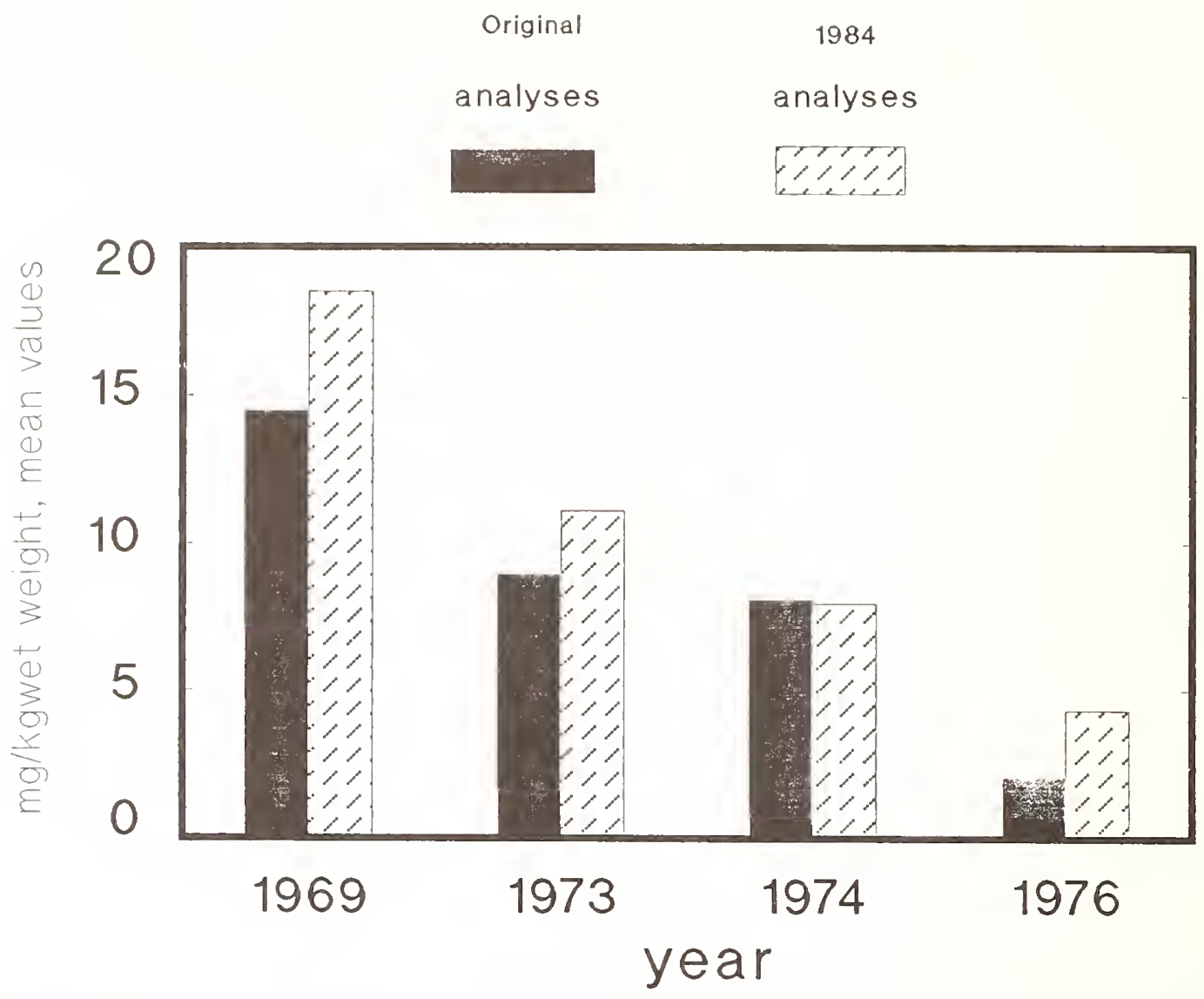

Figure 3. DDE in Gannet eggs, Bonaventure Island, Quebec, 1969-76 Original 1984

analyses

analyses

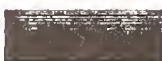

$(2 \div 2)$

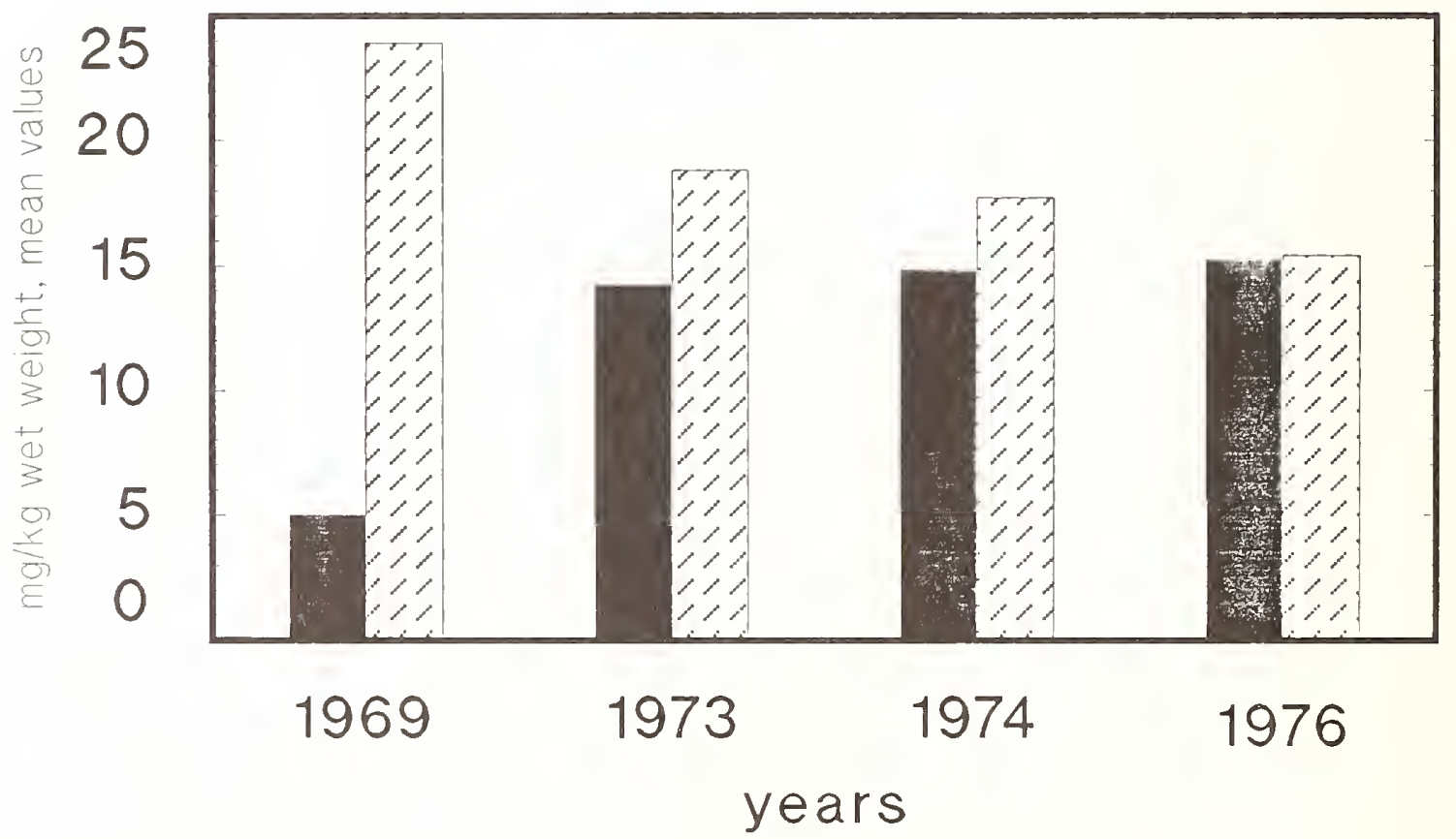

Figure 4. PCBs in Gannet eggs from Bonaventure Island 1969-76 
The DDE results are comparable as can be seen from examining the confidence intervals and ranges in the two data sets, Tables 3 and 4 . The reanalysis suggests that the original determinations in 1969 significantly underestimated PCB levels (Figure 4). However, given that these results are not necessarily obtained from the same samples, the results from 1973 onwards are in excellent agreement. PCB levels appeared to have increased from 1969 to 1976 based on the original data, but this was obviously incorrect. Most probably, much of the data for PCBs from the late 60's and early $70^{\prime} \mathrm{s}$ is questionable and should be interpreted with caution, unless the accuracy of the analysis can be verified by analysis of archived samples. These results show the distinct advantage in being able to retrieve samples from a specimen bank for re-analyses to identify compounds not originally determined, as well as to correct or confirm the original analyses.

In the case of PCBs the difference in results was largely a matter of quantitation, that is, the nature of the "analyte" changed with time. For example, Aroclor 1260 results from earlier analyses are not equivalent to $1: 1$ Aroclor 1254:1260 results, which explains most of the difference in the results of the two analyses of the 1969 egg samples. In 1969, quality assurance was not the concern it is today. Setting up a control or reference material to use over the long haul may have flagged the problems in the earlier analyses.

The lessons from this exercise are several. The first is that the effects of changes in analytical methods with time are not fully recognized by many of those who interpret residue data, and may lead to erroneous conclusions. The classic example is the alleged decline in the levels of silica in Lake Michigan, which is given in many texts [13]. What actually happened is that chemists did their job better and used more accurate methods. Obviously there was a failure in communication between the chemists and the interpreters regarding the bias in individual methods. In preparing this paper, it was quite a challenge to document all the various changes over the period in question. All chemical residue data banks should have a method dictionary and every change should be documented. Also, every time a method is changed there should be a statistical comparison between the old and new methods to ensure they are equivalent and are not biased between one another. This should be part of the quality assurance procedures during the development of rew methods. Ideally, there should be a reasonable period when both methods are in use. If a new method is shown to be more accurate, then re-analysis of stored samples should be carried out to verify that the overall long-term trend is correct. If the new method shows a substantial difference between original and retrieved samples, then correction factors for past analysis may possibly be applied to correct long-term trends. It must, of course, be shown that the difference is not due to slow degradation of the compounds in question. The only alternative to method changes is to freeze methodology, but such a course would not allow analysts to take advantage of new instrumentation and techniques which provide better specificity, accuracy and productivity. There is actually a long-term study where this approach has been taken [14]. 


\section{ASSESSMENT OF ANALYTICAL RESULTS}

How do we prevent data quality problems in the future? Quality control is especially difficult when the majority of analyses are done by a laboratory outside of the organization, which has been the case for a number of years for CWS. We may demand proper quality assurance protocols, but there is no certainty that they will be followed. Ultimately, we must assess the analytical results to see if they are acceptable in terms of prescribed requirements for accuracy and precision. This has required the incorporation of blind-numbered reference materials into a set of samples. While there are a number of good SRMs (Standard Reference Materials) available from the National Bureau of Standards and elsewhere for use in analysis for metals, there are no comparable SRMs for organic constituents. Because of this, several reference materials have been developed by CWS specifically for the assessment of analytical results.

\section{A. CWS Reference Materials}

The first of these materials was developed in 1979, primarily for use with the Herring gull egg surveillance program for the International Joint Commission (IJC) [15]. A second reference material was developed in 1980, mainly because the first had high levels of PCBs. Another reference material was developed in 1986, primarily for use in dioxin analysis. All of these materials are whole egg homogenates. They were initially analyzed in the CWS laboratories and have been used mainly to assess the analytical performance of contractors, and to monitor the in-house laboratory performance. These materials have been re-analyzed over a period of time and have been found to be stable $[1,16]$.

The 1979 reference material has been used to compare CWS results with those of the Ontario Research Foundation and the U.S. Fish and Wildlife Service in Patuxent, Maryland. It has also been used within the Canadian Federal Interdepartmental Committee on Pesticides check sample program. Thus, we have been able to establish good values for levels of a number of chemical constituents for this material (Table 5). A need has been expressed for developing liver and breast muscle reference materials in a similar manner in response to concerns about the edibility of wild foods.

\section{B. Assessment Criteria}

In using reference materials for the assessment of results from a contract laboratory, criteria must be established prior to the awarding of a contract. The three criteria which were originally proposed for the acceptance or rejection of results are based on the concepts of systematic error $\left(E_{s}\right)$, total error $\left(E_{t}\right)$, and acceptable ranges based on multiples of standard deviation (SD), and maximum coefficient of variation $\left(\mathrm{CV}_{\max }\right)[17]$.

The $E_{s}$ criteria (or percent relative bias) is defined as

$$
E_{s}=\left(x-x_{r e f}\right) /\left(x_{x e f}\right) \cdot 100
$$

where $\quad \mathrm{x}=$ mean of replicate SRM analyses,

$\mathrm{x}_{\mathrm{ref}}=$ reference value. 
Table 5. Interlaboratory Comparison of CWS 1979 Reference Material

\begin{tabular}{|c|c|c|c|c|}
\hline Residue & CWS & ORF & FICP & USFWS \\
\hline $\mathrm{HCB}$ & $\begin{array}{r}0.192 \\
\pm 10(21)\end{array}$ & $\begin{array}{r}0.153 \\
\pm 13(15)\end{array}$ & n.a. & n.a. \\
\hline$p, p^{\prime}-D D E$ & $\begin{array}{l}4.83 \\
\pm 16(21)\end{array}$ & $\begin{array}{l}3.903 \\
\pm 10(13)\end{array}$ & $\begin{array}{l}4.64 \\
\pm 13(5)\end{array}$ & $\begin{array}{l}5.38 \\
\pm 7(5)\end{array}$ \\
\hline $\begin{array}{l}\text { Aroclor } \\
1254\end{array}$ & $\begin{array}{l}28.47 \\
\quad \pm 18(10)\end{array}$ & n.a. & n.a. & n.a. \\
\hline $\begin{array}{l}\text { Aroclor } 1254 \\
+12601: 1\end{array}$ & $\begin{array}{l}83.12 \\
\pm 21(11)\end{array}$ & $\begin{array}{l}72.94 \\
\pm 10(13)\end{array}$ & $\begin{array}{l}88.6 \\
\pm 3(4)\end{array}$ & n.a. \\
\hline $\begin{array}{l}\text { Aroclor } \\
1260\end{array}$ & $\begin{array}{l}33.99 \\
\pm 13(21)\end{array}$ & n.a. & n.a. & $\begin{array}{l}34.4 \\
\pm 7 \text { (5) }\end{array}$ \\
\hline Mirex & $\begin{array}{r}0.122 \\
\pm 11(21)\end{array}$ & $\begin{array}{r}0.102 \\
\pm 25(13)\end{array}$ & $\begin{array}{r}0.139 \\
\pm 14(3)\end{array}$ & n.a. \\
\hline oxychlordane & $\begin{array}{l}0.194 \\
\pm 4(21)\end{array}$ & $\begin{array}{r}0.192 \\
\pm 15(13)\end{array}$ & $\begin{array}{r}0.202 \\
\pm 15 \text { (2) }\end{array}$ & $\begin{array}{l}0.184 \\
\pm 6(5)\end{array}$ \\
\hline cis-chlordane & $\begin{array}{l}0.0287 \\
\pm 10(15)\end{array}$ & $\begin{array}{l}0.0215 \\
\pm 13(17)\end{array}$ & n.a. & n.a. \\
\hline cis-nonachlor & $\begin{array}{l}0.0609 \\
\pm 30(15)\end{array}$ & n.a. & n.a. & n.d. \\
\hline$p, p^{\prime}-D D D$ & $\begin{array}{l}0.0581 \\
\pm 15(15)\end{array}$ & $\begin{array}{l}0.0350 \\
\pm 53(13)\end{array}$ & $\begin{array}{l}0.069 \\
\pm 5(4)\end{array}$ & n.d. \\
\hline $\begin{array}{l}\text { heptachlor } \\
\text { epoxide }\end{array}$ & $\begin{array}{l}0.1373 \\
\pm 12(21)\end{array}$ & $\begin{array}{l}0.110 \\
\pm 22(13)\end{array}$ & $\begin{array}{r}0.129 \\
\pm 25(8)\end{array}$ & $\begin{array}{r}0.123 \\
\pm 21(4)\end{array}$ \\
\hline dieldrin & $\begin{array}{l}0.2779 \\
\pm 9(21)\end{array}$ & $\begin{array}{l}0.257 \\
\pm 14(13)\end{array}$ & $\begin{array}{l}0.28 \\
\pm 36(5)\end{array}$ & $\begin{array}{r}0.258 \\
\pm 21(4)\end{array}$ \\
\hline $\mathrm{p}, \mathrm{p}^{\prime}-\mathrm{DDT}$ & $\begin{array}{l}0.0475 \\
\pm 41(10)\end{array}$ & n.d. & $\begin{array}{l}0.065 \\
\pm 9(5)\end{array}$ & $\mathrm{n} \cdot \mathrm{d}$. \\
\hline
\end{tabular}

All results expressed in $\mathrm{mg} / \mathrm{kg}$ wet weight, $\pm \mathrm{CV}(\%)$, number of determinations in parentheses; ORF, Ontario Research Foundation; FICP, Federal Interdepartmental Committee on Pesticides check sample program (6 - 7 labs in duplicate); USFWS, U.S. Fish and Wildlife Service, Patuxent, Maryland.

Note: $\mathrm{n} . \mathrm{a} .=$ not analyzed, n.d. = not detected. 
Normally, the $E_{s}$ should be less than 508, based on the observation of Elgar [18] that, in interlaboratory studies with pesticides at low levels, rarely is there agreement below a $E_{s}=25 \%$. Thus, $E_{s}=50 \%$ is a suitable limit at very low levels when the absolute bias is acceptable but the relative percentage bias can be quite high such as near the detection limit.

The total error, $E_{t}$, provides a value of the effects of both $S E$ and precision

$$
E_{t}=\left(E_{s}+2 S D\right) /\left(x_{r e f}\right) \cdot 100(8)
$$

This concept proposed by McFarren [19] sets an arbitrary value of 508 as the maximum acceptable total error. The total error criterion would consider acceptable a set of analyses of an SRM with a CV $<15 \%$ and $\mathrm{E}_{\mathrm{s}}<208$.

The third criterion of acceptable ranges based on multiples of standard deviations is very useful when there is a history of analyses. We have chose \pm 2 SD for a set of 5 SRM analyses in a batch of samples. Experience has shown that this can be obtained for residue analysis by a single laboratory. It is analogous to the control chart used in many laboratories.

The $\mathrm{CV}_{\max }$ criterion is based on the work of Frehse and Timme [20]. Briefly, it has been shown that, as analyte concentration declines the CV increases. From this they developed a concept of "first category measured value curves".

This can be extended to the general use

$$
C V_{\text {max }}=C V_{0}\left(x_{0} / x\right)^{\log f}
$$

where $\mathrm{CV}_{\mathrm{max}}=$ maximum permissible $\mathrm{CV}$

$\mathrm{CV}_{\mathrm{o}}=\mathrm{CV}$ at the detection limit

$\mathrm{x}=$ mean of replicate analysis of blind sample

$\mathrm{x}_{\mathrm{o}}=$ detection limit

$f=$ the factor by which $\mathrm{CV}_{\mathrm{max}}$ diminishes per order of magnitude.

For example, if $\mathrm{f}=2$ and $\mathrm{CV}_{\circ}=100$, the equation reduces to

$$
C V_{\max }=\left(x_{0} / x\right)^{0.3} \cdot 1008
$$

For pesticide residue analysis, the form of the equation

$$
C V_{\max }=13.7 \mathrm{x}^{-0.431}
$$

based on $\mathrm{x}_{0}=0.01 \mathrm{mg} / \mathrm{kg}, \mathrm{CV}_{0}=1008$ and $\mathrm{CV}_{\mathrm{max}}=158$ at $1 \mathrm{mg} / \mathrm{kg}$. This is equivalent to $\mathrm{f}=2.7$. As an example, for a mean of $0.0895 \mathrm{mg} / \mathrm{kg}, \mathrm{CV}_{\max }$ is 38.88 .

These equations allow $\mathrm{CV}_{\max }$ to increase as concentrations decline in a systematic manner. A practical lower limit of $\mathrm{CV}_{\mathrm{max}}$ is $15 \%$. Normal practice has been to determine the minimum expected value of $\mathrm{CV}_{\mathrm{max}}$ in our own labs by use of replicate analysis. 
These criteria have been grouped so that the data manipulation can be performed by computer, and the data sets failing to meet the criteria can be identified. Thus, acceptability can be based on:

a) $E_{t}<508$

b) $M_{r e f}<M \pm 2 S D$ where $M_{r e f}$ is mean of reference material and $M$ is prior mean of reference material

c) $\mathrm{E}_{\mathrm{s}}<508, \mathrm{CV}<\mathrm{CV}_{\mathrm{max}}$.

Ideally, an acceptable result would pass all three criteria, but this often does not occur for various reasons. When a result fails to pass all criteria, it is compared to previous data sets and judged to see if there is consistent bias, and if previous contracts had similar problems in the past. An example is given in Table 6 .

Table 6. Application of Acceptable Criteria

\begin{tabular}{lrcccc}
\hline & & DDE & DDD & DDT & Oxychlordane \\
\hline \multirow{2}{*}{ Contractor } & Mean & 4.828833 & 0.04 & 0.048333 & 0.21667 \\
& $\mathrm{SD}$ & 0.612185 & 0.01 & 0.024832 & 0.25819 \\
& $\mathrm{n}$ & 6 & 6 & 6 & 6 \\
& $\mathrm{CV}$ & 12.679 & 25 & 51.3782 & 11.9168 \\
Reference & & & & & \\
& Mean & 5.61 & 0.0367 & 0.153 & 0.232 \\
& $\mathrm{SD}$ & 0.28 & 0.004 & 0.024 & 0.010 \\
& $\mathrm{n}$ & 15 & 12 & 12 & 4.4 \\
Systematic Error & $\mathrm{E}_{\mathrm{s}}$ & -13.93 & 11.3 & 16.0 & -6.61 \\
Total Error & $\mathrm{E}_{\mathrm{t}}$ & 35.76 & 8.99 & -68.41 & 28.86
\end{tabular}

Acceptable data?

$\begin{array}{lrrrr}\text { a) } E_{t}<508 & \text { YES } & \text { NO } & \text { NO } & \text { YES } \\ \text { b) } M_{r}-2 S D<M<M_{r}+2 S D & \text { NO } & \text { YES } & \text { NO } & \text { YES } \\ \text { c) } E_{s}<508, C V<C V \max & \text { YES } & \text { YES } & \text { NO } & \text { YES }\end{array}$

In this example, the relatively high CV for DDE has caused the result to fail criterion b), but the accuracy is good. Similarly, the high CV for DDD has resulted in failure to pass criterion a), even though the CV is not unreasonable for a value so near to the detection limit. For these residues, criterion c) seems to give a better assessment of data quality than a) or b). The DDT result clearly fails all criteria because of a large negative bias $\left(E_{s}=-688\right)$, whereas oxychlordane passes all criteria. Thus, only the last 
criterion is written into the contract but the other, criteria are used in the assessment.

\section{CONCLUSIONS}

Accurate analytical determinations are a prerequisite for reliable determination of long term trend monitoring data. Changes in methodology, if not properly documented, may lead to erroneous interpretations. Appropriate uses of specimen banking, reference materials and rigorous quality assurance procedures can be devised to prevent or minimize such errors.

\section{ACKNOWLEDGEMENTS}

The authors wish to thank J. A. Keith, W.K. Marshall, and J. E. Elliott for their interest and comments.

\section{References}

[1] Elliott, J. E. (1985), Specimen Banking in Support of Monitoring for Toxic Contaminants in Canadian Wildlife, In: International Review of Environmental Specimen Banking, S. A. Wise and R. Zeisler, Eds., NBS Spec. Publ. 706, 4-12.

[2] Elliott, J. E. and Norstrom, R. J. (1987), Trends and Effects of Environmental Contaminants Determined from Archived Wildlife Samples, In: These Proceedings.

[3] Ratcliffe, D. A. (1967), Decrease in Eggshell weight in Certain Birds of Prey, Nature 215, 200-210.

[4] Peakall, D. B. (1972), Polychlorinated Biphenyls: Occurrence and Biological Effects, Residue Reviews 44, 1-21.

[5] McCully, K. A. and McKinley, W.P. (1964), Determination of Chlorinated Pesticides in Fat by Electron Capture Gas Chromatography, J.Assoc. Off. Anal. Chem. 47, 652-660.

[6] Reynolds, L. M. (1971), Pesticide Residue Analysis in the Presence of Polychlorinated Biphenyls (PCBs), Residue Reviews 34, 27-57.

[7] Mullin, M. D., Pochini, C. M., McCrindle, S., Romkes, M., Safe, S. M., and Safe, L. M. (1984), High-Resolution PCB Analysis: Synthesis and Chromatographic Properties of All 209 PCB Congeners, Environ. Sci. Technol. 18, 468-476.

[8] Reynolds, L. M., Ontario Research Foundation CWS Contract Report 68-18. 
[9] DeFreitas, A. S, and Norstrom, R. J. (1974), Turnover and Metabolism of PCBs in Relation to Their Chemical Structure and the Movement of Lipids in the Pigeon, Can. J. Physiol. Pharmacol. 52, 1080-1094.

[10] Ballschmiter, K. and Zell, M. (1980), Analysis of Polychlorinated Biphenyls (PCB) by Glass Capillary Gas Chromatography, Fresenius. Z. Anal. Chem. 302, 20-31.

[11] Norstrom, R. J., Patterns and Trends of PCB Contamination in Canadian Wildlife, IEEE MONTECH'86 Conference on PCBs and Replacement Fluids, Montreal, 1986, 1-9.

[12] Elliott, J. E., Norstrom, R. J., and Keith, J. A., Organochlorine Insecticides and Eggshell Thinning in Gannets from Eastern Canada, Environ. Pollut., in press.

[13] Shapiro, J. and Swain, E. B. (1983), Lessons from the Silica Decline in Lake Michigan, Science 221, 457-459.

[14] Addison, R. F., Brodie, P. F. (1984), DDT has Declined More Than PCBs in Eastern Canadian Seals during the 1970s, Environ. Sci. Technol. 18, 935-937.

[15] Won, H. T. and Norstrom, R. J. (1980), Analytical Reference Materials: Organochlorine Residues in CWS-79-1, a Herring Gull Egg Pool from Lake Erie, Canadian Wildlife Service; Manuscript Report No. 41.

[16] Norstrom, R. J. and Won, H. T. (1976), Long-Term Preservation of Egg and Tissue Homogenates for Determination of Organochlorine Compounds: Freezing versus Freeze-Drying, J. Assoc. Off. Anal. Chem. 68, 129-135.

[17] Turle, R. and Norstrom, R. J., Guideline to Practical Quality Assurance for Contract Analysis, Canadian Wildlife Service Technical Report (in press), 1987.

[18] Elgar, K. E. (1979), The Variability of Residue Results, with Particular Reference to the CODEX study on Organochlorines in Butterfat, Advances in Pesticide Science 3, 668-672, Pergammon, Oxford.

[19] McFarren, E. F., Liska, R. J., and Parker, J. M. (1970), Criterion for Judging the Acceptability of Analytical Methods, Anal. Chem. 42, 358-361.

[20] Frehse, H. and Timme, G. (1980), Quantitative Residue Analytical Reliability: Beatitude through Application of Latitude, Residue Reviews $73,27-47$. 


\title{
SECTION 18
}

\section{PREPARATION OF SAMPLE MATERIAL FOR ENVIRONMENTAL SPECIMEN BANKING PURPOSES - MILLING AND HOMOGENIZATION AT CRYOGENIC TEMPERATURES}

\author{
J. D. Schladot and F. W. Backhaus \\ Institute of Applied Physical Chemistry \\ Nuclear Research Center (KFA) Jūlich \\ D-5170 Jülich \\ FEDERAL REPUBLIC OF GERMANY
}

\section{INTRODUCTION}

One of the most important tasks of the environmental specimen bank (ESB) Jülich is the preparation of sample material to be stored for future investigations. The collected material is directly deep frozen in the gaseous phase over liquid nitrogen (see Figure 1). Further sample treatment is carried out only at cryogenic temperatures to avoid any deterioration and losses of organic compounds. For this reason, we implemented a sample preparation procedure (SPP) by which the sample material is treated at very low temperatures $\left(<-140{ }^{\circ} \mathrm{C}\right)$.

The data sheets for sample collection with all the important data (anamnesis of sample, weather conditions, possible visible emission sources, etc.) are complemented by the data of the sample procedure.

The sample preparation procedure is divided into different single steps (see Figure 2). The temporarily stored sample material will be pre-crushed first with a pre-crusher type ZM1, Mercodor, Frankfurt, FRG, with 2 drive shafts with 12 rotating knives each. The 24 knives are all coated with TiN to avoid contamination. By pre-crushing, the sample material is pre-mixed while some of the pre-crushed material is recycled [1]. After this pre-crushing step, the material is temporarily stored in stainless steel containers until the material is milled and homogenized. All data from this first preparation step are gathered in particular data sheets and utilized later on the computer together with all other preparation data.

The next step is milling and homogenization of the sample material at cryogenic temperatures. For this preparation step, we have set up a grinding device, type CRYO PALLA ${ }^{R}$, KHD Klöckner Humboldt Wedag, Köln, FRG. This grinding device is cooled with liquid nitrogen for hours until the cooling capacity of the mill will keep the cold material at cryogenic temperatures. During the milling process, no liquid nitrogen is fed into the device. The pre-crushed sample material is fed to the grinding cylinder by a metering trough. By limiting the speed of the metering trough, the grain size of the sample material can be adjusted. The pre-crushed sample material is milled in the grinding cylinder by stainless steel rods or in some cases by PTFE grinding rods, depending on the strength of the material. The rods have a diameter of $20 \mathrm{~mm}$. About 65-70\% of the volume of the grinding cylinder is filled with the grinding media. By this, the material is milled to a fine powder with grain size $<200 \mu \mathrm{m}$. The cold, fine powdery sample material is collected in stainless steel vessels. 


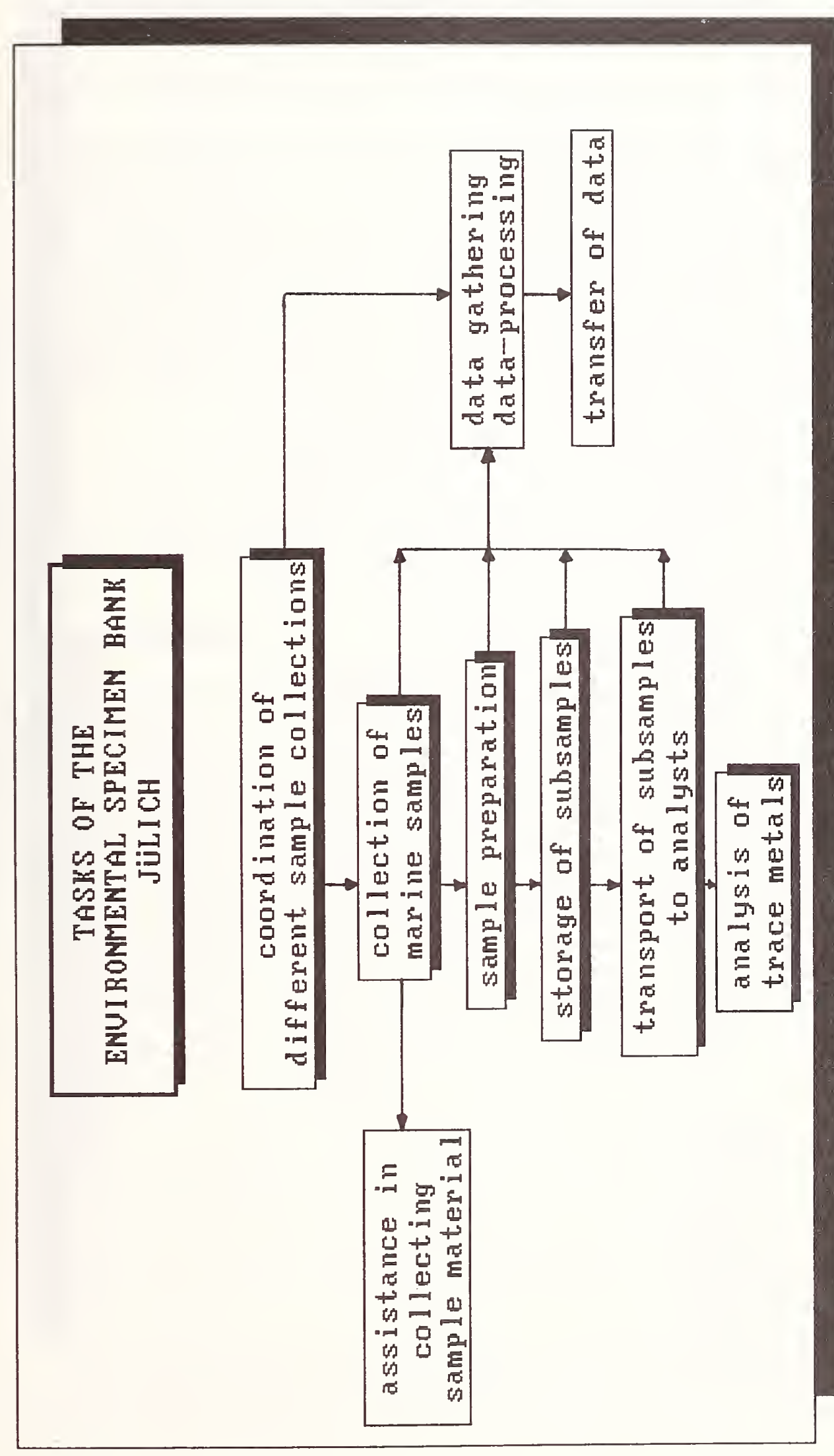

告 


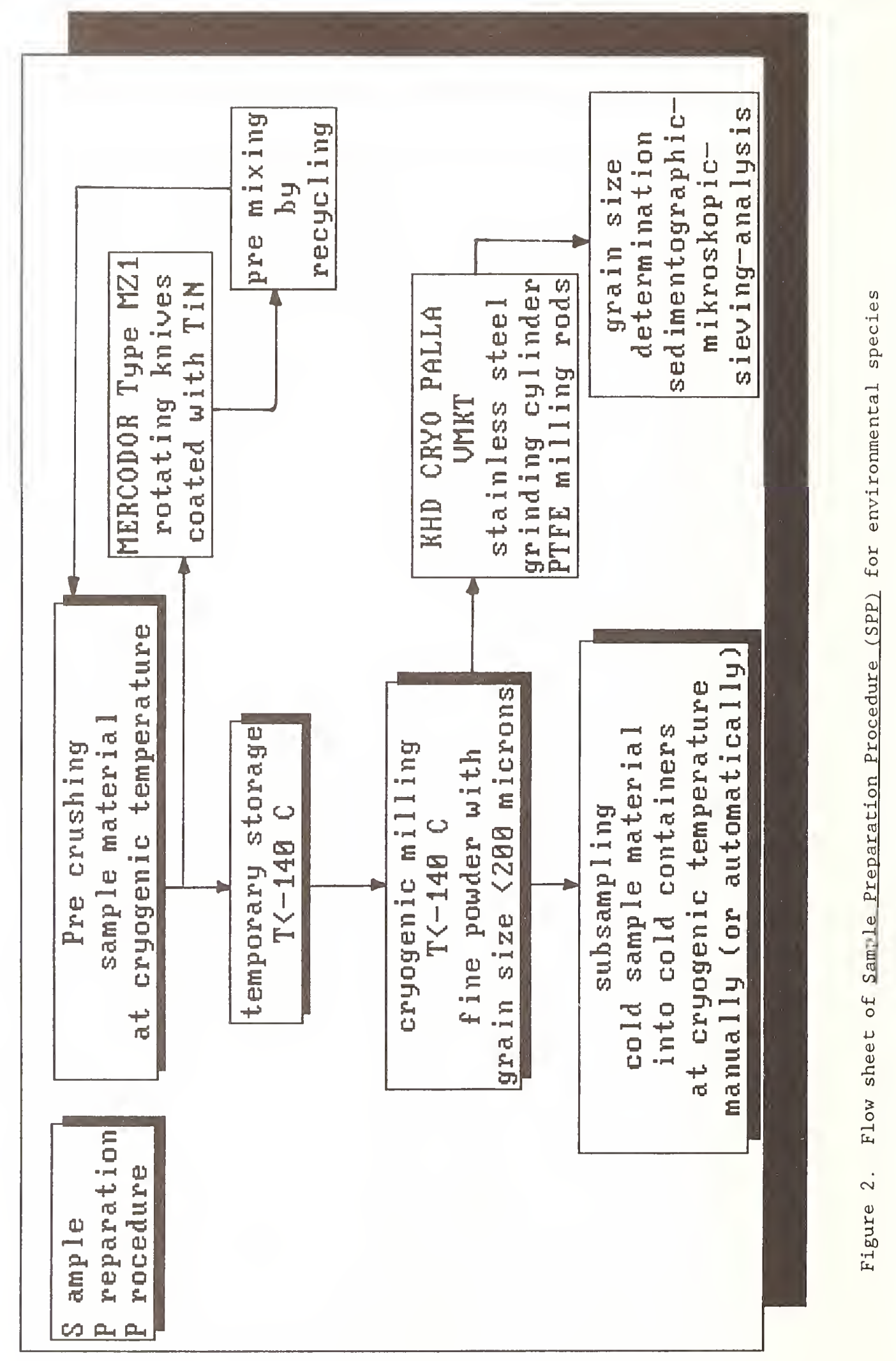


The collected data from this preparation step contain:

1. Amount of material fed into the grinding device.

2. Amount of collected fine powdery sample material.

3. Temperature of material before milling in the grinding cylinder and temperature of homogenized sample material.

4. Feeding speed of the metering trough, etc.

Because of the limited space of the pilot environmental specimen bank building, it is not possible to carry out the sample preparation procedure (SSP) as a one-step process at present.

To test this sample preparation procedure for environmental specimen samples, we have treated comparable material, e.g., fish [dab (limanda limanda) from the Baltic Sea and cod (gadus morhua) from the North Sea], - kale [(brassica oleracea) from the region surrounding the Bornhöved Lakes], and rhubarb [(rheum rhabarbarum) from the Jülich Region].

\section{EXPERIMENTAL SECTION}

In the following, an example of the sample preparation procedure is given for fish material [dab (limanda limanda)]. Sixty-five individuals of dab, weighing about $7.5 \mathrm{~kg}$, were tested according to the sample preparation procedure for environmental specimen bank samples. The material was pre-mixed by crushing it with the Mercodor ZM1 several times. The device was cooled with ice, then cooled to low temperature in liquid nitrogen. The pre-crushed material was collected in stainless steel containers ( $5.5 \mathrm{~L}$ volume) and cooled in the gaseous phase over liquid nitrogen. After a short temporary storage in the gaseous phase of liquid nitrogen, the pre-crushed material was fed to the cold milling device by a metering trough.

The temperature of the material prior to crushing was $-186^{\circ} \mathrm{C}$. By cooling the pre-crusher by deep cold ice the temperature of the material after precrushing was: $-172{ }^{\circ} \mathrm{C}$. For temporary storage the pre-crushed material was cooled again in the gaseous phase over liquid nitrogen.

The grinding device CRYO PALLA ${ }^{R}$ was cooled with liquid nitrogen within a few hours to a temperature of $-190{ }^{\circ} \mathrm{C}$. During the milling process no more liquid nitrogen was fed into the milling device. The temperature of the precrushed sample material was recorded by a measuring system in the metering trough. Another temperature sensing unit is located in the grinding cylinder. The temperature of the grinding cylinder was controlled during the milling process, and the temperature usually increased to $-160{ }^{\circ} \mathrm{C}$.

The powdery sample material (grain size $<200 \mu \mathrm{m}$ ) was then collected in stainless steel containers (volume $5.5 \mathrm{~L}$ ), and cooled over liquid nitrogen. The temperature of the fine powdery material decrease to $-180{ }^{\circ} \mathrm{C}$. 
The fine powdery sample material (dab), weighing about $7.2 \mathrm{~kg}$ was subsampled into cold glass containers (Wheaton scintillation flasks) with quartz spoons under a laminar flow box. The glass flasks were cooled in the gaseous phase over liquid nitrogen. The weight of each subsample was measured and recorded. Generally, the weight of a subsample with dab material is about $7 \mathrm{~g}$ (cold fresh weight). While subsampling, the material in the stainless steel containers and the glass flasks was cooled by liquid nitrogen and the surrounding atmosphere under the laminar flow box was filled with cold nitrogen vapor.

Fifty random subsamples of dab (limanda limanda) out of 950 subsamples were analyzed by our colleagues of the Institut für ökologische Chemie, GSF Neuherberg. They determined different chlorinated hydrocarbons. The obtained values show the homogeneity of the subsampled material (see Table 1). A discussion of these values is presented elsewhere [2]. Other random subsamples were used for the determination of the grain size of the milled material. Various methods were used: e.g., sieving analysis, microscopic measurement, and scanning photo-sedimentographic analysis (see Figure 3). Furthermore, in some random subsamples the distribution of $\mathrm{Pb}, \mathrm{Cd}, \mathrm{As}$, and $\mathrm{Se}$ was analyzed. $\mathrm{Pb}$ and $\mathrm{Cd}$ were analyzed using solid sampling Zeeman AAS (see Figure 4) [3]. As and Se were determined using sodium-borohydride - AAS after wet chemical digestion (see Figures 5 and 6). All these methods show that the homogeneity of the subsamples is satisfactory for most elements.

\section{III . CONCLUSIONS}

The tests proved that we are now able to homogenize the ESB sample material according to a sample preparation procedure (SPP). If all single steps of a "uniform" sample preparation procedure are strictly adhered to and if all resulting data within these steps are recorded, it should be possible to compare samples of the same matrices prepared in different institutions, e.g., common mussel (mytilus edulis) from U.S. coastal waters prepared at the ESB of the National Bureau of Standards (NBS) and common mussel from German coastal waters (North Sea and Baltic Sea) prepared at the ESB in Jülich, or human liver samples prepared at the ESB of the NBS and human liver samples prepared at the ESB for human organs at the University of Münster.

\section{ACKNOWLEDGEMENT}

The authors wish to thank the Ministry of the Interior, and from June 1986, the Ministry of the Environmental, Protection of Nature and Reactor Safety, Bonn, for financial support. We wish to thank DI. M. Burow for the determination of $\mathrm{As}$ and $\mathrm{Se}$ in homogenized fish samples; $N$. Commerscheidt for his helpful assistance in sample preparation; Dipl. Biol. K.-H. Grobecker, Grün Analysengeräte, Wetzlar; and DI. C. Mohl for the determination of $\mathrm{Pb}$ and $\mathrm{Cd}$ with Zeeman Solid Sampling AAS. Furthermore, we wish to thank our colleagues from the Institut für ökologische Chemie, Dir. Prof. Dr. F. Korte, GSF, Neuherberg, Dr. I. Gebefügi and Dr. K. Oxynos, for the determination of chlorinated hydrocarbons in homogenized fish material, and our colleagues from the Institut für Meereskunde, University Kiel, Dr, K. Rumohr and Dr. M. Weigelt 
Table 1. Homogenization Study of Fish Material by Determination of Chlorinated Hydrocarbons ${ }^{a}$

\begin{tabular}{|c|c|c|c|c|c|c|c|c|c|}
\hline Pos. & & & $\mathrm{HCB}$ & $\alpha-\mathrm{HCH}$ & $\gamma-\mathrm{HCH}$ & $\beta-\mathrm{HCH}$ & $\mathrm{DDE}$ & Dieldrin & A $60-1$ \\
\hline 1 & mean $\bar{x}$ & 1. series & 1.1 & 5 & 5.3 & 1.3 & 9.8 & 3.3 & 47 \\
\hline 2 & mean $\bar{x}$ & 2. series & 1.4 & 4.7 & 4.6 & 1.3 & 10.5 & 2.8 & 46 \\
\hline 3 & mean $\underline{x}$ & 3. series & 1.2 & 4.8 & 5.2 & 1.2 & 11.5 & 3.3 & $\mathrm{~b}$ \\
\hline 4 & mean $\bar{x}$ & 4. series & 1 & 4.5 & 4.2 & 0.9 & 7.7 & 3.3 & 53 \\
\hline 5 & mean $\bar{x}$ & 5. series & 1.1 & 6.1 & 5.4 & $\mathrm{~b}$ & 13.6 & 4.4 & 50 \\
\hline 6 & mean $\bar{x}$ & (pos. 1-5) & 1.2 & 5 & 4.9 & 1.2 & 10.6 & 3.4 & 49 \\
\hline 7 & std. dev. S & $($ pos. 1-5) & 0.15 & 0.6 & 0.5 & 0.15 & 2.2 & 0.6 & 3 \\
\hline 8 & $-1.96 \mathrm{~s}$ & (S 958) & 0.8 & 3.8 & 3.9 & 0.8 & 6.3 & 2.2 & $43^{c}$ \\
\hline 9 & $+1.96 \mathrm{~s}$ & (S 95\%) & 1.5 & 6.2 & 5.9 & 1.5 & 14.9 & 6.3 & 55 \\
\hline 10 & median & (pos. 1-5) & 1.1 & 4.8 & 5.2 & 1.2 & 10.5 & 3.3 & 49 \\
\hline 11 & mean $\bar{x}$ & (total) & 1.2 & 4.9 & 4.9 & 1.1 & 10.5 & 3.4 & 49 \\
\hline 12 & std. dev. & (total) & 0.25 & 1 & 1 & 0.4 & 2.3 & 0.85 & 7 \\
\hline 13 & $P \min$ & $(958)$ & 0.9 & 3.8 & 3.8 & 0.7 & 8.2 & 2.6 & $42^{d}$ \\
\hline 14 & $\mathrm{P} \max$ & $(958)$ & 1.4 & 6 & 6 & 1.5 & 12.9 & 4.3 & 56 \\
\hline 15 & median & (total) & 1 & 4.8 & 5 & 1 & 10 & 3 & 50 \\
\hline
\end{tabular}

a Data provided by K. Oxynos, I. Gebefügi, GSF Neuherberg, Inst. of Ecological Chemistry ${ }^{b}$ Missing value

c95\% range of normal distribution, within the range are 95\% of all (900) values.

${ }^{d}$ Forecast interval for the mean value $\bar{x}$ of 5 random samples of the total amount (900). 
SCANNING PHOTO SEDIMENTOGRAPHIC ANALYSIS

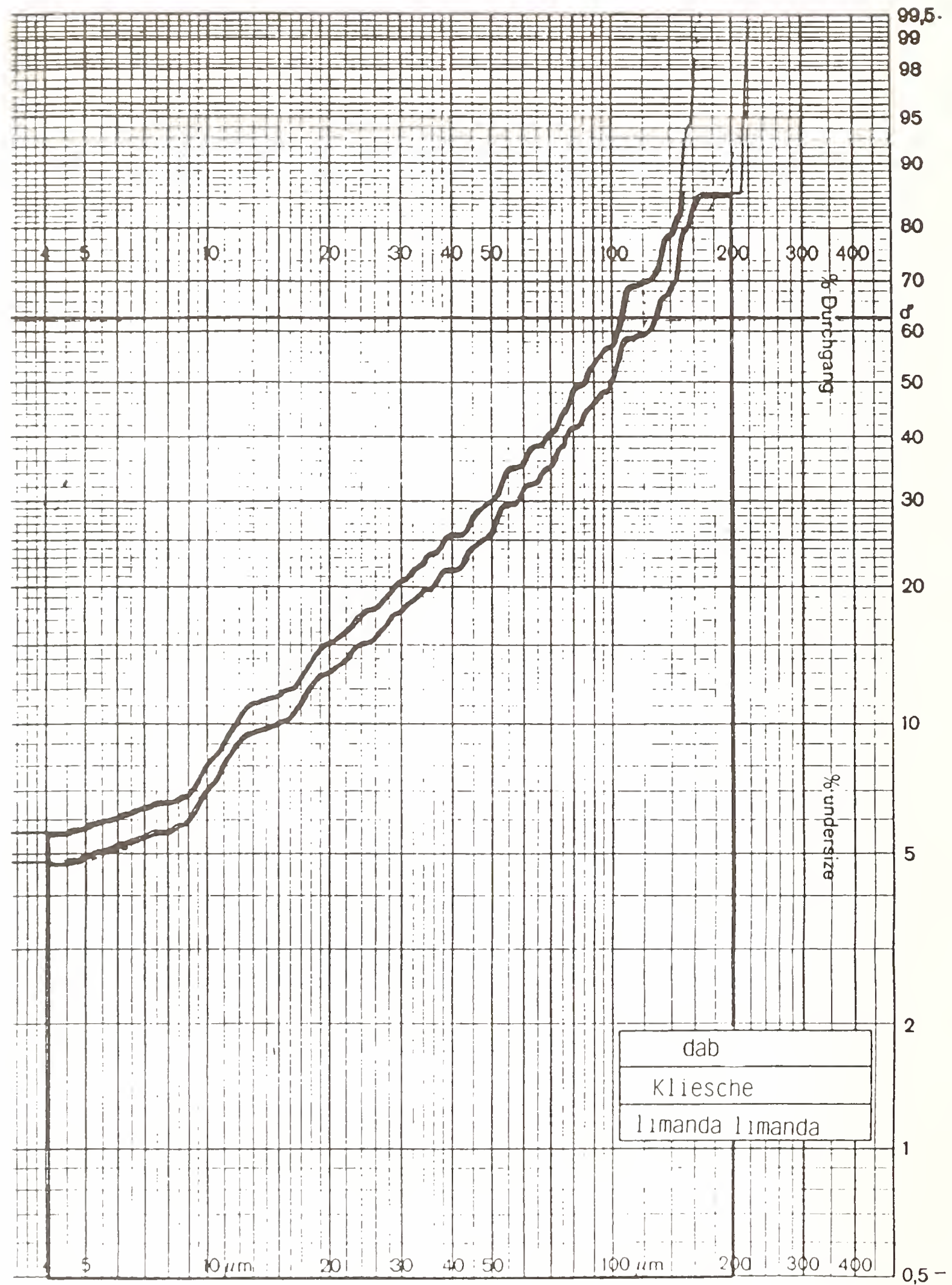

Figure 3. Determination of grain size in fish material-dab (limanda limanda) 
191
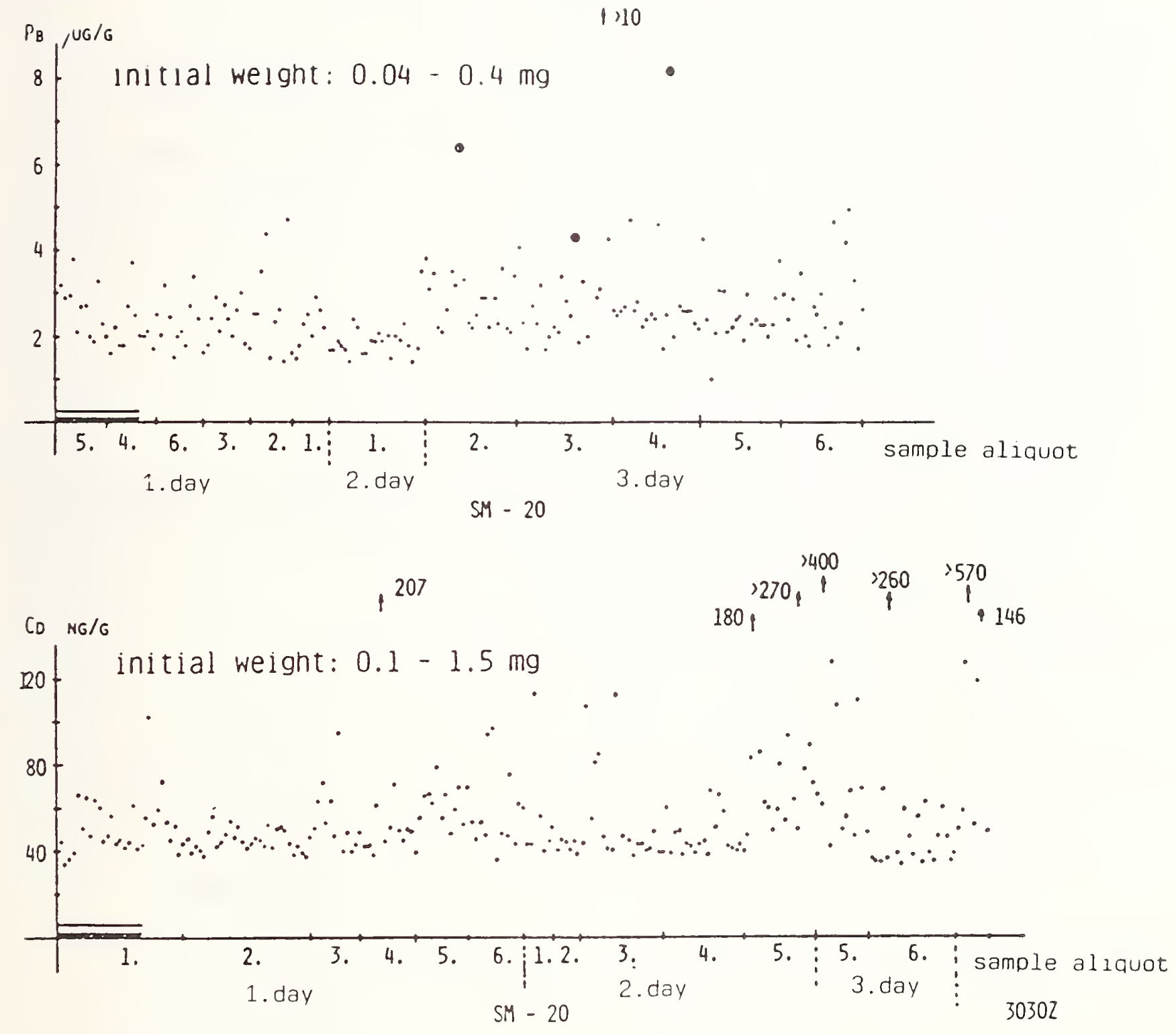

Figure 4. Homogeneity study of fish material-dab (limanda limanda) by determination of $\mathrm{Pb}$ and $\mathrm{Cd}$ in 6 random subsamples out of 950. Determination by solid sampling atomic absorption carried out at different times 


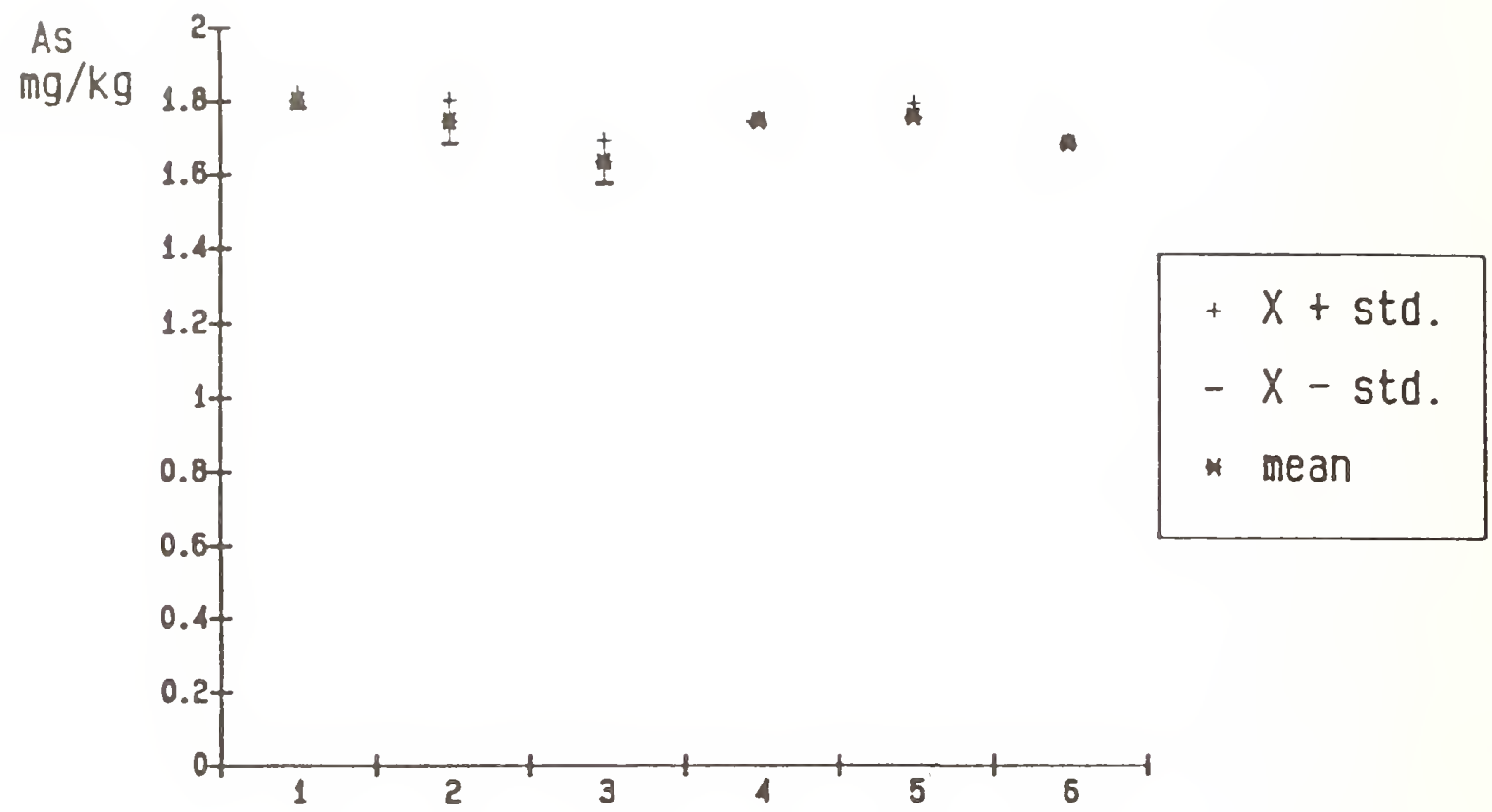

Figure 5. Homogeneity study of fish material-dab (limanda limanda) by determination of As in six random subsamples out of 950

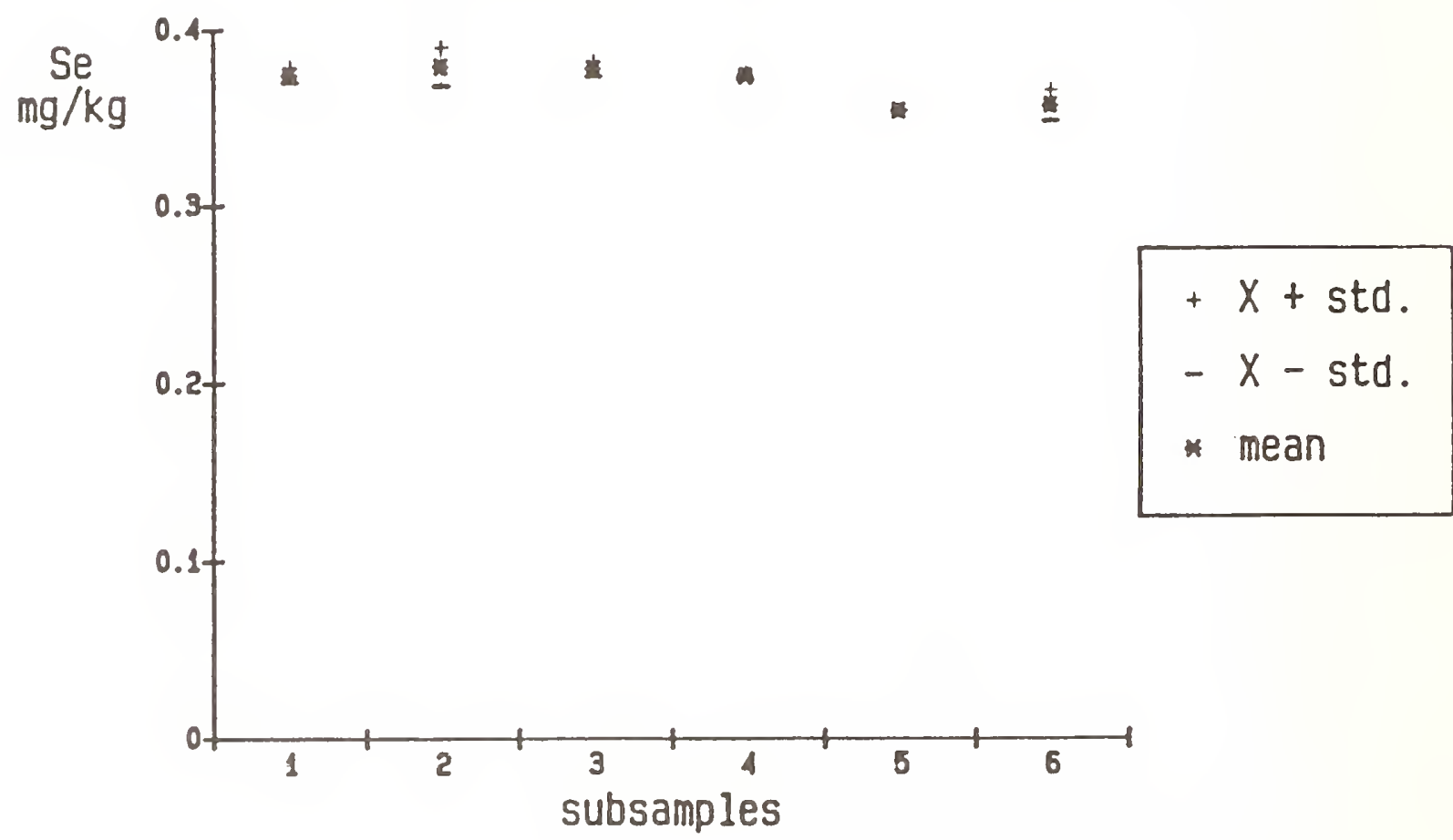

Figure 6. Homogeneity study of fish material-dab (limanda limanda) by determination of Se in six random subsamples out of 960 
for their helpful assistance in collecting the fish material (dab - limanda limanda).

\section{REFERENCES}

[1] Protokoll der Status Seminar Sitzung, November 1982, Reisensburg, FRG.

[2] Schladot, J. D., Backhaus, F., and Reuter, U., Beiträge zur Umweltprobenbank, 1. Studie zur Errichtung einer Kaltmahlapparatur, JüI Spez $330,1985$.

[3] Mohl, C., Grobecker, K. -H., and Stoeppler, M. (1987), Homogeneity Studies in Reference Materials with Zeeman Solid Sampling GFAAS, Fresenius $\mathrm{Z}$. Anal. Chem. 328, 413-418. 


\title{
SECTION 19
}

\section{THE POTENTIAL ROLE OF ENVIRONMENTAL SPECIMEN BANKING IN BIOSPHERE RESERVES}

\author{
William P. Gregg, Jr. \\ U.S. Department of the Interior \\ National Park Service \\ Washington, DC 20013-7127 \\ USA
}

\section{INTRODUCTION}

When the Man and the Biosphere Program (MAB) was officially launched by the United Nations Educational, Scientific, and Cultural Organization (UNESCO) in 1971, one of its thirteen project areas was "The Conservation of Natural Areas and the Genetic Material They Contain." The central focus of this project was the establishment of a global network of protected sites called biosphere reserves, to conserve representative examples of each of the world's biomes as benchmarks of environmental quality and centers of basic and applied ecological research. In 1972, the idea became a key recommendation of the United Nations Conference on the Environment, or Stockholm Conference. In 1973, UNESCO issued criteria for biosphere reserves [1]. In 1975, the International Union for the Conservation of Nature and Natural Resources (IUCN) published a global biogeographic classification as a framework for selection [2]. And in 1976, the UNESCO's International Coordinating Council for MAB designated the first 29 biosphere reserves.

Since that time, the network has grown rapidly to include 266 units in 70 countries (November 1987 data). About two-thirds of these units are in the socalled developed countries. About 100 of the 193 biogeographical provinces in the UNESCO classification are represented. Of the world's major biomes, temperate broad-leaf forests and mixed mountain systems are particularly well represented. Significant gaps remain elsewhere, particularly in major lake systems, coastal and marine areas, and most tropical biomes [3].

Biosphere reserves are selected on the basis of their potential to carry out and integrate conservation, information/logistic, and development function [4].

\section{CONSERVATION FUNCTION}

Biosphere reserves are of exceptional importance in conserving ecosystems and genetic resources. They should be large units of landscape--the majority of existing units exceed 20,000 hectares in size, and about a fourth exceed 100,000 hectares. These landscapes are planned and managed for purposes ranging from strict protection to intensive, yet sustainable production. Throughout, the objective is to sustain natural processes and the evolutionary potential of indigenous biota. However, at the heart of each biosphere reserve are one or more securely protected core areas, which conserve representative examples of natural or minimally disturbed ecosystems where human uses are 
strictly controlled. In the United States, legislatively established wilderness areas within national parks comprise most of the core areas. A few countries--for the most part those lacking well-established systems for land management and environmental regulation--are establishing biosphere reserves by law. However, in most countries, biosphere reserves represent a voluntary approach to conservation, using existing legally protected areas as building blocks.

One promising approach adopted in some countries, including the U.S., is to use the biosphere reserve as a framework for linking ecologically and functionally complementary protected areas in a particular biogeographical region. In this way, the biosphere reserve becomes a symbolic and practical basis for cooperation among governmental and private administrators of important conservation real estate. During the last few years, some significant assemblages of protected areas have been established as biosphere reserves. For example, a recently designated biosphere reserve in the warm deserts of California links five units under four different administrators totalling 1.3 million hectares. It is worth noting that the global network already contains many of the world's outstanding conservation areas, such as the Manu (Peru), the Bavarian Forest (Germany), and Yellowstone (U.S.) National Park. Biosphere reserve status encourages functional linkages between these areas and surrounding lands, and can provide a framework for coordinating efforts to conserve regional ecosystems and provide for their intelligent use and management.

\section{INFORMATION/LOGISTIC FUNCTION}

The International Network of Biosphere Reserves is the only permanent global association of protected areas dedicated to generating, sharing, and applying ecological information for human well-being. Each reserve should be a focus for long-term monitoring, comparative and interdisciplinary research, and related demonstration and training. The core areas should be centers for carefully designed monitoring for early warning of natural and man-caused changes, with special emphasis on chemical contamination. In the surrounding areas, experimental manipulations should be carried out, monitored, and compared with the core to develop and assess ecosystem use and rehabilitation strategies. Throughout, the biosphere reserves are centers for the testing and adapting of new methodologies for monitoring, research, assessment, and prediction. The actual accomplishments and potential of the site in these fields thus are essential considerations in selection. The administrator's commitment to facilitate research is another, as is willingness to participate in MAB's unique international framework for scientific cooperation on environmental problems. Given these considerations, it is not surprising that the network includes many leading field stations for developing the theory and practice of ecology. For example, the biosphere reserves in the U.S. include ten former biome research sites in the International Biological Program and nine of the 15 sites currently supported by the National Science Foundation's long-term ecological research program (November 1987 data). 


\section{THE DEVELOPMENT FUNCTION}

Information and skills developed in the biosphere reserve should provide the basis for ecologically sustainable development. One objective is develop strategies for ecosystem use and management on site which can be transferred from the reserve to the surrounding region. The strategies must be culturally appropriate, economically feasible, and capable of implementation by participating institutions. This process requires cooperation between natural and social scientists in carrying out the necessary research, and, in many countries, continuing involvement of local populations to assure that they benefit from the research and development programs. Another objective is to obtain information on site which can influence national environmental and development policies. For example, many, if not most, biosphere reserves in the U.S. and other developed countries have monitoring programs to detect and assess atmospheric pollutants in natural ecosystems (Gregg and Giogel, 1981). In the U.S., the results of these activities have been important factors in decisions affecting the siting and design of major developments where atmospheric pollution has been an issue.

\section{THE ROLE OF ENUIRONMENTAL SPECIMEN BANKING}

Systematic banking of environmental specimens as part of an integrated program of ecological monitoring is consistent with the mission of biosphere reserves as bellweathers of ecological health (and, in some developing countries, perhaps also of human health). By providing a basis for retrospective assessment of chemical contaminants in the environment, environmental specimen banking could serve all major functions of biosphere reserves. In conservation, it could improve the protected area manager's capability to detect trends potentially affecting the evolutionary potential of indigenous biota. In logistics, it could provide a new and exciting area for interdisciplinary and international cooperation, both in the conceptualization and implementation of effective banking programs, and in developing and testing of research hypotheses based on analysis of banked specimens. In development, it could provide information useful in policy decisions on technology and development, and help ensure that these decisions on technology and development, and help ensure that these decisions minimize or avoid significant effects from environmental toxicity.

For their part, many biosphere reserves afford particular advantages in developing and coordinated specimen banking program. Some of the more important:

- they are representative of larger biogeographic regions, hence results are likely to be widely applicable

- they have an establish mission in ecological research, improving likelihood of logistical and financial support

- many have a good history of scientific activity, required for establishing concepts and goals for banking 
- size of the reserve and distribution of ecosystems are generally adequate for repeated sampling

- secure protection of minimally distributed core areas helps assure continuity in baseline monitoring

- land use practices in designated buffer areas adjoining the core areas are normally defined and predictable, reducing possibility of unexpected human influences

- most are in remote locations; and are generally not subject to acute chemical episodes

- each site is part of an established network suitable for assessing the distribution and effects of chemicals

- the MAB framework for international cooperation facilitates sharing perspective and results, and technology transfer

In a 1984 action plan, UNESCO underscored the role of biosphere reserves for long-term monitoring of ecological processes, global biogeochemical cycles, and effects of human uses on the biosphere [6]. The plan is a unique document for a unique network. It calls for 35 actions, which are being implemented by MAB National Committees and the various United Nations agencies and nongovernmental organizations which have endorsed the plan. It specifically calls on United Nations Environment Programme (UNEP), in collaboration with other United Nations agencies, to seek support for monitoring, among other things, background levels of pollutants and biological indicators of environmental change. In this context, the plan provides ready justification for incorporating specimen banking as an adjunct of monitoring in biosphere reserves.

Notwithstanding these considerations, environmental specimen banking remains to be tested and implemented in biosphere reserves. In discussions with biosphere reserve managers and scientists, I find general acceptance of the need for baseline monitoring of pollutants (e.g., a methodology developed for UNEP's Global Environmental Monitoring Program is now being used in five U.S. reserves [7]), but considerable uncertainty over the requirements and potential benefits of specimen banking.

First, the technology is unfamiliar. Recent conceptual and technical advances in Germany and elsewhere have yet to be effectively communicated widely in the United States. To help address this problem, the U.S. and German MAB National Committees, in cooperation with domestic agencies and institutions in both countries, have recently published an English adaptation of the guidelines prepared for the German National Environmental Specimen Bank [8,9]. In addition, Lewis [10] has prepared a chapter on environmental specimen banking for the National Park Service's Museum Handbook, which is now being revised. These publications will be generally distributed and should raise awareness of the technology, and the many considerations in implementing it effectively. 
Second, there is concern about what to include in a bank. Although, many reserves monitor a range of abiotic and biotic parameters, only a few could reasonably be considered for banking. Even if clear goals and objectives are established, it remains no easy task to select the ecosystem components most likely to be burdened with introduced chemicals, or which govern the transformations and fate of these chemicals in the ecosystem ... much less operate an effective program after these decisions have been made. To my knowledge, no biosphere reserve has undertaken the interdisciplinary planning needed to develop an effective specimen banking program.

Finally, there is concern over the cost of facilities and operations. Relative to the total cost of the integrated monitoring programs in many biosphere reserves, the cost of a banking component is likely to be modest. Nevertheless, the concern is likely to remain until the cost of alternative administrative arrangements $c a n$ be demonstrated on the basis of practical experience.

In conclusion, there seems little question that biosphere reserves can play an important role in developing and applying specimen banking technologies, in concert with monitoring, in early warning and predictive assessment of environmental contaminants. We now have MAB guidelines for planning environmental specimen banks based on the German experience. Preparation of a prototype plan for a biosphere reserve would seem to be an important first step in fostering understanding and support within the biosphere reserve network. It would certainty seem worthwhile at this time to determine the interest of international (e.g., UNESCO, UNEP) and domestic (e.g., national MAB committees) agencies and institutions in supporting such an effort.

\section{REFERENCES}

[1] UNESCO 1973, MAB Expert Panel on Project 8: Conservation of Natural Areas and the Genetic Material They Contain, Morges, Switzerland, 25-27 September 1983, MAB Report Series No. 22, UNESCO, Paris, 66 pp.

[2] Udvardy, M. D. F. (1975), A Classification of the Biogeographical Provinces of the World, I.U.C.N. Occasional Paper No. 18, I.U.C.N., Morges, Switzerland.

[3] I.U.C.N. 1983, MAB Information System: Biosphere Reserves, Complication 3, September 1983, I.U.C.N. Conservation Monitoring Center, Available from UNESCO MAB Secretariat, Paris, $61 \mathrm{pp}$.

[4] UNESCO 1986, Scientific Advisory Panel on Biosphere Reserve, Report of Second Meeting, La Paz, Bolivia, 18-24 August 1984, Unpublished Manuscript (draft), 29 pp.

[5] Gregg, W. P. and Goigel, M. M. (1983), Putting the Biosphere Reserve Concept into Practice: The United States Experience, In: Ecology in Practice, Part I: Ecosystem Management, F. diCastri, et al., Eds., Tycooly International Publishing, Limited, Dublin, Ireland, pp 460-484. 
[6] UNESCO 1984, Action Plan for Biosphere Reserves, Nature and Resources $20(4), 1-12$.

[7] Wiersma, G. B., Brown, K. R., and Crockett, A. B. (1978), Development of Pollutant Monitoring System for Biosphere Reserves, Publication No. EPA600.4-78-052, Environmental Protection Agency, Environmental Monitoring and Support Laboratory, Las Vegas, Nevada.

[8] Lewis, R. A. (1985), Richtlingen fur den Einsatz einer Umweltprobenbank in der Bundesrepublik Deutschland auf Okologischer Grundlage, Universitat des Saarlandes, Saarbrucken, Federal Republic of Germany, 190 pp, Plus Appendices.

[9] Lewis, R. A. (1987), Guidelines for Environmental Specimen Banking with Special Reference to the Federal Republic of Germany, U.S. MAB Report No. 12, U.S. Dept. of the Interior, National Park Service, $182 \mathrm{pp}$.

[10] Lewis, R. A. (1986), Guidelines for Environmental Specimen Banking in the Federal Republic of Germany: Ecological and Managerial Considerations, The Environmental Professional 8, 138-148. 


\section{APPENDIX A}

\section{LIST OF MEETING PARTICIPANTS}

Dr. Yoshinari Ambe

Division of Chemistry and Physics

National Institute for Environmental

Studies

Yatabe-machi, Tsukuba, Ibaraki 305

JAPAN

Dr. Richard Batiuk

Chesapeake Bay Program

U.S. Environmental Protection Agency

410 Severn Avenue

Annapolis, MD 21403

Dr. Ulrich Boehringer

Unwe l tbundesamt

Bismarckplatz 1

1000 Berlin 33

FEDERAL REPUBLIC OF GERMANY

Dr. Jerry J . Bromenshenk

Department of Botany

University of Montana

Missoula, MT 59812

Dr. Stephen N. Chesler

Organic Analytical Research Division A113 Chemistry Building

National Bureau of Standards

Gaithersburg, MD 20899

Dr. Maria Donner

U.S. Environmental Protection Agency MD -56

Environmental Monitoring System

Laboratory

Research Triangle Park, NC 27711

Dr. John Elliott

National Wildlife Research Center

Environment Canada

Ottawa, Ontario K1A OE7

CANADA
Dr. Istvan Gebefugi

Institüt für Okologische Chemie der

Gesellschaft für Strahlen-und

Umwel $t$ forschung-Munchen

Ingolstadter Landstr. 1

Post Obserschleissheim

D-8042 Neuherberg

FEDERAL REPUBLIC OF GERMANY

Dr. Wilfred Goerke

Ministerium für Umwelt, Naturschutz und Reaktorsicherheit

Postfach 120629

D-5300 Bonn 1

FEDERAL REPUBLIC OF GERMANY

Dr. George M. Goldstein

U.S. Environmental Protection Agency

University of North Carolina

Medical Research Building C224-H

Chapel Hill, NC 27514

Dr. Robert R. Greenberg

Inorganic Analytical Research

Division

B108 Reactor Building

National Bureau of Standards

Gaithersburg, MD 20899

Dr. William P. Gregg

Office of Science and Technology

U.S. Department of Interior

National Park Service (484)

Washington, DC 20240

Dr. Jasper Holm

Staatliches Veterinäruntersuchungsamt

Dresdenstrasse 6

D-3300 Braunschweig

FEDERAL REPUBLIC OF GERMANY

Dr. Kenneth Hood

Office of Research and Development (RD-682)

U.S. Environmental Protection Agency 401 M Street, S.W.

Washington, DC 20460 
Dr. Robert J. Huggett

Virginia Institute of Marine Science School of William and Mary

Gloucester Point, VA 23062

Prof. Dr. Jürgen Jacob

Biochemisches Institut für

Umwel tcarcinogene

Lurup 4

D-2070 Grosshansdorf

FEDERAL REPUBLIC OF GERMANY

Prof. Dr. Fritz H. Kemper

Institute for Pharmacology and

Toxicology

University of Münster

Domagkstrasse 12

D-4400 Münster

FEDERAL REPUBLIC OF GERMANY

Ms. Barbara Koster

Organic Analytical Research Division

A133 Chemistry Building

National Bureau of Standards

Gaithersburg, MD 20899

Dr. Reinhard Kruse

Staatliches Veterinäruntersuchungsamt

für Fische and Fischwaren

D-2190 Cuxhaven - F

FEDERAL REPUBLIC OF GERMANY

Mr. Gunnar G. Lauenstein

National Oceanic and Atmospheric

Administration

NOAA/NOS/OOMA

N/OMA32

Rockville, MD 20852

Dr. Robert A. Lewis

Lehrstuhl für Biogeographie

University of Saarland

D-6600 Saarbrucken

FEDERAL REPUBLIC OF GERMANY

Dr. David Mage

Senior Science Advisor

U.S. Environmental Protection Agency

Environmental Monitoring Systems

Laboratory (MD-56)

Research Triangle Park, NC 27711
Dr. Willie E. May

Chief, Organic Analytical Research

Division

A113 Chemistry Building

National Bureau of Standards

Gaithersburg, MD 20899

Dr. Hugh McKinnon

U.S. Environmental Protection Agency

401 M Street, S.W.

Washington, DC 20460

Dr. Ray Merrill

U.S. Environmental Protection Agency

Industrial Environmental Research

Laboratory (MD-62)

Research Triangle Park, NC 27711

Ms. Reenie M. Parris

Organic Analytical Research Division

A113 Chemistry Building

National Bureau of Standards

Gaithersburg, MD 20899

Dr. Curt Reimann

Deputy Director for Resources and

Operations

National Measurement Laboratory

A363 Physics Building

National Bureau of Standards

Gaithersburg, MD 20899

Mr. Phil Robinson

Design and Development Branch

Office of Toxic Substances

U.S. Environmental Protection Agency

401 M Street, S.W.

Washington, DC 20460

Mr. Michele Schantz

Organic Analytical Research Division

A113 Chemistry Building

National Bureau of Standards

Gaithersburg, MD 20899

Dr. Johan Schledot

Kernforschungsanlage Jülich

Institut 4

Angewandte Physikalische Chemie

P.O. Box 1913

D-5170 Jülich

FEDERAL REPUBLIC OF GERMANY 


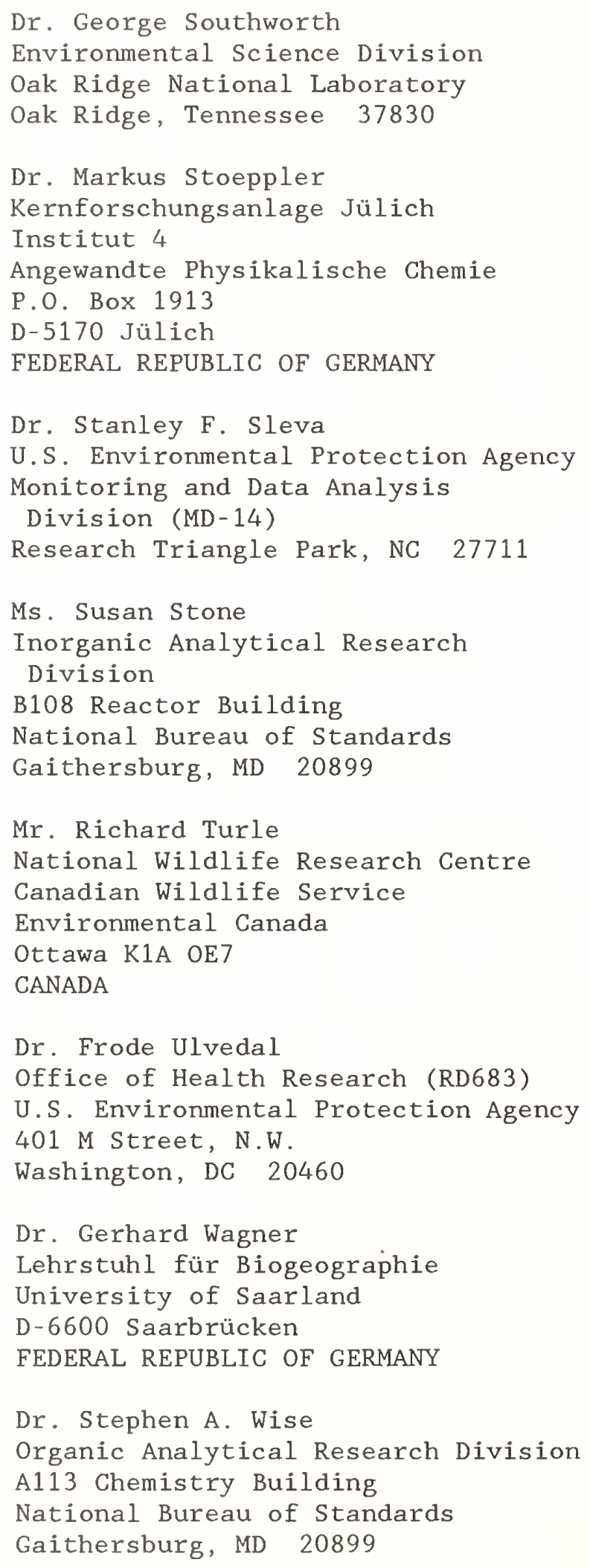

Dr. Wayne R. Wolf

Nutrient Composition Laboratory Human Nutrition Center

U.S. Department of Agriculture Beltsville, MD 20705

Dr. Rolf Zeisler

Inorganic Analytical Research Division B108 Reactor Building

National Bureau of Standards Gaithersburg, MD 20899 
NBS. 114A (REV. 2.8C)

U.S. DEPT. OF COMM.

BIBLIOGRAPHIC DATA

SHEET (See in struction s)

1. PUBLICATION OR

REPORT NO.

NBS/SP-740

2. Performing Organ. Report Noy 3. Publication Date

April 1988

4. TITLE AND SUBTITLE

PROGRESS IN ENVIRONMENTAL SPECIMEN BANKING

5. $\operatorname{AUTHOR}(S)$

Stephen A. Wise, Rolf Zeisler, and George M. Goldstein

6. PERFORMING ORGANIZATION (If joint or other than NBS, see instructions)

NATIONAL BUREAU OF STANDARDS

U.S. DEPARTMENT OF COMMERCE

GAITHERSBURG, MD 20899

7. Contract/Grant No.

8. Type of Report \& Period Covered

Final

9. SPONSORING ORGANIZATION NAME AND COMPLETE ADDRESS (Street, City, Stote, ZIP)

10. SUPPLEMENTARY NOTES

Library of Congress Catalog Card Number 88-600530

[Document describes a computer program; SF-185, FIPS Software Summary, is attached.

11. ABSTRACT (A 200-word or less factual summary of most significant information. If document includes a significant bibliography or literature survey. mention it here)

In the past decade, interest in the corcept of specimen banking for the archiving of biological and environmental samples for future analysis has increased significantly, and specimen banking is now recognized as an integral part of systematic environmental monitoring. Since the establishment of pilot Environmental Specimen Banking Programs in the U. S. and the Federal Rebuplic of Germany (FRG) in the late $1970^{\prime} \mathrm{s}$, formal meetings have been held annually between representatives of these two programs to discuss results and future needs related to specimen banking. In recent years representatives of similar programs in Japan, Canada, and Sweden have joined in these meetings to expand the exchange of information.

In October, 1986, the 10th U.S.-German Seminar of State and Planning on Environmental Specimen Banking was held at the Virginia Institute of Marine Sciences in Gloucester Point, Virginia. At this meeting the current status of specimen banking activities in the U. S., FRG, Canada, and Japan was presented and discussed. This publication contains the proceedings of that meting with contributions describing various activities related to banking and analysis of samples from aquatic, atmospheric, terrestrial, and human monitoring programs.

12. KEY WORDS (Six to twelve entries: alphabetical order; capitalize only proper names; and separate key words by semicolons) atmospheric pollution; gas chromatography; human tissue analysis; inorganic analysis; marine pollution; neutron activation analysis; organic analysis; pollutaants; specimen banking; trace element analysis

13. AVAILABILITY

XX Unlimited

$\square$ For Official Distribution. Do Not Release to NTIS

14. NO. OF

PRINTED PAGES

217

XE] Order From Superintendent of Documents, U.S. Government Printing Office, Washington, D.C. 20402.

Order From National Technical Information Service (NTIS), Springfield, VA, 22161

15. Price 




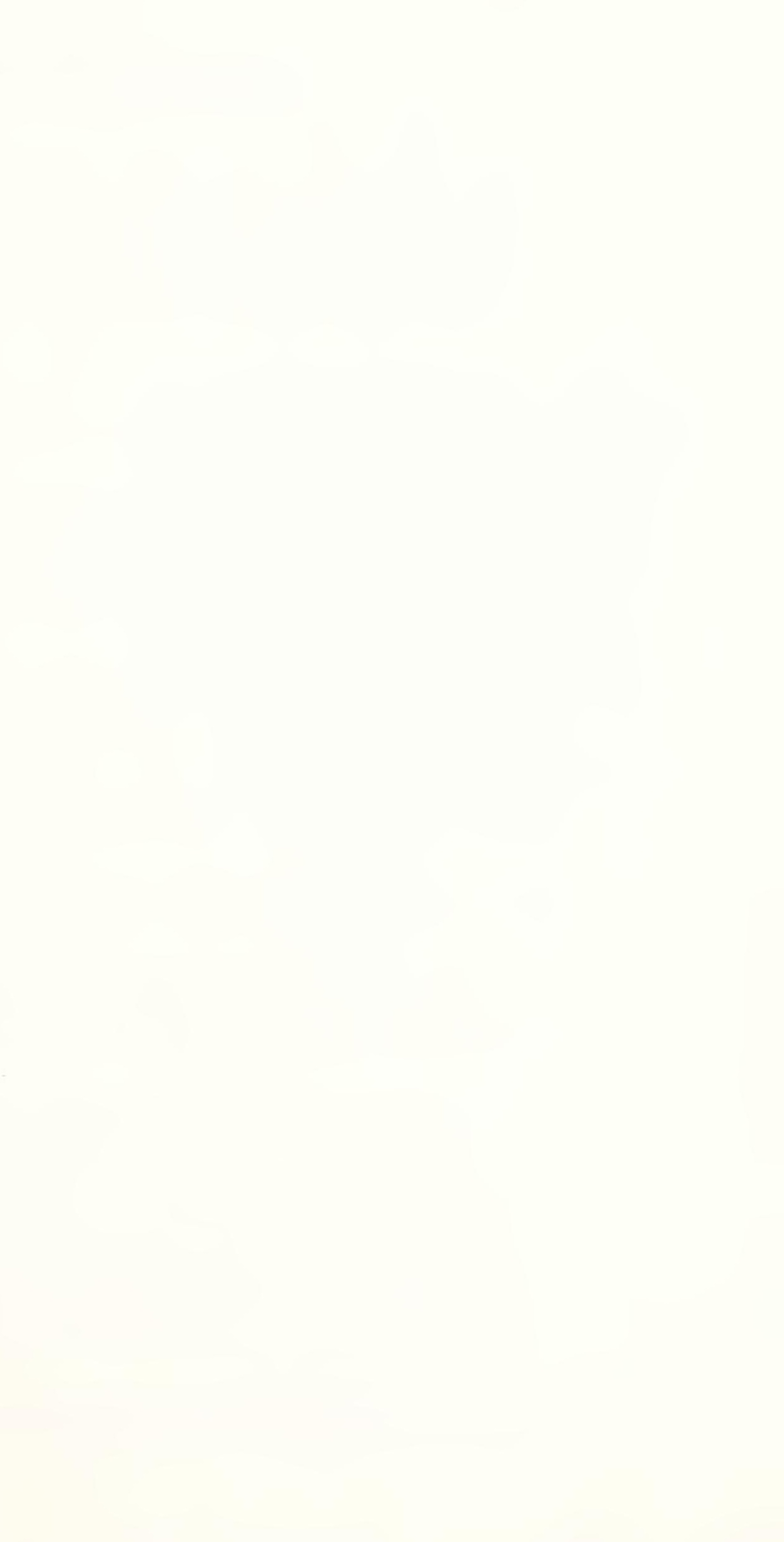





\section{Periodical}

Journal of Research-The Journal of Research of the National Bureau of Standards reports NBS research and development in those disciplines of the physical and engineering sciences in which the Bureau is active. These include physics, chemistry, engineering, mathematics, and computer sciences. Papers cover a broad range of subjects, with major emphasis on measurement methodology and the basic technology underlying standardization. Also included from time to time are survey articles on topics closely related to the Bureau's technical and scientific programs. Issued six times a year.

\section{Nonperiodicals}

Monographs-Major contributions to the technical literature on various subjects related to the Bureau's scientific and technical activities.

Handbooks-Recommended codes of engineering and industrial practice (including safety codes) developed in cooperation with interested industries, professional organizations, and regulatory bodies.

Special Publications-Include proceedings of conferences sponsored by NBS, NBS annual reports, and other special publications appropriate to this grouping such as wall charts, pocket cards, and bibliographies.

Applied Mathematics Series-Mathematical tables, manuals, and studies of special interest to physicists, engineers, chemists, biologists, mathematicians, computer programmers, and others engaged in scientific and technical work.

National Standard Reference Data Series-Provides quantitative data on the physical and chemical properties of materials, compiled from the world's literature and critically evaluated. Developed under a worldwide program coordinated by NBS under the authority of the National Standard Data Act (Public Law 90-396).

NOTE: The Journal of Physical and Chemical Reference Data (JPCRD) is published quarterly for NBS by the American Chemical Society (ACS) and the American Institute of Physics (AlP). Subscriptions, reprints, and supplements are available from ACS, 1155 Sixteenth St., NW, Washington, DC 20056.

Building Science Series-Disseminates technical information developed at the Bureau on building materials, components, systems, and whole structures. The series presents research results, test methods, and performance criteria related to the structural and environmental functions and the durability and safety characteristics of building elements and systems.

Technical Notes-Studies or reports which are complete in themselves but restrictive in their treatment of a subject. Analogous to monographs but not so comprehensive in scope or definitive in treatment of the subject area. Often serve as a vehicle for final reports of work performed at NBS under the sponsorship of other government agencies.

Voluntary Product Standards-Developed under procedures published by the Department of Commerce in Part 10, Title 15, of the Code of Federal Regulations. The standards establish nationally recognized requirements for products, and provide all concerned interests with a basis for common understanding of the characteristics of the products. NBS administers this program as a supplement to the activities of the private sector standardizing organizations.

Consumer Information Series-Practical information, based on NBS research and experience, covering areas of interest to the consumer. Easily understandable language and illustrations provide useful background knowledge for shopping in today's technological marketplace.

Order the above NBS publications from: Superintendent of Documents, Government Printing Office, Washington, DC 20402.

Order the following NBS publications-FIPS and NBSIR'S-from the National Technical Information Service, Springfield, VA 22161.

Federal Information Processing Standards Publications (FIPS PUB)-Publications in this series collectively constitute the Federal Information Processing Standards Register. The Register serves as the official source of information in the Federal Government regarding standards issued by NBS pursuant to the Federal Property and Administrative Services Act of 1949 as amended, Public Law 89-306 (79 Stat. 1127), and as implemented by Executive Order 11717 (38 FR 12315, dated May 11, 1973) and Part 6 of Title 15 CFR (Code of Federal Regulations).

NBS Interagency Reports (NBSIR)-A special series of interim or final reports on work performed by NBS for outside sponsors (both government and non-government). In general, initial distribution is handled by the sponsor; public distribution is by the National Technical Information Service, Springfield, VA 22161, in paper copy or microfiche form. 
U.S. Department of Commerce

National Bureau of Standards

Galthersburg, MD 20899

Officlal Business

Penalty for Private Use $\$ 300$

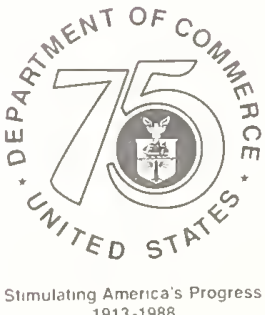

